BNL 50390

(Radioisotope and Radiation Applications - TID-4500)

and

REC-ERC-73-12

\title{
CONCRETE-POLYMER MATERIALS
}

FIFTH TOPICAL REPORT

\author{
Edited by G.W. DEPUY AND L.E. KUKACKA
}

AUTHORS

\begin{tabular}{cl} 
L.E. KuKACKA & G.W. DEPUY - \\
\hline A. AUSKERH & F.E. CAUSEY \\
P. COLOMBO & W.C. COWAN \\
A. ROMAHO & W.T. LOCKMAM \\
M. STEIMBERG & W.G. SMOAK
\end{tabular}

December 1973

by the

RADIATION DIVISION, DEPARTMENT OF APPLIED SCIENCE

BROOKHAVEN NATIONAL LABORATORY, ASSOCIATED UNIVERSITIES, INC.

UPTON, NEW YORK

DIVISION OF GENERAL RESEARCH

BUREAU OF RECLAMATION, ENGINEERING AND RESEARCH CENTER, DENVER, COLORADO

for the

DIVISION OF APPLIED TECHNOLOGY, UNITED STATES ATOMIC ENERGY COMMISSION

BUREAU OF RECLAMATION, UNITED STATES DEPARTMENT OF THE INTERIOR

and the

OFFICE OF SALINE WATER, UNITED STATES DEPARTMENT OF THE INTERIOR

WASHINGTON, D.C. 
NOTICE

This report was prepared as an account of work sponsored by the United States Government. Neither the United States nor the United States Atomic Energy Commission, nor any of their employees, nor any of their contractors, subcontractors, or their employees, makes any warranty, express or implied, or assumes any legal liability or responsibility for the accuracy, completeness or usefulness of any information, apparatus, product or process disclosed, or represents that its use would not infringc privately owned rights.

Printed in the United States of America Available from

National Technical Information Service

U.S. Department of Commerce

5285 Port Royal Road

Springfield, Virginia 22151

Price: Printed Copy \$5.45: Microfiche \$1.45

January 1974

3500 copies 


\section{ACKNOWLEDGMENTS}

The authors wish to acknowledge the helpful aid in program planning of D.S. Ballantine and G. J. Rotariu of the U.S. Atomic Energy Commission, E. J. Meeks of the Office of Saline Water, W.H. Keating and H.J. Cohan of the Bureau of Reclamation, and B. Manowitz of Brookhaven National Laboratory.

The assistance of J. Fontana, W. Becker, J. Varela, L. Jefferson, J. Fedelem, B. Galen, H. Ruge, J. Wagner, C. Klamut, G. Farber, and W. Horn of Brookhaven National Laboratory in performing the numerous experiments associated with the program is acknowledged with thanks.

In addition to those authoring this report, Bureau of Reclamation staff members directly engaged in this work under the general supervision of J.T. Dikeou include R.W. Spencer, C.A. Nelson, L.R. Carpenter, K.B. Hickey, H.C. Riffle, M.C. Redmond, U.M.C. Cis, R.W. Nichols, D.O. Arney, C.C. Gore, T.G. Stratton, M.J. Roddy, and J.L. Aragon. Also contributing were J.D. Richards and L.C. Porter, who furnished guidance and supervision of concrete mix design and durability testing, and E. J. Benton and G.L. Teter, who conducted portions of the fundamental studies and quality control investigations. The report was reviewed by C.E. Selander and J.R. Graham. 


\section{CONTENTS}

Acknowledgments .................................................................................................................. ii

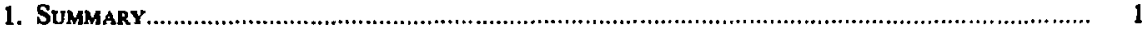

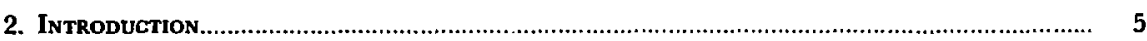

2.1 Background and Program Description................................................................. 5

2.2 Summary of Previous Work .................................................................................... 6

2.3 Cooperative Programs and Other Developments................................................... 7

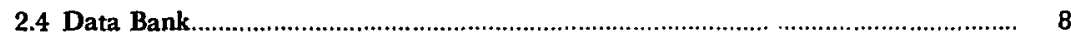

3. Monomer and Composite Survey Experiments................................................................... 8

3.1 Polymer-Impregnated Concrete Studies.............................................................. $\quad 8$

3.1.1 Monomer Selection for High-Temperature Applications.............................. B

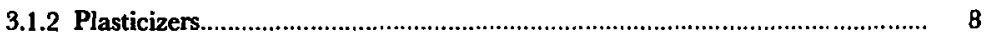

3.2 Polymer-Cement Concrete Studies........................................................................ 9

3.3 Polymer-Concrete Studies.................................................................................. 11

4. Process Teghology Development .......................................................................... 12

4.1 Concrete Composition and Curing ….......................................................... 12

4.2 Full Impregnation Techniques.......................................................................... 14

4.3 Partial Impregnation and Coating Techniques.................................................... $\quad 18$

4.3.1 BNL Studies.......................................................................................... 18

4.3.2 USBR Studies.................................................................................... 19

4.4 Polymer-Concrete Fabrication Techniques........................................................ 20

4.5 Polymerization Techniques............................................................................ 21

4.5.1 Radiation Process.......................................................................................... 21

4.5.2 Promoter-Catalyst Process.................................................................... 23

4.5.3 Thermal-Catalytic Frocess, Under Hot Water............................................. 24

4.5.4 Thermal-Catalytic Process, Using Steam .................................................... 27

5. Test Results on Polymer-Ingregenated Concrete.............................................................. 27

5.1 Polymer-Impregnated Goncrete for Ambient Temperature Applications................ 30

5.1.1 CP Test Series.................................................................................... 30

5.1.1.1 Structural and Physical Properties of $10 \mathrm{wt} \%$

Polyester - 90 wt \% Styrene Impregnated Concrete .................. 30

5.1.1.2 Durability Tests........................................................................ 33

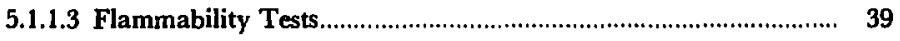

5.1.2 Structural Properties Tests.......................................................................... 43

5.1.2.1 Tensile Strength........................................................................ 43

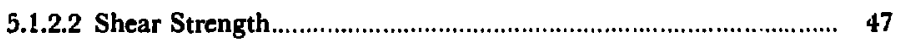

5.1.2.3 Creep................................................................................ 47

5.1.2.4 Flexural Strength of Partially Impregnated Concrete................. 48

5.1.2.5 Flexural and Shear Strengths of Reinforced Polymer-Impregnated Concrete........................ 50 


\section{CONTENTS}

5.1.2.6 Fatigue Tests................................................................................ 53

5.1.3 Durability Properties of Partially Impregnated Concrete............................ 53

5.2 Polymer-Impregnated Concrete for Desalting Applications at Temperatures up to $143^{\circ} \mathrm{C}$..................................... 59

5.2.1 Structural Properties and Design Criteria.................................................. 59

5,2.1.1 Compressive Strength...................................................................... 62

5.2.1.2 Tensile Strength........................................................................... 67

5.2.1.3 Flexural Strength............................................................................ 71

5.2.1.4 Shear Strength............................................................................. 71

5.2.1.5 High-Temperature Creep......................................................... 72

5.2.1.6 Reinforced Beams for Flexure and Shear Tests.............................. 77

5.2.1.7 High-Temperature Loop Tests..................................................... 77

5.2.1.8 Thermal Properties.......................................................................... 81

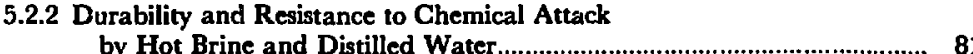

5.2.2.1 Autoclave Tests............................................................................. 82

5.2.2.2 Deionized Water Tests.................................................................. 84

5.2.2.3 Loop Tests........................................................................... 84

5.2.2.4 Environmental Tests..................................................................... 88

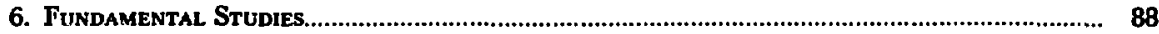

6.1 Polymer-Impregnated Concrete as a Composite Material........................................ 88

6.2 Pore Structure of Hardened Cement and Polymer-Impregnated Cement................ 90

6.3 Stability of 60 wt \% styrene -40 wt \% TMPTMA

and 70 wt \% MMA - 30 wt \% TMPTMA Polymers............................................ 91

6.4 Reactions of Monomers and Polymers with Cement Paste......................................... 93

7. Qualtry and Process Control................................................................................. 95

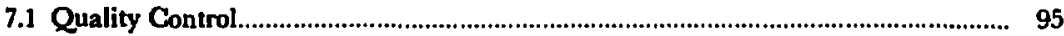

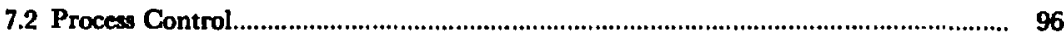

8. Applications DeVELofment........................................................................................... 97

8.1 Pipe Applications.................................................................................................... 97

8.1.1 Concrete Draintile........................................................................................ 97

8.1.2 Sewer and Culvert Pipe: Clooperative Program

8.1.3 Sewer Pipe: Cooperative Program With City of San Diego........................... 102

8.2 Precast Tunnel Supports and Linings..................................................................., 103

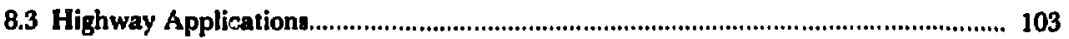

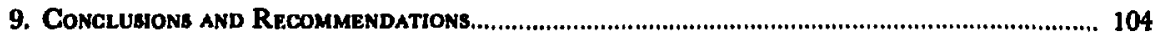

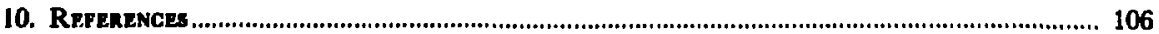


Figure 1. Compressive stress-strain curves for polymer-impregnated concrete....................................

Figure 2. Compressive strength of furfuryl alcohol polymer-concrete - first mix series

Fraure 3. Compressive strength of furfuryl alcohol polymer-concrete - second mix series.

Figure 4. Polymer-concrete specimens after contact with boiling benzene for $24 \mathrm{hr}$.

Figure 5. Compressive stress-strain curves for polymer-concrete.

Figure 6. Impregnation-rate curves and compressive strength measurements for high-pressure steam-cured CP-type concrete.

Figure 7. Impregnation-rate curves and compressive strength measurements for high-pressur: steam-cured concrete containing expanded shale aggregate.

Figure 8. Inpregnation-rate curves and compressive strength measurements for high-pressure steam-cured concrete having a water-to-cement ratio of 0.6.

Figure 9. Impregnation-rate curves and compressive strength measurements for high-pressure steam-cured conerete having a high air content......

Frgure 10. Comparison of impregnation rates and compressive strength measurements of various concretes.

Figure 11. Effect of monomer viscosity on the impregnation rate and final compressive strength of concrete containing expanded shale aggregate......

FraurE 12. Effect of monomer viscosity on the impregnation rate and final compressive strength of concrete having $\mathbf{a}$ high water-ta-cement ratio.......

Figure 13. Effect of moitonier viscosity on the impregnation rate and final compressive strength of concrete having a high air content ...

Frgure 14. Concrete-lined steel pipes being treated with polyester-styrene at the OSW Water Desalting Facility, Frecport, Texas.

Figure 15. Flow sheet of concrete-polymer materials plant.

Fugure 16. Change in viscosity of MMA during initial stages of polymerization by promoter-catalyst techrifiues.

Figure 17. Effects of additives on the change in viscosity of MMA at $32^{\circ} \mathrm{C}$ during initial stages of polymerization by promoter-catalyst techniques

Figure 18. Cross sections of CP-type concrete specimens impregnated with MMA and thermal-catalytically polymerized.

Frgure 19. Flammability test of PIC specimen containing MMA (flame applied).

FIguRE 20. Flammability test of PIC specimen containing MMA (flame removed)

Figure 21. Schematic diagram of direct tension test

Fugure 22. Schematic diagram of single-shear test

Ficure 23. Schematic diagram of double-shear test

Ficure 24. Schematic diagram of flexure test for partially impregnated beams.

Frouxe 25. Schematic diagram of fiexure test for steel-reinforced beams.
Figure 26. Schematic diagram of shear test for steelreinforced beams................................................

Figure 27. Flexure test of bars of unimpregnated and styrene-TMPTMA impregnated CP-type concrete...

Figure 28. Flexure test of bars of MMA-TMPTMA impregnated CP-type concrete

Figure 29. Compressive strength of PIC containing styrene-TMPTMA after immersion in brine at $143^{\circ} \mathrm{C}$.

Figure 30. Predicted and experimental variation of Young's modului for mortar with a water-to-cement ratio of 0.5 as a function of sand content.

Figure 31. Predicted and experimental variation of Young's modulus for mortar with a $-3 / 6$-in. to +4 mesh aggregate content.

Figure 32. Polymer-impregnated concrete and normal concrete after failure.

Figure 33. Polymer-impregnated steel-aggregate concrete and unimpregnated steel-aggregate concrete after failure..

Figure 34. Stress-strain curve for polymer-impregnated steel-aggregate concrete and polymer-impregnated steel-wire-reinforced mortar..

Figure 35. Compaison of pore size distributions for cement pastes.

Figure 36. Differential thermal analysis of styreneTMPTMA, after various exposures

Figur: 37. Differential thermal analysis of MMATMPTMA, after various exposures.................... 92

Figure 38. Cylinders of styrene-TMPTMA polymer after 6 months of ejposure at $150^{\circ} \mathrm{C}$.......................

Figure 39. Differential thermal analysis of calcium methacrylate reaction products........................... 94

Figure 40. Acoustic impact testing unit.................. 95

Figure 41. Vibration spectrum of concrete cylinder 96

Figure 42. ACPA pipe being removed from drying oven prior to impregnation at BNL....................... 100

Figure 43. ACPA pipe being placed in steel container prior to impregnation at BNL...

Figure 44. ACPA pipe and steel container being lowered into BNL impregnation facility.

Figure 45. ACPA pipe and container being lowered into BNL irradiation facility,

Figure 46. ACPA pipe after impregnation with MMA and radiation polymerization..................... 100

Fugure 47. Weighing 36-in,-i.d. concrete pipe........... 101

Figure 48. Concrete pipe placed in $7 \times 4 \times 4-f t$ oven for drying.

Ftoure 49. Concrete pipe with lifting bracket next to 34.5-in.-o.d. spacer.

Figure 50. Concrete pipe on volume displacement spacer being lowered into impregnator.................. 101

Figure 51. Impregnator lid being lowered on top of impregnator tank................................................. 101

Figure 52. Bolting impregnator lid on tank............. 101

Froure 53. Concrete sewer pipes fully impregnated with polyester-styrene and the inner surfaces coated with polyester-styrene. 
Table 1. Polymer-concrete: Effects of silane coupling agent on compressive strength.

Table 2. Summary of the effects of concrete composition and curing method on the absorption, polymer loading, and compressive and tensile strengths of unimpregnated and MMA-impregnated concete

TABle 3. MMA-TMPTMA monomer systems for penetrating and protective coatings..

TABLE 4. Formula for USBR polymer-concrete.....

Table 5. Summary of properties tests on 6-in.-diam $\times$ 12-in.-long polymer-concrete cylinders.

TABle 6. Thermal polymerization of radiationconditioned monomers.

Table 7. Thermal polymerization of monomer-impregnated concrete specimens..

TABL 8. Curing of low-viscosity monomers.

Table 9. Polymerization techniques..

Table i0. Summary of mechanical and physical properties of polymer-impregnated concrete, CP test series.

TABre 11. Compressive and tensile strengths of CPtype concrete impregnated with $10 \mathrm{wt} \%$ polyester 90 wt \% styrene, CP-7 test series.

TABLE 12. Flexural strength of CP-type concrete impregnated with 10 wt \% polyester -90 wt \% styrene, CF-7 test series

Table 13. Shotblast abrasion, CP-7 and CP-8 test series

TABle 14. Summary of durability properties of polymer-impregnated concrete, $\mathbf{C P}$ test series ............ 32-33

Table 15. Resistance to freezing and thawing of polymer-impregnated concrete, $\mathrm{CP}$ test series........

TABle 16. Resistance to sulfate attack of polymerimpregnated concrete, CP test series.

TABle 17. Compressive strength of polymer-impregnated concrete after exposure to $5 \% \mathrm{NaOH}, \mathrm{CP}$ type concrete.

Table 18. Resistance of polymer-impregnated concrete to $5 \% \mathrm{H}_{2} \mathrm{SO}_{4}$

Table 19. Resistance of polymer-impregnated concrete to $15 \% \mathrm{HCl}, \mathrm{CP}$ test series

Table 20. Weatherometer tests, polymer-impregnated concrete.

Table 21. Effect of soil microorganisms on polymerimpregnated concrete.

TABLE 22. Determination of the relative flammability of plastics, polymer-impregnated concrete, and polymer-concrete composites.

TABle 23. Ultimate design tensile strength and elastic properties, polymer-impregnated concrete for ambient-temperature applications.

TaBle 24. Ultimate design compresgive strength and elastic properties, polymer-impregnated concrete for ambient-temperature applicatic ns.

Table 25. Low-temperature tensile strength, short term, MMA-impregnated concrete.,

Table 26. Low-temperature tensile strength, short term, polyester-styrene impregnated concrete........

TABLE 27. Low-temperature tensile strength, short term, unimpregnated concrete.
TAble 28. Comparison of average elastic properties determined in direct tension and compression tests (low temperature, short term) ..............................

TABLE 29. Shear tests, single- and double-shear methods, MMA-impregnated and unimpregnated concrete.

Table 30. 800-psi compressive creep tests, CP test series specimens.

Tarle 31. Compressive strength of creep test specimens 3 to $4 \frac{1}{2}$ years under 800 -psi sustained compressive load.

TABLe 32. High-stress tensile and compressive creep, polymer-impregnated CP-type concrete.

TABLE 33. Partially impregnated concrete in flexure, ultimate load.

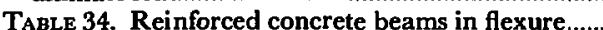

TABLE 35. Reinforced concrete beams in shear..........

Table 36. Flexure tests, MMA-impregnated concrete......

Table 37. Compressive and direct tensile strength tests, MMA-impregnated concrete...........................

TABle 38. Resistance to $15 \% \mathrm{HCl}$, partially impregnated concrete - first test series..............................

TABLE 39. Resistance to sulfate attack, partially impregnated concrete - first test series.

Table 40. Compressive strength, partially impregnated concrete - second test series.........................

TABLE 41. Resistance to freezing and thawing, partially impregnated concrete - second test series......

Table 42. Resistance to $5 \% \mathrm{H}_{2} \mathrm{SO}_{4}$, partially impregnated concrete - second test series.

TABLE 43. Resistance to sulfate attack, partially impregnated concrete - second test series...................

Table 44. Resistance to $5 \% \mathrm{H}_{2} \mathrm{SO}_{4}$, partially im. pregnated CP-type concrete - third test series........

TABLE 45. Resistance to $5 \% \mathrm{H}_{2} \mathrm{SO}_{4}$, partially impregnated high-entrained-air concrete - third test series.

Table 46. Ultimate design compressive strength and elastic properties, polymer-impregnated concrete for high-temperature applications.

TABLE 47. Ultimate design direct tensile strength and elastic properties, polymer-impregnated concrete for high-temperature applications.

TABLE 48. Comparison of tensile strength average and design values determined in direct tension and tensile splitting tests.

TARLE 49. Compressive strength of unimpregnated and styrene-TMPTMA impregnated concrete after short-term exposure at $177^{\circ} \mathrm{C}$.

Table 50. Compressive strength of MMA-TMPTMA impregnated concrete after short-term exposure at $21^{\circ}, 121^{\circ}$, and $143^{\circ} \mathrm{C}$

TABLE 51. Compresnive strength of MMA-TMPTMA impregnated concrete, initial tests for long-term exposure tests at $-23^{\circ}, 21^{\circ}, 121^{\circ}$, and $143^{\circ} \mathrm{C} \ldots .$.

TAnle 52. Compressive strength of unimpregnated and MIMA-TMPTMA impregnated concrete, initial tests at $121^{\circ}$ and $143^{\circ} \mathrm{C}$ for three-phase brineloop exposure tests. 
Table 53. Average values for compressive strength and elastic properties, unimpregnated, styreneTMPTMA impregnated, and MMA-TMPTMA impregnated concrete.

TaBue 54. Direct tensile strength of unimpregnated concrete after short-term exposure at $21^{\circ}, 121^{\circ}$, and $143^{\circ} \mathrm{C}$.

TABle 55. Direct tensile strength of styrene-TMP. TMA impregnated concrete after short-term exposure at $21^{\circ}, 121^{\circ}$, and $143^{\circ} \mathrm{C}$.

Table 56. Comparison of direct tensle strength with tensile splitting strength, unimpregnated and styrene-TMPTMA impregnated concrete... 。

TABLE 57. Tensile splitting after short-term exposure at $177^{\circ} \mathrm{C}$, unimpregnated and styrene-TMPTMA impregnated CP-type concrete.

Table 58. Tensile splitting strength after short-term exposure at various temperatures, MMA-TMPTMA impregnated concrete.

TABLE 59. Tensile splitting strength after short-term exposure of MMA-TMPTMA impregnated concrete at various temperatures, initial tests for longterm exposure.

TABle 60. Flexural strength of unimpregnated concrete and styrene-TMPTMA impregnated concrecte at $21^{\circ} \mathrm{D}$.

TABr.E 6! Flexural strength of uninipregnated concrete and styrene-TMPTMA impregnated concrete after short-term expesure at $121^{\circ} \mathrm{C}$..

TABle 62. Flexural strength of unimpregnated concrete and styrent-'TMPTMA impregnated concrete after short-term exposure at $143^{\circ} \mathrm{C}$.

TABLe 63. Flexural strength of MMA-TMPTMA impregnated concrete at $21^{\circ} \mathrm{C}$.

Table 64. Flexural strength of MMA-TMPTMA impregnated concrete after short-term exposure at $121^{\circ} \mathrm{C}$.

TABle 65. Flexural strengtix of MMA-TMPTMA impregnated concrete after short-term exposure at $143^{\circ} \mathrm{C}$.

TABLE 66. Average values for strength and modulus of elasticity as determined from flexure tests, unimpregnated, styrene-TMPTMA impregnated, and MMA-TMPTMA impregnated concrete..............

TABle 67. Shear strength of unimpregnated concrete, single-shear test method.

TABLE 6B. Shear strength of styrene-TMPTMA impregnated concrete, single-shear test method..........

TABLe 69. Shear strength of MMA-TMPTMA impregnated concrete, single-shear test method..........

TABLe 70. Comparison of shear test results, singleshear and double-shear methods.

TABle 71. High-temperature high-stress creep, polymer-impregnated OSW-type concrete....................

TABLE 72. High-temperature strength of creep test specimens, polymer-impregnated OSW-type con.crete.

TA BLe 73. High-temperature high-stress creep, polymer-impregnated CP-type concrete .

TABLE 74. High-temperature strength of companion specimens for creep test, polymer-impregnated CP. type concrete.

TABle 75. Flexural strength of reinforced concrete and reinforced impregnated conc. ete after shortterm exposure at $143^{\circ} \mathrm{C}$

TABLE 76. Shear strength of reinforced concrete and reinforced impregnated concrete after short-term exposure at $143^{\circ} \mathrm{C}$.

TABLE 77. Flexural strength of unimpregnated and polymer-impregnated concrete after short-term exposure at $143^{\circ} \mathrm{C}$.

Table 78. Compressive and tensile strengths of unimpregnated and styrene-TMPTMA impregnated concrete after short-term exposure at $143^{\circ} \mathrm{C}$...........

Table 79. Compressive strength and elasticity of styrene-TMPTMA impregnated concrete after two-year exposure to brine at $121^{\circ} \mathrm{C}$.

TaBle 80. Compressive strength and elasticity of styrene-TMPTMA impregnated concrete after two-year exposure to brine at $143^{\circ} \mathrm{C}$.

Tafle 81. Coinpressive strength and elasticity of styrene-TMPTMA impregnated concrete after one-vear exposure at $143^{\circ} \mathrm{C}$ in three-phase test loops...

Table 82. Compressive strength and elasticity of unimpregnated concrete after one-year exposure at $143^{\circ} \mathrm{C}$ in three-phase test loops..

TaBle 85. Effect of length of exposure in three-phase loops at $143^{\circ} \mathrm{C}$ on the compressive strength of unimpregnated and styrene-TMPTMA impregnated concrete.

Taule 84. Thermal coefficient of expansion of styreneTMPTMA impregnated CP-type concrete.............

Table 85. High-temperature thermal properties of unimpregnated and styrene-TMPTMA impregnated OSW-type concrete.

Table 86. Dimensional and weight changes in polymer-impregnated concrete after exposure to hot brine.

TABLe 87. Compressive strength and weight loss, polymer-impregnated concrete exposed to deionized water at $143^{\circ} \mathrm{C}$.

TABle 88. Properties of styrene-TMPTMA impregnated OSW-type concrete exposed to brine ai elevated temperatures.

TABle 89. Properties of styrene-TMPTMA impregnated CP-type concrete exposed to brine, vapor, and brine-vapor interface at elevated temperatures

TABle 90. Pore content of polymer-impregnated cement.............................................................

TABLe 91. Stability of 60 wt $\%$ styrene -40 wt $\%$ TMPTMA polymer after 6 months' exposure at $150^{\circ} \mathrm{C}$ to brine, water, air, and $\mathrm{Ca}(\mathrm{OH})_{2}$ slurry ${ }^{\prime} .$.

TABle 92. Dielectric tests, MMA-impregnated concrete.

Table 93. Stability of various chemical initiatons in methyl methacrylate at $23^{\circ} \pm 2^{\circ} \mathrm{C}$.

TABle 94. Resistance to sulfate attack, polymer-impregnated concrete draintile.

TABLE 95. Preliminary impregnation data for $\mathrm{ACPA}$ test program.......................................................... 99

Table 96. San Diego sewer pipe, summary of results 102 


\title{
CONCRETE-POLYMER MATERIALS
}

\author{
FIFTH TOPICAL REPORT
}

\section{SUMMARY}

This report covers work performed from July 1 , 1971, to June 30, 1972.

The development program for concrete-polymer materials covers three distinct types of material: polymer-impregnated concrete (PIC), polymerconcrete (PC), and polymer-cement concrete (PCC).

Concrete-polymer materials offer potential advantages of high strength and improved durability, as compared with conventional concrete. Because consistently good results were obtained with PIC in early tests, the main efforts in the program have been directed toward its development. Investigations are continuing with PC and PCC because these materia's have many potential applications.

Progress in the development of $\mathrm{PC}$ as a practical construction material has continued with the development of an economical fabrication process. The new process uses conventional concrete mixing and placing equipment and produces a product which, on the basis of initial tests, has about the same polymer content and compressive strength as standard PIC. The product may be polymerized at room temperature by promoter-catalyst methods. PG should be more economical to produce than PIC since it does not require special process equipment and it can be field-installed using the techniques used for conventional concrete. Studies were continued on increasing the compressive strength of PC through the use of silane coupling agents. An investigation was started to determine whether the plasticity of PC could be increased by copolymerizing methyl methacrylate (MMA) and butyl acrylate.

Investigation of PCC continued on a limited basis with a preliminary study of furfuryl alcohol PCC. Studies to date have shown strength improvements with furfuryl alcohol similar to those found previously with epoxy resins. ${ }^{14}$ However, large amounts of epuxy resins were required to increase compressive strengths. Furfuryl alcohol appears proinising since it can be polymerized in an alkaline environment, does not appear to interfere with the hydration of portland cement, and is much lower in cost than epoxy resins. Increases in compressive strength of up to $24 \%$ were obtained with relatively small amounts of furfuryl alcohol.

Monomer survey experiments continued with an evaluation of diallyl isophthalate (DAIP), a mixture of $50 \mathrm{wt} \% \mathrm{MMA}$ and $50 \mathrm{wt} \%$ ethylene glycol dimethacrylate (EGDM), and a mixture of $70 \mathrm{wt} \%$ MMA and $30 \mathrm{wt} \%$ trimethylolpropane trimethacrylate (TMPTMA) for high-temperature applications in desalting plants. Based on short-term exposure tests to brine and vapor at $143^{\circ}$ and $177^{\circ} \mathrm{C}$, the MMA-TMPTMA system was selected for further testing.

Several plasticizers were tested as additives for monomer systems to increase the flexibility or plasticity of PIC. Stress-strain curves showed that using 35 wt \% butyl acrylate - 65 wt \% MMA produced the most pronounced effect in PIC. However, it appears that the concrete itself has an overriding effect and that for a wider change in mechanical properties, energy-absorbing materials should be incorporated into the concrete.

The basic procedure for fully impregnating precast concrete, described in detail in the First and Second Topical Reports, ${ }^{1,2}$ consists of oven-drying the concrete, evacuating the dried sample, soaking it in monomer, wrapping the specimen, and polymerizing it by radiation or chemical initiators. Work is in progress to evaluaie process variables and to improve specimen preparation techniques. These studies include the determination of the effects of concrete composition, method of curing, monomer-filling techniques, the use of different catalysts and polymerization techniques, and the development of methods for reducing monomer evaporation and drainage losses and elimination of specimen wrapping.

Studies were continued on the effects of composition of the concrete and concrete curing conditions on compressive strength and polymer loading of PIC. Compressive strengths of PIC specimens ranged from about 17,000 psi for PIC made with 
a poor-quality high-porosity limestone aggregate to 32,400 psi for a high-strength, high-pressure steam-cured specimen; this is the highest compressive strength obtained to date. These tests indicate that good-quality PIC can be produced from concrete containing very-poor-quality aggregates. The primary factors in producing good-quality high-strength PIC appear to be achievement of a high degree of impregnation and complete polymerization. For production of very-high-strength PIC, a high-strength concrete mix with high-pressure steam curing is advantageous.

Experiments are in progress to determine the vacuum time, soaking time, and pressure requirements for full impregnation of various types of concrete: Impregnation rates depend on the porosity of the portland cement matrix and to a certain extent on the porosity of the aggregate. For impregnation of standard-weight, high-pressure steam-cured concrete specimens up to 12 in. thick, the recommended process consists of oven-drying the specimens to constant weight, evacuation at $30 \mathrm{in}$. $\mathrm{Hg}$ for $\mathbf{3 0} \mathrm{min}$, soaking in monomer for 60 $\min$ at $10 \mathrm{psig}$, and polymerization under water by radiation or thermal-catalytic methods.

Partial impregnation and coating techniques were developed for protective treatment of concrete linings in desalting plants. The concrete liner of a flash distillation chamber and various sections of mortar-lined steel pipe were treated and are being field-tested at the OSW Water Desalting Facility in Freeport, Texas. Two monomer systems werc used: $60 \mathrm{wt} \%$ styrene $-40 \mathrm{wt} \%$ TMPTMA followed by a seal coat of 53 wt \% polyester - 28 wt \% styrene - 19 wt \% TMPTMA; and 70 wt \% MMA - 30 wt \% TMPTMA followed by a seal coat prepared by dissolving 20\% MMA prepolymer and a small amount of paraffin wax in some of this mixture. Polymerization of both systems was accomplished at ambient temperatures by promoter-catalyst methods. Preliminary inspection after 6 weeks of normal operation indicated no deterioration in the treated areas.

Stindies of polymerization techniques have included experiments to remove the inhibitor in a monomer by radiation and then thermally polymerize the uninhibited and uncatalyzed monomer. A process flow sheet was developed for impregnating concrete and other porous materials and polymerizing by the thermal method. Other polymerization techniques studied were promoter-catalyst methods for ambient-temperature polymeriza- tion, polymerization of impregnated specimens immersed in water to reduce monumer drainage and evaporation, and thermal-catalytic polymerization of specimens in the impregnation tank with use of steam heat.

The testing program on PIC for ambient-temperature applications is continuing. Structural properties of MMA, styrene, acrylonitrile, MMA 10 wt \% TMPTMA, chlorostyrene-impregnated concrete, and MMA-impregnated concrete polymerized under water, are given in previous topical reports. ${ }^{1-4}$ Results for $10 \mathrm{wt} \%$ polyester - $90 \mathrm{wt} \%$ styrene-impregnated concrets are given in this report. The polyester and styrene specimens were polymerized by radiation and had an average compressive strength of $20,500 \mathrm{psi}$, modulus of elasticity of $6.5 \times 10^{6} \mathrm{psi}$, direct tensile strength of $1530 \mathrm{psi}$, and modulus of rupture of $3300 \mathrm{psi}$.

Structural properties tests during the year included direct tension tests at $-12^{\circ} \mathrm{C}$ and $20^{\circ} \mathrm{C}$, single- and double-shear tests, continuation of long-term creep tests under several compressive and tensile loadings, flexural strength tests of beams impregnated from one and two sides, and flexure and shear tests of steel-reinforced PIC beams. Preliminary design values were obtained for tensile strength at $-12^{\circ} \mathrm{C}$ and $20^{\circ} \mathrm{C}$ of MMA and of 10 wt \% polyester - 90 wt \% styrene PIC. Shear tests indicated that single-shear or double-shear test methods have little effect on results with PIC. The shear strength of MMA-impregnated concrete is $\approx 3700 \mathrm{psi}$, two to three times greater than that of unimpregnated concrete.

Durability tests include resistance to freezing and thawing, acids, sulfates, sodium hydroxide, and weathering. Freeze-thaw tests of PIC show all specimens to have greatly improved durability when compared with unimpregnated concrete. An MMA-impregnated and radiation-polymerized specimen that has been in test for the longest time has shown only $0.5 \%$ weight loss after 12,010 cycles, an improvement of $>1523 \%$ over unimpregnated concrete. Unimpregnated concrete generally fails the test at about 740 cycles with a $25 \%$ weight loss. PIC specimens still under test include MMA - 10 wt \% TMPTMA with no weight loss at 9450 cycles, acrylonitrile with $11 \%$ weight loss at 8910 cycles, MMA radiation-polymerized under water with $2 \%$ weight loss at 2780 cycles, and $10 \mathrm{wt} \%$ polyester - $90 \mathrm{wt} \%$ styrene with $1 \%$ weight loss at 1530 cycles. Testing has been concluded on MMA, styrene, chlorostyrene, and the bulk of the 
MMA - 10 wt \% TMPTMA and acrylonitrile specimens.

In the accelerated sulfate attack test, PIC specimens have shown moderately to greatly improved resistance as compared with unimpregnated concrete. MMA-impregnated concrete has been under test longer than other CP test series specimens and has shown from 0.016 to $0.032 \%$ expansion after 1436 cycles. Unimpregnated concrete failed the test at 480 cycles with $0.5 \%$ expansion.

Unimpregnated concrete and MMA, $10 \mathrm{wt} \%$ polyester - $90 \mathrm{wt} \%$ styrene, and $60 \mathrm{wt} \%$ styrene 40 wt \% TMPTMA PIC specimens were continuously exposed to a $5 \%$ solution of sodium hydroxide for $>1$ year. All specimens showed no loss in weight and no visible signs of deterioration. After removal from test, specimens had compressive strengths ranging from 16,000 to 19,000 psi for PIC specimens and 6500 psi for unimpregnated concrete.

Acid-resistance tests were conducted with PIC specimens immersed in $15 \% \mathrm{HCl}$ and $5 \% \mathrm{H}_{2} \mathrm{SO}_{4}$. Weight losses from exposure to $15 \% \mathrm{HCl}$ ranged from 10 to $12 \%$ for MMA specimens after 1395 days of exposure to about $12 \%$ for chlorostyrene specimens after 882 days. Unimpregnated concrete specimens failed with $25 \%$ weight loss after 105 days. In the $5 \% \mathrm{H}_{2} \mathrm{SO}_{4}$ test, which is still in progress, $10 \mathrm{wt} \%$ polyester - $90 \mathrm{wt} \%$ styrene and MMA specimens polymerized under water show a weight loss of about $17 \%$ after 252 days. Unimpregnated concrete failed the test with a $32 \%$ weight loss after $\mathbf{2 1 0}$ days. Sewer pipe impregnated with MMA and coated with polyester-styrene has shown no attack after exposure for 150 days to $5 \% \mathrm{H}_{2} \mathrm{SO}_{4}$.

Flammability tests patterned after ASTM D 635-68, Flammability of Self-Supporting Plastics, were performed on PIC an $A$ PC specimens and on the polymers themselves. Most of the polymers support combustion according to this test, but when incorporated in PIC or PC, the composite materials are either self-extinguishing or do not burn at all.

Development of partially impregnated concrete as a less costly alternative to fully impregnated concrete continued during the year. Durability tests (freeze-thaw, sulfate attack, and resistance to acid) show generally beneficial but somewhat erratic improvement in durability as compared with unimpregnated concrete. A new series of tests was started to evaluate partially impregnated con- crete prepared from a concrete mix with a high entrained air content, and high-pressure steamcured concrete.

Development of PIC for desalting plant applications continued with testing of 60 wt \% styrene 40 wt \% TMPTMA and 70 wt \% MMA - 30 wt \% TMPTMA impregnated concrete for compressive strength, tensile strength, flexural strength, shear strength, thermal properties, creep deformation, and long-term exposure to distilled water, brine, vapor, and the brine-vapor interface. Tests were conducted at temperatures ranging from $-23^{\circ}$ to $177^{\circ} \mathrm{C}$.

Preliminary design values have been calculated for compressive strength, Poisson's ratio, and modulus of elasticity for 70 wt \% MMA - 30 wt \% TMPTMA and 60 wt \% styrene - 40 wt \% TMPTMA impregnated concrete at various temperatures. The values were obtained from compressive strength tests and are for short-term exposures at the various temperatures. A trend toward lower values with increasing temperature was observed. The lowest values for compressive strength, found at $143^{\circ} \mathrm{C}$, are 13,700 psi for the styrene - TMP. TMA and 12,000 psi for the MMA - TMPTMA impregnated concrete.

OSW-type concrete impregnated with $60 \mathrm{wt} \%$ styrene -40 wt \% TMPTMA has been exposed for 2 years to brine at $121^{\circ}$ and $143^{\circ} \mathrm{C}$. CP-type concrete impregnated with the same monomer system has been exposed for 1 year to brine, vapor, and the brine-vapor interface at $121^{\circ}$ and $143^{\circ} \mathrm{C}$. The PIC specimens show a trend toward lower compressive strengths with increases in exposure time and temperature. Compressive strengths ranged from 16,200 psi for specimens exposed for 215 days in $121^{\circ} \mathrm{C}$ brine to 10,300 psi for specimens exposed for 2 years in $143^{\circ} \mathrm{C}$ brine. The specimens also show minor increases in weight, due to moisture absorption, and '. small progressive expansion with increase in exposure time and temperature. Specimens of 70 wt \% MMA - 30 wt \% TMPTMA impregnated concrete are being tested, but results are not yet available. In pressure vessel tests of PIC specimens exposed to brine and distilled water, 70 wt \% MMA - 30 wt \% TMPTMA PIC specimens were observed to undergo failure after 270 days of exposure at $143^{\circ} \mathrm{C}$ and 83 days at $177^{\circ} \mathrm{C}$. Analysis of these results will determine whether continued testing of this system is desirable.

In the area of fundamental studies, composite materials theory was used to calculate the modulus 
of elasticity of concrete-polymer materials, porosimetry studies of high-pressure steam-cured cement paste were made, and the stability of $60 \mathrm{wt}$ \% styrene - 40 wt \% TMPTMA polymer exposed to brine at high temperatures was determined. The high modulus of elasticity of PIC appears to result from the stiffening produced by incorporation of a rigid polymer into the pores of the cement paste.

High-pressure mercury porosimetry studies showed that cement paste with a high water-tocement ratio has a group of large pores that are not present in cement paste with a low water-tocement ratio. Studies were also conducted to determine whether steam-cured and water-cured polymer-impregnated cement pastes undergo changes in porosity when exposed to a high-pressure steam environment. Results indicate that steam-cured cement is more stable than watercured cement in a high-pressure steam environment, and that polymer impregnation does not completely seal either water-cured or steam-cured cement.

The studies of 60 wt $\%$ styrene - 40 wt \% TMPTMA indicate that this polymer is stable in sealed exposure to brine, air, $\mathrm{Ca}(\mathrm{OH})_{2}$ slurry, and distilled water at $150^{\circ} \mathrm{C}$. In preliminary studies of 70 wt \% MMA - 30 wt \% TMPTMA PIC, several specimens have failed in exposure to hot brine. Differential thermal analysis has revealed changes in the MMA-TMPTMA polymer after exposure to hot brine, which indicates that the failure of PIC is due to degradation of the polymer rather than of the concrete.

Fundamental studies were conducted of the reaction between $\mathrm{MMA}$ and $\mathrm{Ca}(\mathrm{OH})_{2}$. One study indicated that $\mathrm{MMA}$ reacts with $\mathrm{Ca}(\mathrm{OH})_{2}$ during thermal polymerization. The other showed that MMA reacts rapidly with $\mathrm{Ca}(\mathrm{OH})_{2}$ in the presence of water to form calcium methacrylate and methyl alcohol. The significance of these findings is not understood.

In the search for nondestructive test methods for quality control of PIC, the acoustic impact and the dielectric methods were investigated. The acoustic method appeared more suitable for measuring resonant frequency than dampening of transmitted signals. Further work on dielectric and electrical resistivity measurements indicated that the dielectric method was not feasible for PIC.

The use of PIC as a construction material is under investigation in such diverse areas of applica- tion as desalting plants, concrete pipe, bridge decks, piling, housing construction, marine applications, and tunnel lining and support systems.

PIC draintile has been under test for 3 years in the laboratory and in the field at the Westlands Experimental Drainage Plot, Tranquillity, California. This area has a high concentration of sulfates in the soil. A field inspection last year revealed no indication of sulfur attack; further inspection is planned.

In a cooperative program with the American Concrete Pipe Association, 3-ft-i.d. $\times$ 6-ft-long lengths of concrete pipe are being impregnated and polymerized at the USBR and BNL. Steelfiber-reinforced concrete pipe has also been included in the program. The PIC pipes will be tested at the USBR next year. The testing program includes three-edge bearing and hydrostatic pressure tests and tests for resistance to attack by sulfate and sulfuric acid. The performance of the unreinforced PIC pipe will be compared with that of conventional steel-reinforced precast concrete pipe. The goal of the program is to provide design information, determine service requirements and manufacturing techniques, and make an evaluation of economic benefits.

Field tests of PIC sewer pipe are in progress in the San Diego sewage system in a cooperative program with the city of San Diego. In laboratory tests, PIC pipe specimens treated with a polyesterstyrene seal coat and exposed to 5\% sulfuric acid show no deterioration. PIC pipe installed in the San Diego sewage system is scheduled for inspection after 18 months in service.

A lov-cost high-strength PIC tunnel lining and support system is under development. A full-scale laboratory test was conducted on an 8-ft-i.d. tunnel test chamber. Tunnel liner segments of PIC and unimpregnated concrete were assembled in the test chamber, backfilled with concrete, and loaded until failure. Single segments were also tested for arch deflection and failure and analysis of the joint. The tests showed that 2-in.-thick PIC segments with 3.5 in. of concrete backfill can support $60 \%$ more load than a similar system composed of unimpregnated concrete segments. Further full-scale tests are planned for next year.

The Federal Highway Administration is interested in the potential of concrete-polymer materials for use in a number of highway applications. These include bridge decks, pilings, and culverts. Programs have started on design of a precast, pre- 
stressed PIC bridge-deck system, repair of deteriorated bridge decks, and treatment of new concrete bridge decks to improve durability.

\section{INTRODUCTION}

\subsection{Background and Program Description}

The Concrete-Polymer Materials Program was initiated in 1967 by the Division of Applied Technology, Isotopes Development Section (formerly the Division of Isotopes Development), of the U.S. Atomic Energy Commission (AEC) as a cooperative research and development program between the Department of Applied Science at Brookhaven National Laboratory (BNL) and the U.S. Department of the Interior's Bureau of Reclamation (USBR). Because of its interest in the potential application of concrete-polymer materials for the construction of vessels for sivater desalination plants, the Office of Saline Water (OSW) also contributed to the support of the program the same year. The OSW has a direct interest in improving the properties of concrete so that it can be effectively used as an economical material of construction in, for example, multistage distillation units in water desalting plants. The main characteristics required are resistance to chemical attack by hot brine and distilled water, and high strength. The Materials Technology Division of the OSW has provided ma. jor funding support for a portion of the ConcretePolymer Program and has contributed to the planning and development of the program. This function is now being performed by the Materials Research Division of the OSW.

Four topical reports have been published on the work performed to date. The first, 1 issued in January 1969 , covered the results to the end of June 1968. The second ${ }^{2}$ extended coverage through June 1969. The third ${ }^{3}$ and fourth ${ }^{4}$ describe work through June 1970 and June 1971, respectively. On the basis of this work a patent on the thermalcatalytic process for the production of PIC has been issued. ${ }^{5}$ The current report deals with work performed through June 1972.

A number of other governmental agencies and industrial associations have become interested in specific applications of concrete-polymer materials. Cooperative programs have been initiated with these agencies, as described in Section 2.3.

The long-range objectives of the program are the investigation and development of concretepolymer coinposite materials for use as improved or new materials of construction. At least three distinct types of material have been under investigation: (1) polymer-cement concrete (PCC), a premixed material of water, portland cement, and aggregate to which monomer or resin is added during mixing and subsequently cured and polymerized in place; (2) polymer-concrete (PC), consisting of an aggregate mixed with a monomer or resin that is subsequently polymerized in place; and (3) polymer-impregnated concrete (PIC), which consists of a precast portland cement concrete impregnated with a monomer system that is subsequently polymerized in situ. A fourth type of material, a further development of PIC, could be added to the list. This is precast concrete that has been partially impregnated to a finite depth with a monomer that is subsequently polymerized in situ. For each of these main types of material, process variations can be exercised, with resultant variations in properties and characteristics.

The main, and most successful, effort in improving the structural and durability properties of a portland cement concrete has been with PIC. As a result, the reports issued to date deal mainly with the development of this material. The least success has been attained with PCC. Since PCC would have the greatest potential for field applications, attempts to improve it have been continued. For a premixed material, PC seems most promising. This relatively new material has interesting properties, but to bring it into actual application will require great effort.

The Concrete-Polymer Materials Program has been divided into the following major tasks: (1) evaluation and selection of monomers for incorporation in concrete-polymer composites; (2) development of process techniques for preparation of the composites; (3) testing and measurement of pertinent physical, mechanical, and chemical properties; (4) development of applications including the design, preparation, and testing of full-scale specimens; (5) development of preliminary cost estimates for concrete-polymer products; and (6) conducting fundamental s'udies of concrete-polymer composites to obtain a basic understanding of the nature of these materials.

In the cooperative program for PIC development, the USBR fabricates the concrete specimens and ships them to BNL for impregnation and polymerization. At BNL, polymerization is initiated by ${ }^{60} \mathrm{Co} \gamma$ radiation or by thermal-catalytic techniques. The PIC specimens are returned to the 
USBR for measurement of structural and durability properties. In 1971 the USBR constructed and put in operation a facility for impregnation and for polymerization by the thermal-catalytic technique. BNL also prepares some concrete test specimens and performs preliminary structural and durability measurements. In the past year BNL has completed construction of a large-scale impregnation facility and placed it in operation. Both the USBR and BNL perform studies on PC materials. A lowlevel effort on PCC is being conducted at the USBR. A joint program plan is developed each year and at least two meetings are held annually for technical review of the programs in order to avoid duplication and to ensure augmentation and complementation of each laboratory's investigations.

\section{2 summuar of Pasmous Wonk}

The principal findings in the four previous topical reports are summarized below.

The testing program is continuing on PIC for ambient-temperature applications. Structural properties of MMA, styrene, acrylonitrile, MMA $10 \mathrm{wt} \%$ TMPTMA, and chlorostyrene-impregnated concrete have been measured. The properties of MMA-impregnated concrete radiationpolymerized under water have also been measured. Data from a test series impregnated with $10 \mathrm{wt} \%$ polyester $-90 \mathrm{wt} \%$ styrene are given in this report.

In general, all the composite systems showed significant improvements in strength and durability. The MMA and MMA-TMPTMA impregnated concretes have given the best results. High-pressure steam-cured samples impregnated with MMA in glass forms and radiation-polymerized had strengths up to $27,200 \mathrm{psi}$. The improvements in strength appear to be a function of polymer loading, and radiation polymerization gives slightly better strength properties than thermal-catalytic polymerization. Improvements in durability seem to be mainly a function of the polymer loading and the degree of success in sealing the surfaces of the concrete.

A number of preparation variables including concrete composition, method of curing, and duration of curing have been studied. Processing variables such as monomer-filling techniques, the use of different catalysts, and the development of methods for reducing monomer evaporation and drainage loseses are also being investigated.

On the basis of limited data it appears that minor changes in concrete composition do not sig- nificantly affect the compressive strength of PIC. This work has been expanded to include a wider range of mix variables and the results are given in this report.

Three methods of concrete curing, fog, low-pressure steam, and high-pressure steam, have been studied. The impregnation of high-pressure steamcured concrete with MMA produced PIC specimens with the highest compressive strengths obtained in the Concrete-Polymer Program.

Radiation-induced polymerization under water appeared to be a practical method for reducing monomer evaporation and drainage losses from concrete. Test data indicated that underwater polymerization of MMA had no detrimental effects on properties. The use of heated water as a means of initiating the thermal-catalytic polymerization of MMA has also been tested in the laboratory and appears to be an alternative processing method.

Two monomer systems, $60 \mathrm{wt} \%$ styrene $-40 \mathrm{wt}$ \% TMPTMA and $90 \mathrm{wt} \%$ diallyl phthalate (DAP) - 10 wt \% MMA, have been evaluated to determine the high-temperature structural properties and durability for applications such as would be encountered in desalting plants. Preliminary design values have been established for operating temperatures up to $143^{\circ} \mathrm{C}$. Resistance of specimens to chemical attack by hot brine and distilled water at temperatures up to $177^{\circ} \mathrm{C}$ is being measured in autoclave screening experiments and recirculating loops. Data for exposures for up to 1 year were available. The rate of attack on the styreneTMPTMA system by hot distilled water was very small. In brine, a trend to lower strengths with increased exposure time and temperature was indicated. Rapid deterioration of the DAP-MMA system was noted and as a result the tests were terminated. Six additional monomers were surveyed for OSW applications, and a system consisting of 70 wt \% MMA - 30 wt \% TMPTMA was selected for additional study. This work is discussed in the current report.

Investigations to develop reliable methods for quality control of concrete-polymer products were being continued. Although several promising methods have been explored, no simple, convenient, nondestructive technique that meets the unique requirements of concrete-polymer materials has been found.

Considerable progress has been made in the development of PC. Specimens produced by using 
MMA containing a silane coupling agent for improved bonding had polymer loadings of 5 to $6 \%$ and compressive strengths of 16,000 psi compared with strengths of 11,000 psi for sainples without silane. The monomer content of this material has been reduced to approximately that used in PIC.

To date little success has been obtained with PCC. Several monomer systems have been used to prepare samples; only epoxy resin showed limited promise of producing concrete with increased compressive strength. However, high concentrations of epoxy are required.

In this report, data are presented on the structural properties of PIC as well as on the longerterm mechanical properties, such as creep. Extensive data are given on durability properties, such as freeze-thaw, acid, and sulfate resistance, and data on resistance to chemical attack by brine and distilled water at temperatures up to $177^{\circ} \mathrm{C}$ are also presented.

Experiments to evaluate processing techniques for producing PIC have been continued and the results are summarized. Investigations on the incorporation of monomers in premixed concrete and the study of PC composites are described.

In addition, brief status reports on programs to evaluate the potential of PIC for use in pipes, tunnel supports, and bridge decks are presented.

\subsection{Coomipative Paograms} and OnHER DEvLlopments

Several government agencies have joined the Concrete-Polymer Program to investigate specific applications.

The Federal Highway Administration (FHWA) of the U.S. Department of Transportation is interested in the potential use of concrete-polymer materials for a number of highway applications, including improvement in the strength and durability of pavements, bridge decks, pilings, and culverts. Work has been performed at BNL on the use of structural lightweight and insulating lightweight concrete for breakaway lampposts and sign posts. Three-dimensional finite-element structural analysis for design of bridge decks has also been performed. Design and construction of reinforced PIC bridge-deck panels have been initiated at the USBR in a cooperative program between the USBR, the FHWA, and the Prestressed Concrete Institute (PCI). Recently, studies were initiated by the FHWA on partial in-depth impregnation in the field of new concrete bridge decks (USBR) and on the repair of deteriorated bridge decks (BNL). Several reports have been prepared on the FHWA work and the program is continuing. ${ }^{6-9}$

The Naval Givil Engineering Laboratory (NCEL), at Port Hueneme, California, has been interested in high-strength concrete with low water permeability for use in underwater applications. In cooperation with BNL exploratory tests on impregnated hulls have been conducted. ${ }^{10}$ More recently independent studies of partial impregnation have been conducted at NCEL.11

The Construction Engineering Research Laboratory (CERL) of the Department of the Army, Champaign, Illinois, has shown interest in polymer-impregnated lightweight concrete for military housing applications.

The Bureau of Mines (USBM) of the U.S. Department of the Interior is interested in applying the technology developed in the concrete-polymer program to the strengthening of rock structures in mines for improving underground support and mine safety systems. The first annual report on the USBM work has been issued. 12 The program involves impregnation of coal-mine rock and development of a pumpable polymer rockbolt to replace conventional steel rockbolts.

A cooperative program with the city of San Diego to test polymer-impregnated sewer pipe is in progress. The effort involved development of techniques for impregnating 8-in.-diam sewer pipe conforming to ASTM Designation C-14 and the testing of $\mathbf{4 0} \mathrm{ft}$ of impregnated sewer pipe in the San Diego sewer system.

A program at the USBR on the design and construction of PIC tunnel linings is part of an overall program conducted by the Department of the Interior on rapid tunneling techniques and testing of various linings. PIC tunnel linings give promise of providing a more competent and economical installation. Plans are being made to install a test section in a tunnel.

A cooperative program between the USBR, BNL, USAEC, and the American Concrete Pipe Association (ACPA) was established in 1970 to study polymer-impregnated sewer and culvert pipe. A number of 3-ft sections of 12- and 24-in.diam pipe were impregnated and tested. The results of three-edge bearing and hydrostatic tests showed sufficient improvement in strength to warrant further investigation. As a result, twenty-eight 6-ft lengths of 36-in.-diam pipe made by two methods, the roller suspension and the packer head 
process, have been impregnated and are being tested. The properties of unimpregnated steel-reinforced pipe will te compared with those of radiation- and thermal-catalytically polymerized unreinforced pipe. A detailed economic evaluation is planned at the end of these tests.

The Perlite Institute has become interested in the possibility of producing a structurally strong lightweight concrete by polymer impregnation of perlite cement. ${ }^{13}$

The work on concrete-polymer materials has stimulated worldwide interest in conducting studies and in developing applications of these materials. Reports of such work come from Japan, Italy, the Union of South Africa, Norway, Spain, France, Sweden, Great Britain, West Germany, and the Soviet Union.

In the past year the American Concrete Institute (ACI) has established Committee 548 to report on all phases of development of polymers in concrete. Symposia were held in November 1972 in Hollywood, Florida, and March 1973 in Atlantic City, and a seminar was held in Denver in April 1973. A state-of-the-art review is also being planned for publication by the ACI.

\subsection{Data Bayk}

The information for each specimen examined or tested as part of the Concrete-Polymer Materials Program will be made available through a data bank or data information system. Programming of the data bank of concrete-polymer materials was initiated last year. Upon completion, it will be possible to extract any one item, selected items, or all items of information pertaining to an individual specimen. This information can also be obtained for any group of specimens whose data are within some predetermined parameters. Thus, it will be possible to retrieve as much or as little information as desired. The data bank will be operational on the Control Data Corporation 3800 computer system and, after modification, other computer systems.

\section{MONOMER AND COMPOSITE SURVEY EXPERIMENTS}

The selection of monomers for use in the preparation of concrete-polymer materials depends primarily on the requirements of the proposed application. In general, monomers are selected for two operating conditions: ambient temperature $\left(<100^{\circ} \mathrm{C}\right)$, and temperatures $>100^{\circ} \mathrm{C}$.

\subsection{POlymer-Impatenated CONCRmE Studies}

3.1.1 Monomer Selection for High-Tomporeture Applications. A series of screening tests for high-temperature polymer systems has been completed. The systems under study were diallyl isophthalate (DAIP), a mixture of $50 \mathrm{wt} \%$ MMA and $50 \mathrm{wt} \%$ ethylene glycol dimethacrylate (EDGM), and a mixture of $70 \mathrm{wt} \% \mathrm{MMA}$ and 30 wt \% trimethylolpropane trimethacrylate (TMPTMA). The screening procedures and the thermal and mechanical properties for these systems were described in Ref. 4 . The system that appeared most stable after short-term autoclave tests in brine and water vapor at $143^{\circ}$ and $177^{\circ} \mathrm{C}$ was the mixture of MMA and TMPTMA. This system has since been subjected to additional testing in hot brine and distilled water (see Section 5.2.2.1).

A concentrated effort has been made to develop a low-temperature polymerization method for the 60 wt \% styrene - 40 wt \% TMPTMA system using promoter-catalyst systems. The thermalcatalytic and radiation-induced polymerization of the styrene-TMPTMA system has been studied previously with satisfactory results. ${ }^{2-4}$ The development of a promoter-catalyst system (see Section 4.5.2) extends the use of a high-temperature polymer to partial impregnations and coatings for field-type application. This has been demonstrated in a field application for the OSW (see Section 4.3.1).

A sealant that will resist high temperature has also been developed for increasing the durability of concrete. The formulation consists of an unsaturated polyester dissolved in a $60 \mathrm{wt} \%$ styrene -40 wt \% TMPTMA monomer mixture. The polyester concentraition of the mixture can be varied to obtain the desired viscosity. Formulations containing as much as $65 \mathrm{wt} \%$ polyester that have been tested in accordance with screening procedures previously described ${ }^{4}$ have shown good thermal, mechanical, and durability properties. The ability of the material to cure rapidly at ambient temperature when $1 \mathrm{wt} \%$ benzoyl peroxide and $1 \mathrm{wt} \%$ dimethyl aniline are used makes it applicable for direct use as an impregnant for concrete or as a coating on an impregnated specimen. The application of this system in an OSW facility is discussed in Section 4.3.1.

3.1.2 Plasticizors. The compressive stressstrain properties of MMA-impregnated concrete indicate that the composite is a hard, brittle mate- 


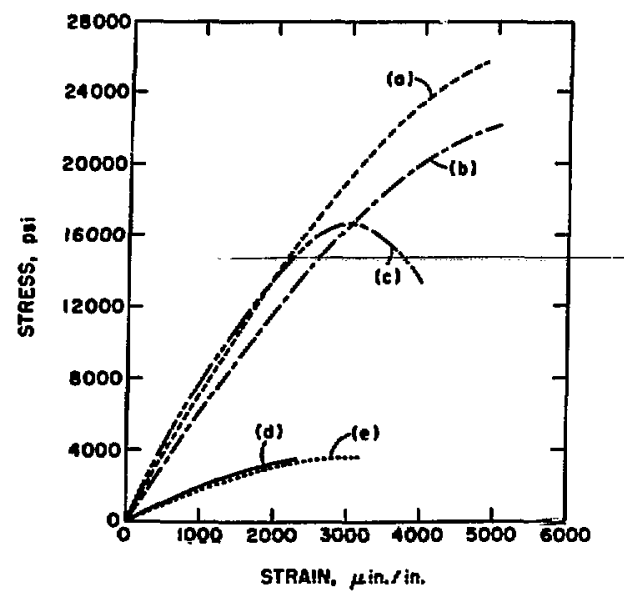

Figure 1. Compressive stress-strain curves for polymerimpregnated concrete. Curve $a$, MMA; curve 6,75 wt $\%$ MMA - 25 wt $\%$ dibutyl phthalate; curve $c, 65$ wt $\%$ MMA - 35 wt $\%$ butyl acrylate; curve $d$, unimpregnated concrete; curve e, butyl acrylate.

rial. ${ }^{3}$ The data show that the ultimate stress is only a few percent more than the yield stress. Normally polymethyl methacrylate (PMMA) in the glassy state yields at $\approx \mathbf{2 5 \%}$ of the ultimate stress, but this effect is obscured in the composite, primarily because of the low polymer content and the inelastic properties of concrete.

Attempts have been made to reduce the brittleness of the composite by adding plasticizers to the monomer system. Polymer chains are bound to each other by Van der Waal forces. The strength of these bonds determines the rigidity or flexibility of the polymer. Plasticizer molecules mixed into the matrix tend to weaken the Van der Waal forces and thus produce a more flexible material.

Two types of plasticizer, external and internal, were investigated. The former do not react chemically with monomers; the latter react to form copolymers that have mechanical properties differing from those of the homopolymers. In these studjes dibutyl phthalate was used as an external-type plasticizer. This material is used commercially in the manufacture of PMMA sheet. Butyl acrylate was used as an internal plasticizer. This monomer has a low glass temperature of $-55^{\circ} \mathrm{C}$ and can be homopolymerized or readily copolymerized with MMA.

The compressive stress-strain curves for concrete and PIC are given in Figure 1. The composite con- taining MMA (curve $a$ ) is an elastic material. The addition of up to $25 \mathrm{wt} \%$ dibutyl phthalate produced no detectable changes in the curve. With 25 wt \% dibutyl phthalate (curve $b$ ) a decrease in yield stress was observed, but the stress-strain curve was otherwise similar to that for MMA alone.

The addition of butyl acrylate to MMA showed similar trends until a monomer mixture of $65 \mathrm{wt} \%$ MMA - 35 wt \% butyl acrylate was used (curve $c$ ). This is an elastic material with a yield stress $\approx 35 \%$ lower than that obtained with MMA. The differences in strain between the yield stress and the rupture stress for the two materials indicate that the mixture is more ductile than MMA alone.

Specimens were also prepared of concrete impregnated with butyl acrylate. Because of its low glass temperature this polymer is a rubbery material. The stress-strain behavior of butyl acrylate impregnated concrete (curve $e$ ) is similar to that of unimpregnated concrete (curve $d$ ).

In view of the overbearing effect of the concrete on the stress-strain properties of these composites, materials that can act as plasticizers for concrete should also be investigated. A combination of plasticized monomer and energy absorbers in the concrete, such as polymer and metal fibers, should produce composites with a wide range of mechanical properties.

\subsection{PolYmen-Cumant Concrete Studizs}

Investigators at Washington State University made a preliminary evaluation for the USBR of the feasibility of preparing PCC with furfuryl alcohol resins. $1 \div$ The study was limited to a determination of the effects of various proportions of aniline hydrochloride catalyst and calcium chloride on the development of compressive strength. The system has been reported in the Soviet Union as producing increases in the tensile and compressive strengths of concrete as well as increases in resistance to frost and to corrosion by salt solutions. ${ }^{15}$

Test specimens were prepared from a mix containing $480 \mathrm{~g}$ cement, $1200 \mathrm{~g}$ graded Ottawa sand, and $240 \mathrm{~g}$ water. Portland cement, a shrinkagecompensating cement, and a blend of fly ash and portland cement in equal weight proportions were used. The additives were furfuryl alcohol, aniline hydrochloride, and calcium chloride. Cylindrical specimens 2 in. in diameter and 4 in. long were cast and cured in a mojst atmosphere for periods of $7,14,28$, or 45 days and then placed in a cold oven and heated to $110^{\circ} \mathrm{C}$ for $6 \mathrm{hr}$. Specimens 


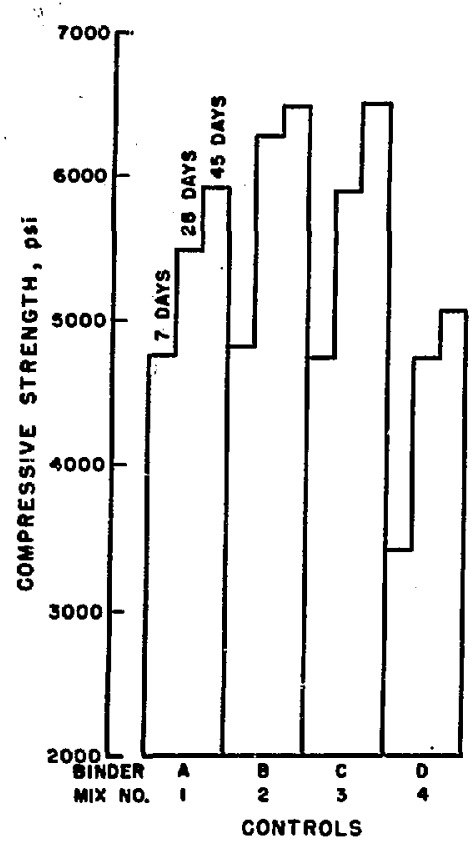

A. Portiand Cament

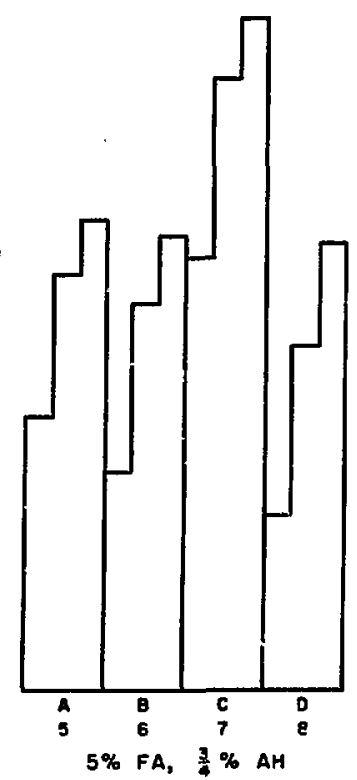

B. Shrinkoge-Gompensoting Cement

D. Portlond Cement + Fly Ash FA = Furfuryl Alcohol

C. Portland Cement $+1 \% \mathrm{CoCl}_{2}$ $\mathbf{A H}=$ Aniline Hydrochloride

Figure 2. Compressive strength of furfuryl alcohol polymer-cement concrete after curing for $7, \mathbf{2 8}$, and $\mathbf{4 5}$ days - first mix series.

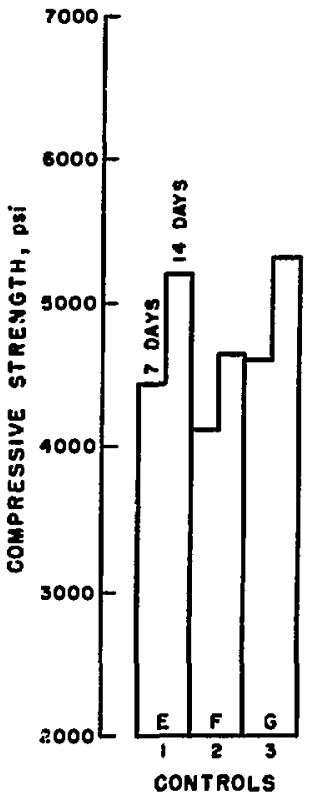

E. Portlond Comant
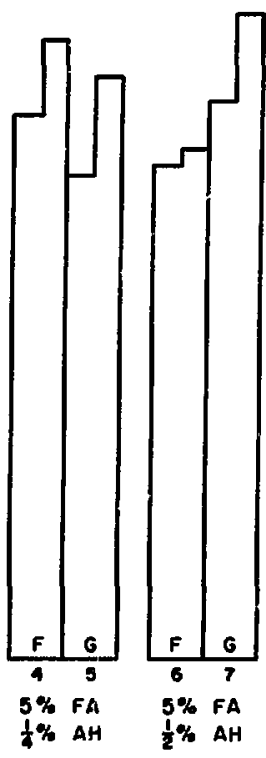

F. Portiand Cament $+2 \% \mathrm{CaCl}_{2}$

G. Portlond Cament $+3 \% \mathrm{CaCl}_{\mathrm{R}}$

Figure 3. Compressive strength of furfuryl alcohol polymer-cement concrete after curing for 7 and 14 days - second mix series.
Table 1

Polymer-Concrete

Effects of Silane Coupling Agent on Compressive Strength

Specimens, 3-in.-diam $\times 6$-in.-long cylinders Monomer, 60 wt \% styrene - 40 wt \% TMPTMA Average polymer loading, 6.4 wt \%

\begin{tabular}{cccc}
\hline $\begin{array}{c}\text { Specimen } \\
\text { No. }\end{array}$ & $\begin{array}{c}\text { Silane con- } \\
\text { centration, } \%\end{array}$ & $\begin{array}{r}\text { Test temper- } \\
\text { ature, }{ }^{\circ} \mathrm{C}\end{array}$ & $\begin{array}{r}\text { Compressive } \\
\text { strength, psi }\end{array}$ \\
\hline 206 & 1 & 21 & 12,500 \\
208 & 1 & 21 & 12,100 \\
209 & 1 & 121 & 9,520 \\
228 & 1 & 121 & 9,880 \\
231 & 1 & 143 & 8,670 \\
232 & 1 & 143 & 8,840 \\
234 & 0 & 21 & 6,420 \\
238 & 0 & 21 & 6,200 \\
235 & 0 & 121 & 5,260 \\
240 & 0 & 121 & 4,670 \\
242 & 0 & 143 & 3,650 \\
246 & 0 & 143 & 4,090 \\
\hline
\end{tabular}

Aggregate Size Distribution

\begin{tabular}{cc}
\hline Mesh size & $\begin{array}{c}\text { Concentration, } \\
\text { wt \% }\end{array}$ \\
\cline { 2 - 2 } $170-270$ & 6.1 \\
$40-60$ & 10.2 \\
$20-30$ & 23.0 \\
0.5 -in. stone & 60.7
\end{tabular}



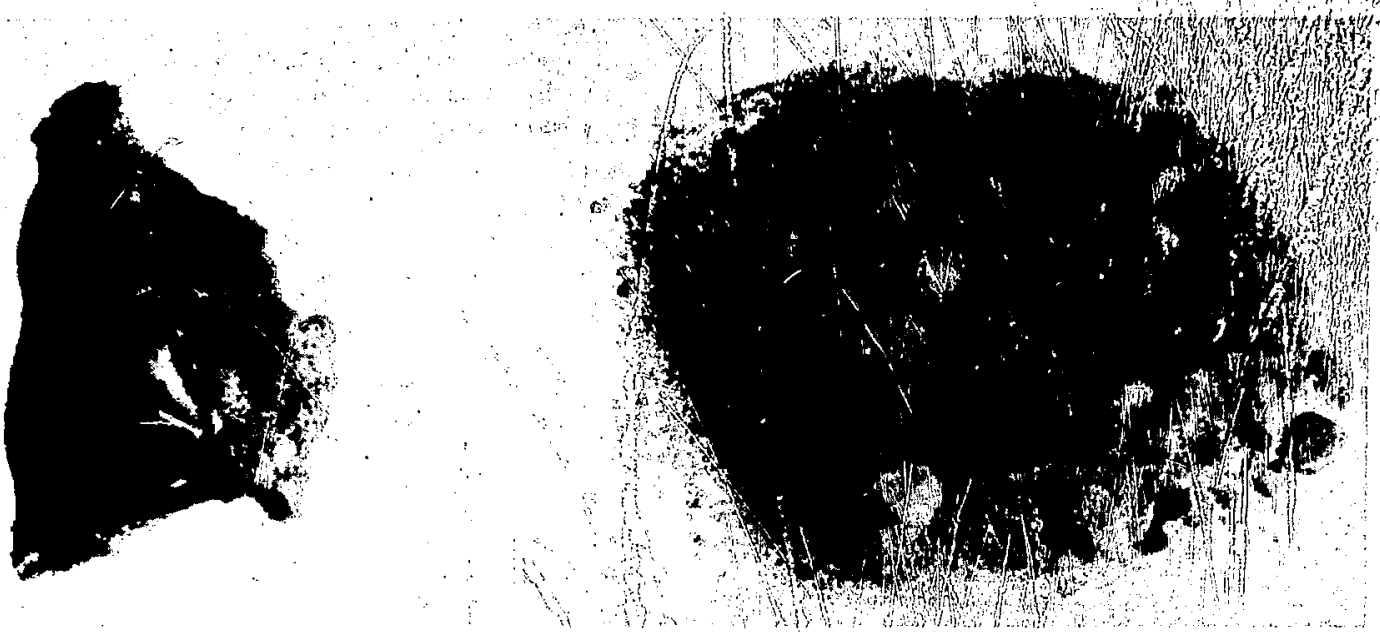

Figure 4. Polymer-concrete specimens after contact with boiling benzene for

24 hr. Left, PC containing MMA; right, PC containing MMA and silane.

were then allowed to cool to room temperature and were tested for compressive strength.

The first series of tests (Figure 2) showed that mix combination No. 7 , containing $5 \%$ furfuryl alcohol, $0.75 \%$ aniline hydrochloride, and $1 \% \mathrm{cal}$ cium chloride, developed a compressive strength of 6700 psi after 45 days of moist curing and appeared to have the best potential for further development. Mixes with furfuryl alcohol in amounts $>5 \%$ produced lower compressive strengths.

A second series of specimens was prepared to improve on mix combination No. 7. The amount. of furfuryl alcohol was held constant at $5 \%$, but the amounts of aniline hydrochloride and calcium chloride were varied. These specimens were tested after 7 and 14 days of moist curing (see Figure 3). Mix combination No. 7 had a compressive strength of 6500 psi at 14 days, which is $24 \%$ higher than that of the control mix at the same age.

The furfuryl alcohol PGG looks promising in view of the strengths developed and the relatively small amounts of shemicals required. Furfuryl alcohol apparently does not retard cement hydration and can be polymerized in an alkaline environment. The materials are easily incorporated in a cement mix with use of conventional equipment. In future investigations durability will be evaluated, and attempts will be made to increase the curing rate by using other catalysts and to further improve strength properties.

\subsection{POLYmeR-COHCRTE STUdie\&}

The effects of sand size and distribution on the monomer loading and compressive strength of $P C$ composites have been given in previous reports. ${ }^{3,4}$ The data indicate that when fairly uniform sand sizes are used, $\approx 20$ wt $\%$ of monomer is required to fill the void volume, regardless of the sand particle size. It was also indicated that sand graded to specific sizes and proportions resulted in a lower void volume and consequently in lower monomer loadings ( $\approx 6 \mathrm{wt} \%$ ). With MMA as the monoiner, compressive strengths of $\approx 11,500$ psi were obtained, regardless of sand size or sand size proportions.

The effects of the addition of silane coupling agents on the compressive strength of $P G$ were also discussed in previous reports. ${ }^{3,4}$

During the current report period PG materials have been produced with use of : monomer mixture consisting of 60 wt \% styrene - 40 wt \% TMPTMA. Compressive strength data at $21^{\circ}$, $121^{\circ}$, and $143^{\circ} \mathrm{C}$ are given in Table 1 . The effect of adding a coupling agent, $\gamma$-methacryloxypropyltrimethoxysilane, on the strength at each temperature is also shown. The silane coupling agent was added to the monomer system prior to forming the composite. At $21^{\circ} \mathrm{C}$, the specimens containing silane had an average compressive strength of 12,300 psi, compared with 6310 psi for specimens 


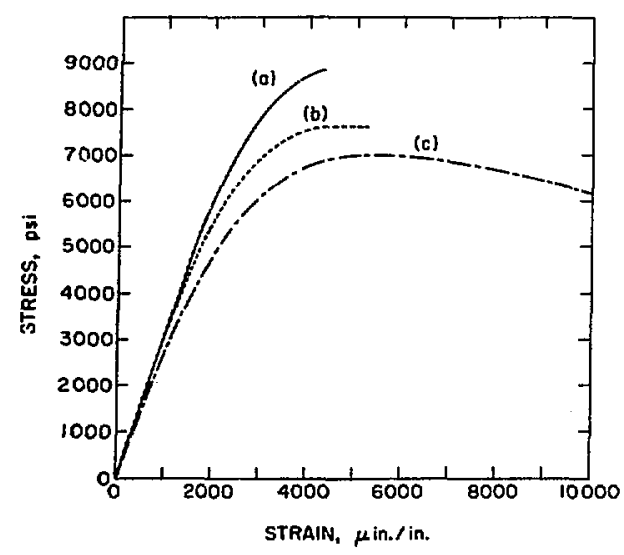

Figure 5. Compressive stress-strain curves for polymerconcrete. Curve a, MMA; curve b, 95 wt \% MMA - 5 wt $\%$ butyl acrylate; curve $c, 80$ wt \% MMA - 20 wt \% butyl acrylate.

without silane. This strength ratio $(\approx 2.1)$ was maintained at all test temperatures. At $143^{\circ} \mathrm{C}$ the specimens containing silane had an average compressive strength of $8750 \mathrm{psi}$. As show $\mathrm{x}$ here and in previous reports, the increase in strength obtained by using silane coupling agents at concentrations as low as $1 \%$ has been significant.

The role of the silane coupling agent is to form a covalent bond between the silica and the polymer. The effectiveness of this reaction was confirmed by solvent extraction methods. PC specimens containing MMA with and without $\gamma$-methacryloxypropyltrimethoxysilane were exposed to boiling benzene for $24 \mathrm{hr}$. The PMMA in the composite containing no silane completely dissolved in benzene. The polymer in the composite containing silane did not dissolve, and the sample retained its original configuration, as shown in Figure 4.

A control experiment was performed in which mixtures of MMA and silane were polymerized under the same conditions as the PC specimens. These polymers dissolved when subjected to the benzene extraction test. This indicates that the significant improvement in the chemical and mechanical properties of the PC composite containing silane is a result of the formation of a covalent bond between the polymer and the silica.

PC formed with MMA is a brittle material (see Figure 5). Its brittleness has been greatly reduced by the addition of a comonomer, butyl acrylate. This monomer readily reacts with MMA to form a copolymer with mechanical properties different from those of each homopolymer. Figure 5 indicates that addition of $5 \mathrm{wt} \%$ butyl acrylate has little effect on the stress-strain properties of the composite (curve $b$ ). However, when $20 \mathrm{wt} \%$ is added, the properties are significantly affected. The stress-strain curve identified as $c$ in Figure 5 shows a more ductile material with probably a higher impact strength than that of MMA (curve $a$ ).

Compared with PIC, the plasticizing effects are more pronounced for PC. In the latter, the polymer is the only binder, and thus the thermal and mechanical properties of the composite reflect those of the polymer. It is therefore important that monomer formulations be further investigated so that highly desirable properties such as plasticity can be incorporated in PC composites.

\section{PROCESS TELHNOLOGY DEVELOPMENT}

\subsection{Concrete Composition and Curing}

Studies were initiated in the previous year to investigate the effects of concrete-mix design variables and concrete curing conditions on the compressive strength and polymer loading of PIC. ${ }^{4}$ These studies have been broadened to include a wider range of differences in concrete composition. Specimens were fabricated of expanded shale aggregate, high-quality low-porosity limestone aggregate, low-quality high-porosity limestone aggregate, pit-run Clear Creek aggregate, and processed Clear Creek aggregate in mixes designed to produce high- and low-entrained-air and high- and low-strength concrete. These specimens were given 28-day fog and high-pressure steam cures. Another set of specimens was made with CP-type concrete and given 28-day fog, high-pressure steam, and low-pressure steam cures. Specimens were ovendried at $110^{\circ} \mathrm{C}$, impregnated with $\mathrm{MMA}$, radiation-polymerized in water, and tested for strength and absorption (Table 2).

The average absorption of unimpregnated fogcured concrete control specimens ranged from $6.2 \%$ for the high-strength specimens to $17.6 \%$ for the high-porosity limestone specimens, and in general reflected the differences in concrete composition. High-pressure steam-cured specimens in general had from 0.3 to $1.0 \%$ higher absorption than companion fog-cured specimens, but ranged from $3.3 \%$ greater absorption for expanded shale specimens to $6.2 \%$ less absorption for the highporosity limestone specimens. 
Polymer loadings were generally equal to or slightly greater than the water absorptions for the denser concrete mixes and significantly greater than the absorptions for the expanded shale and high-porosity limestone specimens. Polymer loadings were consistently higher in high-pressure steamcured specimens than in fog-cured specimens, ranging from about 0.5 to $2.0 \%$ for the denser mixes to about $4 \%$ for the expanded shale specimens.

The absorption of polymer-impregnated specimens ranged from an average of $0.3 \%$ for the highstrength fog-cured specimens to $1.2 \%$ for highporosity limestone, high-pressure steam-cured specimens. High-pressure steam-cured specimens consistently had a slightly higher absorption than companion fog-cured specimens.

The compressive strengths of the PIC specimens were fairly high, ranging from about $17,000 \mathrm{psi}$ for the high-porosity limestone specimens to 32,400 psi for a high-strength, high-pressure steam-cured specimen; this is the highest compressive strength yet obtained in the program. The compressive strengths of the high-pressure steam-cured specimens were 700 to 5200 psi higher than those for companion fog-cured specimens for the low-porosity limestone, expanded shale, low-strength, and

\section{Table 2}

Summary of the Effects of Concrete Composition and Curing Method on the Absorption, Polymer Loading, and Compressive and Tensile Strengths of Unimpregnated and MMA-Impregnated Concrete

\begin{tabular}{|c|c|c|c|c|c|c|c|c|c|}
\hline \multirow[b]{2}{*}{ Concrete mixb } & \multicolumn{4}{|c|}{ Unimpregnated concrete } & \multicolumn{5}{|c|}{ MMA-impregnated concrete ${ }^{2}$} \\
\hline & $\begin{array}{l}\text { Concrete } \\
\text { cure }\end{array}$ & $\begin{array}{l}\text { Absorption, } \\
\text { wt \% }\end{array}$ & $\begin{array}{l}\text { Compressive } \\
\text { strength, } \\
\text { psi }\end{array}$ & $\begin{array}{c}\text { Direct } \\
\text { tensile } \\
\text { strength, } \\
\text { psi }\end{array}$ & $\begin{array}{l}\text { Absorption, } \\
\text { wt \% }\end{array}$ & $\begin{array}{c}\text { Polymer } \\
\text { loading, } \\
\text { wt } \%\end{array}$ & $\begin{array}{l}\text { Compressive } \\
\text { strength, } \\
\text { psi }\end{array}$ & $\begin{array}{l}\text { Polymer } \\
\text { loading, } \\
\text { wt \% }\end{array}$ & $\begin{array}{c}\text { Direct } \\
\text { tensile } \\
\text { strength, } \\
\text { psi }\end{array}$ \\
\hline Low-entrained air & $\begin{array}{l}\text { Foge } \\
\text { HPS d }\end{array}$ & $\begin{array}{l}6.3 \\
7.4\end{array}$ & $\begin{array}{l}8,200 \\
2,900\end{array}$ & - & $\begin{array}{l}0.4 \\
0.5\end{array}$ & $\begin{array}{l}5.9 \\
7.3\end{array}$ & $\begin{array}{l}24,600 \\
23,700\end{array}$ & $\begin{array}{l}- \\
-\end{array}$ & $\begin{array}{l}- \\
-\end{array}$ \\
\hline High-entrained air & $\begin{array}{l}\text { Fog } \\
\text { HPS }\end{array}$ & $\begin{array}{l}8.0 \\
8.3\end{array}$ & $\begin{array}{l}1,800 \\
1,800\end{array}$ & $\begin{array}{l}- \\
-\end{array}$ & $\begin{array}{l}0.5 \\
0.5\end{array}$ & $\begin{array}{r}9.9 \\
10.4\end{array}$ & $\begin{array}{l}24,200 \\
21,800\end{array}$ & - & $\overline{-}$ \\
\hline Low strength & $\begin{array}{l}\text { Fog } \\
\text { HPS }\end{array}$ & $\begin{array}{l}6.5 \\
7.3\end{array}$ & $\begin{array}{l}5,900 \\
4,200\end{array}$ & - & $\begin{array}{l}0.3 \\
0.6\end{array}$ & $\begin{array}{l}7.4 \\
8.4\end{array}$ & $\begin{array}{l}24,800 \\
27,000\end{array}$ & $\overline{-}$ & - \\
\hline High strength & $\begin{array}{l}\text { Fog } \\
\text { HPS }\end{array}$ & $\begin{array}{l}6.2 \\
5.8\end{array}$ & $\begin{array}{l}9,000 \\
8,400\end{array}$ & $\begin{array}{l}- \\
-\end{array}$ & $\begin{array}{l}0.3 \\
0.3\end{array}$ & $\begin{array}{l}6.1 \\
7.2\end{array}$ & $\begin{array}{l}\mathbf{2 5 , 5 0 0} \\
30,700\end{array}$ & - & - \\
\hline Pit-run aggregate & $\begin{array}{l}\text { Fog } \\
\text { HPS }\end{array}$ & $\begin{array}{l}10.0 \\
10.2\end{array}$ & $\begin{array}{l}5,100 \\
2,6 C 5\end{array}$ & $\begin{array}{l}- \\
-\end{array}$ & $\begin{array}{l}0.3 \\
0.9\end{array}$ & $\begin{array}{l}10.2 \\
12.2\end{array}$ & $\begin{array}{l}21,800 \\
19,900\end{array}$ & $\overline{-}$ & $\overline{-}$ \\
\hline $\begin{array}{l}\text { Low-portasity } \\
\text { limestone aggregate }\end{array}$ & $\begin{array}{l}\text { Fog } \\
\text { HPS }\end{array}$ & $\begin{array}{l}6.5 \\
7.8\end{array}$ & $\begin{array}{l}6,300 \\
2,600\end{array}$ & $\begin{array}{l}- \\
-\end{array}$ & $\begin{array}{l}0.3 \\
0.6\end{array}$ & $\begin{array}{l}6.9 \\
8.5\end{array}$ & $\begin{array}{l}22,500 \\
23,200\end{array}$ & - & - \\
\hline $\begin{array}{l}\text { High-porosity } \\
\text { limestone aggregate }\end{array}$ & $\begin{array}{l}\text { Fog } \\
\text { HPS }\end{array}$ & $\begin{array}{l}17.6 \\
11.5\end{array}$ & $\begin{array}{l}2,500 \\
2,300\end{array}$ & - & $\begin{array}{l}1.1 \\
1.2\end{array}$ & $\begin{array}{l}18.0 \\
20.3\end{array}$ & $\begin{array}{l}17,100 \\
17,100\end{array}$ & $\overline{-}$ & - \\
\hline $\begin{array}{l}\text { Expanded shale } \\
\text { aggregate }\end{array}$ & $\begin{array}{l}\text { Fog } \\
\text { HPS }\end{array}$ & $\begin{array}{l}12.9 \\
16.2\end{array}$ & $\begin{array}{l}7,800 \\
5,200\end{array}$ & $\dot{-}$ & $\begin{array}{l}0.7 \\
0.9\end{array}$ & $\begin{array}{l}25.9 \\
30.3\end{array}$ & $\begin{array}{l}24,000 \\
26,200\end{array}$ & - & $\overline{-}$ \\
\hline CP concreteb & $\begin{array}{l}\text { Fog } \\
\text { HPS } \\
\text { LPS }\end{array}$ & $\begin{array}{l}- \\
-\end{array}$ & $\begin{array}{l}6,100 \\
4,100 \\
5,000\end{array}$ & $\begin{array}{l}440 \\
230 \\
340\end{array}$ & $\begin{array}{l}- \\
-\end{array}$ & $\begin{array}{l}7.3 \\
6.6 \\
7.0\end{array}$ & $\begin{array}{l}24,400 \\
21,200 \\
24,700\end{array}$ & $\begin{array}{l}7.2 \\
6.4 \\
7.1\end{array}$ & $\begin{array}{l}1,800 \\
1,300 \\
1,900\end{array}$ \\
\hline $\begin{array}{l}3 \times \text { G-in. opecimens } \\
\text { Radiation-induced } \\
\text { aMA = methyl m } \\
\text { bValues are averagea } \\
\text { 'Fog }=28 \text {-day fog c } \\
\text { dHPS = high-preau } \\
\text {-HPS = nonstandar } \\
\text { 'LPS = low-pressur }\end{array}$ & $\begin{array}{l}\text { oven-dried } \\
\text { polymeriza } \\
\text { ethacrylate } \\
\text { of three sp } \\
\text { ure. } \\
\text { ire steam cu } \\
\text { d HPS cure } \\
\text { e steam cur }\end{array}$ & $\begin{array}{l}110^{\circ} \mathrm{C} \text { prior } \\
\text { ion in water. } \\
\text { cimens, except } \\
\text { re. }\end{array}$ & $\begin{array}{l}\text { to impregnatio } \\
\text { that those for } \\
\text { am-cured after }\end{array}$ & $\begin{array}{l}\text { CP concrete } \\
\text { 24-hr fog c }\end{array}$ & $\begin{array}{l}\text { e are averages } \\
\text { ure. }\end{array}$ & of 10 speci & imens. & & \\
\hline
\end{tabular}


high-strength mixes. Compressive strengths of highpressure steam-cured specimens were from 900 to $2400 \mathrm{psi}$ lower than those for companion fog-cured specimens for the low-entrained-air, pit-run aggregate, and high-air specimens. For the PIC CP-mix specimens in the curing-method test series, lowpressure steam-cured specimens had about the same compressive strength as fog-cured specimens, 24,690 and 24,430 psi, respectively. The high-pressure steam-cured specimens were not given the standard treatment and were high-pressure steamcured after a 24-hr fog cure; these specimens had a compressive strength of $21,240 \mathrm{psi}$. The improvement in strength due to polymer impregnation ranged from 2.8 to 13.4 times that of companion unimpregnated concrete.

It is of interest to note that good-quality PIC could be produced with concrete containing two poor-quality aggregates. The pit-run aggregate had not been washed or graded. The high-porosity limestone (marl) is a soft, highly absorptive, poorquality rock with a high clay content that weakens in water and is abraded during concrete mixing. These two aggregates are of much poorer quality than those normally used for concrete, yet the compressive strengths after polymer impregnation were in the range of 17,000 psi for the high-porosity limestone and 20,000 psi for the pit-run aggregate. The relatively high compressive strengths apparently are due to a high polymer loading.

In producing good-quality PIC, the strength and quality of the concrete prior to impregnation do not appear to be as important as achieving a high degree of impregnation and complete polymerization. However, the porosity of concrete will affect the costs of producing PIC, since highporosity concrete will require more monomer for full impregnation. At this point in the program it seems that good-quality PIC can be made from concretes of widely varying composition. The entrained-air content primarily affects the polymer loading and has little effect on compressive strength. For very-high-strength $\mathrm{PIC}$, the high-strength mix and high-pressure steam curing are definitely acvantageous. Use of a very-high-quality aggregate would also contribute to increasing compressive strength.

\subsection{FUL Imraionation TICHNIQULs}

The process conditions required to fully impregnate various types of concrete are being determined. In the current work the effects of degree of vacuum, soaking time, and pressure are being studied. Methods to reduce monomer evaporation and drainage losses during polymerization are also being evaluated. These studies are summarized below.

The effects of vacuum, pressure, and soaking time on the impregnation rate of 3 -in.-diam $\times 6$ in.-long concrete specimens were studied. Test specimens of CP concrete and three of its variations, all high-pressure steam-cured (HPS), were compared. The mix variations were (1) high air content (10\%), (2) structural lightweight (expanded shale aggregate), and (3) low strength (low cement factor). The specimens were ovendried at $110^{\circ} \mathrm{C}$, impregnated with MMA, dipped in a prepolymer solution of PMMA, wrapped in foil, and radiation-polymerized under water. Encapsulation methods were also evaluated; in these studies, the impregnation and polymerization conditions differed. This work will be discussed later in this section.

The impregnation rates were measured with and without prior vacuum treatment and at two levels of soak pressure, 10 and 100 psig. The effect of vacuum treatment was determined by comparing results from fully evacuated samples (held at $30 \mathrm{in} . \mathrm{Hg}$ for $15 \mathrm{~min}$ ) with those from partially evacuated (equilibrated at $\approx 15 \mathrm{in} . \mathrm{Hg}$ ) samples and samples that were not evacuated.

Impregnation-rate measurements for CP concrete under various impregnation conditions are given in Figure 6. Without prior vacuum treatment and with use of 100 psig pressure, the monomer loading approached equilibrium (polymer loading, $6.2 \mathrm{wt} \%$ ) after about $10 \mathrm{~min}$. At $10 \mathrm{psig}$, equilibrium had no: seen achieved after $1000 \mathrm{~min}$. The data also indicate that holding a sample at 30 in. $\mathrm{Hg}$ vacuum for $15 \mathrm{~min}$ and then soaking at 10 psig for $\approx 30$ min was adequate to reach saturation. At 100 psig, saturation was achieved in considerably less time ( $\approx 9 \mathrm{~min}$ ). Partial evacuation of samples to $15 \mathrm{in} . \mathrm{Hg}$ followed by pressurization to 10 and 100 psig gave intermediate filling rates and momomer loadings. Compressive strength measurements of the polymerized samples indicated that strength was related to monomer loading, i.e., 27,200 psi at $7.6 \mathrm{wt} \%$ to 19,150 psi at 5.6 wt \%.

Impregnation-rate measurements for concrete containing structural-lightweight (expanded-shale) aggregate are given in Figure 7. The saturation level for this material was considerably higher $(\approx 28$ wt \%) than that for CP concrete because of 
its higher porosity. The effect of $30 \mathrm{in.} \mathrm{Hg}$ vacuum treatment on the filling rate and saturation time was consistent with that observed for CP concrete. At 100 psig and $10 \mathrm{psig}$, saturation at a monomer loading of $\approx \mathbf{2 8 \%}$ was achieved after $\approx \mathbf{2 0}$ and $\approx 200 \mathrm{~min}$, respectively. Without vacuum treatment, saturation had not been achieved after 1000 min. The saturation times measured for this material were greater than for CP concrete. Partial

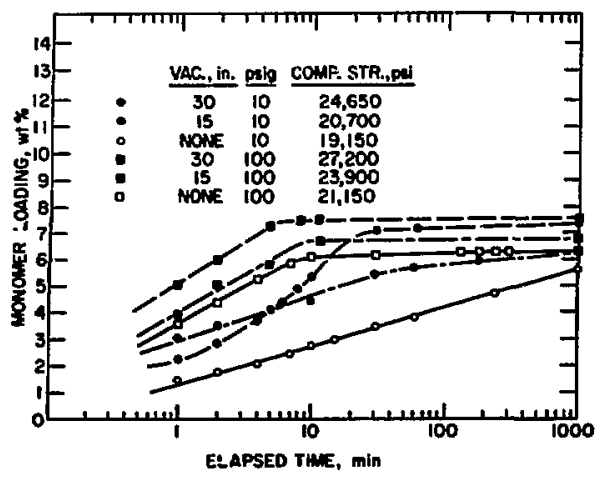

Figure 6. Impregnation-rate curves and compressive strength measurements for high-pressure steam-cured CP-type concrete. Specimens (3-in.-diam X6-in.-long) were oven-dried ai $110^{\circ} \mathrm{C}$, impregnated with MMA, and radiation-polymerized under water.

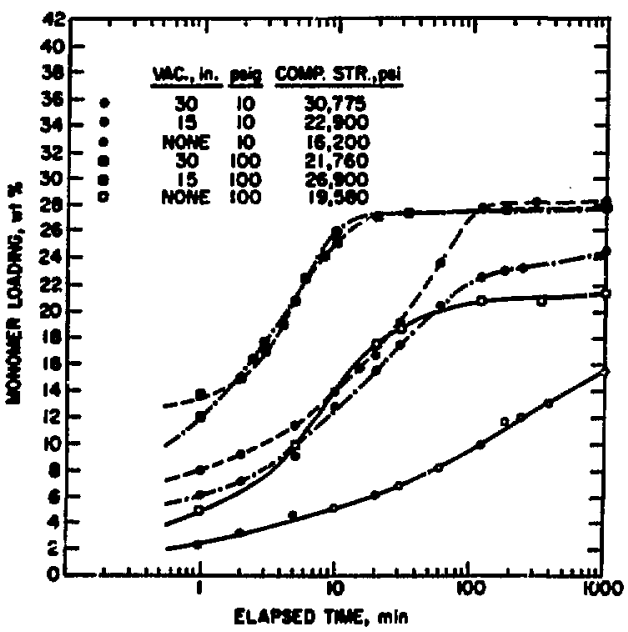

Figure 7. Impregnation-rate curves and compreasive sirength measurements for high-presure steam-curud concrete containing expanded thale aggregate. Specimen vize and ireatment as in Figure 6. evacuation ( $15 \mathrm{in.} \mathrm{Hg}$ ), followed by soaking at 100 psig, was as effective as full vacuum treatment. The highest compressive strength measured on any sample in this entire investigation $(30,775 \mathrm{psi})$ was obtained from one of the polymer-impregnated shale-concrete specimens. Compressive strength measurements made on these specimens were generally in agreement with monomer loading, but were not as consistent as the results for CP concrete.

Impregnation-rate measurements for the high water-to-cement ratio $(0.6)$ specimens are given in

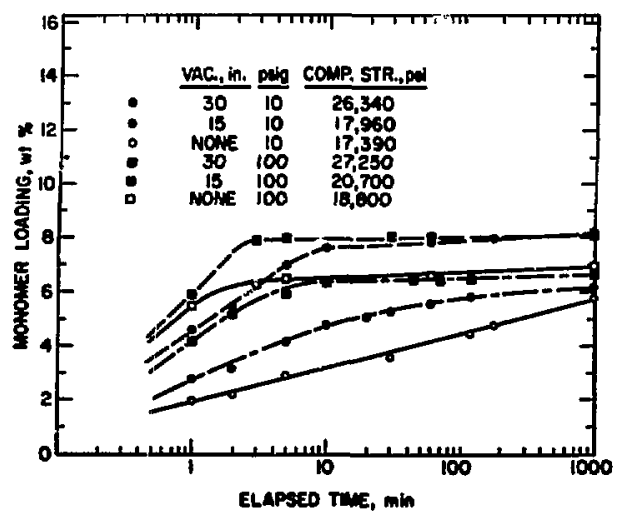

Figure 8. Impregnation-rate curves and compresive atrength measurements for high-presure steam-cured concrete having a water-to-cement ratio of 0.6. Specimen size and treatment as in Fizure 6.

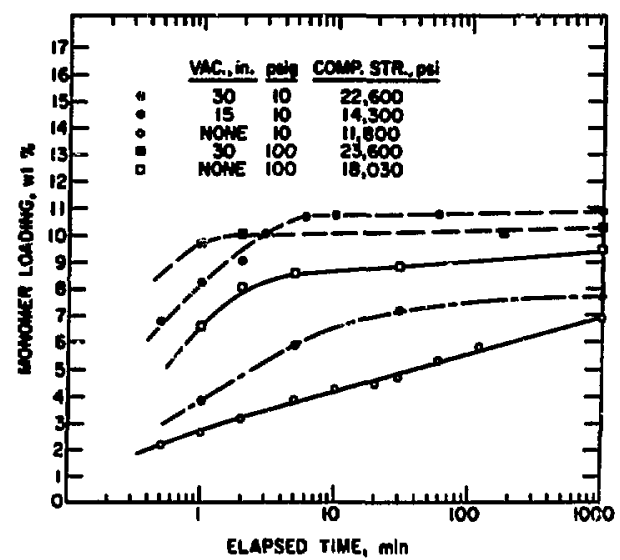

Figure 9. Impregnation-rate curves and compresaive strength measureinents for high-pressure steam-cured concrete having a high air content $(\approx 10 \%)$. Syecimen size and treatment as in Figure 6. 
Figure 8. The trends obtained are similar to those obtained with CP concrete. However, the saturation levels achieved are higher, probably because of the higher porosity. An average compressive strength of 26,790 psi was measured for fully evacuated specimens.

Impregnation-rate measurements for the highair-content $(\approx 10 \%)$ specimens are given in Figure 9. The results are similar to those discussed above, namely, the monomer loadings at saturation are

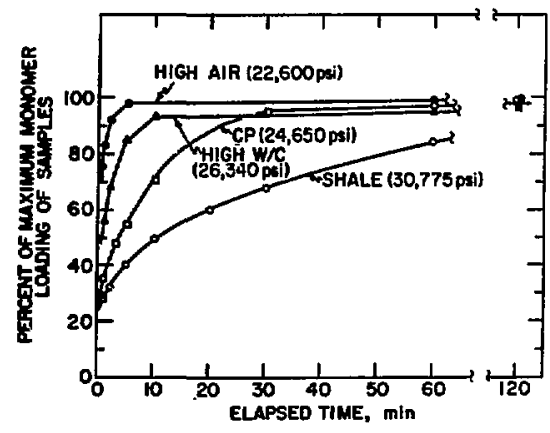

Figure 10. Comparison of impregnation rates and compressive strength measurements for CP-type concrete, concrete containing expanded shale aggregate, concrete with a high water-to-cement ratio, and concrete having a high air content. Specimens (3-in.-diam $\times 6$-in.-long) were oven-dried at $110^{\circ} \mathrm{C}$, evacuated to $30 \mathrm{in}$. $\mathrm{Hg}$ for $15 \mathrm{~min}$, soaked in MMA at 10 psig, and radiation-polymerized under water.

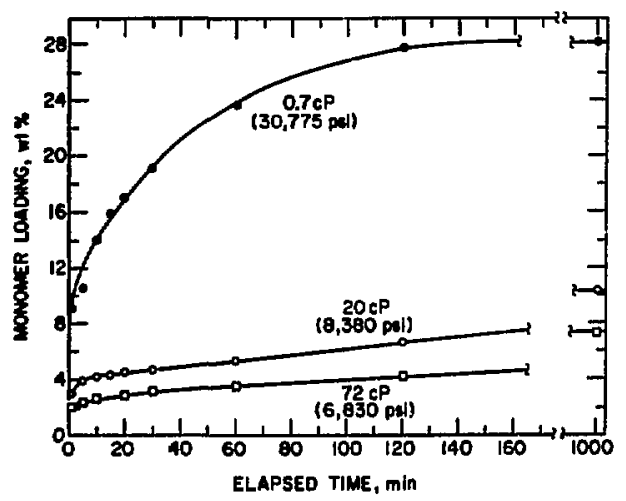

Figure 11. Effect of monomer viscosity on the impregnation rate and final compressive strength of concrete containing expanded shale aggregate. Specimens (3-in.-diam X6-in.-long) were oven-dried at $110^{\circ} \mathrm{C}$, evacuated to 30 in. $\mathrm{Hg}_{\mathrm{g}}$ for $15 \mathrm{~min}$, soxked in MMA and solutions of PMMA at 10 paig, and radiation-polymerized under water. higher but the strengths are generally lower than for CP concrete and concrete with a high waterto-cement ratio. After polymerization, an average compressive strength of 23,100 psi was measured for the fully evacuated specimens. Unevacuated samples soaked at pressures of 10 and 100 psig had strengths of 14,300 and $18,030 \mathrm{psi}$, respectively.

The initial impregnation rate of the high-aircontent concrete is significantly higher than that of any of the other concretes tested, as shown in Figure 10. The data given are for specimens under identical impregnation and polymerization conditions, $30 \mathrm{in}$. $\mathrm{Hg}$ vacuum, and 10 psig soak pressure. The curves are normalized for the different

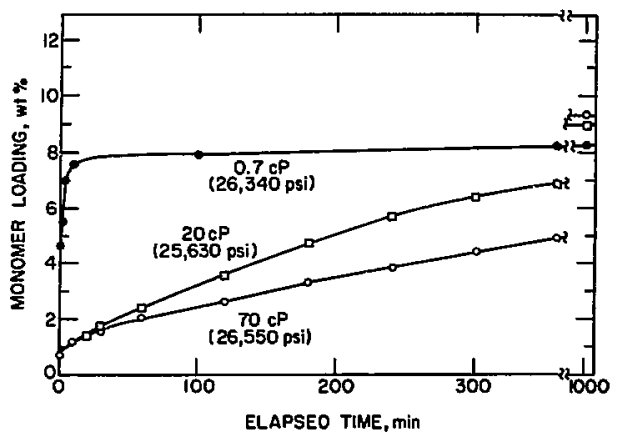

Figure 12. Effect of monomer viscosity on the impregnation rate and final compressive strength of concrete having a high water-to-cement ratio (0.6). Specimen size and treatment as in Figure 11.

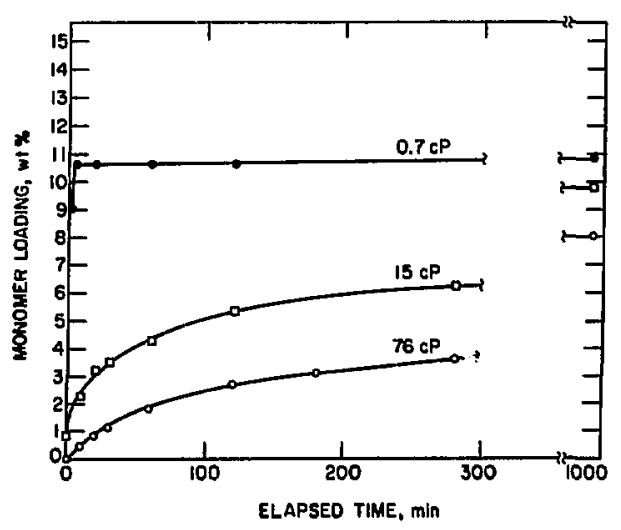

Figure 13. Effect of monomer viscosity on the impregnation rate and final compressive strength of concrete having a high air content $(\approx 10 \%)$. Specimen size and treatment as in Figure 1. 
saturation levels, determined by comparing elapsed time with percent of maximum monomer loading. On the basis of these data, the impregnation rates seem to be directly related to the cementphase porosity. For the shale aggregate, long impregnation times are required, probably because of the large number of pores.

The effect of monomer viscosity on the impregnation rates of three concrete mixes was measured (see Figures 11 to 13). Prepolymer solutions were prepared by dissolving PMMA in MMA until viscosities of $\approx 20$ and $\approx 70 \mathrm{cP}$ were measured. These data are compared with impregnation data using normal MMA $(0.7 \mathrm{cP})$ with impregnation conditions of 30 in. $\mathbf{H g}$ vacuum and soaking at 10 psig. Both specimens of concrete with a high water-tocement ratio (see Figure 12) were fully impregnated with the higher viscosity monomer solutions in $1000 \mathrm{~min}$, whereas the concretes with a high air content or shale aggregate were only partially filled in that time period. Compressive strength measurements reflect the lower monomer loadings achieved in each case.

Impregnation parameters such as vacuum, pressure, soaking time, and method of encapsulation were all found to affect the strength of PIC. The degree of evacuation of a concrete sample is one of the most important parameters. Complete saturation of concrete is accomplished only after prior evacuation to $\approx 30$ in. Hg. Without prior evacuation, soak pressures of $\approx 100$ psig are required in order to approach saturation in a short time ( $\approx 60 \mathrm{~min}$ ).

The simplest type of impregnation process would consist of soaking unevacuated samples at atmospheric pressure. This would result in partially saturated specimens and therefore somewhat lower strengths. In general, overnight soaking of dried CP-type concrete in MMA will result in filling $\approx 70$ to $80 \%$ of the voids that can be filled by prior evacuation. Compressive strengths of $15,0 \mathrm{NJ}$ to 17,000 psi would be anticipated.

Concrete composition has a significant effect on the monomer impregnation rate. Samples of concrete having high air and high water contents were saturated with monomer in shorter periods of time than CP-type concrete. Samples containing expanded shale aggregate were saturated with monomer in longer periods of time than CP-type concrete, probably because of the high porosity of the aggregate.

As part of an effort to develop methods for reducing monomer evaporation and drainage losses during processing, encapsulation experiments were performed with each of the aforementioned types of concrete. All the specimens were impregnated with MMA and radiation polymerized. The studies covered (1) the effect of dryness of the concrete, (2) the effectiveness of aluminum foil wrapping, (3) irradiation in air or under water, (4) encapsulation in forms, (5) the effectiveness of prepolymer dip coating, and (6) the use of higher viscosity solutions. The observations were in general agreement with those in earlier reports. 4,8 A specimen dried at $150^{\circ} \mathrm{C}$, impregnated with MMA by the vacuum-soak method, dip-coated with a viscous prepolymer solution, wrapped in aluminum foil, and irradiated under water had the most uniform distribution of polymer and least evaporation from the surface. Samples immersed in water without being wrapped in aluminum foil exhibited slight surface evaporation, but final compressive strengths were not affected.

On the basis of this work, a processing cycle requiring the shortest time period was selected. It consisted of evacuating for $15 \mathrm{~min}$ and rapidly pressurizing for $15 \mathrm{~min}$, after which the sample was removed and polymerized under water. Although the data indicated little difference between pressurizing to 10 or to $100 \mathrm{psig}$, the latter was selected. One sample of each type of concrete, with the exception of expanded shale concrete, was processed. The results, in agreement with previous trends, are listed below.

\begin{tabular}{lccc}
\multicolumn{1}{c}{ Concrete } & $\begin{array}{c}\text { Monomer } \\
\text { loading, } \%\end{array}$ & $\begin{array}{c}\text { Compressive } \\
\text { strength, psi }\end{array}$ \\
CP type & & & 24,230 \\
High air content & 9.5 & & 21,200 \\
High w/c ratio & 7.7 & & 21,700
\end{tabular}

High-quality PIC can be made from concretes varying widely in composition. For best results, the use of standard-weight concretes containing low-porosity aggregate is recommended. With this type of concrete, HPS curing appears to be advantageous.

For HPS-cured, standard-weight concrete containing a low-porosity aggregate, the following processing cycle is recommended for sections up to $\approx 12$ in. thick.

1. Oven-dry to constant weight at $150^{\circ} \mathrm{C}$. Dryness should be achieved in $\approx 24 \mathrm{hr}$.

2. Evacuate at $\approx \mathbf{3 0} \mathrm{in} . \mathrm{Hg}$ and maintain for $\approx 30$ min.

3. Introduce monomer under vacuum and subsequently pressurize to $\approx 10$ psig. Pressure-soak for $\approx 60 \mathrm{~min}$. 
4. Remove monorner.

5. Remove and place section under water or, for larger sections, backfill impregnator with water.

6. Polymerize monomer in situ with radiation, hot water, or steam. The method of polymerization should be based on a detailed process cost analysis for each specific product.

7. Remove water and clean section.

Data on larger sized sections are currently being obtained.

As described above, when attempts were made to impregnate concrete without the use of vacuum and pressure, full saturation could not be obtained.

Experiments are being conducted to impregnate concrete by using a condensation filling process, which would minimize or eliminate the need to evacuate prior to impregnation. Attempts have also been made to minimize the pressure requirements by using a porous concrete. The concrete has a high water-to-cement ratio $(w / c=0.7)$ and is steam-cured for several hours at a temperature slightly above $105^{\circ} \mathrm{C}$. After curing, the hot specimen is imnediately immersed in a bath containing monomer and catalyst. During quenching in the monomer, condensation of the residual water vapor in the voids produces a pressure differential and therefore a flow of monomer into the specimen.

The process can be adapted to thermal-catalytic polymerization by using a catalyzed monomer, or to radiation polymerization by using monomer without catalyst. Specimens containing monomer and catalyst can also be polymerized at room temperature in a radiation field. The presence of catalyst in the monomer greatly reduces the radiation dose required for polymerization.

Experiments were performed using a concrete with a water absorption of $\approx 11.5 \%$. After condensation filling, the monomer loadings obtained were between 11 and $11.5 \%$. This indicates that the amount of water remaining in the specimen after steam curing is very small. The soaking time required to obtain a fully impregnated specimen ranged between 3 and $5 \mathrm{hr}$. After polymerization, the ccmpressive strengths of MMA and styreneimpregnated specimens were 22,000 and 16,000 psi, respuctively.

\subsection{Pantial Imprianation and COAmio Trenniguns}

Partially impregnated concrete is characterized by durability rather than high strength, and therefore requires les monomer than fully impregnated concrete. The concrete is impregnated to controlled depths of penetration. The monomers should effectively seal the surface and penetrate far enough to avoid separation of the impregnated layer and premature failure. Viscous monomer systems are generally used because penetration depths are more easily controlled, voids in the penetrated portion remain filled, and monomer losses due to evaporation and drainage during the time between impregnation and complete polymerization are lower. However, for field applications such as the repair of concrete-lined vessels and bridge decks, lowviscosity monomers such as MMA, MMA-TMPTMA, and styrene-TMTPMA are preferred since they penetrate concrete more readily than higherviscosity monomers. These studies are summarized below.

4.3.1 BNL Studies. Laboratory techniques have been developed for controlling the depth of penetration of MMA and polyester-styrene in the following types of concrete: CP-type, CP-type containing $\approx 10 \%$ entrained air, and structural lightweight containing expanded shale aggregate. Methods for the partial impregnation of CP-type concrete were described previously. ${ }^{4}$

Controlled and reproducible depths of penetration can be obtained with both of the monomer systems listed above. Based upon water absorption measurements made prior to impregnation, the amount of monomer required for any desired depth of penetration can be calculated. By monitoring the monomer liquid level during impregnation, the specimens can be removed when the desired amount of monomer has been absorbed.

Fifty-four 3-in.-diam. $\times$ 6-in.-long samples have been impregnated to nominal depths of $1 / 4,3$, and $1 / 2$ in. and are being tested for water absorption, freeze-thaw durability, and resistance to chemical attack by $5 \% \mathrm{H}_{2} \mathrm{SO}_{4}$. The results to date are discussed in Section 5.1.3.

Partial impregnation and coating techniques are being tested in a field experiment at the OSW Water Desalting Facility in Freeport, Texas. The field application required partially impregnating the concrete liner of a vertical tube evaporator (VTE) to a depth of $\approx 1 / 4$ in. The VTE was fabricated of steel plate lined with $\approx 1$ in. of lumnite concrete. A mixture of $60 \mathrm{wt} \%$ styrene - $40 \mathrm{wt} \%$ TMPTMA containing $1 \%$ benzoyl peroxide catalyst and $1 \%$ dimethyl aniline promoter was applied to the concrete surfaces with brushes and rollers, and a second coat was then applied. Because 
of its low viscosity (2 cP), this monomer system was readily absorbed by the concrete. One percent concentrations of the promoter and catalyst were used, and a working time of $45 \mathrm{~min}$ was possible before gelation occurred.

After the partial impregnation, a seal coat of 53 wt $\%$ polyester, 28 wt $\%$ styrene, and 19 wt \% TMPTMA was applied. The mixture, which had a viscosity of $\approx 400 \mathrm{cP}$, appeared to be effective in reducing evaporation of the impregnating monomer system; it also sealed cracks and other flaws in the concrete surface. Gelation of the sealant coat occurred in $15 \mathrm{~min}$.

In addition to the VTE, mortar-lined steel pipes of 6,8, and 10-in. diam were treated. Tees and ells were also treated. Partial impregnation and coating of short-length pipes, tees, and ells was accomplished with brushes. Longer-length pipes (up to $20 \mathrm{ft}$ ) were impregnated by using a long-handled swab, a 4-in.-thick piece of open-cell polyurethane foam cut to the diameter of the pipe (see Figure 14). The swab was saturated with monomer and then slowly pushed through the pipe. Several applications were required to obtain a 1/4-in. penetration. A seal coat was then applied in the same manner.

On visual inspection after 6 weeks of normal plant operation, the impregnated sections showed no signs of deterioration. Testing is continuing.

4.3.2 USBR Studies. A two-coat MMA-TMPTMA-based monomer system was applied to one of the multistage flash distillation chambers and to various sections of mortar-lined pipe at the OSW Demonstration Plant, Freeport, Texas. The first application was a low-viscosity monomer system designed to saturate the mortar-lined chamber to a depth of about $1 / 4$ in. A lightly promoted catalyst system was added to this monomer system to enable the monomer to soak into the mortar before polymerization began.

The second application, or top coat, consisted of a higher-viscosity monomer system that polymerizes rapidly at room temperature. This material acted as a sealant to prevent evaporative loss of the first monomer system and to provide surface protection to the mortar lining.

The low-viscosity monomer system was prepared by mixing 70 wt \% MMA with 30 wt \% TMPTMA. The estimated quantity needed was then measured into two equal parts, $A$ and $B$. Two wt \% benzoyl peroxide (BP) was then added to part $A$ which was then dissolved in part $B$, which contained $0.25 \%$ of the promoter dimethyl-ptoluidine (DMT). The resulting catalyst-promoter concentration gave the mixture a pot life of about 15 to 25 min at $24^{\circ} \mathrm{C}$.

The high-viscosity seal coat was prepared by dissolving Rohm and Haas Acryloid A-11 polymer in a 70 wt \% MMA - 30 wt \% TMPTMA monomer system at a concentration of $20 \% \mathrm{~A}-11$ to $80 \%$ monomer. To accelerate the mixing process, the

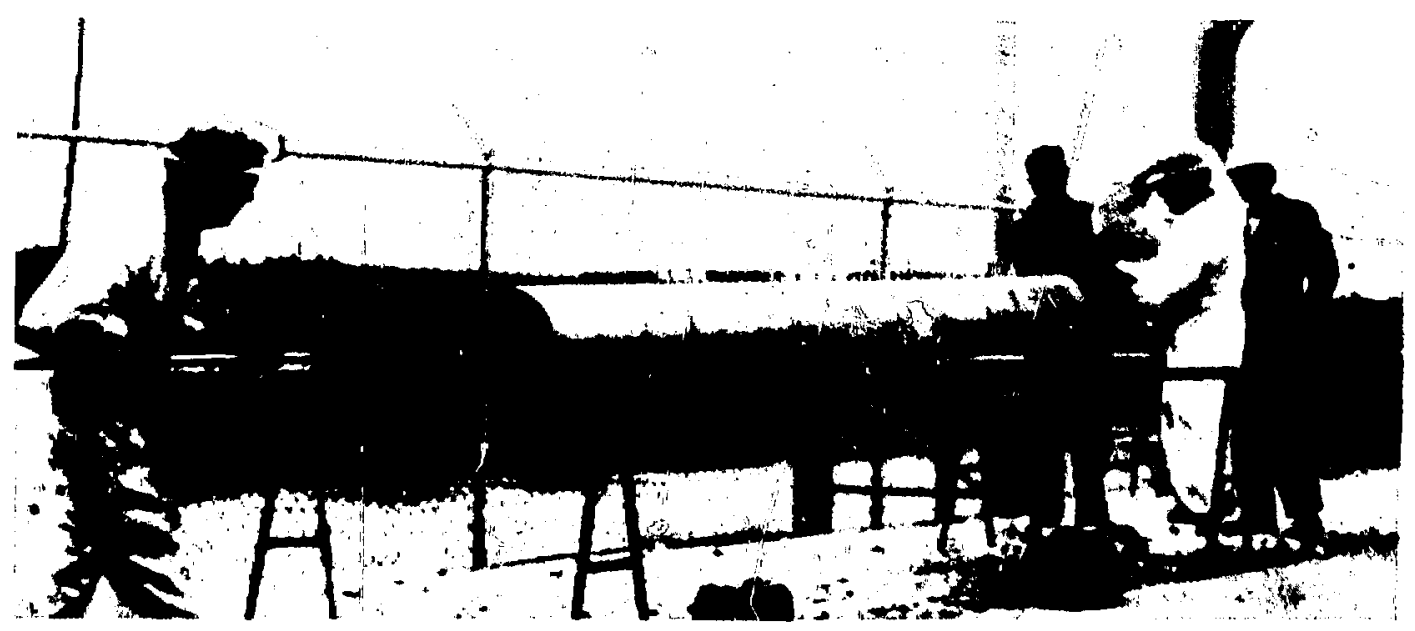

Figure 14. Concrete-lined steel pipes being treated with polyester-styrene at the OSW Water Desalting Facility, Freeport, Texas. 
monomer was heated to $60^{\circ} \mathrm{C}$ before the Acryloid powder was added. While the A-11 was being dissolved, paraffin wax (3wt \% of MMA) was added to the monomer-polymer system. After the A-11 and wax were completely dissolved in the monomer, the system was cooled and divided into two equal parts, A and B.

Just prior to application, BP (2 wt \% of part A) was dissolved in part A, and DM'T (4 wt \% of part $B$ ) was dissolved in part $B$. The high viscosity of this system made the use of a high-shear mixer necessary.

Several techniques for applying the two monomer systems, including the use of two-part spray equipment, were available for use at the Freeport plant. For simplicity, however, both applications were made by paintbrush and roller. Parts $A$ and $B$ of the low-viscosity monomer system were mixed in a 1:1 ratio and applied to the mortar lining. Several applications were made to ensure complete saturation of the mortar surface. Immediately afterward, the seal coat was applied. The monomer system for this coat was formulated to polymerize very rapidly to prevent evaporative loss of the impregnating monomer system. In order to apply this short-pot-life system by brush and roller it was necessary to chill the components prior to use. The two parts were then mixed in a 1:1 ratio and quickly brushed onto the saturated mortar surfaces. Complete polymerization of the seal coat generally occurred in 2 to $4 \mathrm{~min}$ after mixing. Formulas for preparing both monomer systems are shown in 'Table 3.

Preliminary inspections of the treated areas after about 6 weeks of normal plant operation indicated no deterioration of the protective systems.

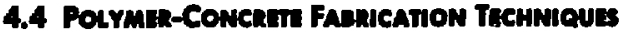

During this report period the USBR has developed a method of preparing PC specimens that closely approach standard PIC in compressive strength and polymer content.

In initial work, a graded sand-aggregate $\mathrm{mix}$ closely approximating that of CP-type concrete was integrally mixed by hand with catalyzed MMA and polymerized at $70^{\circ} \mathrm{C}$. The heat generated during polymerization of these specimens was quite high and as a result the samples developed relatively low compressive strengths, of the order of 8000 to 12,000 psi. Subsequent work on the method and incremental temperature control during polymerization resulted in more consistent specimens with compressive strengths of 11,000 to $12,000 \mathrm{psi}$. The addition of cross-linking and coupling agents,
Table 3

MMA-TMPTMA Monomer Systems for Penetrating and Protective Coatings

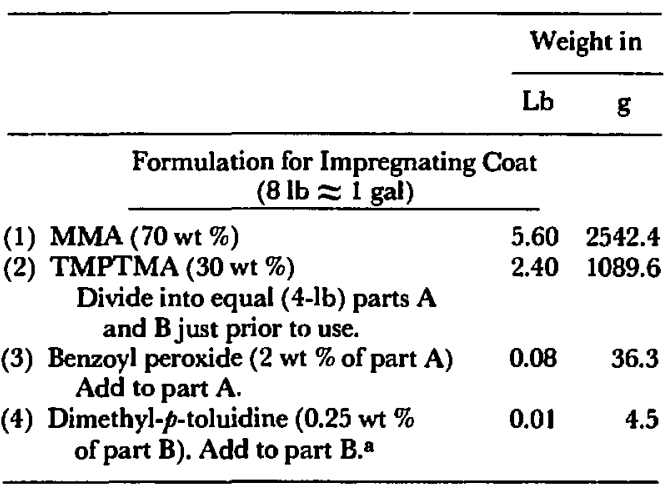

Formulation for Seal Coat $(8 \mathrm{lb} \approx 1 \mathrm{gal})$

(1) MMA (70 wt \%)

$4.48 \quad 2033.9$

(2) TIMPTMA (30 wt \%)

$1.92 \quad 871.7$

(3) Acryloid A-11 polymer

$1.60 \quad 726.4$

(4) Paraffin wax ( 0.3 wt \% of MMA)
Divide into equal parts $A$ and $B$ after cooling to $\approx 21^{\circ} \mathrm{C}$ just prior to use.

(5) Benzoyl peroxide ( 2 wt \% of part A) $\quad 0.08$ Add to part $\mathrm{A}$.

(6) Dimethyl-p-toluidine ( 4 wt \% $\quad 0.16$ of part B). Add to part $B$.

a This ratio of promoter will give an $\approx 24$-min pot lifi. at $23^{\circ} \mathrm{C}$.

glass-fiber reinforcement, and a change to tert.butylazoisobutyronitrile catalyst improved the strength to $14,800 \mathrm{psi}$. As the test program advanced, hand mixing of individual $6 \times 12-$ in. specimens became impractical, and a conventional 3/4-cu ft concrete mixer was used in accordance with the standard mixing and placing procedures for portland cement concrete.

Development of the method has continued until in its present form oven-dried Clear Creek aggregate is machine-mixed with the monomer system, placed in molds, and polymerized at room temperature hy the promoter-catalyst technique. The specimens are prepared with 7 to $8 \%$ monomer by tuial weight of the wet mix. Depending on the maximum size of the aggregate and the amount of cross-linking agent in the monomer system, the specimens develop average compressive strengths varying from 18,400 to $20,000 \mathrm{psi}$. These mixes 
Table 4

Formula for USBR Polymer-Concretea

\begin{tabular}{ccccc}
\hline \multicolumn{2}{c}{ Aggregate $^{\mathrm{b}}$} & & \\
\cline { 1 - 1 } Sieve size & Weight, lb & Monomer system & Weight, g \\
\hline Pan & 14.8 & MMA & 3457.0 \\
100 & 5.6 & TMPTMA & 88.7 \\
50 & 8.5 & BP & 35.5 \\
30 & 8.8 & DMA & 17.7 \\
16 & 5.3 & Silane & 17.7 \\
8 & 5.3 & & \\
$4 \%$ in. & 19.2 & & \\
* to 34 in. & 28.8 & & \\
\hline
\end{tabular}

MMA = methyl inethacrylate.

TMPTMA = trimethanol propane trimethacrylate.

$\mathrm{BP}=$ benzoyl peroxide.

DMA = dimethyl analine.

Silane $=\gamma$-methacryloxypropyltrimethoxysilane.

-Quantity to prepare three 6-in.-diam X 12-in. cylinders.

- Local Clear Creek sand and aggregate oven-dried at $163^{\circ} \mathrm{C}$ to constant weight.

have produced very consistent specimens with individual strengths that vary $<2 \%$ from the nix average. The formula for a mix for three $6 \times 12$-in. cylinders is shown in Table 4.

Specimens prepared with this mix, using conventional concrete-mixing procedures and roomtemperature polymerization, have been tested for compressive stress-strain, tensile splitting, unit weight and specific gravity, and water absorption (see Table 5.) Other specimens have been exposed to a $5 \% \mathrm{H}_{2} \mathrm{SO}_{4}$ solution for two months without any apparent effect on their properties.

Initial tests have been performed in which PC was used to prepare three tunnel-lining segments. These segments were cast in the same molds as the PIC segments discussed in Section 8.2. Singlesegment tests on one of the PC segments gave strength results comparable to those for PIC.

Some initial work has bsen done on styrenebased monomer systerns polymerized at $60^{\circ}$ to $70^{\circ} \mathrm{C}$. As with the oven-cured MMA specimens, the compressive strengths have been relatively low $(11,000$ to 13,000 psi). A test series is under way to deterınine the behavior of styrene $\mathbf{P C}$ specimens polymerized at room temperature.

\subsection{PoLymansatron Techmous:}

4.5.1 Rediation Process. In processes involving large quantities of catalyzed monomers, potentially
Table 5

Summary of Properties Tests on 6-in.-Diam $\times 12$-in.-Long Polymer-Concrete Cylinders

\begin{tabular}{|c|c|c|}
\hline Test & $\begin{array}{l}\text { Temper- } \\
\text { ature, }{ }^{\circ} \mathrm{C}\end{array}$ & Result \\
\hline Tensile splitting strength ${ }^{\mathrm{a}}$ & $\begin{array}{r}-26 \\
21 \\
88\end{array}$ & $\begin{array}{l}1,510 \mathrm{psi} \\
1,430 \mathrm{psi} \\
1,370 \mathrm{psi}\end{array}$ \\
\hline Compressive strength stress ${ }^{*}$ & $\begin{array}{r}-26 \\
21 \\
49 \\
88\end{array}$ & $\begin{array}{l}24,600 \text { psi } \\
19,600 \text { psi } \\
15,800 \text { psib }^{b} \\
14,100 \text { psi }\end{array}$ \\
\hline Modulus of elasticity & $\begin{array}{r}-26 \\
21 \\
88\end{array}$ & $\begin{array}{l}6.11 \times 10^{6} \mathrm{psi} \\
5.28 \times 10^{6} \mathrm{psi} \\
4.44 \times 10^{6} \mathrm{psi}\end{array}$ \\
\hline Prisson's ratio ${ }^{\mathrm{a}}$ & $\begin{array}{r}-26 \\
21 \\
88\end{array}$ & $\begin{array}{l}0.24 \\
0.23 \\
0.22\end{array}$ \\
\hline Elastic limit stress & $\begin{array}{r}-26 \\
21 \\
88\end{array}$ & $\begin{array}{r}14,000 \mathrm{psi} \\
7,500 \mathrm{psi} \\
4,800 \mathrm{psi}\end{array}$ \\
\hline Ultimate compressive strain & $\begin{array}{r}-26 \\
21 \\
88\end{array}$ & $\begin{array}{l}5,360 \mu \text { in./in. } \\
7,080 \mu \mathrm{in.} / \mathrm{in.}{ }^{\mathrm{c}} \\
>8,000 \mu \mathrm{in} . / \mathrm{in} .\end{array}$ \\
\hline Unit weight & - & $149.1 \mathrm{lb} / \mathrm{ft}^{\mathrm{c}}$ \\
\hline Specific gravitya & .- & 2.40 \\
\hline Water absorption ${ }^{c}$ & - & $0.6 \%$ \\
\hline
\end{tabular}

a Average values for three specimens.

bValue for single specimen.

c Average value for two specimens.

hazardous conditions can exist. One method of reducing this hazard is to eliminate reuse of excess monomer, but this may be uneconomical.

Experimental work was initiated to find a safer and more economical method of handling excess monomer from the concrete impregnation process. The method proposed was to first remove inhibitors from the bulk monomers by exposure to $y$ radiation, then impregnate the concrete with the radiation-conditioned monomer, and subsequently polymerize thermally in the absence of chemical initiators.

Initial experiments were to establish the principle of radiation conditioning followed by thermal polymerization in bulk. Test tube quantities $(10 \mathrm{~g})$ of various monomers containing inhibitors were irradiated and tested for polymer conversion. $\mathrm{Po}$ lymerization occurs after the inhibitor has decomposed. The radiation doses required to remove the 
Table 6

Thermal Polymerization of Radiation-Conditioned Monomers"

\begin{tabular}{|c|c|c|c|c|c|c|c|c|}
\hline \multirow[b]{2}{*}{ Monomer } & \multirow[b]{2}{*}{ Inhibitor } & \multirow{2}{*}{$\begin{array}{l}\text { Conc., } \\
\text { ppm }\end{array}$} & \multirow{2}{*}{$\begin{array}{l}\text { Dose rate, } \\
10^{5} \mathrm{rads} / \mathrm{hr}\end{array}$} & \multirow{2}{*}{$\begin{array}{l}\text { Dose, } \\
10^{5} \text { rads }\end{array}$} & \multirow{2}{*}{$\begin{array}{l}\text { Conver- } \\
\text { sion, \% }\end{array}$} & \multicolumn{2}{|c|}{ Polymerization } & \multirow{2}{*}{$\begin{array}{l}\text { Conver- } \\
\text { sion, \% }\end{array}$} \\
\hline & & & & & & $T,{ }^{\circ} \mathbf{C}$ & Time, hr & \\
\hline $\mathbf{M M A}^{\mathbf{b}}$ & $\mathbf{H Q}^{\mathbf{c}}$ & $30-40$ & 1.65 & 4.95 & $1-3$ & 80 & 48 & 100 \\
\hline MMA & $H \widehat{Q}$ & $30-40$ & - & - & - & 80 & 48 & - \\
\hline MMA & HQ & $30-40$ & 1.65 & 4.95 & $1-3$ & 85 & 24 & 100 \\
\hline MMA & HQ & $30-40$ & 1.65 & 4.95 & $1-3$ & 90 & $<24$ & 100 \\
\hline Styrene & $t-\overrightarrow{B P C} C^{d}$ & $45-55$ & 1.60 & 8.05 & $1-3$ & 95 & $\approx 72$ & 100 \\
\hline $\begin{array}{l}\text { 60\% styrene - } \\
\text { 40\% TMPTMA }\end{array}$ & $\begin{array}{l}\text { t-BPC } \\
\text { MEHQ }\end{array}$ & $\left.\begin{array}{l}30 \\
\mathbf{8 0}\end{array}\right\}$ & 1.60 & 4.80 & $1-3$ & 95 & 30 & 100 \\
\hline $\begin{array}{l}\text { 60\% styrene - } \\
40 \% \text { TMPTMA }\end{array}$ & $\begin{array}{l}\text { t-BPC } \\
\text { MEHQ }\end{array}$ & $\begin{array}{l}30 \\
80\end{array}$ & 3.00 & 2.75 & $1-3$ & 90 & 2 & 100 \\
\hline $\begin{array}{l}\text { 60\% styrene - } \\
\text { 40\% TMPTMA }\end{array}$ & $\begin{array}{l}\text { t-BPC } \\
\text { MEHQ }\end{array}$ & $30\}$ & - & - & - & 90 & 2 & - \\
\hline $\begin{array}{l}\text { 60\% styrene - } \\
\text { 40\% TMPTMA }\end{array}$ & $\begin{array}{l}\text { t-BPC } \\
\text { MEHQ }\end{array}$ & $\left.\begin{array}{l}30 \\
80\end{array}\right)$ & 3.00 & 2.75 & $1-3$ & 90 & 4 & 100 \\
\hline $\begin{array}{l}\text { 60\% styrene - } \\
\text { 40\% TMPTMA }\end{array}$ & $\begin{array}{l}\text { t-BPC } \\
\text { MEHQ }\end{array}$ & $\left.\begin{array}{l}30 \\
80\end{array}\right)$ & - & - & - & 90 & 4 & 100 \\
\hline $\begin{array}{l}\text { tert.-butyl styrene } \\
\text { tert.-butyl styrene }\end{array}$ & $\begin{array}{l}\text { t-BCe } \\
\text { t-BC }\end{array}$ & $\begin{array}{l}10 \\
10\end{array}$ & $\begin{array}{l}1.60 \\
3.00\end{array}$ & $\begin{array}{l}5.06 \\
5.25\end{array}$ & $\begin{array}{l}1-3 \\
1-3\end{array}$ & $\begin{array}{l}95 \\
90\end{array}$ & $\begin{array}{l}48 \\
13\end{array}$ & $\begin{array}{r}100 \\
<100\end{array}$ \\
\hline tert.-butyl styrene & $t-B C$ & 10 & - & - & - & 90 & 13 & - \\
\hline tert.-butyl styrene & $t-B C$ & 10 & 3.00 & 5.25 & $1-3$ & 150 & 4 & 100 \\
\hline tert.-butyl styrene & t-BC & 10 & - & - & - & 150 & 4 & 100 \\
\hline \multicolumn{3}{|c|}{$\begin{array}{l}\text { Bulk polymerization; sample size, } 10 \mathrm{~g} \text {. } \\
\text { "MMA, methyl methacrylate. } \\
\text { cHQ hydroquinone. } \\
\text { dt-BPC, tert.-butyl pyrocathechol. }\end{array}$} & \multicolumn{5}{|c|}{$\begin{array}{l}\text { 'TMPTMA, trimethylolpropane trimethacrylate. } \\
\text { 'MEHQ monomethyl etier of hydroquinone. } \\
\text { st-BC, tert.-butyl cathechol. }\end{array}$} & \\
\hline
\end{tabular}

Table 7

Thermal Polymerization of Monomer-Impregnated Concrete Sperimens

\begin{tabular}{|c|c|c|c|c|c|c|}
\hline \multirow[b]{2}{*}{ Sample No." } & \multirow[b]{2}{*}{ Monomer system } & \multirow{2}{*}{$\begin{array}{l}\text { Radiation } \\
\text { dose, } \\
10^{5} \mathrm{rads}\end{array}$} & \multirow{2}{*}{$\begin{array}{l}\text { Polymer } \\
\text { loading, } \\
\text { wt \% }\end{array}$} & \multicolumn{2}{|c|}{$\begin{array}{l}\text { Thermal } \\
\text { polymerization }\end{array}$} & \multirow{2}{*}{$\begin{array}{l}\text { Compressive } \\
\text { strength, } \\
\text { psi }\end{array}$} \\
\hline & & & & $T,{ }^{\circ} \mathrm{C}$ & Time, hr & \\
\hline $\begin{array}{l}\text { CP-5R-11C } \\
\text { CP-5A-15C } \\
\text { CP-5B-12C } \\
\text { CP-5A-Y } \\
\text { 72.T1-10 } \\
\text { CP-R-8 } \\
\text { CP-5B-14E } \\
\text { CP-5B-14C } \\
\text { CP-4B-14C } \\
\text { CP-0-11A } \\
\text { CP-HB-15C } \\
\text { CP-2A-11B } \\
\text { CP-R-41 } \\
\text { CP-4B-15E } \\
\text { CP-5B-13F } \\
\text { CP-4B-Y } \\
\text { CP-4B-15B } \\
\text { CP-4B-13F }\end{array}$ & $\begin{array}{l}\text { MMAb } \\
\text { MMA - 1\% TMPTMAd } \\
\text { MMA - 5\% methacrylic acid } \\
\text { Styrene } \\
\text { Styrene } \\
\text { Styrene } \\
\text { Styrene - 1\% TMPTMA } \\
60 \% \text { styrene - 40\% TMPTMA } \\
60 \% \text { styrene - 40\% TMPTMA } \\
60 \% \text { styrene - 40\% TMPTMA } \\
60 \% \text { styrene - 40\% TMPTMA } \\
90 \% \text { styrene - 10\% TMPTMA } \\
80 \% \text { styrene - 20\% TMPTMA } \\
70 \% \text { styrene - 30\% TMPTMA } \\
\text { tert.-butyl styrene } \\
\text { tert.-butyl styrene } \\
\text { tert.-butyl utysene } \\
\text { tert.-butyl atyrene }\end{array}$ & $\begin{array}{c}3.30 \\
3.30 \\
2.40 \\
8.05 \\
- \\
- \\
8.05 \\
3.20 \\
1.60 \\
- \\
- \\
- \\
- \\
- \\
5.06 \\
5.06 \\
5.06 \\
-\end{array}$ & $\begin{array}{l}6.8 \\
4.3 \\
- \\
6.5 \\
6.0 \\
5.3 \\
6.6 \\
8.1 \\
6.5 \\
6.6 \\
7.0 \\
5.4 \\
6.0 \\
6.2 \\
5.7 \\
5.7 \\
6.1 \\
6.1\end{array}$ & $\begin{array}{l}95 \\
90 \\
85,145 \\
95 \\
125,200 \\
150,200 \\
95 \\
95 \\
90-95 \\
90-95 \\
90-95 \\
90-95 \\
90-95 \\
90-95 \\
90,150 \\
90,150 \\
150 \\
150\end{array}$ & $\begin{array}{l}48 \\
18 \\
20,20 \\
72 \\
24,8 \\
24,24 \\
72 \\
48 \\
6 \\
6 \\
10 \\
72 \\
72 \\
72 \\
20,20 \\
20,20 \\
7.5 \\
7.5\end{array}$ & $\begin{array}{c}6,670^{\circ} \\
7,100^{\circ} \\
11,420^{c} \\
4,780 \\
14,300^{c} \\
14,285 \\
8,310^{\circ} \\
21,400 \\
15,850^{\circ} \\
14,250^{\circ} \\
19,600 \\
16,550^{\circ} \\
18,170 \\
18,342 \\
17,630 \\
17,550 \\
15,750^{\circ} \\
8,400^{\circ}\end{array}$ \\
\hline $\begin{array}{l}\text { Specimen } \\
\text { Methyl me } \\
\text { - Not fully p } \\
\text {-Trimethylo }\end{array}$ & $\begin{array}{l}\text { ylate. } \\
\text { rized; detected strong odor o } \\
\text { ane trimethacrylate. }\end{array}$ & aeror $f$ & a & & & \\
\hline
\end{tabular}




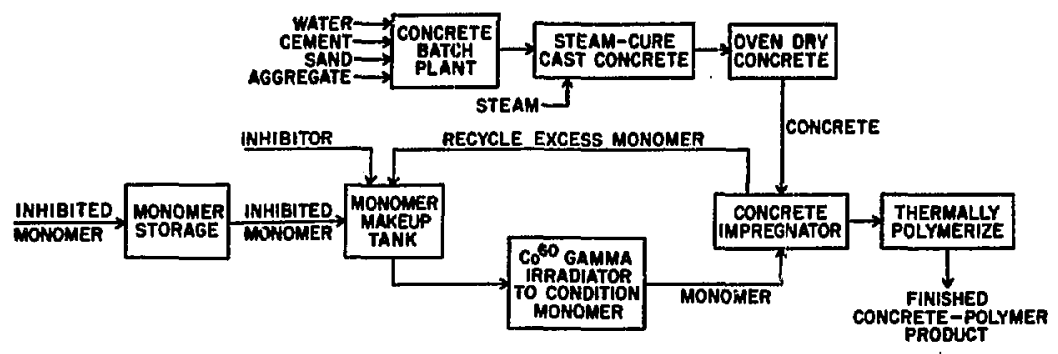

Figure 15. Flow sheet of concrete-polymer materials plant for production of polymer-impregrated concrete by thermal polymerization of radiation-conditioned monomers.

inhibitor from various monomers are given in Table 6. The initial inhibitor concentrations shown in the table are as received from the manufacturer. The total dose requirements for destruction of inhibitor will vary with the type and concentration of inhibitor in each monomer. MMA containing 30 to $40 \mathrm{ppm}$ hydroquinone required a total dose of $\approx 4.95 \times 10^{5}$ rads to overcome the inhibitor. After conditioning, mono:ter samples were exposed to temperatures of $80^{\circ}, 85^{\circ}$, and $90^{\circ} \mathrm{C}$. Polymerization at $90^{\circ} \mathrm{C}$ was completed in $<24 \mathrm{hr}$. At $80^{\circ} \mathrm{C}, \approx 48 \mathrm{hr}$ were required for complete polymerization. The rate of polymerization for MMA is highly temperature dependent. Data for styrene, styrene-TMPTMA and tert.-butyl styrene are also included in Table 6.

Following the initial bulk monomer studies, a series of tests was performed in which 3-in.-diam $\times 6$-in.-long concrete specimens were impregnated with radiation-conditioned monomer and thermally polymerized. Complete polymerization was obtained with several monomer systems, and for those materials the strength values were comparable with those obtained for PIC produced by radiation or chemically initiated polymerization. The results of these experiments are given in Table 7.

Asshown in Table 7, low strength values were obtained for several specimens that did not fully polymerize. This was particularly the case with MMAimpregnated specimens. Although the specimens were completely impregnated, the monomer at the center did not polymerize. This was observed in repeated experiments. Addition of 5\% methacrylic acid to the MMA produced some improvement in strength, but complete polymerization was not achieved.

To minimize loss of monomer through evaporation at the temperatures required to give satisfactory polymerization at all times, the polymerization was performed by subjecting the specimen to several temperatures (see Table 7). A low temperature was maintained until the gel point was reached. The temperature was then increased to complete the polymerization.

Figure 15 is a conceptual flow sheet for the production of PIC by the thermal polymerization of radiation-conditioned monomers. In this process, standard mixes of concrete are cast and cured in a concrete batch plant, then dried and placed in a closed vessel for impregnation. After evacuation the radiation-conditioned monomer is introduced and the concrete specimen is allowed to soak.

The inhihited monomer is delivered to the plant and placed in storage tanks. From these it is fed to a monomer makeup tank, where it is mixed with excess uninhibited monomer from the impregnator. The mixed recycled monomer is fed to a ${ }^{60} \mathrm{Co}$ $\gamma$ irradiator for the time required to remove inhibitor. The monomer is then used for impregnation. Atier saturation, the concrete specimens are placed in ovens for polymerization.

The method of radiation conditioning followed by thermal polymerization is also applicable to the process for impregnating other porous materials and for PC composites.

4.5.2 Promotor-Catalyst Process. The thermalcatalytic and radiation polymerization techniques are normally used to produce PC and PIC composites. Currently promoter-catalyst systems are being investigated. The use of promoter-catalysts for effecting rapid polymerization at ambient temperature is particularly desirable in field-type applications, where it is impractical to use elevated temperature or radiation. A typical field application was described in Sections 4.3.1 and 4.3.2.

Promoters are chemical compounds that decompose catalysts to form free radicals, which in turn initiate the polymerization reaction. Depending 
on the promoter-catalyst and monomer system used, polymerization can be initiated at temperatures well below $15^{\circ} \mathrm{C}$. Increasing the temperature tends to accelerate the polymerization rate.

Several promoter-catalyst systems have been developed to initiate polymerization of the monomers currently being used to form concrete-polymer materials. These are listed in Table 8, together with data on monomer viscosity, promoter-catalyst concentrations, and the times for gel and complete polymerization at $22^{\circ} \mathrm{C}$. For some systems, the gel and cure times can be changed by varying the concentrations of promoter-catalyst.

A monomer containing a promoter-catalyst system usually has a short gel time. This is a disadvantage in processing $\mathbf{P I C}$, for which relatively long monomer soaking times are normally required. The short curing time at ambient temperature is an advantage, however, in surface-sealing applications such as on bridge decks or concretelined vessels (see Sections 4.3.1 and 4.3.2). It is also a convenient technique for producing $\mathbf{P C}$.

Because of the nature of the reaction, the polymerization of monomer with promoter-catalysts starts immediately after both components have been added. The reaction is slow initially and accelerates with time. Figure 16 shows the increase in monomer viscosity with time at $20^{\circ}$ and $32^{\circ} \mathrm{C}$ for MMA containing a promoter and a catalyst. At the higher temperature, polymerization occurs more rapidily, as indicated by viscosity changes. Although the monomer contains 35 ppm hydroquinone inhibitor, the onset of polymerization is immediate.
For some applications, such as surface impregnation of dense concrete, the increase in viscosity with time imposes limitations on the degree of penetration. Attempts have been made to decrease the polymerization rate by the use of additives or retarders. The results of these experiments are given in Figure 17. An increase in inhibitor concentration from 35 to 85 pprn did not appreciably extend the induction period and only slightly retarded the polymerization. The amount of inhibitor that can be added is limited, since its tendency to destroy the catalyst can result in incomplete polymerization.

The effect of adding incremental amounts of styrene monomer, which is not polymerized by the promoter-catalyst system, is also shown in Figure 17. The addition of styrene retarded the polymerization rate of MMA appreciably. The gel time was not appreciably affected by the addition of styrene in concentrations up to $5 \%$; however, the curing time was significantly extended. Studies are being made in an attempt to predictably vary the polymerization rates of various monomer systems according to the promoter-catalysts used.

4.5.3 Thermal-Catalytic Process, Under Hot Water. Experiments have been conducted to determine the feasibility of using water to reduce monomer evaporation and drainage from concrete specimens during polymerization by radiation or thermal-catalytic techniques.

A detailed testing program is under way to determine the effects of the presence of water during the polymerization reaction on the structural and durability properties of the composite. The struc-

Table 8

Curing of Low-Viscosity Monomers

\begin{tabular}{|c|c|c|c|c|c|}
\hline Monomer mixture & $\begin{array}{l}\text { Viscosity, } \mathrm{cP} \\
\text { at } 25^{\circ} \mathrm{C}\end{array}$ & Promoter, " ، \% & Initiator & $\begin{array}{l}\text { Cure time, } \\
\text { min }\end{array}$ & $\begin{array}{l}\text { Gel time, } \\
\text { min }\end{array}$ \\
\hline $\begin{array}{l}60 \text { wt \% styrene - } \\
40 \text { wt \% TMPTMA }\end{array}$ & 2.0 & $\begin{array}{l}0.5 \% \mathcal{N}, \mathcal{N} \text {-dimethyl-p-toluidine } \\
+0.5 \% \text { dimethyl aniline }\end{array}$ & $1.0 \%$ benzoyl peroxide & 45 & 15 \\
\hline $\begin{array}{l}70 \text { wt \% MMA - } \\
30 \text { wt \% TMPTMA }\end{array}$ & 1.9 & $1.0 \% \mathcal{N}, \mathcal{N}$-dimethyl- $p$-toluidine & $1.0 \%$ benzoyl peroxide & $10-15$ & $5-10$ \\
\hline MMA & 0.5 & $\begin{array}{l}0.5 \%, \mathcal{N}, N \text {-dimethy]-p-toluidine } \\
+0.5 \% \text { dimethyl aniline }\end{array}$ & $\begin{array}{l}0.5 \% \text { benzoy] perox- } \\
\text { ide }+0.5 \% \text { AIBNa }\end{array}$ & $\approx 60$ & $\approx 20$ \\
\hline $\begin{array}{l}90 \text { wt \% styrene - } \\
10 \text { wt \% polyester }\end{array}$ & 1.8 & $1.0 \%$ Advacat $30^{\mathrm{b}}$ & $\begin{array}{l}1.0 \% \text { methyl ethyl } \\
\text { ketone peroxide }\end{array}$ & & $\approx 60$ \\
\hline
\end{tabular}

Temperature, $22^{\circ} \mathrm{C}$.

Azobisisobutyronitrile,

bCobalt(II) halide azinate. 
tural properties of MMA-impregnated CP-type concrete polymerized by radiation while in direct contact with water (test series CP-8) were given in Ref. 4. Current data on durability testing are surnmarized in Section 5.1.1. In general, they indicate that underwater radiation-induced polymerization has no detrimental effects on the properties and may even produce benefits because of reductions in monomer loss. Similar effects have been observed

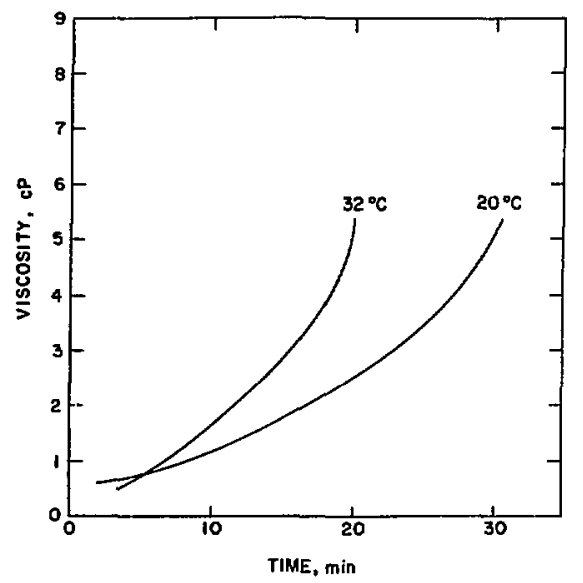

Figure 16. Change in viscosity of MMA during initial stages of polymerization by promoter-catalyst techniques. Catalysts, 1 wt $\%$ AIBN and 1 wt \% benzoyl peroxide; promoters, 1 wt \% dimethyl aniline and 1 wt \% dimethyl toluidine.

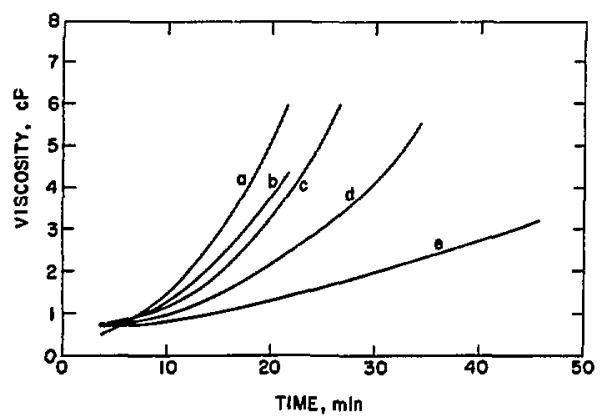

Figure 17. Effects of additives on the change in viscosity of MMA at $32^{\circ} \mathrm{C}$ during initial slages of polymerization by promoter-catalyst techniques. Curve $a$, MMA containing 35 ppm hydroquinone; curve $b$, MMA containing 85 ppm hydroquinone; curve $6,99.5$ wt \% MMA - 0.5 wt $\%$ styrene; curve d, 98 wt \% MMA - 2 wt \% styrene; curve e, 95 wt \% MMA -5 wt \% styrene. with normal-weight and structural lightweight concretes supplied by the FHWA. ${ }^{8}$

The effectiveness of underwater thermal-catalytic polymerization is also being determined. Variables studied include water depth, temperature, and the use of primary encapsulating materials such as foil. It was observed that MMA evaporation losses from concrete specimens polymerized at $75^{\circ} \mathrm{C}$ could be essentially eliminated by the use of a 20 in. head of monomer-saturated water (MMA solubility in water at $30^{\circ} \mathrm{C}$ is $1.5 \%$ ). PIC produced by immersing monomer-saturated samples in water preheated to $75^{\circ} \mathrm{C}$ was similar to that obtained by using $20^{\circ} \mathrm{C}$ water and subsequently heating it to $75^{\circ} \mathrm{C}$. Specimens polymerized at $75^{\circ} \mathrm{C}$ under 6 in. of unsaturated water exhibited surface depletions of $\approx 1 / 8$ in. Cross sections of PIC specimens produced by several techniques are compared in Figure 18.

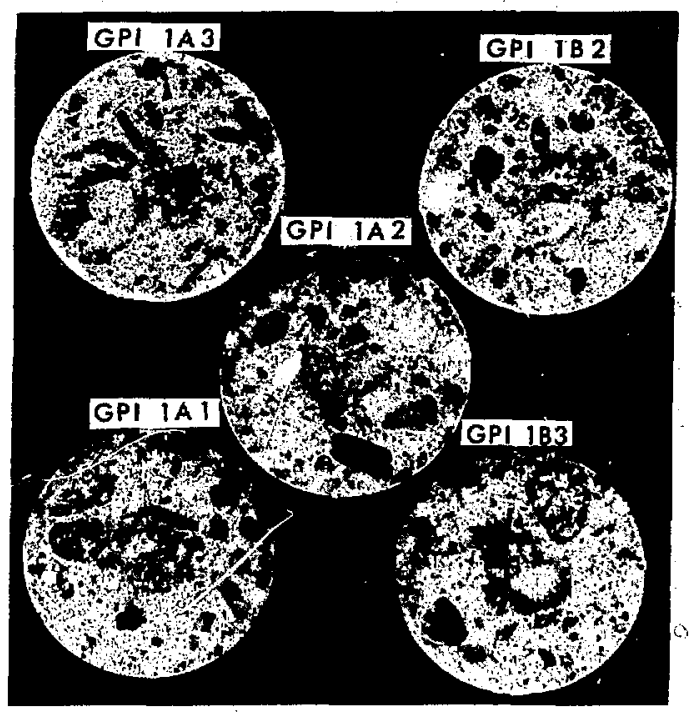

Figure 18. Cross sections of CP-type concrete specimens impregnated with MMA and thermal-catalytically polymerized. GPl-1Al : wrapped in foil and polymerized under a 20 -in. head of water at $75^{\circ} \mathrm{C}$, with no surface depletion; GPl-1B3: wrapped in foil, immersed under a 20-in. head of water at $20^{\circ} \mathrm{C}$ and subsequently polymerized at $75^{\circ} \mathrm{C}$, with no surface depletion; GPl-1A2: wrapped in foil, polymerized in an oven at $75^{\circ} \mathrm{C}$, with surface depletion =1/16 in,; GPI-1 B2: unwrapped, polymerized under a 20in. head of unsaturated water at $75^{\circ} \mathrm{C}$, with surface depletion $\approx 1 / 16$ in.; GP1-1A3: unwrapped, polymerized under a 6 -in, head of water at $75^{\circ} \mathrm{C}$, with surface depletion $\approx 1 / 8$ in. 
On the basis of these results, the use of warm water to reduce evaporation and drainage during thermal-catalytic polymerization is completely feasible.

It should be noted that the underwater method for the radiation and thermal-catalytic processes re- sults in the formation of polymer in the water. On draining, some polymer may adhere to the walls of the impregnator and collect in piping and valves. The problem is essentially one of design and arises primarily from the polymerization of nondrainatie monomer. However, less polymer is formed in the

Table 9

Polymerization Techniquesa

\begin{tabular}{|c|c|c|c|c|c|}
\hline $\begin{array}{c}\text { Series } \\
\text { No. }\end{array}$ & Thermal-catalytic polymerization technique & $\begin{array}{c}\text { Polymerization } \\
\text { temperature, } \\
{ }^{\circ} \mathrm{C}\end{array}$ & $\begin{array}{c}\text { Specimen } \\
\text { No. }\end{array}$ & $\begin{array}{c}\text { Polymer } \\
\text { loading, } \\
\text { wt } \%\end{array}$ & $\begin{array}{l}\text { Compressive } \\
\text { strength, } \\
\text { psi }\end{array}$ \\
\hline 1 & Steam in vessel and water jacket & 80 & $\begin{array}{r}5372 \\
100 \\
76 \\
86 \\
5322\end{array}$ & $\begin{array}{l}5.5 \\
5.6 \\
5.4 \\
5.0 \\
5.0\end{array}$ & $\begin{array}{l}17,700 \\
16,270 \\
17,500 \\
19,100 \\
16,450\end{array}$ \\
\hline 2 & Steam in vessel and water jacket & 80 & $\begin{array}{l}5206 \\
5226\end{array}$ & $\begin{array}{l}4.5 \\
6.2\end{array}$ & $\begin{array}{l}16,900 \\
17,500\end{array}$ \\
\hline 3 & Steam in vessel and water jacket, with atomization & 75 & $\begin{array}{l}5220 \\
5259 \\
5276\end{array}$ & $\begin{array}{l}5.2 \\
5.3 \\
4.9\end{array}$ & $\begin{array}{l}18,500 \\
18,000 \\
17,300\end{array}$ \\
\hline 1 & Steam in vessel and water jacket & 75 & $\begin{array}{l}\text { SC1 } \\
\text { SC2 } \\
\text { Can } 6 \\
\text { Can } 7\end{array}$ & $\begin{array}{r}10.9 \\
10.0 \\
9.5 \\
8.7\end{array}$ & $\begin{array}{l}17,000 \\
16,900 \\
18,600 \\
18,500\end{array}$ \\
\hline 5 & Steam in water jacket & 60 & $\begin{array}{l}72.209 .18 \\
72.209 .71 \\
72.209 .77 \\
72.209 .85\end{array}$ & $\begin{array}{l}5.0 \\
5.9 \\
4.7 \\
4.6\end{array}$ & $\begin{array}{l}17,000 \\
16,900 \\
16,700 \\
15,900\end{array}$ \\
\hline 6 & Wrapped and placed in oven & 75 & $\begin{array}{l}\text { TE-47 } \\
\text { TE-6 }\end{array}$ & $\begin{array}{l}5.5 \\
5.9\end{array}$ & $\begin{array}{l}20,860 \\
21,230\end{array}$ \\
\hline 7 & Wrapped and placed in oven & 75 & $\begin{array}{l}\text { TE-12 } \\
\text { TE-56 }\end{array}$ & $\begin{array}{l}6.0 \\
5.4\end{array}$ & $\begin{array}{l}21,210 \\
20,820\end{array}$ \\
\hline 8 & Wrapped and placed in oven & 75 & $\begin{array}{l}\text { TE-16 } \\
\text { TE-27 }\end{array}$ & $\begin{array}{l}5.4 \\
5.9\end{array}$ & $\begin{array}{l}21,140 \\
20,960\end{array}$ \\
\hline 9 & Wrapped and placed in oven & 75 & $\begin{array}{l}\text { TE-4 } \\
\text { TE-64 }\end{array}$ & $\begin{array}{l}5.5 \\
5.8\end{array}$ & $\begin{array}{l}20,960 \\
20,610\end{array}$ \\
\hline 10 & Wrapped and placed in oven & 75 & $\begin{array}{c}\text { TE-33 } \\
\text { TE-58 }\end{array}$ & $\begin{array}{l}5.8 \\
4.8\end{array}$ & $\begin{array}{l}19,890 \\
19,890\end{array}$ \\
\hline 11 & Wrapped and placed in oven & 75 & $\begin{array}{l}\text { TE-13 } \\
\text { TE-21 }\end{array}$ & $\begin{array}{l}5.2 \\
5.3\end{array}$ & $\begin{array}{l}20,860 \\
18,710\end{array}$ \\
\hline 12 & Wrapped and placed in oven & 75 & $\begin{array}{l}\text { TE-37 } \\
\text { TE-38 }\end{array}$ & $\begin{array}{l}5.4 \\
5.9\end{array}$ & $\begin{array}{r}18,960 \\
18,960\end{array}$ \\
\hline 13 & Wrapped and placed in oven & 75 & $\begin{array}{l}\text { TE-5 } \\
\text { TE-10 }\end{array}$ & $\begin{array}{l}5.4 \\
5.3\end{array}$ & $\begin{array}{l}18,820 \\
21,070\end{array}$ \\
\hline 14 & Wrapped and placed in oven & 75 & $\begin{array}{l}72.209 .42 \\
72.209 .69\end{array}$ & $\begin{array}{l}5.9 \\
6.0\end{array}$ & $\begin{array}{l}20,100 \\
19,800\end{array}$ \\
\hline
\end{tabular}

•6.jn,-diam X 12-in.-long cylinders impregnated with MMA and catalyzed with tert.-butylazoisobutyronitrile (D-A79). 
thermal-catalytic than in the radiation process, probably because of the decreased solubility of MMA in water at the elevated temperature. The problem can be minimized by proper design, and reduced evaporation and drainage losses more than compensate for it.

Large-scale testing of underwater polymerization is being done in the preparation of pipe specimens for the ACPA and in the USBR tunnel support and lining program. These studies are discussed in Sections 8.1.2 and 8.2, respectively.

4.5.4 Thermal-Catalytic Process, Using Steam. Experiments were conducted to evaluate the feasibility of thermal-catalytic polymerization of tert.butylazoisobutyronitrile-catalyzed MMA-impregnated concrete specimens by filling the impregnation vessel with steam. This method eliminates the wrapping of specimens for the polymerization process and reduces handling of specimens. $\mathrm{Po}-$ lymerization heat was applied to the specimens by two procedures: (1) injecting steam directly into the impregnation vessel (inner tank steam) and steam-heating the water in the water jacket surrounding the vessel, and (2) steam-heating only the water in the water jacket. Results to date indicate that compressive strengths for both steamheating methods are lower than those obtained with wrapped specimens polymerized in an oven. These data are shown in Table 9. Polymerization times for steam heating and oven heating are nearly the same.

Solenoids controlled by thermoswitches were used to automatically open and close steam valves in order to reach and maintain the desired vessel temperature. After this temperature had been maintained for an hour, the controls were switched off and steam valves closed. The insulation around the vessel helped to maintain the temperature until polymerization had started. The polymerization reaction is exothermic; thus the temperature in the vessel increased.

Temperature controls for specimens polymerized by using the inner tank steam and water jacket simultaneously were set for $75^{\circ}$ and $80^{\circ} \mathrm{C}$, respectively. In one experiment, only the water in the jacket was steam-heated, with the temperature control set at $60^{\circ} \mathrm{C}$. The oven temperature during polymerization was controlled at $75^{\circ} \mathrm{C}$ by a thermostat.

Specimens polymerized by both steam techniques showed a monomer loss from the exterior surfaces varying from about $1 / 16$ to $1 / 4$ in, in depth. This loss is greater than that normally obtained with wrapped specimens and is assumed to result from evaporation during heating and polymerization.

An attempt was made to reduce MMA monomer loss by atomizing MMA monomer vapor into the top of the impregnation vessel during the polymerization cycle. By saturating the air inside the vessel with monomer vapor, it was hoped that evaporation from the surfaces would be reduced. The technique reduced monomer loss from exterior surfaces in some instances, but was difficult to control and in general gave inconsistent results.

The compressive strengths for steam-polymerized specimens are lower than those for wrapped and oven-polymerized specimens (see Table 9). This is probably because of the increased evaporation losses. The average compressive strength of 6-in.-diam $\times 12$-in.-long oven-polymerized specimens was 20,000 psi. Specimens polymerized with the combined inner-vessel steam and water-jacket heat gave an average strength of $17,800 \mathrm{psi}$. In one test in which only the steam-heated water jacket was used as a source of heat, the strengths averaged 16,600 psi. Specimens from this test showed large amounts of monomer depletion from the exterior surfaces.

Since wrapping large specimens is impractical and expensive, work will continue to develop improved steam polymerization techniques. At present the use of steam to heat water in which the monomer-saturated specimens are immersed (see Section 4.5.3) appears to be the best method of reducing monomer depletion in a practical manner.

\section{TEST RESULTS \\ ON POLYMER-IMPREGNATED CONCRETE}

Tests of structural and durability properties are conducted on PIC for normal-temperature applications and for high-temperature desalting plant applications. PIC for these two applications is currently made from one basic type of concrete, but different monomer systems are used. Those for desalting plant applications produce polymers that withstand high temperature and exposure to brine and water without softening or decomposing. Monomers for normal-temperature applications are generally polymerized by $\gamma$ radiation from a ${ }^{60}$ Co source, and monomers for high-temperature applications are thermal-catalytically polymerized. In addition, tests are performed on partially impregnated CP-type concreit is develop a tech- 
Table 10

\begin{tabular}{|c|c|c|c|c|c|c|c|}
\hline \multirow[b]{3}{*}{ Property } & \multicolumn{3}{|c|}{ Unimpregnated concrete } & \multirow{2}{*}{\multicolumn{2}{|c|}{$\begin{array}{l}\text { MMA impregnated, }, a \\
\text { CP-1 series }\end{array}$}} & \multirow{2}{*}{\multicolumn{2}{|c|}{$\begin{array}{l}S \text { impregnated, }{ }^{a} \\
\text { CP-2 series }\end{array}$}} \\
\hline & \multirow{2}{*}{$\begin{array}{l}\text { Controls, } \\
\text { CP-0 series }\end{array}$} & \multicolumn{2}{|c|}{ CP-3 series } & & & & \\
\hline & & $\mathbf{R}^{\mathbf{b}}$ & $T^{b}$ & $\mathbf{R}$ & $T$ & $\mathbf{R}$ & $\mathbf{T}$ \\
\hline $\begin{array}{l}\text { Compressive strength, psi } \\
\text { \% improvement }\end{array}$ & 5,270 & $\begin{array}{r}4,950 \\
-6\end{array}$ & $\begin{array}{r}5,260 \\
0\end{array}$ & $\begin{array}{r}20,260 \\
285\end{array}$ & $\begin{array}{r}18,160 \\
244\end{array}$ & $\begin{array}{r}14,140 \\
168\end{array}$ & $\begin{array}{r}8,790 \\
67\end{array}$ \\
\hline $\begin{array}{l}\text { Modulus of elasticity, } 10^{5} \mathrm{psi} \\
\text { \% improvement }\end{array}$ & $\begin{array}{l}3.5 \\
-\end{array}$ & $\begin{array}{l}2.7 \\
-23\end{array}$ & $\begin{array}{c}2.9 \\
-17\end{array}$ & $\begin{array}{l}6.3 \\
80\end{array}$ & $\begin{array}{c}6.2 \\
77\end{array}$ & $\begin{array}{l}6.3 \\
83\end{array}$ & $\begin{array}{l}5.2 \\
48\end{array}$ \\
\hline $\begin{array}{l}\text { Tensile strength, } \mathbf{p s i} \\
\text { \% improvement }\end{array}$ & $\begin{array}{r}420 \\
-\end{array}$ & $\begin{array}{r}335 \\
-19\end{array}$ & $\begin{array}{l}388 \\
-7\end{array}$ & $\begin{array}{r}1,630 \\
290\end{array}$ & $\begin{array}{r}1,510 \\
262\end{array}$ & $\begin{array}{r}1,100 \\
165\end{array}$ & $\begin{array}{r}720 \\
73\end{array}$ \\
\hline $\begin{array}{l}\text { Modulus of rupture, psi } \\
\% \text { improvement }\end{array}$ & $\begin{array}{r}740 \\
-\end{array}$ & $\begin{array}{r}632 \\
-15\end{array}$ & $\begin{array}{r}666 \\
-10\end{array}$ & $\begin{array}{r}2,640 \\
256\end{array}$ & $\begin{array}{r}2,290 \\
210\end{array}$ & $\begin{array}{r}2,300 \\
211\end{array}$ & $\begin{array}{r}1,060 \\
44\end{array}$ \\
\hline $\begin{array}{l}\text { Flexural elasticity modulus, } 10^{6} \mathrm{psi} \\
\text { \% improvement }\end{array}$ & $\begin{array}{l}4.3 \\
-\end{array}$ & $\begin{array}{l}3.0 \\
-30\end{array}$ & -21 & $\begin{array}{l}6.2 \\
44\end{array}$ & 65 & $\begin{array}{l}6.3 \\
47\end{array}$ & $\begin{array}{l}5.1 \\
19\end{array}$ \\
\hline Creep, ${ }^{d} \mu$ in./in. & $200^{\circ}$ & $117^{I}$ & $42^{\mathrm{r}}$ & $6 \mathrm{~B}$ & $141^{\mathrm{g}, \mathrm{h}}$ & $i, j$ & $222^{i}$ \\
\hline $\begin{array}{l}\text { Hardness, "L" type impact hammer } \\
\text { \% improvement }\end{array}$ & $\begin{array}{r}32 \\
-\end{array}$ & $\begin{array}{r}27 \\
-15\end{array}$ & $\begin{array}{r}27 \\
-15\end{array}$ & $\begin{array}{l}55 \\
73\end{array}$ & $\begin{array}{l}52 \\
62\end{array}$ & $\begin{array}{l}48 \\
51\end{array}$ & $\begin{array}{l}50 \\
56\end{array}$ \\
\hline $\begin{array}{l}\text { Abrasion loss, in. } \\
\text { \% improvement }\end{array}$ & $\begin{array}{l}0.0497 \\
-\end{array}$ & $\begin{array}{ll}0.0352 \\
35\end{array}$ & $\begin{array}{l}0.0357 \\
28\end{array}$ & $\begin{array}{ll}0.0163 \\
67\end{array}$ & $\begin{array}{l}0.0147 \\
70\end{array}$ & $\begin{array}{l}0.0400 \\
19\end{array}$ & $2^{0.0365}$ \\
\hline $\begin{array}{l}\text { Loss in weigint, } \mathrm{g} \\
\text { \% improvement }\end{array}$ & 14 & $\begin{array}{r}6 \\
57\end{array}$ & $\begin{array}{r}7 \\
50\end{array}$ & $\begin{array}{r}4 \\
71\end{array}$ & $\begin{array}{r}4 \\
71\end{array}$ & $\begin{array}{r}9 \\
36\end{array}$ & $\begin{array}{r}6 \\
57\end{array}$ \\
\hline $\begin{array}{l}\text { Cavitation, in., 2-hr exposure } \\
\text { \% improvement }\end{array}$ & $\begin{array}{l}0.320 \\
-\end{array}$ & $\begin{array}{l}0.368 \\
-15\end{array}$ & $\begin{array}{l}0.262 \\
18\end{array}$ & $\begin{array}{l}0.064 \\
80\end{array}$ & $\begin{array}{l}0.020 \\
94\end{array}$ & $\begin{array}{l}0.035 \\
89\end{array}$ & $\begin{array}{l}0.009 \\
97\end{array}$ \\
\hline $\begin{array}{l}\text { Water absorption, \% } \\
\text { \% decrease }\end{array}$ & $\begin{array}{l}6.40 \\
-\end{array}$ & -2.5 & $\begin{array}{l}6.2 \\
3\end{array}$ & $8^{1.08}$ & $\begin{array}{l}0.34 \\
95\end{array}$ & $\begin{array}{l}0.51 \\
92\end{array}$ & $\begin{array}{l}0.70 \\
89\end{array}$ \\
\hline $\begin{array}{l}\text { Water permeability, } 10^{4} \mathrm{ft} / \mathrm{yr} \\
\text { \% decrease }\end{array}$ & $\begin{array}{l}5.3 \\
-\end{array}$ & $\begin{array}{l}32.0 \\
-500\end{array}$ & $\begin{array}{r}29.0 \\
-450\end{array}$ & $\begin{array}{l}-0.8 \\
85\end{array}$ & $\begin{array}{l}1.4 \\
73\end{array}$ & $\begin{array}{r}8.2 \\
-55\end{array}$ & $\begin{array}{l}1.5 \\
72\end{array}$ \\
\hline $\begin{array}{l}\text { Thermal conductivity, } 23^{\circ} \mathrm{C}, \mathrm{Btu} / \mathrm{ft}-\mathrm{hr}-{ }^{\circ} \mathrm{C} \\
\text { \% decrease }\end{array}$ & $\begin{array}{l}2.398 \\
-\end{array}$ & $20^{1.915}$ & 1.989 & $\begin{array}{l}2.351 \\
2\end{array}$ & $\begin{array}{l}2.277 \\
5\end{array}$ & $\begin{array}{l}2.246 \\
4\end{array}$ & $\begin{array}{l}2.349 \\
2\end{array}$ \\
\hline $\begin{array}{l}\text { Diffusivity at } 23^{\circ} \mathrm{C}, \mathrm{ft}^{2} / \mathrm{hr} \\
\text { \% increase }\end{array}$ & $\begin{array}{l}0.0697 \\
-\end{array}$ & $\begin{array}{l}0.0637 \\
-9\end{array}$ & $\begin{array}{l}0.0704 \\
1\end{array}$ & $\begin{array}{l}0.0736 \\
6\end{array}$ & $\begin{array}{l}0.0693 \\
0\end{array}$ & $\begin{array}{l}0.0715 \\
3\end{array}$ & $\begin{array}{l}0.0734 \\
5\end{array}$ \\
\hline $\begin{array}{l}\text { Coefficient of expansion, } \mu \mathrm{in} . / \mathrm{in} .{ }^{\circ} \mathrm{C} \\
\% \text { increase }\end{array}$ & $\begin{array}{l}7.24 \\
-\end{array}$ & $\begin{array}{l}7.60 \\
5\end{array}$ & $\begin{array}{l}7.70 \\
6\end{array}$ & 9.65 & $\begin{array}{l}9.45 \\
31\end{array}$ & $\begin{array}{l}9.16 \\
27\end{array}$ & $\begin{array}{l}9.00 \\
24\end{array}$ \\
\hline $\begin{array}{l}\text { Specific heat, } 23^{\circ} \mathrm{C}, \mathrm{Btu} / \mathrm{lb}-{ }^{\circ} \mathrm{C} \\
\text { \% reduction }\end{array}$ & $\begin{array}{l}0.434 \\
-\end{array}$ & - & - & 11 & $\begin{array}{l}0.396 \\
9\end{array}$ & $\begin{array}{ll}0.382 \\
12\end{array}$ & $\begin{array}{l}0.398 \\
8\end{array}$ \\
\hline Specific gravity & 4.171 & - & - & 4.304 & 4.295 & 4.419 & 4.261 \\
\hline $\begin{array}{l}\text { Results are representative values, based } \\
\text { Specimens oven-dried at } 150^{\circ} \mathrm{C} \text { prior to } \\
\text { Specimen sizes: compressive strength, } 3 \\
\text { reep tests, } 6 \times 12 \text {-in. cylinders. Other speci } \\
\text { - MiMA }=\text { methyl methacrylate; } \mathrm{S}=\text { sty } \\
\text { tyrene; } \mathrm{PE}=\text { polyester. } \\
\text { bR = radiation treatment; } \mathrm{T}=\text { thermal } \\
\text { - Tensile strengths are obtained by the dir } \\
\text { dCreep under sustained compressive load } \\
\text { - Loaded for } 1482 \text { days. }\end{array}$ & $\begin{array}{l}\text { on } 3 \text { or more } \\
\text { impregnatio } \\
\times 6 \text {-in. cylinc } \\
\text { imens sized ac } \\
\text { yrene; TMP1 } \\
\text { 1-catalytic tre } \\
\text { rect tension } \\
\text { d of } 800 \text { psi. }\end{array}$ & $\begin{array}{l}\text { specimens, fo } \\
\text { on. } \\
\text { iders; tensile st } \\
\text { ccording to te } \\
\text { TMA = trim } \\
\text { eatment. } \\
\text { method. }\end{array}$ & st requiren & ty. & (1) & 2. $2 \times 9 x$ & = chloro \\
\hline
\end{tabular}


Summary of Mechanical and Physical Properties of Polymer-Impregnated Concrete

\begin{tabular}{|c|c|c|c|c|c|c|c|c|c|c|c|}
\hline \multicolumn{2}{|c|}{$\begin{array}{c}\text { MMA+10TMPTMA } \\
\text { CP-4 series }\end{array}$} & \multicolumn{2}{|c|}{$\begin{array}{l}\text { AN impregnated, }{ }^{\mathrm{a}} \\
\text { CP- } 5 \text { series }\end{array}$} & \multicolumn{2}{|c|}{$\begin{array}{c}\text { CS impregnated,a } \\
\text { CP-6 series }\end{array}$} & \multirow{2}{*}{ 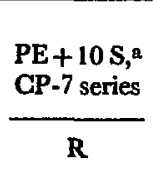 } & \multirow{2}{*}{\multicolumn{2}{|c|}{$\begin{array}{c}\text { MMA impregnated, } \\
\text { polymerized under water, } \\
\text { GP-8 series }\end{array}$}} & & \\
\hline $\mathbf{R}$ & $\mathbf{T}$ & $\mathbf{R}$ & $\mathbf{T}$ & $\mathbf{R}$ & $\mathbf{T}$ & & & & & & \\
\hline $\begin{array}{r}21,590 \\
310\end{array}$ & $\begin{array}{r}19,000 \\
260\end{array}$ & $\begin{array}{r}14,410 \\
174\end{array}$ & $\begin{array}{r}10,750 \\
104\end{array}$ & $\begin{array}{r}16,090 \\
205\end{array}$ & $\begin{array}{r}14.2 n c \\
173\end{array}$ & $\begin{array}{r}20,500 \\
289\end{array}$ & $\begin{array}{r}23,800 \\
352\end{array}$ & & & & \\
\hline $\begin{array}{l}6.1 \\
75\end{array}$ & $\begin{array}{l}4.8 \\
38\end{array}$ & $\begin{array}{l}5.9 \\
67\end{array}$ & $\begin{array}{l}4.2 \\
20\end{array}$ & $\begin{array}{l}5.6 \\
60\end{array}$ & $\begin{array}{l}5.6 \\
60\end{array}$ & $\begin{array}{l}6.5 \\
86\end{array}$ & $\begin{array}{l}6.4 \\
83\end{array}$ & . & & & \\
\hline $\begin{array}{r}1,510 \\
261\end{array}$ & $\begin{array}{r}1,250 \\
200\end{array}$ & $\begin{array}{r}1,040 \\
150\end{array}$ & $\begin{array}{l}870 \\
113\end{array}$ & $\begin{array}{r}1,120 \\
167\end{array}$ & $\begin{array}{r}1,200 \\
190\end{array}$ & $\begin{array}{r}1,530 \\
264\end{array}$ & $\begin{array}{r}1,700 \\
305\end{array}$ & & & & \\
\hline $\begin{array}{r}2,220 \\
200\end{array}$ & - & $\begin{array}{r}1,470 \\
99\end{array}$ & $\begin{array}{r}620 \\
-16\end{array}$ & $\begin{array}{r}2,380 \\
223\end{array}$ & $\begin{array}{r}1,580 \\
114\end{array}$ & $\begin{array}{r}3,300 \\
346\end{array}$ & $\begin{array}{r}2,100 \\
184\end{array}$ & & & & \\
\hline $\begin{array}{l}6.1 \\
40\end{array}$ & - & $\begin{array}{l}4.5 \\
5\end{array}$ & $\begin{array}{r}35 \\
-19\end{array}$ & $\begin{array}{l}6.3 \\
47\end{array}$ & $\begin{array}{l}5.0 \\
16\end{array}$ & $\begin{array}{l}6.4 \\
49\end{array}$ & $\begin{array}{l}7.6 \\
77\end{array}$ & & & & \\
\hline $32^{\mathrm{k}}$ & - & $45^{1}$ & 731 & $50^{\mathrm{m}}$ & $47 \mathrm{~m}$ & $3^{n}$ & $28^{n}$ & & & & \\
\hline $\begin{array}{l}54 \\
69\end{array}$ & - & $\begin{array}{l}47 \\
48\end{array}$ & $\begin{array}{r}34 \\
5\end{array}$ & $\begin{array}{r}30 \\
-6\end{array}$ & $\begin{array}{r}28 \\
-11\end{array}$ & - & - & & & & \\
\hline $\begin{array}{l}0.044 \\
10\end{array}$ & 6.019 & $\begin{array}{l}0.030 \\
40\end{array}$ & $\begin{array}{l}0.026 \\
49\end{array}$ & - & - & 52 & $\begin{array}{l}0.025 \\
50\end{array}$ & & & & \\
\hline $\begin{array}{l}10 \\
29\end{array}$ & $\begin{array}{r}5 \\
64\end{array}$ & $\begin{array}{r}8 \\
45\end{array}$ & $\begin{array}{r}6 \\
57\end{array}$ & - & - & $\begin{array}{r}3 \\
79\end{array}$ & $\begin{array}{r}2 \\
86\end{array}$ & & & & \\
\hline $\begin{array}{l}0.074 \\
77\end{array}$ & - & $\begin{array}{l}0.099 \\
69\end{array}$ & $\begin{array}{l}0.092 \\
71\end{array}$ & $7_{77}^{0.072}$ & 6.115 & $\begin{array}{l}0.019 \\
94\end{array}$ & $\begin{array}{l}0.016 \\
95\end{array}$ & & & & \\
\hline $83^{1.09}$ & $\begin{array}{l}0.21 \\
97\end{array}$ & $\begin{array}{l}2.95 \\
54\end{array}$ & $1^{5.68}$ & $\begin{array}{l}0.88 \\
86\end{array}$ & $69^{1.97}$ & $\begin{array}{l}0.67 \\
90\end{array}$ & $\begin{array}{l}0.06 \\
-\end{array}$ & & & & \\
\hline $\begin{array}{l}0.01 \\
99\end{array}$ & $\begin{array}{l}1.2 \\
77\end{array}$ & - & - & - & - & $\begin{array}{r}0 \\
100\end{array}$ & $\begin{array}{r}0 \\
100\end{array}$ & & & & \\
\hline $\begin{array}{l}2.381 \\
1\end{array}$ & - & $\begin{array}{l}2.243 \\
6\end{array}$ & $\begin{array}{l}2.245 \\
6\end{array}$ & $\begin{array}{l}2.340 \\
2\end{array}$ & $\begin{array}{l}2.394 \\
0\end{array}$ & - & $\begin{array}{l}2.279 \\
5\end{array}$ & & & & \\
\hline$\underbrace{0.0792}_{14}$ & - & $\begin{array}{l}0.0738 \\
6\end{array}$ & $\begin{array}{l}0.0702 \\
0\end{array}$ & $\begin{array}{l}0.0792 \\
13\end{array}$ & $\begin{array}{l}0.0720 \\
3\end{array}$ & - & $\begin{array}{l}0.0754 \\
8\end{array}$ & & & & \\
\hline $\begin{array}{l}9.11 \\
26\end{array}$ & $\begin{array}{l}9.11 \\
26\end{array}$ & $\begin{array}{l}8.84 \\
22\end{array}$ & $\begin{array}{l}8.24 \\
14\end{array}$ & $\begin{array}{c}8.41 \\
16\end{array}$ & $\begin{array}{c}8.59 \\
19\end{array}$ & - & $\begin{array}{l}2^{8.80} \\
22\end{array}$ & & & & \\
\hline $\begin{array}{l}0.3 .3 \\
14\end{array}$ & - & $\begin{array}{c}0.376 \\
1 . ?\end{array}$ & $\begin{array}{l}0.396 \\
9\end{array}$ & $\begin{array}{l}0.362 \\
17\end{array}$ & $\begin{array}{l}0.405 \\
6\end{array}$ & - & $\begin{array}{c}0.3699 \\
15\end{array}$ & & & & \\
\hline 4.219 & - & 4.185 & 4.192 & 4.248 & 4.271 & 4.207 & 4.261 & & & & \\
\hline
\end{tabular}

'Loaded for 1451 days.

LLoaded for 1552 days.

WSpecimens exhibit negative creep, i.e., an expa usion in length under compressi-• load.

'Loaded for 1534 days.

I Radiation-polymerized styrene-impregnated specimens show a large difference in creep. One specimen has $17 \mu \mathrm{in} . / \mathrm{in}$. creeg mprovement of $89 \%$ as compared with control concrete); the other has a negative creep of $1.50 \mu \mathrm{in}$./in.

kLoaded for 344 days.

1 Loaded for 1056 days.

mLoaded for 1010 days.

nLoaded for 204 days. 
nique for impregnating the surfaces of concrete to a controlled depth.

Originally, two types of concrete were tested, one designed for normal-temperature applications (CP-type concrete), and the other for high-temperature applications (OSW-type concrete). Tests have shown that CP-type concrete, impregnated with the same monomers for high-temperature applications as those used with OSW-type concrete, has strength comparable to that of OSWtype PIC. References to the OSW-type concrete will be found throughout the text because longterm tests are still in progress.

Concrete designated as CP-type is of a standard mix made with 5.5 sacks/cu yd of type II laboratory-blend portland cement, Clear Creek aggregate graded to $\%$-in. maximum size, 0.51 water-tocement ratio, 3-in. slump, and $6 \%$ entrained air. When the specimen size is such that $1 \frac{1}{2} 2$-in. maximum-sized aggregate should be used, the mix is adjusted accordingly.

Concrete designated as OSW-type is a special high-strength mix designed for use in desalting plants. It is made with 6 sacks/cu yd of type $V$ portland cement, 1.8 sacks/cu yd of fly ash pozzolan, 0.35 water-to-cement plus pozzolan ratio a water-reducing agent, air entrainment, and a

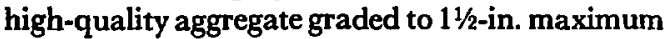
size.

Tests are usually made on concrete at 120 days of age. In monomer survey tests, both undried concrete (exposed to air following removal from the 28-day fog cure) and oven-dried concrete are monomer impregnated. Experience with the monomer systems tested has shown that oven-dried concrete is more fully impregnated by monomer and has greater improvements in properties than the undried concrete. Unless otherwise stated, te st results on PIC are for concrete oven-dried prior to impregnation.

The majority of the test results are obtained from relatively few specimens and are to be considered indicative of the properties of PIC. They are not intended to be used as a basis for final design of engineering structures.

Freliminary design values for both the unimpregnated control and the impregnated concrete have been determined where sufficient test data are available. The design values were obtained on the assumption that the group of specimens tested represented a random sample of all future specimens of a given type made under the same con- ditions. The mean value, standard deviation, and coefficient of variation were obtained in each group of tests. If the coefficient of variation is $\leqslant 15 \%$, the design value equals the mean value minus the standard deviation. If the coefficient of variation is $>15 \%$, the value reported is the same as the design value, but it is noted that in this area more test data are needed. Design values for preliminary design purposes are presented in Section 5.1.2 for normal-temperature applications, and in Section 5.2.1 for high-temperature applications. These are initial values and will be refined as additional data become available.

\subsection{Polymer-Impregnated Concrete FOR AMBIFNT-TEMPERATURE APPLICATIONS}

5.1.1 CP Test Series. The program consists of a series of structural and durability tests on CP. type concrete impregnated with various monomers. Each test series consists of 38 specimens. Descriptions of specimen preparation and test procedures are given in Ref. 1 .

The CP test series are designated as follows:

CP-0 Control (unimpregnated concrete).

CP-1A MMA, radiation polymerized.

CP-1B MMA, thermal-catalytically polymerized.

CP-2A Styrene, radiation polymerized.

CP-2B Styrene, thermal-catalytically polymerized.

CP-3A Unimpregnated, radiation treated.

CP-3B Unimpregnated, thermally treated.

CP-4A MMA - 10 wt \% TMPTMA, radiation polymerized.

CP-4B MMA - 10 wt \% TMPTMA, thermalcatalytically polymerized.

CP-5A Acrylonitrile, radiation polymerized.

CP-5B Acrylonitrile, thermal,catalytically polymerized.

CP-6A Chlorostyrene, radiation polymerized.

CP-6B Chlorostyrene, thermal-catalytically polymerized.

CP-7A 10 wt \% polyester -90 wt \% styrene, radiation polymerized.

CP-8A and

CP-UA MMA, radiation polymerized under water.

Test results for all but the CP-7A series have been presented in previous topical reports ${ }^{1-4}$ and are summarized in Table 10. Tests on CP-7A specimens are in progress and results to date are reported below.

5.1.1.1 StRuctural ahd Physical Properties of $\mathbf{1 0}$ wt \% POLYester - 90 wt \% Styrene Impaeghated Concrete. The CP-7A test specimens were prepared from CP-type concrete, impregnated with $10 \mathrm{wt} \%$ polyester - $90 \mathrm{wt}$ $\%$ styrene by the standard vacuum-soak method and polymerized by radiation. The series includes 
Table 11

Compressive and Tensile Strengths of CP.Type Concrete

Impregnated With $10 \mathrm{wt} \%$ Polyester - 90 wt \% Styrene

CP-7 Test Series

\begin{tabular}{|c|c|c|c|c|c|c|c|c|}
\hline \multicolumn{5}{|c|}{ Compression tests } & \multicolumn{4}{|c|}{ Direct tension tests } \\
\hline $\begin{array}{c}\text { Specimen } \\
\text { No., } \\
\text { CP-7- }\end{array}$ & $\begin{array}{c}\text { Polymer } \\
\text { loading, } \\
\text { wt \% }\end{array}$ & Treatment & $\begin{array}{c}\text { Compressive } \\
\text { strength, } \\
\text { psi }\end{array}$ & $\begin{array}{l}\text { Modulus of } \\
\text { elasticity, } \\
.10^{6} \mathrm{psi}\end{array}$ & $\begin{array}{c}\text { Specimen } \\
\text { No., } \\
\text { CP-7- }\end{array}$ & $\begin{array}{c}\text { Polymer } \\
\text { loading, } \\
\text { wt \% }\end{array}$ & Treatment & $\begin{array}{c}\text { Tensile } \\
\text { strength, } \\
\text { psi }\end{array}$ \\
\hline $\begin{array}{l}1 A^{a} \\
1 B^{a} \\
1 C^{a}\end{array}$ & $\begin{array}{l}4.1 \\
3.9 \\
4.9\end{array}$ & $\begin{array}{l}\mathbf{U} \\
\mathbf{U} \\
\mathbf{U}\end{array}$ & $\begin{array}{l}9,480 \\
8,910 \\
9,280\end{array}$ & $\begin{array}{l}4.5 \\
4.8 \\
4.4\end{array}$ & $\begin{array}{l}2 B^{b} \\
2 C\end{array}$ & $\begin{array}{l}4.6 \\
4.0\end{array}$ & $\underset{\mathbf{U}}{\mathbf{U}}$ & $\begin{array}{l}\mathbf{4 8 0} \\
\mathbf{5 4 0}\end{array}$ \\
\hline Av & 4.3 & & 9,220 & 4.6 & & 4.3 & & 510 \\
\hline $\begin{array}{l}\text { ID } \\
1 E \\
\text { IF }\end{array}$ & $\begin{array}{l}6.8 \\
6.3 \\
7.0\end{array}$ & $\begin{array}{l}\mathbf{D} \\
\mathbf{D} \\
\mathbf{D}\end{array}$ & $\begin{array}{l}20,820 \\
19,940 \\
20,760\end{array}$ & $\begin{array}{l}6.4 \\
6.7 \\
6.3\end{array}$ & $\begin{array}{l}2 \mathrm{D} \\
2 \mathbf{E} \\
2 \mathbf{F}\end{array}$ & $\begin{array}{l}6.8 \\
6.7 \\
6.8\end{array}$ & $\begin{array}{l}\mathbf{D} \\
\mathbf{D} \\
\mathbf{D}\end{array}$ & $\begin{array}{l}1,680 \\
1,120 \\
1,800\end{array}$ \\
\hline Av & 6.7 & & 20,510 & 6.5 & & 6.8 & & 1,530 \\
\hline
\end{tabular}

$3 \times 6$-in. specimens, radiation polymerized.

$\mathbf{U}=$ specimens not o ven-dried prior to impregnation.

$\mathrm{D}=$ specimens oven-dried at $110^{\circ} \mathrm{C}$ prior to impregnation.

-Only about two-thirds of cross section appeared impregnated on visual inspection after testing.

bspecimen cracked prior to testing.

Table 12

Flexural Strength of CP-Type Concrete Impregnated With $10 \mathrm{wt} \%$ Polyester - $90 \mathrm{wt} \%$ Styrene CP Test Series

\begin{tabular}{|c|c|c|c|c|}
\hline $\begin{array}{c}\text { Specimen } \\
\text { No., } \\
\text { CP-7- }\end{array}$ & $\begin{array}{c}\text { Polymer } \\
\text { loading, } \\
\text { wt \% }\end{array}$ & $\begin{array}{l}\text { Specimen } \\
\text { treatment }\end{array}$ & $\begin{array}{c}\text { Modulus } \\
\text { of } \\
\text { rupture, } \\
\text { psi }\end{array}$ & $\begin{array}{c}\text { Modulus } \\
\text { of } \\
\text { elasticity, } \\
10^{6} \mathrm{psi}\end{array}$ \\
\hline $\begin{array}{l}5 A \\
5 B \\
5 C\end{array}$ & $\begin{array}{l}3.2^{\mathrm{a}} \\
3.6^{\mathrm{a}} \\
2.6^{\mathrm{a}}\end{array}$ & $\begin{array}{l}\mathbf{U} \\
\mathbf{U} \\
\mathbf{U}\end{array}$ & $\begin{array}{l}1400 \\
1730 \\
1480\end{array}$ & $\begin{array}{l}6.1 \\
6.4 \\
6.3\end{array}$ \\
\hline Av & 3.1 & & 1540 & 6.3 \\
\hline $\begin{array}{l}\mathbf{5 E} \\
\mathbf{5 F}\end{array}$ & $\begin{array}{l}7.4 \\
6.9\end{array}$ & $\begin{array}{l}\mathbf{D} \\
\mathbf{D}\end{array}$ & $\begin{array}{l}3350 \\
3300\end{array}$ & $\begin{array}{l}7.0 \\
5.8\end{array}$ \\
\hline Av & 7.2 & & 3330 & 6.4 \\
\hline
\end{tabular}

$3 \times 3 \times 16^{1 / 4-i n . ~ b e a m s . ~}$

Radiation-initiated polymerization.

$\mathrm{U}=$ specimens not oven-dried prior to impregnation.

$\mathrm{D}=$ specimens oven-dried at $110^{\circ} \mathrm{C}$ prior to impregnation.

'Specimens not fully impregnated; unimpregnated zones were observed in the center of the beams.
Table 13

Shotblast Abrasion

CP-7 and CP-8 Test Series

\begin{tabular}{rrrcc}
\hline & & \multicolumn{2}{c}{ Abrasiol. } \\
\cline { 3 - 5 } Specimen No. & $\begin{array}{c}\text { Polymer } \\
\text { loading, wt \% }\end{array}$ & $\begin{array}{c}\text { Depth, } \\
\text { in. }\end{array}$ & $\begin{array}{c}\text { Weight } \\
\text { loss, } 8\end{array}$ \\
\hline CP-7-10A & 6.8 & 0.020 & 3 \\
10B & 6.7 & 0.033 & 3 \\
10C & 6.5 & 0.020 & 2 \\
& Av & 6.7 & 0.024 & 3 \\
CP-UA-10A & 6.8 & 0.025 & 2 \\
10B & 6.7 & 0.029 & 2 \\
10C & 6.7 & 0.020 & 1 \\
& Av & 6.7 & 0.025 & 2 \\
\hline
\end{tabular}

CP-type concrete, $2 \times 3 \times 7$-in. specimens.

CP-7 specimens oven-dried at $110^{\circ} \mathrm{C}$ and impregnated with $10 \mathrm{wt} \%$ polyester $-90 \mathrm{wt} \%$ styrene.

CP.UA specimens (CP. 8 test series) oven-dried at $105^{\circ} \mathrm{C}$, impregnated with MMA, dipped in PMMA, and polymerized under water.

All specimens polymerized by radiation. 
undried specimens and specimens oven-dried at $105^{\circ} \mathrm{C}$ prior to impıegnation.

(a) Compressive Strength and Modulus of Elasticlity. The oven-dried PIC specimens had an average compressive strength of $20,500 \mathrm{psi}$ and a modulus of elasticity of $6.5 \times 10^{6}$ psi as compared with 9200 psi and $4.6 \times 10^{6}$ psi for the undried PIC specimens. The compressive strength of oven-dried specimens is comparable with that of the ovendried MMA-impregnated (CP-1), MMA - 10 wt \% TMPTMA impregnated (CP-4), and MMAimpregnated, underwater-polymerized (CP-8) specimens, and is an improvement of $289 \%$ over the strength of unimpregnated concrete. Visual examination of specimens after testing disclosed that the undried specimens were not fully impregnated. Test results are given in Table 11.

(b) Tensile StRength. Direct tensile strengths averaged 1530 psi for oven-dried and 510 psi for undried PIC specimens (Table 11). The oven-dried specimens are comparable with the corresponding specimens from the CP-1, CP-4, and CP-8 series and show an improvement of $264 \%$ over unimpregnated concrete.

(c) Fiexural Strength. Modulus of rupture averaged $3330 \mathrm{psi}$ for oven-dried and $1540 \mathrm{psi}$ for undried PIC specimens (Table 12). The modulus for the oven-dried specimens is the highest obtained so

Table 14

\begin{tabular}{|c|c|c|c|c|c|c|c|}
\hline \multirow[b]{3}{*}{ Property } & \multicolumn{3}{|c|}{ Unimpregnated concrete } & \multirow{2}{*}{\multicolumn{2}{|c|}{$\begin{array}{l}\text { MMA impregnated, }{ }^{\mathrm{a}} \\
\text { CP-1 test series }\end{array}$}} & \multirow{2}{*}{\multicolumn{2}{|c|}{$\begin{array}{l}\text { S impregnated,a } \\
\text { CP-2 test series }\end{array}$}} \\
\hline & \multirow{2}{*}{$\begin{array}{l}\text { Controls, } \\
\text { CP-0 test series }\end{array}$} & \multicolumn{2}{|c|}{ CP-3 test series } & & & & \\
\hline & & $\mathbf{R}^{\mathbf{b}}$ & $\mathbf{T}^{\mathrm{b}}$ & $\mathbf{R}$ & $\mathbf{T}$ & $\mathbf{R}$ & $\mathbf{T}$ \\
\hline $\begin{array}{l}\text { Freeze-thaw durability } \\
\text { Polymer loading, \% } \\
\text { No. of cycles } \\
\text { \% weight loss } \\
\text { \% improvement }\end{array}$ & $\begin{array}{r}740 \\
25 \\
-\end{array}$ & $\begin{array}{r}440 \\
28 \\
-\end{array}$ & $\begin{array}{r}4 \overline{-} \\
35 \\
-\end{array}$ & $\begin{array}{r}5.9 \\
10,340 \\
12 \\
>1,297\end{array}$ & $\begin{array}{r}6.8 \\
3,650 \\
2 \\
>393\end{array}$ & $\begin{array}{c}4.9 \\
2,635 \\
25 \\
256\end{array}$ & $\begin{array}{c}4.4 \\
6,015 \\
25 \\
713\end{array}$ \\
\hline $\begin{array}{l}\text { Sulfate attack } \\
\text { Polymer loading, \% } \\
\text { Test cycle, days } \\
\text { \% expansion } \\
\text { \% improvement }\end{array}$ & $\begin{array}{l}-\overline{0} \\
0.467 \\
-\end{array}$ & $\begin{array}{c}-\overline{-} \\
750 \\
0.553 \\
56\end{array}$ & $\begin{array}{l}-\overline{-} \\
605 \\
0.522 \\
26\end{array}$ & $\begin{array}{c}6.6^{d} \\
1,436 \\
0.032 \\
>199\end{array}$ & $\begin{array}{c}6.4 \\
1,436 \\
0.017 \\
>199\end{array}$ & $\begin{array}{c}5.4 \\
1,420 \\
0.039 \\
>196\end{array}$ & $\begin{array}{c}4.5^{d} \\
1,420 \\
0.04 \\
>196\end{array}$ \\
\hline $\begin{array}{l}\text { Rexistance to acid (15\% HC) } \\
\text { Polymer loading, \% } \\
\text { Exposure, days } \\
\text { \% weight low } \\
\text { \% improvement }\end{array}$ & $\begin{array}{r}105 \\
27 \\
-\end{array}$ & $\begin{array}{r}103 \\
26 \\
-\end{array}$ & $\begin{array}{r}106 \\
26 \\
-\end{array}$ & $\begin{array}{r}6.1^{\mathrm{h}} \\
1,395 \\
13 \\
>1,229\end{array}$ & $\begin{array}{r}6.4^{d} \\
1,395 \\
10 \\
>1,229\end{array}$ & $\begin{array}{r}4.9 \\
1,395 \\
17 \\
>1,229\end{array}$ & $\begin{array}{r}4.6 \\
1,395 \\
14 \\
>1,229\end{array}$ \\
\hline $\begin{array}{l}\text { Revistance to acid ( } 15 \% \mathrm{H}_{2} \mathrm{SO}_{4} \\
\text { Polymer loading, \% } \\
\text { Exposure, days } \\
\text { \% weight low } \\
\text { \% improvement }\end{array}$ & $\begin{array}{r}49 \\
35 \\
-\end{array}$ & $\begin{array}{l}- \\
63 \\
30 \\
29\end{array}$ & $\begin{array}{l}77 \\
30 \\
17\end{array}$ & $\begin{array}{c}5.7 \\
126 \\
29 \\
157\end{array}$ & $\begin{array}{l}119^{5.7^{d}} \\
26 \\
143\end{array}$ & $\begin{array}{l}5.4 \\
91 \\
27 \\
86\end{array}$ & $\begin{array}{l}4.0 \\
77 \\
29 \\
57\end{array}$ \\
\hline $\begin{array}{l}\text { Reciatance to acid }\left(5 \% \mathrm{H}_{2} \mathrm{SO}_{4}\right) \\
\text { Polymer loading, \% } \\
\text { Expouure, days } \\
\text { \% weight low } \\
\text { \% improvement }\end{array}$ & $\begin{array}{r}210 \\
33 \\
-\end{array}$ & $\begin{array}{l}- \\
- \\
-\end{array}$ & $\begin{array}{l}- \\
- \\
-\end{array}$ & $\begin{array}{c}5.9^{1} \\
210 \\
14 \\
-\end{array}$ & $\begin{array}{l}- \\
- \\
-\end{array}$ & $\begin{array}{l}- \\
- \\
-\end{array}$ & $\begin{array}{l}- \\
- \\
-\end{array}$ \\
\hline $\begin{array}{l}\text { 3X6-in. apecimens, oven-dri } \\
\text { Revultu are averages for two } \\
\text { "MMA = methyl methacryl } \\
\text { tyrene; } \mathrm{PE}=\text { polyeater. } \\
\text { 'R = radiation treatment; } T \\
\text { 'Single specimen; companion }\end{array}$ & $\begin{array}{l}\text { late; } S=\text { styrene } \\
\text { lo thermal-catal }\end{array}$ & $\begin{array}{l}\text { noted. } \\
\text { iPTM } \\
\text { treatm }\end{array}$ & trimethy & mene & thacrylate; & acrylonitri & = chloro \\
\hline
\end{tabular}


far in the CP test series. The previous high value (2640 psi) was for MMA-impregnated and radia.tion-polymerized specimens. Unimpregnated conventional concrete had a modulus of rupture of 740 psi.

(d) Agrasion Resistance. Shotblast abrasion test results, given in Table 13, show good abrasion resistance for CP-7 specimens. Abrasion losses averaged 0.024 in. and $3 \mathrm{~g}$. CP-8 specimens had comparable abrasion resistance, with losses averaging $0.025 \mathrm{in}$. and $2 \mathrm{~g}$.

(e) Permeabuity. Water permeability tests, conducted under a pressure of $400 \mathrm{psi}$, showed no measurable permeability for both CP-7 and CP-8 specimens.
5.1.1.2 DununuIry TesTs. Tests were made of freszethaw durability and resistance to chemical attack. by sulfates, acids, and sodium hydroxide. The acid tests have included $15 \% \mathrm{HCl}$ and $15 \% \mathrm{H}_{2} \mathrm{SO}_{4}$; current testing is with $5 \% \mathrm{H}_{2} \mathrm{SO}_{4}$; which was selected as being more representative of a severe exposure for sewer pipe. Test results to date are summarized in Table 14.

(a) Freezz-Thaw Durability. In this test, specimens are immersed in water and alternately frozen at - : ${ }^{\circ} \mathrm{C}$ and thawed at $20^{\circ} \mathrm{C}$ at a rate of about 50 cycles per week. The criterion for failure is $25 \%$ weight loss. According to past experience, conventional concrete withstanding $\mathbf{5 0 0}$ to 700 cycles is

Summary of Durability Properties of Polymer-Impregnated Concrete, CP Test Series

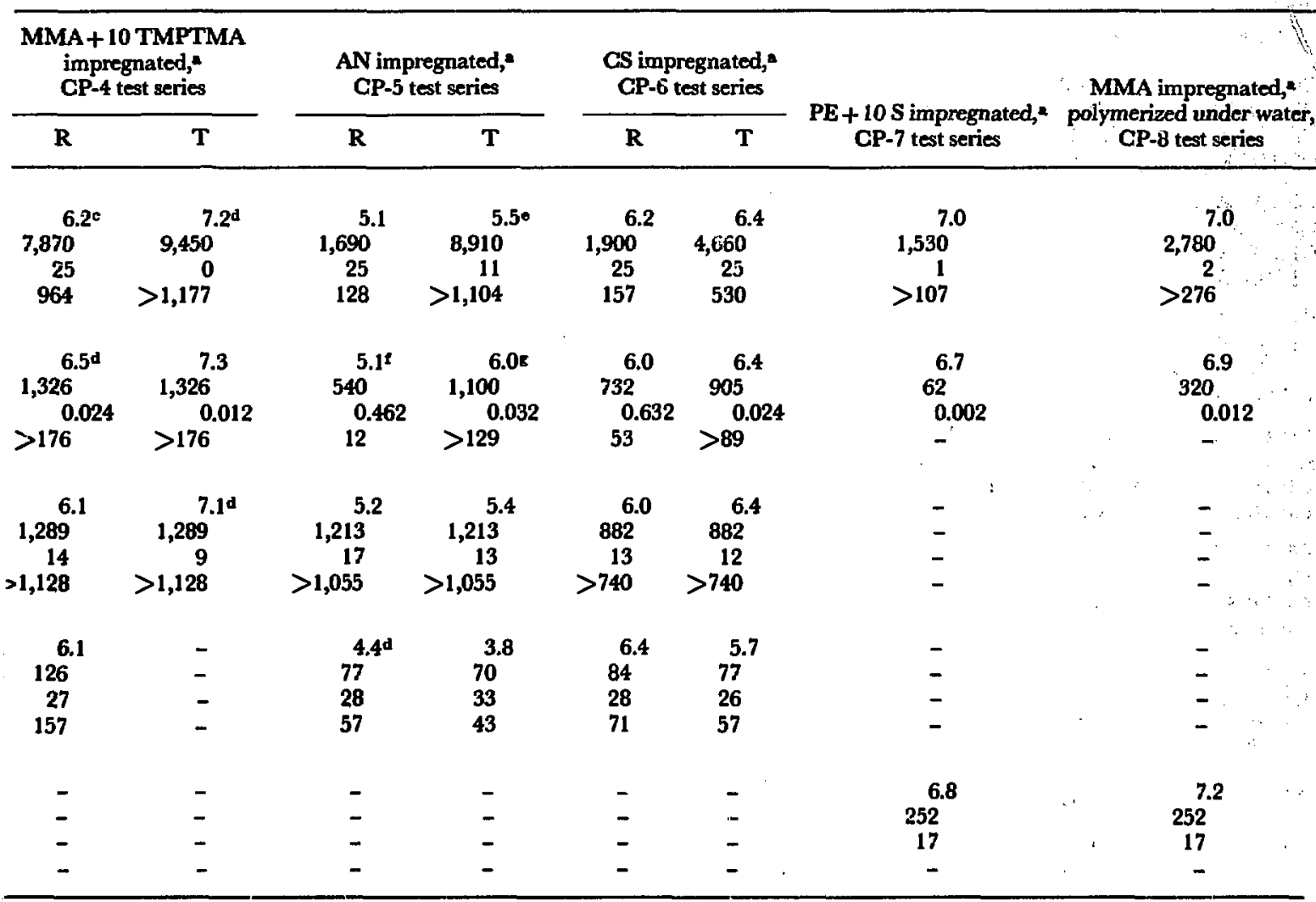

Single specimen; companion removed for display.

Single specimen; companion filed (25\% weight loas) at 8710 cycles.

Single specimen; companion removed at 180 days because of excessive deterioration.

Single specimen; companion removed at $\mathbf{3 9 0}$ days because of excessive deterioration.

Single specimen; companion removed at 1216 days with $13 \%$ weight loas.

Average of six specimens. 
considered to be of good quality, and that withstarding 1009 cycles is considered of excellent quality. The unimpregnated concrete used as a control failed at 740 cycles. All CP-series PIC specimens show greatly improved resistance to freezing and thawing, ranging from 128 to $>1279 \%$ improvement as compared with conventional con- crete (Table 15). The PIC specimen with the greatest improvement in freeze-thaw durability is an MMA-impregnated and radiation-polymerized specimen from an earlier survey. This specimen has a weight loss of only $0.5 \%$ after 12,010 cycles, an improvement of $>1523 \%$ over unimpregnated concrete. GP-series specimens that have

Table 15

Rexistance to Freezing and Thawing of Polymer-Impregnated Concrete

CP Test Series

\begin{tabular}{|c|c|c|c|c|c|}
\hline Specimen No. & Monomer" & $\begin{array}{c}\text { Polyner } \\
\text { loading, wt \% }\end{array}$ & $\begin{array}{c}\text { Method of } \\
\text { polymerization }\end{array}$ & $\begin{array}{c}\text { Number } \\
\text { of test cycles }\end{array}$ & $\begin{array}{l}\text { Weight } \\
\text { loss, \% }\end{array}$ \\
\hline $\begin{array}{l}\text { Control } \\
\text { BNL-1-3c }\end{array}$ & $\overline{\mathbf{M M A}}$ & $\overline{6} .7$ & $\overline{\mathbf{R}}$ & $\begin{array}{c}590^{d} \\
12,010\end{array}$ & $\begin{array}{r}26.5 \\
0.5\end{array}$ \\
\hline $\begin{array}{l}\text { CP-0-3A } \\
\text { CP-0-3B }\end{array}$ & $\overline{-}$ & $\begin{array}{l}- \\
-\end{array}$ & - & $\begin{array}{l}490^{d} \\
990^{d}\end{array}$ & $\begin{array}{l}25.0 \\
26.0\end{array}$ \\
\hline $\begin{array}{l}\text { CP-1A-3A } \\
\text { CP-1A-3B } \\
\text { CP-1B-3A } \\
\text { CP-1B-3B }\end{array}$ & $\begin{array}{l}\text { MMA } \\
\text { MMA } \\
\text { MMA } \\
\text { MMA }\end{array}$ & $\begin{array}{l}5.9 \\
5.9 \\
6.9 \\
6.6\end{array}$ & $\begin{array}{l}\mathbf{R} \\
\mathbf{R} \\
\mathbf{T} \\
\mathbf{T}\end{array}$ & $\begin{array}{r}8,310^{\circ} \\
10,340^{f} \\
3,650^{\circ} \\
3,650^{\circ}\end{array}$ & $\begin{array}{r}9.0 \\
12.5 \\
1.5 \\
2.0\end{array}$ \\
\hline $\begin{array}{l}\text { CP-2A-3A } \\
\text { C.P-2A-3B } \\
\text { CP-2B-3A } \\
\text { CP-2B-3B }\end{array}$ & $\begin{array}{l}\mathbf{S} \\
\mathbf{S} \\
\mathbf{S} \\
\mathbf{S}\end{array}$ & $\begin{array}{l}4.8 \\
4.9 \\
4.5 \\
4.3\end{array}$ & $\begin{array}{l}\mathbf{R} \\
\mathbf{R} \\
\mathbf{T} \\
\mathbf{T}\end{array}$ & $\begin{array}{l}2,010^{d} \\
3,260^{d} \\
6,290^{d} \\
5,740^{d}\end{array}$ & $\begin{array}{l}25.0 \\
26.0 \\
25.0 \\
26.0\end{array}$ \\
\hline $\begin{array}{l}\text { CP-3A-3A } \\
\text { CP-3A-3B } \\
\text { CP-3B-3A } \\
\text { CP-3B-3B }\end{array}$ & $\begin{array}{l}- \\
- \\
-\end{array}$ & $\begin{array}{l}- \\
- \\
- \\
-\end{array}$ & $\begin{array}{l}\mathbf{R} \\
\mathbf{R} \\
\mathbf{T} \\
\mathbf{T}\end{array}$ & $\begin{array}{l}390^{d} \\
490^{d} \\
440^{d} \\
440^{d}\end{array}$ & $\begin{array}{l}30.0 \\
26.0 \\
40.0 \\
30.0\end{array}$ \\
\hline $\begin{array}{l}\text { CP-4A-3A } \\
\text { CP-4A-3B } \\
\text { CP-4B-3A } \\
\text { CP-4B-3B }\end{array}$ & $\begin{array}{l}\text { MMA + TMPTMA } \\
\text { MMA + TMPTMA } \\
\text { MMA + TMPTMA } \\
\text { MMA + TMPTMA }\end{array}$ & $\begin{array}{l}6.2 \\
6.2 \\
7.2 \\
7.1\end{array}$ & $\begin{array}{l}\mathbf{R} \\
\mathbf{R} \\
\mathbf{T} \\
\mathbf{T}\end{array}$ & $\begin{array}{l}3,350^{d} \\
7,870^{d} \\
1,230^{d} \\
9,450\end{array}$ & $\begin{array}{c}33.0 \\
24.5 \\
0.5 \\
0\end{array}$ \\
\hline $\begin{array}{l}\text { CP-5A-3A } \\
\text { CP-5A-3B } \\
\text { CP-5B-3A } \\
\text { CP-5B-3B }\end{array}$ & $\begin{array}{l}\text { AN } \\
\text { AN } \\
\text { AN } \\
\text { AN }\end{array}$ & $\begin{array}{l}5.1 \\
5.0 \\
5.6 \\
5.3\end{array}$ & $\begin{array}{l}\mathbf{R} \\
\mathbf{R} \\
\mathbf{T} \\
\mathbf{T}\end{array}$ & $\begin{array}{l}1,840^{d} \\
1,540^{d} \\
8,910^{d} \\
8,710^{d}\end{array}$ & $\begin{array}{l}25.0 \\
25.0 \\
11.0 \\
25.0\end{array}$ \\
\hline $\begin{array}{l}\text { CP-6A-3A } \\
\text { CP-6A-3B } \\
\text { CP-6B-3A } \\
\text { CP-6B-3B }\end{array}$ & $\begin{array}{l}\text { CS } \\
\text { CS } \\
\text { CS } \\
\text { CS }\end{array}$ & $\begin{array}{l}6.3 \\
6.2 \\
6.3 \\
6.5\end{array}$ & $\begin{array}{l}\mathbf{R} \\
\mathbf{R} \\
\mathbf{T} \\
\mathbf{T}\end{array}$ & $\begin{array}{l}2,000^{d} \\
1,800^{d} \\
4,710^{d} \\
4,610^{d}\end{array}$ & $\begin{array}{l}25.0 \\
25.0 \\
25.0 \\
25.0\end{array}$ \\
\hline $\begin{array}{l}\text { GP-UA-3A } \\
\text { GP-UA-3B }\end{array}$ & $\begin{array}{l}\text { MMA } \\
\text { MMA }\end{array}$ & $\begin{array}{l}7.1 \\
6.9\end{array}$ & $\begin{array}{l}\mathbf{R} \\
\mathbf{R}\end{array}$ & $\begin{array}{l}2,780 \\
2,780\end{array}$ & $\begin{array}{l}1.0 \\
3.0\end{array}$ \\
\hline $\begin{array}{l}\text { CP-7-3A } \\
\text { CP-7-3B }\end{array}$ & $\begin{array}{l}\text { PE-S } \\
\text { PE-S }\end{array}$ & $\begin{array}{l}7.0 \\
6.9\end{array}$ & $\begin{array}{l}\mathbf{R} \\
\mathbf{R}\end{array}$ & $\begin{array}{l}1,530 \\
1,530\end{array}$ & $\begin{array}{l}1.0 \\
1.5\end{array}$ \\
\hline
\end{tabular}

$3 \times 6$-in. cylinden, oven-dried at $105^{\circ} \mathrm{C}$ prior to impregnation.

MMA = methyl methacrylate; S = styrene; TMPTMA = trimethylolpropane trimethacrylate; MMA+TMPTMA $=$ MMA -10 wt \% TMPTMA; AN = acrylonitrile; CS : : chlorostyrene; PE-S = 10 wt \% polyester -90 wt \% styrene. $\mathbf{R}=$ radiation; $\mathbf{T}=$ thermal-catalytic.

- Specimen not oven-dried prior to impregnation.

dRemoved from test.

- Failed (weight lon >25\%) and removed from test.

ISpecimen eplit into two pieces. 
not reached failure and are still under test include a thermal-catalytically polymerized MMA - 10 wt \% TMPTMA specimen with no weight loss after 9450 cycles, a thermal-catalytically polymerized acrylonitrile specinen with $11 \%$ weight loss after 8910 cycles, two underwater radiation-polymerized MMA specimens (CF-UA series) with
$2 \%$ weight loss after 2780 cycles, and two radiationpolymerized polyester-styrene specimens (CP-7 series) with $1 \%$ weight loss at 1530 cycles. A radiation-polymerized specimen (CP-1 series) split in half at 10,340 cycles with a weight loss of $12.5 \%$.

(b) Resistance to SULEATE ATtACK. Results of accelerated sulfate attack tests are updated in Table 16. The

Table 16

Resistance to Sulfate Attack of Polymer-Impregnated Concrete

CP Test Series

\begin{tabular}{|c|c|c|c|c|c|}
\hline Specimen No. & Monomera & $\begin{array}{c}\text { Polymer } \\
\text { loading, wt \% }\end{array}$ & $\begin{array}{l}\text { Methud of } \\
\text { polymerization }\end{array}$ & $\begin{array}{c}\text { Test } \\
\text { cycles, days }\end{array}$ & $\begin{array}{c}\text { Net } \\
\text { expansion, \% }\end{array}$ \\
\hline $\begin{array}{l}\text { Control } \\
\text { MMA-10c } \\
\text { S-14c }\end{array}$ & $\begin{array}{l}\overline{M M A} \\
\text { S }\end{array}$ & $\begin{array}{l}\overline{6.3} \\
6.2\end{array}$ & $\begin{array}{l}-\bar{R} \\
\mathbf{R}\end{array}$ & $\begin{array}{l}1486 \\
1486 \\
1477\end{array}$ & $\begin{array}{c}0.550^{\mathrm{d}} \\
-0.030 \\
0.006\end{array}$ \\
\hline $\begin{array}{l}\text { CP-0-4A } \\
\text { CP-0-4B }\end{array}$ & $\begin{array}{l}- \\
-\end{array}$ & - & - & $\begin{array}{l}480 \\
480\end{array}$ & $\begin{array}{l}0.502^{\mathrm{d}} \\
0.432^{\mathrm{d}}\end{array}$ \\
\hline $\begin{array}{l}\text { CP-1A-4A } \\
\text { CP-1A-4B } \\
\text { CP-1B-4A } \\
\text { CP-1B-4B }\end{array}$ & $\begin{array}{l}\text { MMA } \\
\text { MMA } \\
\text { MMA } \\
\text { MMA }\end{array}$ & $\begin{array}{l}6.1 \\
6.6 \\
6.3 \\
6.6\end{array}$ & $\begin{array}{l}\mathbf{R} \\
\mathbf{R} \\
\mathbf{T} \\
\mathbf{T}\end{array}$ & $\begin{array}{r}540 \\
1436 \\
1436 \\
1436\end{array}$ & $\begin{array}{l}0.016^{e} \\
0.032 \\
0.018 \\
0.016\end{array}$ \\
\hline $\begin{array}{l}\text { CP-2A-4A } \\
\text { CP-2A-4B } \\
\text { CP-2B-4B }\end{array}$ & $\begin{array}{l}\mathbf{S} \\
\mathbf{S} \\
\mathbf{S}\end{array}$ & $\begin{array}{l}5.1 \\
5.7 \\
4.5\end{array}$ & $\begin{array}{l}\mathbf{R} \\
\mathbf{R} \\
\mathbf{T}\end{array}$ & $\begin{array}{l}1420 \\
1420 \\
1420\end{array}$ & $\begin{array}{l}0.036 \\
0.042 \\
0.042\end{array}$ \\
\hline $\begin{array}{l}\text { CP-3A-4A } \\
\text { CP-3A-4B } \\
\text { CP-3B-4A } \\
\text { CP-3B-4B }\end{array}$ & $\begin{array}{l}- \\
- \\
- \\
-\end{array}$ & $\begin{array}{l}- \\
- \\
-\end{array}$ & $\begin{array}{l}\mathbf{R} \\
\mathbf{R} \\
\mathbf{T} \\
\mathbf{T}\end{array}$ & $\begin{array}{l}750 \\
750 \\
605 \\
605\end{array}$ & $\begin{array}{l}0.580^{d} \\
0.536^{d} \\
0.496^{d} \\
0.548^{d}\end{array}$ \\
\hline $\begin{array}{l}\text { CP-4A-4A } \\
\text { CP-4A-4B } \\
\text { CP-4B-4A } \\
\text { CP-4B-4B }\end{array}$ & $\begin{array}{l}\text { MMA+TMPTMA } \\
\text { MMA + TMPTMA } \\
\text { MMA +TMPTMA } \\
\text { MMA+TMPTMA }\end{array}$ & $\begin{array}{l}6.1 \\
6.5 \\
7.4 \\
7.2\end{array}$ & $\begin{array}{l}\mathbf{R} \\
\mathbf{R} \\
\mathbf{T} \\
\mathbf{T}\end{array}$ & $\begin{array}{r}360 \\
1326 \\
1326 \\
1326\end{array}$ & $\begin{array}{l}0.004 \\
0.024 \\
0.018 \\
0.006\end{array}$ \\
\hline $\begin{array}{l}\text { CP-5A-4A } \\
\text { CP-5A-4B } \\
\text { CP-5B-4A } \\
\text { CP-5B-4B }\end{array}$ & $\begin{array}{l}\text { AN } \\
\text { AN } \\
\text { AN } \\
\text { AN }\end{array}$ & $\begin{array}{l}5.1 \\
5.3 \\
5.0 \\
6.0\end{array}$ & $\begin{array}{l}\mathbf{R} \\
\mathbf{R} \\
\mathbf{T} \\
\mathbf{T}\end{array}$ & $\begin{array}{r}540 \\
180 \\
390 \\
1100\end{array}$ & $\begin{array}{l}0.462^{d} \\
0.096^{i} \\
0.150^{4} \\
0.034\end{array}$ \\
\hline $\begin{array}{l}\text { CP-6A-4A } \\
\text { CP-6A-4B } \\
\text { CP-6B-4A } \\
\text { CP-6B-4B }\end{array}$ & $\begin{array}{l}\text { CS } \\
\text { CS } \\
\text { CS } \\
\text { CS }\end{array}$ & $\begin{array}{l}6.1 \\
5.8 \\
6.3 \\
6.6\end{array}$ & $\begin{array}{l}\mathbf{R} \\
\mathbf{R} \\
\mathbf{T} \\
\mathbf{T}\end{array}$ & $\begin{array}{l}732 \\
732 \\
905 \\
905\end{array}$ & $\begin{array}{l}0.466^{d} \\
0.798^{d} \\
0.028 \\
0.020\end{array}$ \\
\hline $\begin{array}{l}\text { CP7-4A } \\
\text { CP7-4B }\end{array}$ & $\begin{array}{l}\text { PE-S } \\
\text { PE-S }\end{array}$ & $\begin{array}{l}6.6 \\
6.8\end{array}$ & $\begin{array}{l}\mathbf{R} \\
\mathbf{R}\end{array}$ & $\begin{array}{l}62 \\
62\end{array}$ & 0 \\
\hline $\begin{array}{l}\text { CP-UA-4A } \\
\text { CP-UA-4B }\end{array}$ & $\begin{array}{l}\text { MMA } \\
\text { MMA }\end{array}$ & $\begin{array}{l}7.1 \\
6.7\end{array}$ & $\begin{array}{l}\mathbf{R} \\
\mathbf{R}\end{array}$ & $\begin{array}{l}390 \\
390\end{array}$ & $\begin{array}{l}0.016 \\
0.014\end{array}$ \\
\hline
\end{tabular}

$3 \times 6$-in. specimens, oven-dried at $105^{\circ} \mathrm{C}$ prior to impregnation.

-MMA = methyl methacrylate; $\mathrm{S}=$ styrene; TMPTMA = trimethylolpropane trimethacrylate; MMA+TMPTMA $=$ MMA $-10 \mathrm{wt} \%$ TMPTMA; AN = acrylonitrile; CS = chlcrostyrene; PE-S = $10 \mathrm{wt} \%$ polyenter $-90 \mathrm{wt} \%$ styrene.

$\mathbf{b}_{\mathbf{R}}=$ radiation; $\mathbf{T}=$ thermal-catalytic.

- Specimen not oven-dried.

dSpecimen failed, removed from test.

- Removed from test for display.

tLoose invert from specimen deterioration, removed from test. 
Table 17

Compressive Strength of Polymer-Impregnated Concrete After Exposure to 5\% NaOH CP-Tyne Concrete

\begin{tabular}{lccccc}
\hline & & & \multicolumn{2}{c}{ Exposure in 5\% NaOH } & \\
\cline { 5 - 5 } \multicolumn{1}{c}{ Monomer } & $\begin{array}{c}\text { Specimen } \\
\text { No. }\end{array}$ & $\begin{array}{c}\text { Polymer } \\
\text { loading, wt \% }\end{array}$ & Days & $\begin{array}{c}\text { Weight } \\
\text { change, \% }\end{array}$ & $\begin{array}{c}\text { Compressive } \\
\text { strength, psi }\end{array}$ \\
\hline Unimpregnated controls & 17 & - & 382 & +0.4 & 6,800 \\
PE-S & 18 & - & 382 & +0.5 & 6,700 \\
& 7 & 7.1 & 382 & +0.8 & 15,700 \\
MMA & 8 & 5.7 & 382 & +1.0 & 9,000 \\
Unimpregnated controls & 2 & 7.3 & 382 & +0.6 & 18,900 \\
S-TMPTMA & 6 & 5.6 & 382 & +0.6 & 16,300 \\
& 20 & - & 382 & +0.5 & 6,400 \\
DAP-MMA & 21 & 7.1 & 382 & +0.4 & 6,200 \\
& 5 & 7.5 & 382 & +0.4 & 19,300 \\
& 12 & 8.3 & 382 & +0.5 & 16,000 \\
& 4 & 7.9 & 382 & +0.8 & 16,300 \\
& 13 & +0.8 & 12,200 \\
\hline
\end{tabular}

$3 \times 6$-in. specimens, oven-dried at $150^{\circ} \mathrm{C}$ prior to impregnation.

PE-S $=10 \mathrm{wt} \%$ polyester $-90 \mathrm{wt} \%$ styrene, radiation polymerized.

MMA = methyl methacrylate, radiation polymerized.

S-TMPTMA $=60 \mathrm{wt} \%$ styrene $-40 \mathrm{wt} \%$ TMPTMA, thermal-catalytically polymerized.

DAP-MMA = $90 \mathrm{wt} \%$ DAP - $10 \mathrm{wt} \%$ MMA, thermal-catalytically polymerized.

Table 18

Resistance of Polymer-Impregnated Concrete to $5 \% \mathrm{H}_{2} \mathrm{SO}_{4}$

\begin{tabular}{|c|c|c|c|c|}
\hline Monomer & Specimen No. & Polymer loading, wt \% & Exposure, days & Weight loss, \% \\
\hline PE-S & $\begin{array}{r}C P \cdot 7-17 A \\
19 B\end{array}$ & $\begin{array}{l}6.6 \\
6.9\end{array}$ & $\begin{array}{l}252 \\
252\end{array}$ & $\begin{array}{l}17.5 \\
16.3\end{array}$ \\
\hline MMA" & $\begin{array}{r}\text { CP-UA-19A } \\
\text { 19B }\end{array}$ & $\begin{array}{l}7.3 \\
7.1\end{array}$ & $\begin{array}{l}252 \\
252\end{array}$ & $\begin{array}{l}13.2 \\
21.3\end{array}$ \\
\hline PE_S & $\begin{array}{r}\text { CP-R- } 2 \\
22\end{array}$ & $\begin{array}{l}6.5 \\
6.6\end{array}$ & $\begin{array}{l}210 \\
210\end{array}$ & $\begin{array}{l}14.5 \\
14.2\end{array}$ \\
\hline$\because$ & & $\begin{array}{l}6.4 \\
6.5\end{array}$ & $\begin{array}{l}210 \\
210\end{array}$ & $\begin{array}{l}14.6 \\
13.4\end{array}$ \\
\hline$\because$ & $\begin{array}{r}64 \\
. \quad 72\end{array}$ & $\begin{array}{l}6.3 \\
6.4\end{array}$ & $\begin{array}{l}210 \\
210\end{array}$ & $\begin{array}{l}15.0 \\
16.4\end{array}$ \\
\hline $\begin{array}{l}\mathbf{M M A} \\
\vdots \\
\vdots \\
\vdots \\
\vdots\end{array}$ & $\begin{array}{r}\text { CP-4B-15A } \\
\text { 4B-15D } \\
\text { 5B-11A } \\
\text { 5B-12D } \\
\text { 5B-14A } \\
\text { 5B-15B }\end{array}$ & $\begin{array}{l}6.5 \\
5.6 \\
6.3 \\
5.6 \\
5.4 \\
6.0\end{array}$ & $\begin{array}{l}210 \\
210 \\
210 \\
210 \\
210 \\
210\end{array}$ & $\begin{array}{l}10.2 \\
18.5 \\
15.9 \\
13.0 \\
14.7 \\
13.3\end{array}$ \\
\hline Unimpregnated & $\begin{array}{r}\text { CP-DP-76 } \\
82\end{array}$ & $\overline{-}$ & $\begin{array}{l}210 \\
210\end{array}$ & $\begin{array}{l}33.6^{b} \\
32.4^{b}\end{array}$ \\
\hline $\begin{array}{l}3 \times 6 \text {-in. spec } \\
\text { Radiation po } \\
\text { PE.S }=10 \mathrm{~W}\end{array}$ & $\begin{array}{l}\text { ven-dried at } 110 \\
\text { tion. } \\
\text { ester }-90 \text { wt } \%\end{array}$ & & $\begin{array}{l}\text { MMA = methyl } \\
\text {-Radiation polym } \\
\text { bFailed (weight lo }\end{array}$ & $\begin{array}{l}\text { acrylate. } \\
\text { ion under water. } \\
5 \% \text { ). }\end{array}$ \\
\hline
\end{tabular}


Table 19

Resistance of Polymer-Impregnated Concrete to $15 \% \mathrm{HCl}$

CP Test Series

\begin{tabular}{|c|c|c|c|c|c|c|}
\hline Specimen No. & Monomera & $\begin{array}{c}\text { Polymer } \\
\text { loading, wt \% }\end{array}$ & $\begin{array}{c}\text { Method of } \\
\text { polymerization }\end{array}$ & $\begin{array}{l}\text { Days } \\
\text { in test }\end{array}$ & $\begin{array}{l}\text { Weight } \\
\text { loss, \% }\end{array}$ & $\begin{array}{l}\text { Compressive } \\
\text { strength, poi }\end{array}$ \\
\hline $\begin{array}{l}\text { CP-0-17A } \\
\text { CP-0-17B }\end{array}$ & - & - & - & $\begin{array}{l}105 \\
105\end{array}$ & $\begin{array}{l}27.0^{\circ} \\
26.1^{\circ}\end{array}$ & $\overline{-}$ \\
\hline $\begin{array}{l}\text { CP-1A-17A } \\
\text { CP-1A-17B } \\
\text { CP-1B-17A } \\
\text { CP-1B-17B }\end{array}$ & $\begin{array}{l}\text { MMA } \\
\text { MMA } \\
\text { MMA } \\
\text { MMA }\end{array}$ & $\begin{array}{l}6.1 \\
6.0 \\
6.6 \\
6.1\end{array}$ & $\begin{array}{l}\mathbf{R} \\
\mathbf{R} \\
\mathbf{T} \\
\mathbf{T}\end{array}$ & $\begin{array}{r}1395 \\
1216 \\
1395 \\
497\end{array}$ & $\begin{array}{c}12.5 \\
13.4^{\mathrm{d}} \\
10.2 \\
7.6^{\mathrm{d}}\end{array}$ & $\begin{array}{r}2300 \\
2300 \\
1780 \\
-\end{array}$ \\
\hline $\begin{array}{l}\text { CP-2A-17A } \\
\text { CP-2A-17B } \\
\text { CP-2B-17A } \\
\text { CP-2B-17B }\end{array}$ & $\begin{array}{l}\mathbf{S} \\
\mathbf{S} \\
\mathbf{S} \\
\mathbf{S}\end{array}$ & $\begin{array}{l}4.9 \\
4.9 \\
4.6 \\
4.6\end{array}$ & $\begin{array}{l}\mathbf{R} \\
\mathbf{R} \\
\mathbf{T} \\
\mathbf{T}\end{array}$ & $\begin{array}{l}1395 \\
1395 \\
1395 \\
1395\end{array}$ & $\begin{array}{l}17.2 \\
17.6 \\
12.6 \\
14.5\end{array}$ & $\begin{array}{r}1400 \\
1300 \\
850 \\
820\end{array}$ \\
\hline $\begin{array}{l}\text { CP-3A-17A } \\
\text { CP-3A-17B } \\
\text { CP-3B-17A } \\
\text { CP-3B-17B }\end{array}$ & $\begin{array}{l}- \\
- \\
-\end{array}$ & $\begin{array}{l}- \\
- \\
-\end{array}$ & $\begin{array}{l}\mathbf{R} \\
\mathbf{R} \\
\mathbf{T} \\
\mathbf{T}\end{array}$ & $\begin{array}{r}96 \\
110 \\
102 \\
110\end{array}$ & $\begin{array}{l}25.0^{\mathrm{c}} \\
28.3^{\mathrm{c}} \\
26.7^{\mathrm{c}} \\
26.1^{\mathrm{c}}\end{array}$ & $\begin{array}{l}- \\
- \\
-\end{array}$ \\
\hline $\begin{array}{l}\text { CP-4A-17A } \\
\text { CP-4A-17B } \\
\text { CP-4B-17A } \\
\text { CP-4B-17B }\end{array}$ & $\begin{array}{l}\text { MMA+TMPTMA } \\
\text { MMA+TMPTMA } \\
\text { MMA+TMPTMA } \\
\text { MMA+TMPTMA }\end{array}$ & $\begin{array}{l}6.2 \\
6.0 \\
7.2 \\
7.1\end{array}$ & $\begin{array}{l}\mathbf{R} \\
\mathbf{R} \\
\mathbf{T} \\
\mathbf{T}\end{array}$ & $\begin{array}{r}1289 \\
1289 \\
1289 \\
391\end{array}$ & $\begin{array}{c}13.8 \\
15.1 \\
8.6 \\
5.7^{\mathrm{d}}\end{array}$ & $\begin{array}{l}2400 \\
2200 \\
2100 \\
--\end{array}$ \\
\hline $\begin{array}{l}\text { CP-5A-17A } \\
\text { CP-5A-17B } \\
\text { CP-5B-17A } \\
\text { CP-5B-17B }\end{array}$ & $\begin{array}{l}\text { AN } \\
\text { AN } \\
\text { AN } \\
\text { AN }\end{array}$ & $\begin{array}{l}5.2 \\
5.3 \\
5.4 \\
5.4\end{array}$ & $\begin{array}{l}\mathbf{R} \\
\mathbf{R} \\
\mathbf{T} \\
\mathbf{T}\end{array}$ & $\begin{array}{l}1213 \\
1213 \\
1213 \\
1213\end{array}$ & $\begin{array}{l}17.1 \\
16.8 \\
13.4 \\
12.6\end{array}$ & $\begin{array}{l}1500 \\
1500 \\
1100 \\
1000\end{array}$ \\
\hline $\begin{array}{l}\text { CP-6A-17A } \\
\text { CP-6A-17B } \\
\text { CP-6B-17A } \\
\text { CP-6B-17B }\end{array}$ & $\begin{array}{l}\text { CS } \\
\text { CS } \\
\text { CS } \\
\text { CS }\end{array}$ & $\begin{array}{l}6.0 \\
6.1 \\
6.5 \\
6.3 \\
\end{array}$ & $\begin{array}{l}\mathbf{R} \\
\mathbf{R} \\
\mathbf{T} \\
\mathbf{T}\end{array}$ & $\begin{array}{l}882 \\
882 \\
882 \\
882\end{array}$ & $\begin{array}{l}13.4 \\
13.2 \\
12.3 \\
11.2\end{array}$ & $\begin{array}{l}1600 \\
1800 \\
1800 \\
1800\end{array}$ \\
\hline
\end{tabular}

$3 \times 6$-in. cylinders, oven-dried at $105^{\circ} \mathrm{C}$ prior to impi egnation.

- MMA = methyl methacrylate; $\mathrm{S}=$ styrene; TMPTMA = trimethylolpropane trimethacrylate; MMA + TMPTMA $=$ MMA -10 wt \% TMPTMA; AN = acrylonitrile; $C$ S = chlorostyrene.

$\mathrm{b} R=$ radiation; $T=$ thermal-catalytic.

- Failed (weight loss $>25 \%$ ), removed from test.

dRemoved from test.

Table 20

Weatherometer Tests

Polymer-Impregnated Concrete

\begin{tabular}{|c|c|c|c|c|}
\hline $\begin{array}{l}\text { Sample } \\
\text { No. }\end{array}$ & Monomer & $\begin{array}{c}\text { Polymer } \\
\text { loading, wt \% }\end{array}$ & $\begin{array}{l}\text { Exposure } \\
\text { time, hr }\end{array}$ & Remarks \\
\hline $\begin{array}{r}2.5 .2-B-1 \\
-2\end{array}$ & $\begin{array}{l}\text { MMA } \\
\text { PE-S }\end{array}$ & $\begin{array}{l}6.5 \\
6.5\end{array}$ & $\begin{array}{l}3000 \\
3000\end{array}$ & $\begin{array}{l}\text { No deterioration } \\
\text { No deterioration }\end{array}$ \\
\hline $\begin{array}{r}2.5 .3 .5 .5-1 \\
-2 \\
-3\end{array}$ & $\begin{array}{l}\text { S-TMPTMA } \\
\text { DAP-MMA } \\
\text { Unimpregnated }\end{array}$ & $\begin{array}{l}4.4 \\
4.1 \\
-\end{array}$ & $\begin{array}{l}5900 \\
5900 \\
5900\end{array}$ & $\begin{array}{l}\text { Minor scaling ( }<10 \% \text { of surface area) } \\
\text { Polymer in voids is yellowing and shrinking } \\
\text { Entire surfare area leached to depth of } 1 / 6 \text { in. }\end{array}$ \\
\hline $\begin{array}{c}\text { OSW-CP } \\
1,2,3 \\
4,5,6\end{array}$ & $\begin{array}{l}\text { Unimpregnated } \\
\text { S-TMPTMA }\end{array}$ & $\overline{6.5}$ & $\begin{array}{l}6000 \\
6000\end{array}$ & $\begin{array}{l}\text { Entire surface area leached } \\
\text { Minor scaling ( }<10 \% \text { of nurface area) }\end{array}$ \\
\hline
\end{tabular}

MMA = methyl methacrylate, radiation polymerized.

$\mathrm{PE}-\mathrm{S}=10 \mathrm{wt} \%$ polyester $-90 \mathrm{wt} \%$ styrene, radiation polymerized.

S-TMPTMA $=60 \mathrm{wt} \%$ styrene $-40 \mathrm{wt} \%$ trimethylolpropane trimethacrylate, thermal-catalytically polymerized.

DAP-MMA $=90 \mathrm{wt} \%$ diallyl phthalate $-10 \mathrm{wt} \% \mathrm{MMA}$, thermal-cutalytically polymerized. 
accelerated test consists of 1 cycle per day of soaking in a $2.1 \% \mathrm{Na}_{2} \mathrm{SO}_{4}$ solution at $22^{\circ} \mathrm{C}$ and drying in air at $54^{\circ} \mathrm{C}$. Net expansion of $0.5 \%$ is the criterion for failure. The unimpregnated concrete serving as a control was removed at 480 cycles with a net expansion of $0.467 \%$.

The PIC specimens have shown moderately to greatly improved resistance to sulfate attack as compared with the unimpregnated concrete. After 1436 cycles, the MMA-impregnated specimens show from 0.016 to $0.032 \%$ expansion, an improvement of $>199 \%$ over the unimpregnated concrete. The styrene specimens have expansions of 0.036 to $0.042 \%$ at 1420 cycles. The MMA-TMPTMA specimens have expansions of 0.006 to $0.024 \%$ at 1326 cycles. The remaining acrylonitrile specimen has an expansion of $0.034 \%$ at 1100 cycles, and the remaining chlorostyrene specimens have expansions of 0.020 to $0.028 \%$ at 705 cycles. The CP-7 polyester-styrene and CP-UA MMA underwater-

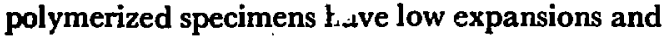
have not been in test long enough for results to be significant.

(c) ExpOSURE To 5\% NAOH. Specimens were tested for resistance to exposure in $5 \% \mathrm{NaOH}$ at room temperature for $\mathbf{3 8 2}$ days. Unimpregnated concrete, $10 \mathrm{wt} \%$ polyester - $90 \mathrm{wt} \%$ styrene impregnated and radiation-polymerized specimens, and MMAimpregnated specimens dipped in a PMMA solution and radiation-polymerized were tested. Also tested were thermal-catalytically polymerized 60 wt \% styrene - 40 wt \% TMPTMA and 90 wt \% DAP - 10 wt \% MMA specimens, which were prepared for the high-temperature applications. The test results (Table 17) indicate no adverse effect from exposure to $5 \% \mathrm{NaOH}$. All specimens showed a slight gain in weight and no visible signs of deterioration. The specimens were removed from test and compressive strengths were determined. These averaged $6500 \mathrm{psi}$ for the unimpregnated concrete specimens and were generally in the range of about 16,000 to 19,000 psi for the PIC specimens, with one specimen of polyester-styrene having a low strength of 9000 psi and one DAP-MMA specimen a low strength of $12,200 \mathrm{psi}$.

(d) Resistance to Chemical Attack From acids. Test specimens are immersed in $5 \% \mathrm{H}_{2} \mathrm{SO}_{4}$ and $15 \% \mathrm{HCl}$ at room temperature. The criterion for failure is $25 \%$ weight loss. In the $5 \% \mathrm{H}_{2} \mathrm{SO}_{4}$ test (Table 18) the unimpregnated specimens had a weight loss of $>32 \%$ at 210 days. The CP.7 polyester-styrene specimens and the CP.UA underwater polymer- ized MMA specimens show somewhat greater acid resistance, with a weight loss of about $17 \%$ after 252 days. The other polyester-styrene and MMA specimens show a weight loss of about $15 \%$ after 210 days. Test results from exposure to $15 \% \mathrm{HCl}$, given in Table 19, show significantly greater resistance for PIC specimens than for unimpregnated concrete. Weight losses ranged from 10 to $12 \%$ for MMA specimens and 12 to $17 \%$ for styrene specimens at 1395 days, 9 to $15 \%$ at 1287 days for MMA-TMPTMA specimens, 13 to $17 \%$ at 1213 days for acrylonitrile specimens, and 11 to $13 \%$ at 882 days for chlorostyrene specimens. The unimpregnated concrete control specimens failed after 105 days. The weight loss data indicate improvements in acid resistance ranging from $>740 \%$ to $>1229 \%$ as compared with unimpregnated concrete.

Although these data indicate that in general PIC has far greater resistance to acids than unimpregnated concrete, the specimens are slightly absorptive and the cement paste is slowly attacked by acid. To obtain some data on loss of strength after prolonged exposure to acid, the PIC specimens still exposed to $15 \% \mathrm{HCl}$ were removed from the acid a d d tested for compressive strength (see Table 19). Acid exposure periods ranged from 882 to 1395 days, with weight losses of about 9 to $17 \%$. Compressive strengths ranged from about 800 to 2400 psi. No corrections were made for cross-sectional areas reduced through deterioration, and the strengths are to be considered approximations only.

(e) Weatherometer Tests. Unimpregnated concrete and concrete impregnated with MMA, $10 \mathrm{wt} \%$ polyester - $90 \mathrm{wt} \%$ styrene, $60 \mathrm{wt} \%$ styrene - 40 wt \% TMPTMA, and 90 wt \% DAP - 10 wt \% MMA are under test in a Weatherometer apparatus. The apparatus is used primarily for accelcrated exposure tests of paints and protective coatings and simulates exposure to sunlight and rain. Samples are exposed to a total of $20 \mathrm{hr} /$ day of light from 2 carbon arc lamps and receive a 12-min cold, demineralized water spray each hour. Test results to date are given in Table 20 . The MMA and the polyester-styrene impregnated specimens have shown no visual indications of deterioration after $3000 \mathrm{hr}$ of exposure. Samples of PIC for desalting plant applications, which include styreneTMPTMA after exposure for 5900 and $6000 \mathrm{hr}$ and DAP-MMA after $5900 \mathrm{hr}$ of exposure, show some surface scaling affecting $<10 \%$ of the surface 
area. Unimpregnated samples show fairly uniform leaching of cement paste over the entire surface area to a depth of about $1 / 16$ in.

(e) EffECT OF SOIL MiCroORGANISUS. Samples of unimpregnated concrete and PIC are under test to determine whether soil microorganisms have an adverse effect on the materials. Samples are buried in compost-enriched soil at $27^{\circ} \mathrm{C}$ and $80 \%$ relative humidity, which are optimum conditions for soil microorganism growth. The specimens were examined visually after 18 months' burial for evidence of soil microorganism growth and surface appearance (Table 21). The samples, which contain MMA, 10 wt \% polyester - 90 wt \% styrene, 90 wt \% DAP - 10 wt \% MMA, and 60 wt \% styrene - 40 wt \% TMPTMA-impregnated concrete, had no microorganism growths and showed no changes in surface appearance. These observations indicate that the materials are highly resistant to soil microorganisms.

5.1.1.3 FLAMmAnLITY TESTS. Standard fire resistance tests for plastics and various building materials have been reviewed for application to concretepolymer materials. The existing test methods are designed to measure burning characteristics or fire resistance of specific materials, such as plastics, roofing materials, painted surfaces, and lumber, and are not intended for evaluating all materials. The only generally accepted procedure is conducted under ASTM E 84-68, Surface Burning Characteristics of Building Materials, which requires a specimen $25 \mathrm{ft}$ long and $20 \mathrm{in}$. wide. Final evaluation of a concrete-polymer material should be made by this procedure; however, the method is expensive and not suitable for screening tests. In preliminary studies several samples of PIC exposed to a gas flame ignited, appeared to contribute fuel to support combustion, and emitted smoke in varying amounts. The results of these studies apparently were affected by the presence of excess polymer on the surface. Additional studies on a limited basis were performed at BNL and the USBR to gather more information on flammability and to plan for a more comprehensive and meaningful test in next year's program.

(a) BNL STUDIEs. A study was undertaken to determine the flammability of the polymers currently used in the program and of the composite materials containing them. The purpose of the study was to measure the relative burning rates for PIC and $P C$ composites and to determine whether the addition of flame retardants was necessary.

The apparatus for determining the relative flammabilities of these materials under ASTM D 635-68, Flammability of Self-Supporting Plastics, is shown in Figures 19 and 20. In Figure 19 the flame source is being applied to a test specimen, and in Figure 20 it has been removed.

The relative burning rates for some bulk polymers are given in Table 22. Of the polymers tested, only chlorostyrene did not support combustion after removal of the flame source. Its noncombus-

Table 21

Effect of Soil Microorganisms

on Polymer-Impregnated Concrete Buried in Compost-Enriched Soil

\begin{tabular}{|c|c|c|c|c|}
\hline Sample No. & Monomer & $\begin{array}{c}\text { Polymer } \\
\text { loading, wt \% }\end{array}$ & $\begin{array}{l}\text { Exposure } \\
\text { time, months }\end{array}$ & Observations. \\
\hline $\begin{array}{r}2.5 .2-3 \\
-5\end{array}$ & $\begin{array}{l}\text { MMA } \\
\text { MMA }\end{array}$ & $\begin{array}{l}6.9 \\
5.7\end{array}$ & $\begin{array}{l}18 \\
18\end{array}$ & $\begin{array}{l}\text { No microorganism growths. Surface appearance } \\
\text { unchanged - no pitting, good gloss reterition }\end{array}$ \\
\hline-9 & PE-S & 7.0 & 18 & $\begin{array}{lll}x & =0\end{array}$ \\
\hline-11 & PE-S & 6.7 & 18 & $\therefore$ \\
\hline-13 & Unimpregnated & - & 18 & $\ldots \cdots$ \\
\hline-15 & Unimpregnated & - & 18 & \\
\hline $2.5 .3 .5 .5-10$ & DAP-MMA & 8.1 & 18 & \multirow{2}{*}{$\begin{array}{l}\text { No microorganism growths. Surface appearance } \\
\text { unchanged - no pitting, good gloss retention. }\end{array}$} \\
\hline-19 & Unimpregnated & - & 18 & \\
\hline
\end{tabular}

MMA = methyl methacrylate, radiation polymerized.

PE-S $=10$ wt $\%$ polyester -90 wt $\%$ styrene, radiation polymerized.

DAP-MMA $=90 \mathrm{wt} \%$ diallyl phthaliate $-10 \mathrm{wt} \% \mathrm{MMA}$, thermal-catalytically polymerized.

S-TMPTMA $=60 \mathrm{wt} \%$ styrene $-40 \mathrm{wt} \%$ trimethylolpropane trimethacrylate, thermal-catalytically polymerized. 


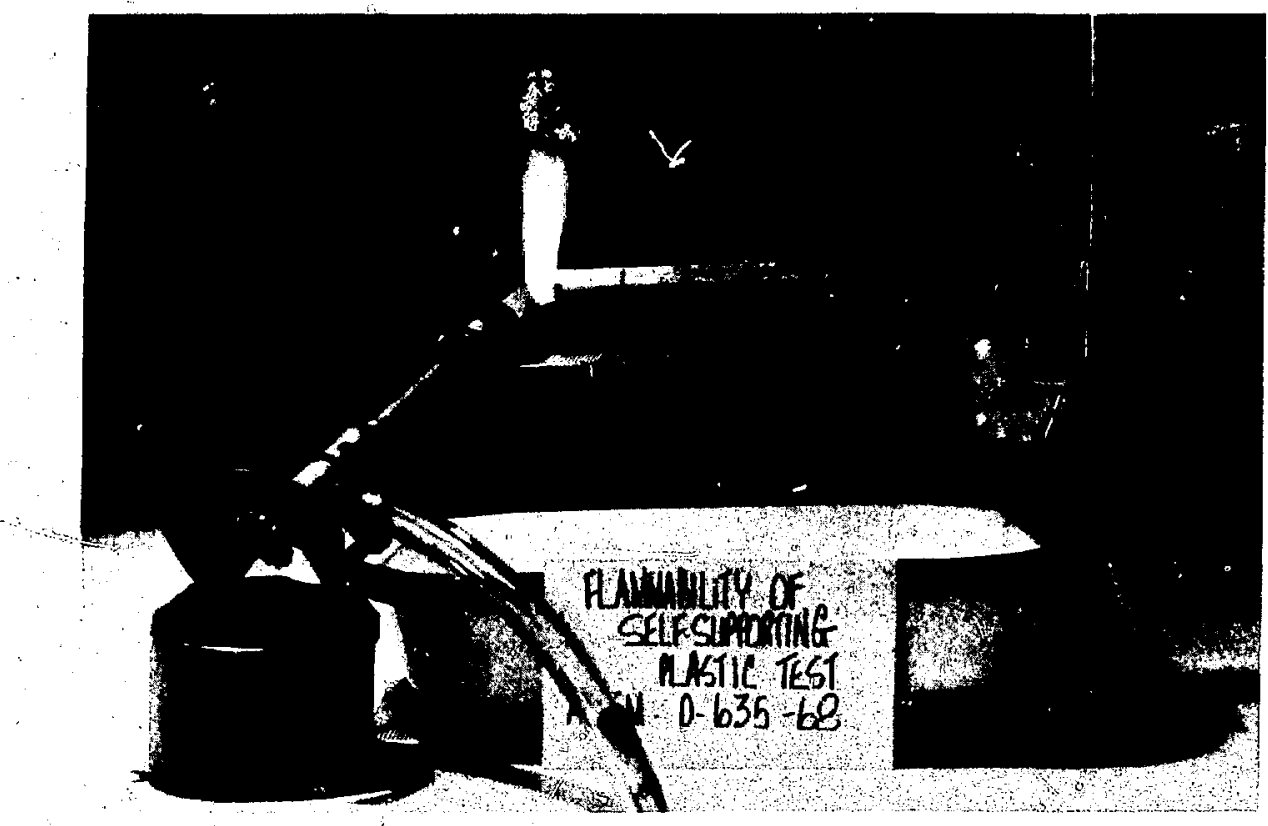

Figure 19. Flammability test of PIC specimen containing MMA. Specimen burns while flame is applied.

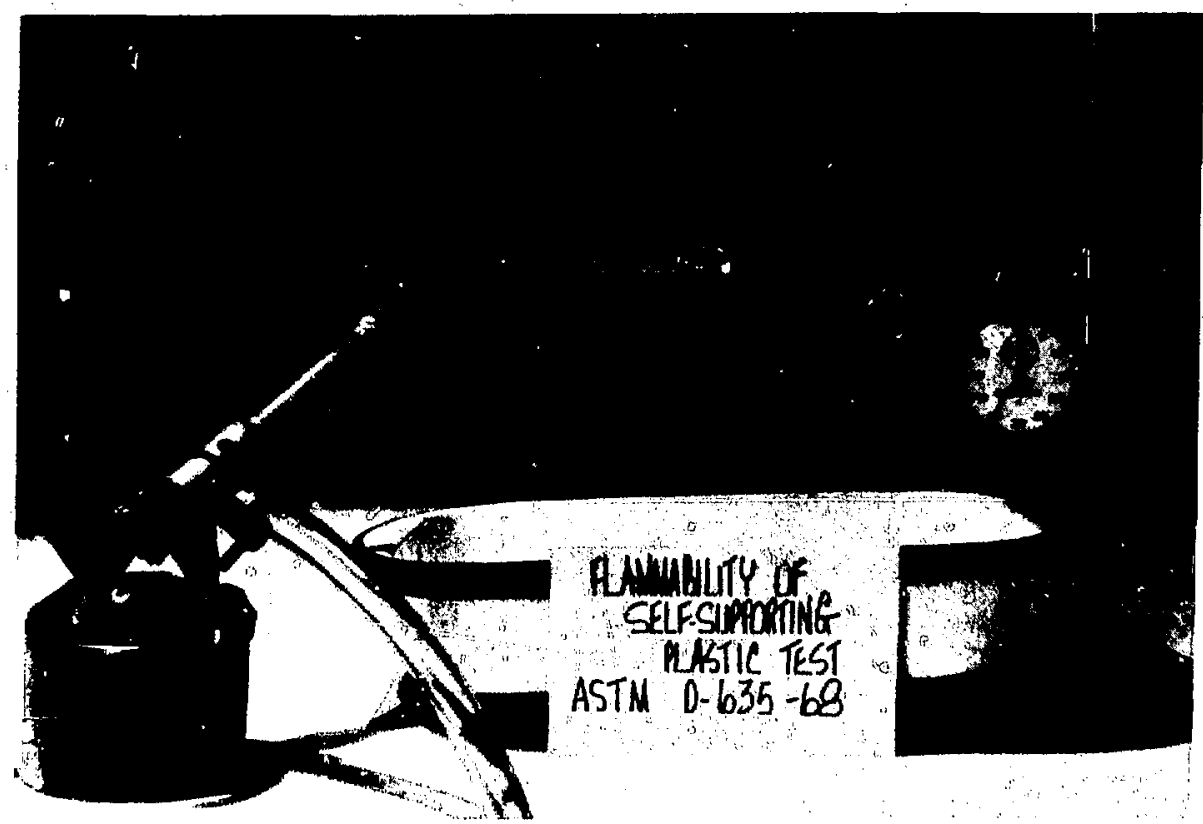

Figure 20. Flammability test of PIC specimen containing MMA.

On removal of flame source, flame dies out almost immediately. 
Table 22

Determination of the Relative Flammability of Plastics,

Polyner-Impregnated Concrete, and Polymer-Concrete Composites

\begin{tabular}{lcccl}
\hline \multicolumn{1}{c}{ Polymer } & Composite & $\begin{array}{c}\text { Polymer } \\
\text { conc., } \\
\text { wt \% }\end{array}$ & $\begin{array}{c}\text { Burning } \\
\text { rate, } \\
\text { in min }\end{array}$ & \multicolumn{1}{c}{ Remarks } \\
\hline Methyl methacrylate & - & 100 & 1.2 & Burning by this test \\
Styrene & - & 100 & 1.0 & Burning by this test \\
tert.-butyl styrene & - & 100 & 0.9 & Burning by this test \\
Chlorostyrene & - & 100 & 0 & Self-extinguishing by this test \\
10\% Polyester - 90\% styrene & - & 100 & 0.9 & Burning by this test \\
60\% Styrene - 40\% TMPTMA & - & 100 & 0.8 & Burning by this test \\
Methyl methacrylate & PIC & 6.5 & - & Self-extinguishing in 45 sec; two 30-sec ignitions \\
Styrene & PIC & 6.3 & - & Self-extinguishing in 30 sec; two 30-sec ignitions \\
tert.-butyl ityrene & PIC & 6.5 & - & Does not support combustion; two ignitions \\
Chlorostyrene & PIC & 6.2 & - & Does not support conbustion; two ignitions \\
60\% Styrene - 40\% TMPTMA & PIC & 6.5 & - & Self-extinguishing in 10 sec; two ignitions \\
Methyl methacrylate & PC & 8.0 & - & Self-extinguishing flame; travels 2 in. in 2.5 min \\
Styrene & PC & 7.6 & - & Self-extinguishing; < 1 in. flame travel in 2.5 min \\
tert.-butyl styrene & PC & 7.4 & - & Does not support combustion \\
Chlorostyrene & PC & 7.6 & - & Does not support combustion \\
10\% Polyester - 90\% styrene & PC & 6.9 & - & Self-extinguishing; burns for 1.5 sec \\
60\% Styrene-40\% TMPTMA & PC & 7.0 & - & Self-extinguishing; burns for 15 sec \\
\hline
\end{tabular}

aASTM D 635-68, Flammability of Self-Supporting Plastics.

tibility is probably due to the chlorine portion of the monomer molecule, which acts as a flame retardant.

When these polymers are incorporated into concrete, the burning characteristics change drastically. As shown in Table 22, under the conditions of this test all the PIC composites are either selfextinguishing or do not burn at all. This may be due to the small amount $(\approx 6 \mathrm{wt} \%$ ) of polymer in the composite. The surface polymer exposed to the flame burns or is pyrolyzed quickly and leaves a charred residue which acts as a protective blanket for polymer beneath the surface. In addition, the concrete acts as a heat sink, and the heat resulting from combustion is not sufficient to sustain pyrolysis.

The burning rates obtained for PC were similar to those for PIC. In some cases, however, defn:mation and disintegration took place at the point of burning. Composites containing MMA, styrene, tert.-butyl styrene and chlorostyrene showed disintegration at the point of application when the flame was sustained for 30 sec. A portion of the polymer pyrolyzed, and the remainder melted and dropped off the test specimen along with the aggregate. After removal of the flame, deformation was noted in the heated area. The softenirg points for the polymers tested range between $\approx 80^{\circ}$ and $120^{\circ} \mathrm{C}$. Melting was not observed in composites containing $10 \mathrm{wt} \%$ polyester -90 wt \% styrene and 60 wt \% styrene -- 40 wt \% TMPTMA, although slight deformation at the point where the flame was applied was observed in the former. The absence of melting and the resistance to deformation in these two systems can be attributed to cross-linking within the polymer network. Crosslinked polymers do not flow-melt and are more resistant to thermal deformation.

(b) USBR STUDiEs. Flammability studies patterned after ASTM D 635-68, Flammability of Self-Supporting Plastics, were performed r,n six $60 \mathrm{wt} \%$ styrene $-40 \mathrm{wt} \%$ TMPTMA and six 70 wt \% MMA - 30 wt \% TMPTMA PIC specimens. Specimens measuring $1 \times 2 \times 12$ in, were mounted on a ringstand with the 12-in. axis horizontal and the 2-in. axis inclined $45^{\circ}$. The extended end of the sample was heated for $30 \mathrm{sec}$ with a Bunsen. burner flame showing a 1 -in. inner blue cone. The burner was removed for $30 \mathrm{sec}$, then reapplied to the specimen for an additional $60 \mathrm{sec}$. To ensure 
that PIC and not the excess polymer lirequently observed on the surface of PIC specimen; was being tested, surface coatings of polymer were removed with a grinding wheel. The following results were obtained.

i. No sustained combustion was observed. The PIC specimens are classified "nonburning" by this test. ii. During the second, more prolonged heating period, a small flame was observed playing on the vertical surface of the test specimen. The flame went out almost immediately on removal of the flame source. PIC is nonburning by this test.

iii. For comparison, a specimen with a surface layer of 70 wt \% MMA - 30 wt \% TMPTMA polymer was tested. It burned with a yellow,

Table 23

Ultimate Design Tensile Strength and Elastic Properties

Polymer-Impregnated Concrete for Ambient-Temperature Applications

\begin{tabular}{|c|c|c|c|c|c|c|}
\hline \multirow[b]{2}{*}{ Type of material } & \multirow[b]{2}{*}{$\begin{array}{c}\text { Test } \\
\text { temperature, } \\
{ }^{\circ} \mathbf{C}\end{array}$} & \multicolumn{2}{|c|}{ Design valuesb } & \multicolumn{3}{|c|}{ Average values $\mathrm{c}$} \\
\hline & & $\begin{array}{c}\text { Tensile } \\
\text { strength, psi }\end{array}$ & $\begin{array}{l}\text { Modulus of } \\
\text { elasticity, } \\
10^{6} \mathrm{psi}\end{array}$ & $\begin{array}{c}\text { Polymer } \\
\text { loading, wt \% }\end{array}$ & $\begin{array}{l}\text { Poisson's } \\
\text { ratiod }\end{array}$ & $\begin{array}{l}\text { Ultimate strain, } \\
\mu \text { in /in. }\end{array}$ \\
\hline Unimpregnated & $\begin{array}{r}-12 \\
21\end{array}$ & $\begin{array}{l}210 \\
250\end{array}$ & $\begin{array}{l}2.9 \\
3.3\end{array}$ & - & $\begin{array}{l}0.15 \\
0.13\end{array}$ & $\begin{array}{l}177 \\
121\end{array}$ \\
\hline MMA & $\begin{array}{r}-12 \\
21\end{array}$ & $\begin{array}{l}600 \\
980\end{array}$ & $\begin{array}{l}6.1 \\
6.9\end{array}$ & $\begin{array}{l}5.5 \\
5.7\end{array}$ & $\begin{array}{l}0.18 \\
0.22\end{array}$ & $\begin{array}{l}117 \\
156\end{array}$ \\
\hline PE-S & $\begin{array}{r}-12 \\
21\end{array}$ & $\begin{array}{r}860 \\
1250\end{array}$ & $\begin{array}{l}6.6 \\
6.9\end{array}$ & $\begin{array}{l}5.2 \\
5.2\end{array}$ & $\begin{array}{l}0.18 \\
0.26\end{array}$ & $\begin{array}{l}151 \\
210\end{array}$ \\
\hline
\end{tabular}

Direct tension tests on $4 \frac{1}{2} \times 12 \frac{1}{2}$-in. cylinders.

¿MMA = methyl methacrylate, radiation polymerized; PE-S $=10 \mathrm{wt} \%$ polyester $-90 \mathrm{wt} \%$ styrene, radiation polymerized.

'Design values $=$ mean minus standard deviation.

${ }^{c}$ Average values $=$ mean of 4 or 5 specimens.

APoisson's ratio determined on one specimen only.

Table 24

Ultimat Design Compressive Strength and Elastic Properties

Polymer-Impregnated Concrete for Ambient-Temperature Applications

\begin{tabular}{|c|c|c|c|c|c|c|c|}
\hline \multirow[b]{2}{*}{$\begin{array}{l}\text { Type of } \\
\text { material }\end{array}$} & \multirow[b]{2}{*}{$\begin{array}{c}\text { Test } \\
\text { temperature, } \\
{ }^{\circ} \mathrm{C}\end{array}$} & \multicolumn{3}{|c|}{ Design values } & \multicolumn{3}{|c|}{ Average values } \\
\hline & & $\begin{array}{l}\text { Compressive } \\
\text { strength } \\
\left(f^{\prime} c\right), \mathrm{psi}\end{array}$ & $\begin{array}{l}\text { Poisson's } \\
\text { ratio }\end{array}$ & $\begin{array}{c}\text { Modulus of } \\
\text { elasticity, } \\
10^{6} \mathrm{psi}\end{array}$ & $\begin{array}{c}\text { Polymer } \\
\text { loading, } \\
\text { wt } \%\end{array}$ & $\begin{array}{l}\text { Elastic limit } \\
\text { stress, psi }\end{array}$ & $\begin{array}{l}\text { Ultimate } \\
\text { strain, } \\
\text { in./in. }\end{array}$ \\
\hline $\begin{array}{l}\text { Unimpregnated } \\
\text { Unimpregnated }\end{array}$ & $\begin{array}{r}-12 \\
21\end{array}$ & $\begin{array}{l}5,100 \\
4,900\end{array}$ & $\begin{array}{l}0.16 \\
0.13^{\mathrm{a}}\end{array}$ & $\begin{array}{l}3.6 \\
3.8\end{array}$ & - & $\begin{array}{l}1,200 \\
1,400\end{array}$ & $\begin{array}{l}0.0022 \\
0.0022\end{array}$ \\
\hline $\begin{array}{l}\text { MMA } \\
\text { MMA }\end{array}$ & $\begin{array}{r}-12 \\
21\end{array}$ & $\begin{array}{l}15,400 \\
14,100^{\mathrm{a}}\end{array}$ & $\begin{array}{l}0.20 \\
0.19\end{array}$ & $\begin{array}{l}6.7 \\
6.5\end{array}$ & $\begin{array}{l}5.6 \\
5.6\end{array}$ & $\begin{array}{l}8,000 \\
8,000\end{array}$ & $\begin{array}{l}0.0027 \\
0.0028\end{array}$ \\
\hline $\begin{array}{l}\text { PE-S } \\
\text { PE-S }\end{array}$ & $\begin{array}{r}-12 \\
21\end{array}$ & $\begin{array}{l}18,900 \\
18,900\end{array}$ & $\begin{array}{l}0.18^{a} \\
0.19\end{array}$ & $\begin{array}{l}6.9 \\
6.9\end{array}$ & $\begin{array}{l}5.4 \\
5.4\end{array}$ & $\begin{array}{l}3,400 \\
6,800\end{array}$ & $\begin{array}{l}0.0032 \\
0.0031\end{array}$ \\
\hline
\end{tabular}

$6 \times 12$-in. cylinders oven-dried at $75^{\circ} \mathrm{C}$ prior to impregnation.

MMA = methyl methacrylate.

PE-S $=10 \mathrm{wt} \%$ polycster $-90 \mathrm{wt} \%$ styrene.

Radiation polymerization.

"CP-type-concrete coefficient of variation of measurements was $>15 \%$. 
smoky flame, and molten, burning polymer splattered from the surface. The flame died out within 5 sec after removal of the burner.

Several fragments of PC (containing 8 wt \% MMA) were similarly tested and were observed to have similar flammability characteristics in that no sustained combustion was observed. The heated portion of the sample decomposed into a mixture of fine and coarse aggregate which could be brushed away with the fingers. A very thin fragment (measuring $\approx 2 \times 6 \times 1 / 8$ in.) burned with a pale yellow flame for about 50 sec after removal of the burner and left a loose pile of aggregate beneath the test specimen.

Flammability appears to be less important than loss of strength upon exposure to fire. PC is completely destroyed, and it may be assumed that PIC loses strength.

5.1.2 Structural Properties Tests. Tests of structural properties during the past year have included direct tension tests at $-12^{\circ}$ and $20^{\circ} \mathrm{C}$, single- and double-shear tests, a continuation of the long-term 800-psi compressive creep studies tests of flexural strength of concrete beams partially impregnated from one and from two sides, flexure and shear tests of steel-reinforced PIC, and preliminary work on a fatigue testing program for PIC beams.

Preliminary design values for tensile strength and modulus of elasticity at $-12^{\circ}$ and $21^{\circ} \mathrm{C}$ were obtained (see Section 5.1.2.1 and Tables 25 to 27). These design values for the MMA and $10 \mathrm{wt} \%$ polyester - 90 wt \% styrene systems, radiation polymerized, are given in Table 23. For comparison with the tensile values, the preliminary design values for compressive strength, modulus of elasticity, and Poisson's ratio determined earlier ${ }^{4}$ are reproduced in Table 24.

Shear tests (see Section 5.1.2.2) showed an average ultimate shear stress of about 3700 psi for MMA-impregnated concrete in both the singleshear and the double-shear test. The test procedure apparently has little effect on the results because PIC is sufficiently strong to resist the small bending moment induced in the single-shear test. The shear strength of MMA-impregnated concrete is some 2 to 3 times greater than that of unimpregnated concrete.

Creep tests on CP-series specimens under 800psi sustained load and on MMA-impregnated and chlorostyrene-impregnated concrete under lowand high-stress tensile and compressive loads are continuing. These tests are discussed in Section 5.1.2.3. Results to date indicate that PIC undergoes significantly lower creep deformation than unimpregnated concrete.

Flexural strength tests were conducted on partially impregnated beams (see Section 5.1.2.4). The beams were impregnated from one and two sides to determine the effects of polymer impregnation on tension and compression of beams in flexure. Beams impregnated only on the tension side sustained an average ultimate load nearly twice as great as that for unimpregnated beams. The tests with beams impregnated on both the tension and compression sides were inconclusive.

Flexural and shear tests of steel-reinforced PIC beams are discussed in Section 5.1.2.5. The PIC beams carried more load than unimpregnated beams, but the difference was not considered significant. A check of the results indicated that the beams were underreinforced and that what had been tested was the reinforcement rather than the concrete.

5.1.2.1 Tensile STReneth. Direct tensile strength has been determined for concrete impregnated with MMA and $10 \mathrm{wt} \%$ polyester - $90 \mathrm{wt} \%$ styrene, both radiation polymerized (Tables 25 and 26)

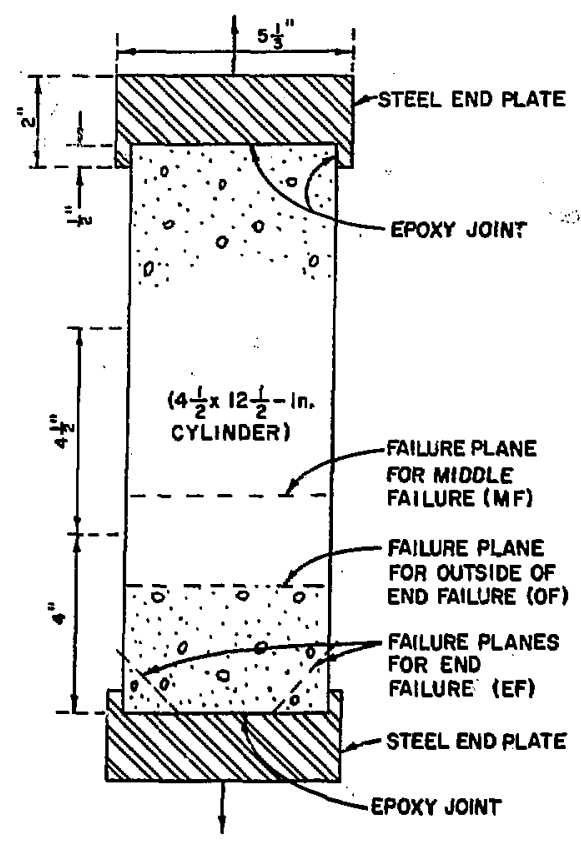

Figure 21. Schematic diagram of direct tension test. 
Table 25

Low-Temperature Tensile Strength, Short Term

MMA-Impregnated Concretea

\begin{tabular}{|c|c|c|c|c|c|c|c|}
\hline $\begin{array}{c}\text { Test } \\
\text { temperature, } \\
{ }^{\circ} \mathrm{C}\end{array}$ & $\begin{array}{c}\text { Specimen } \\
\text { No., } \\
6.1 .1 \text { - }\end{array}$ & $\begin{array}{c}\text { Polymer } \\
\text { loading, } \\
\text { wt } \%\end{array}$ & $\begin{array}{c}\text { Tensile } \\
\text { strength, } \\
\text { psi }\end{array}$ & $\begin{array}{c}\text { Poisson's } \\
\text { ratio }\end{array}$ & $\begin{array}{c}\text { Modulus of } \\
\text { elasticity, } \\
10^{6} \text { psi }\end{array}$ & $\begin{array}{l}\text { Ultimate } \\
\text { strain, } \\
\text { ( } \mu \text { in./in.) }\end{array}$ & $\begin{array}{l}\text { Type of } \\
\text { failureb }\end{array}$ \\
\hline \multirow[t]{2}{*}{-12} & $\begin{array}{l}53 \\
54 \\
56 \\
59 \\
65\end{array}$ & $\begin{array}{l}5.7 \\
5.4 \\
5.3 \\
5.4 \\
5.8\end{array}$ & $\begin{array}{l}740 \\
710 \\
550 \\
680 \\
670\end{array}$ & $\begin{array}{c}- \\
\overline{0.18} \\
- \\
-\end{array}$ & $\begin{array}{l}7.0 \\
6.8 \\
5.8 \\
6.4 \\
6.9\end{array}$ & $\begin{array}{l}111 \\
126 \\
140 \\
111 \\
100\end{array}$ & $\begin{array}{l}\text { EF } \\
\text { OF } \\
\text { MF } \\
\text { EF } \\
\text { EF }\end{array}$ \\
\hline & $\begin{array}{l}\text { Mean } \\
\text { S.D. }\end{array}$ & $\begin{array}{c}5.5 \\
-\end{array}$ & $\begin{array}{r}670 \\
70\end{array}$ & $\begin{array}{c}0.18 \\
-\end{array}$ & $\begin{array}{l}6.6 \\
0.5\end{array}$ & $\begin{array}{c}117 \\
-\end{array}$ & \\
\hline \multirow[t]{2}{*}{20} & $\begin{array}{l}57 \\
61 \\
62 \\
69 \\
75^{c}\end{array}$ & $\begin{array}{l}5.8 \\
5.3 \\
5.7 \\
6.2 \\
5.4\end{array}$ & $\begin{array}{r}1180 \\
1060 \\
950 \\
1080 \\
-\end{array}$ & $\begin{array}{c}- \\
0.22 \\
- \\
- \\
-\end{array}$ & $\begin{array}{c}6.9 \\
7.0 \\
7.0 \\
7.0 \\
-\end{array}$ & $\begin{array}{c}176 \\
153 \\
140 \\
154 \\
-\end{array}$ & $\begin{array}{l}\text { EF } \\
\text { MF } \\
\text { EF } \\
\text { EF } \\
\text { MF }\end{array}$ \\
\hline & $\begin{array}{l}\text { Mean } \\
\text { S.D. }\end{array}$ & $\begin{array}{c}5.7 \\
-\end{array}$ & $\begin{array}{r}1070 \\
90\end{array}$ & $\begin{array}{c}0.22 \\
-\end{array}$ & $\begin{array}{l}7.0 \\
0.1\end{array}$ & $\begin{array}{c}156 \\
-\end{array}$ & \\
\hline
\end{tabular}

-MMA = methyl methacrylate, radiation polymerized.

bFailure occurring (1) in middle of specimen (MF); (2) outside recessed portion of end plate (OF); (3) inside of end plate (EF).

c Half of cross section was impregnated and polymerized.

Table 26

Low-Temperature Tensile Strength, Short Term

10 wt \% Polyester - 90 wt \% Styrene Impregnated Concrete

\begin{tabular}{|c|c|c|c|c|c|c|c|}
\hline $\begin{array}{c}\text { Test } \\
\text { temperature, } \\
{ }^{\circ} \mathrm{C}\end{array}$ & $\begin{array}{c}\text { Specimen } \\
\text { No., } \\
6.1 .1-\end{array}$ & $\begin{array}{c}\text { Polymer } \\
\text { loading, } \\
\text { wt \% }\end{array}$ & $\begin{array}{c}\text { Tensile } \\
\text { strength, } \\
\text { psi }\end{array}$ & $\begin{array}{l}\text { Poisson's } \\
\text { ratio }\end{array}$ & $\begin{array}{l}\text { Modulus of } \\
\text { elasticity, } \\
10^{6} \text { psi }\end{array}$ & $\begin{array}{l}\text { Ultimate } \\
\text { strain, } \\
\mu \text { in./in. }\end{array}$ & $\begin{array}{l}\text { Type of } \\
\text { failure }^{a}\end{array}$ \\
\hline \multirow[t]{2}{*}{-12} & $\begin{array}{l}58 \\
60 \\
67 \\
68 \\
73\end{array}$ & $\begin{array}{l}5.4 \\
5.0 \\
5.0 \\
5.0 \\
5.4\end{array}$ & $\begin{array}{r}1080 \\
790 \\
1020 \\
970 \\
1150\end{array}$ & $\begin{array}{l}- \\
0.18 \\
- \\
- \\
-\end{array}$ & $\begin{array}{l}6.9 \\
6.4 \\
7.0 \\
7.6 \\
7.2\end{array}$ & $\begin{array}{l}161 \\
129 \\
158 \\
143 \\
166\end{array}$ & $\begin{array}{l}\text { EF } \\
\mathbf{M F} \\
\mathbf{E F} \\
\mathbf{E F} \\
\mathbf{E F}\end{array}$ \\
\hline & $\begin{array}{l}\text { Mean } \\
\text { S.D. }\end{array}$ & $\begin{array}{c}5.2 \\
-\end{array}$ & $\begin{array}{r}1000 \\
140\end{array}$ & $\begin{array}{c}0.18 \\
-\end{array}$ & $\begin{array}{l}7.0 \\
0.4\end{array}$ & $\begin{array}{c}151 \\
-\end{array}$ & \\
\hline \multirow[t]{2}{*}{20} & $\begin{array}{l}63 \\
66 \\
70 \\
71 \\
72\end{array}$ & $\begin{array}{l}5.0 \\
5.0 \\
5.4 \\
5.3 \\
5.4\end{array}$ & $\begin{array}{l}1550 \\
1400 \\
1380 \\
1160 \\
1460\end{array}$ & $\begin{array}{l}-\overline{0.26} \\
- \\
-\end{array}$ & $\begin{array}{l}7.0 \\
7.2 \\
7.1 \\
7.3 \\
6.9\end{array}$ & $\begin{array}{l}238 \\
205 \\
199 \\
168 \\
240\end{array}$ & $\begin{array}{l}\mathbf{E F} \\
\mathbf{M F} \\
\mathbf{E F} \\
\mathbf{E F} \\
\mathbf{E F}\end{array}$ \\
\hline & $\begin{array}{l}\text { Mean } \\
\text { S.D. }\end{array}$ & $\begin{array}{c}5.2 \\
-\end{array}$ & $\begin{array}{r}1390 \\
140\end{array}$ & $\begin{array}{c}0.26 \\
-\end{array}$ & $\begin{array}{l}7.1 \\
0.2\end{array}$ & $\begin{array}{c}210 \\
-\end{array}$ & \\
\hline
\end{tabular}

Radiation-induced polymerization.

Failure occurring (1) in middle of specimen (MF); (2) inside of end plate (EF). 
Table 27

Low-Temperature Tensile Strength, Short Term

Unimpregnated Concrete

\begin{tabular}{|c|c|c|c|c|c|c|}
\hline $\begin{array}{c}\text { Test } \\
\text { temperature, } \\
{ }^{\circ} \mathrm{C}\end{array}$ & $\begin{array}{c}\text { Specimen } \\
\text { No., } \\
6.1 .1-\end{array}$ & $\begin{array}{c}\text { Tensile } \\
\text { strength, } \\
\text { psi }\end{array}$ & $\begin{array}{l}\text { Poisson's } \\
\text { ratio }\end{array}$ & $\begin{array}{l}\text { Modulus of } \\
\text { elasticity, } \\
10^{6} \mathrm{psi}\end{array}$ & $\begin{array}{l}\text { Ultimate } \\
\text { strain, } \\
\mu \text { in./in. }\end{array}$ & $\begin{array}{l}\text { Type of } \\
\text { failure }\end{array}$ \\
\hline \multirow[t]{2}{*}{-12} & $\begin{array}{l}76 \\
80 \\
81 \\
82 \\
85\end{array}$ & $\begin{array}{l}210 \\
280 \\
270 \\
210 \\
220\end{array}$ & $\begin{array}{c}- \\
- \\
0.15 \\
- \\
-\end{array}$ & $\begin{array}{l}2.8 \\
3.1 \\
3.1 \\
3.7 \\
3.2\end{array}$ & $\begin{array}{r}104 \\
206 \\
281 \\
66 \\
230\end{array}$ & $\begin{array}{l}\text { MF } \\
\text { OF } \\
\text { MF } \\
\text { EF } \\
\text { MF }\end{array}$ \\
\hline & $\begin{array}{l}\text { Mean } \\
\text { S.D. }\end{array}$ & $\begin{array}{r}240 \\
30\end{array}$ & $\begin{array}{c}0.15 \\
-\end{array}$ & $\begin{array}{l}3.2 \\
0.3\end{array}$ & $\begin{array}{c}177 \\
-\end{array}$ & \\
\hline \multirow[t]{2}{*}{20} & $\begin{array}{l}77 \\
78^{\mathrm{b}} \\
79 \\
83 \\
84\end{array}$ & $\begin{array}{c}230 \\
- \\
300 \\
290 \\
300\end{array}$ & $\begin{array}{c}0.13 \\
- \\
- \\
- \\
-\end{array}$ & $\begin{array}{r}3.9 \\
- \\
3.8 \\
4.0 \\
3.2\end{array}$ & $\begin{array}{c}68 \\
- \\
111 \\
100 \\
205\end{array}$ & $\begin{array}{l}\text { MF } \\
\text { MF } \\
\text { OF } \\
\text { OF } \\
\text { OF }\end{array}$ \\
\hline & $\begin{array}{l}\text { Mean } \\
\text { S.D. }\end{array}$ & $\begin{array}{r}280 \\
30\end{array}$ & 0.13 & $\begin{array}{l}3.7 \\
0.4\end{array}$ & $\begin{array}{c}121 \\
-\end{array}$ & \\
\hline
\end{tabular}

a Failure occurring (1) in middle of specimen (MF); (2) outside recessed portion of end plate (OF); (3) inside of end plate (EF).

bSpecimen failed during preload cycle.

Table 28

Comparison of Average Elastic Properties Determined in Direct Tension and Compression Tests

(Low temperature, short term.)

\begin{tabular}{|c|c|c|c|c|c|}
\hline \multirow[b]{2}{*}{$\begin{array}{l}\text { Type of } \\
\text { material }\end{array}$} & \multirow[b]{2}{*}{$\begin{array}{c}\text { Test } \\
\text { temperature, } \\
{ }^{\circ} \mathrm{C}\end{array}$} & \multicolumn{2}{|c|}{ Direct tension } & \multicolumn{2}{|c|}{ Compression : } \\
\hline & & $\begin{array}{l}\text { Modulus of } \\
\text { elasticity, } \\
10^{6} \mathrm{psi}\end{array}$ & $\begin{array}{l}\text { Poisson's } \\
\text { ratio }\end{array}$ & $\begin{array}{l}\text { Modulus of } \\
\text { elasticity, } \\
10^{6} \mathrm{psi}\end{array}$ & $\begin{array}{l}\text { Poisson's } \\
\text { ratio }\end{array}$ \\
\hline $\begin{array}{l}\text { Control } \\
\text { Control }\end{array}$ & $\begin{array}{r}-12 \\
20\end{array}$ & $\begin{array}{l}3.2 \\
3.7\end{array}$ & $\begin{array}{l}0.15 \\
0.13\end{array}$ & $\begin{array}{l}3.8 \\
3.8\end{array}$ & $\begin{array}{l}0.18 \\
0.16\end{array}$ \\
\hline $\begin{array}{l}\text { MMA } \\
\text { MMA }\end{array}$ & $\begin{array}{r}-12 \\
20\end{array}$ & $\begin{array}{l}6.6 \\
7.0\end{array}$ & $\begin{array}{l}0.18 \\
0.22\end{array}$ & $\begin{array}{l}6.9 \\
6.7\end{array}$ & $\begin{array}{l}0.22 \\
0.21\end{array}$ \\
\hline $\begin{array}{l}\text { PE-Sa } \\
\text { PE-S }\end{array}$ & $\begin{array}{r}-12 \\
20\end{array}$ & $\begin{array}{l}7.0 \\
7.1\end{array}$ & $\begin{array}{l}0.18 \\
0.26\end{array}$ & $\begin{array}{l}7.0 \\
7.0\end{array}$ & $\begin{array}{l}0.22 \\
0.22\end{array}$ \\
\hline
\end{tabular}

Polymer loadings in both test series were similar for each monomer system.

n 10 wt \% polyester - 90 wt \% styrene, radiation polymerized.

and for unimpregnated concrete (Table 27). Measurements were made at $-12^{\circ}$ and $20^{\circ} \mathrm{C}$. Modulus of elasticity and a few Poisson's ratios were obtained from electrical resistant strain gages bonded to the cylinders. A schematic diagram of the test is shown in Figure 21. The numbers of end failures (EF) and failures within 4 in. of the end plates (OF), that occurred during the tests were not considered significant because these strengths were not much different from those found with middle failures (MF). (See Tables 25 to 27 for definition of types of failure.) 


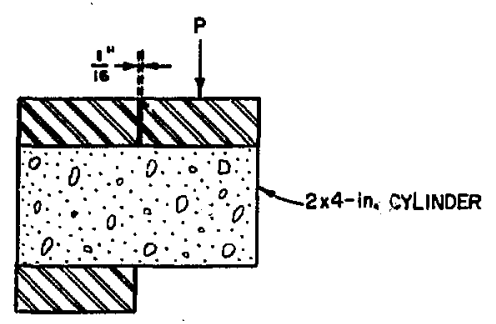

Figure 22. Schematic diagram of single-shear test.

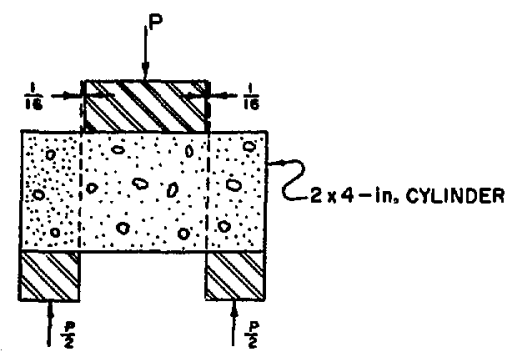

Figure 23. Schematic diagram of double-shear test.
Three tests were made on each cylinder. The first two were used to obtain values of Poisson's ratio and modulus of elasticity. The third run was made to obtain stress-strain plots to failure. Study of these plots shows the stress-strain relationship of impregnated concrete to be much more linear than that of plain concrete.

A comparison of average values for each type of PIC indicates a lower tensile strength at the lower temperature. However, when these same materials were tested in compression, the average compressive strengths at the two temperatures were approximately the same. ${ }^{4}$ The reason for the apparent decrease in tensile strength with decreased temperature is not known. Additional work to investigate this point is planned.

Elastic proper.ues at $-12^{\circ}$ and $20^{\circ} \mathrm{C}$ have been determined in both direct tension and compression tests. As can be seen in Table 28, the elastic properties under direct tension are very similar to those under compression.

5.1.2.2 SHEAR STRENGTH. Shear tests were conducted on $2 \times 4$-in. cylinders of both unimpregnated con-

Table 29

Shear Tests, Single- and Double-Shear Methods

MMA-Impregnated and Unimpregnated Concrete

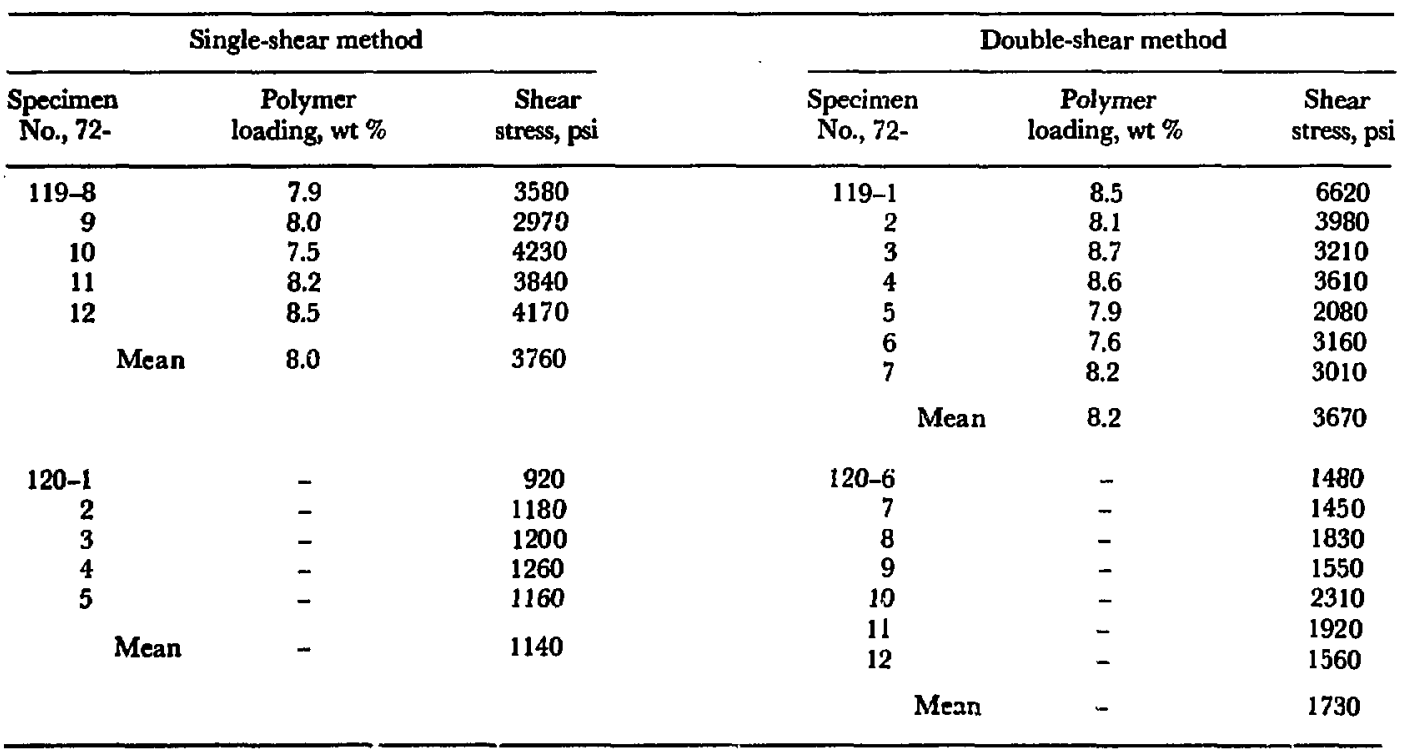

2X4-in. cylinders, tested at room temperature.

MMA = methyl methacrylate, radiation-polymerized under water. 
crete and MMA-impregnated concrete prepared by the underwater radiation-initiated polymerization method. The specimens were tested with use of a USBR standard single-shear apparatus and a newly constructed double-shear apparatus. The latter was developed to eliminate a bending moinent that may be induced when the single-shear apparatus is used. The single-shear and doubleshear methods are illustrated in Figures 22 and 23, and test results are given in Table 29.

MMA-impregnated specimens tested in singleand double-shear tests showed no significant differences. An average ultimate shear stress of 3760 psi was obtained in the single-shear test, and 3670 psi in the doujle-shear test. However, the unimpregnated concrete specimens tested in double shear showed $\approx \mathbf{5 1 \%}$ greater ultimate shear stress than those tested in single shear, averaging 1730 psi in double shear and $1140 \mathrm{psi}$ in single shear.

The orientation and location of large aggregate particles has more effect on shear strength in unimpregnated concrete than in PIC. In addition, PIC has a higher tensile strength which resists the bending moment introduced by the test method. These tests are as close to a pure shear test as could be performed at this time.

Single-shear test results on $60 \mathrm{wt} \%$ styrene $40 \mathrm{wt} \%$ TMPTMA and $70 \mathrm{wt} \% \mathrm{MMA}-30 \mathrm{wt} \%$ TMPTMA impregnated concrete (specimens tested for desalting plant applications) and a comparison with MMA-impregnated concrete are discussed in Section 5.2.1.4.

5.1.2.3 CEEEP. Long-term creep deformation studies made on PIC specimens at room temperature include tests on CP-series specimens under a sustained compressive load of 800 psi, and a highstress test on MMA and chlorostyrene-impregnated specimens under sustained compressive and tensile loads.

(a) 800-PSI COMPRESSIVE CREEP. Results on CP-series specimens under load for periods of 270 to 1500 days are given in Table 30. Creep deformation is given in terms of millionths of an inch per inch under 800-psi load. All tests have been terminated, except for the CP-7 and CP-8 (CP.UA) series. After 1500 days under load, MMA-impregnated specimens show a small negative creep (an elongation in length under the compressive load) ranging from 17 to $25 \mu \mathrm{in}$./in., which with some minor fluctuations has been fairly constant since the test began. The styrene specimens have shown the greatest amount and the most variation of creep deformation, ranging from $267 \mu \mathrm{in}$./in. to a negative creep of $183 \mu \mathrm{in}$./in.; these values are somewhat questionable because the measurements were made on only one gage line. The MMA $10 \mathrm{wt} \%$ TMPTMA spcimens were under test for only 1 year and underwent a very minor creep deformation of 0 and $32 \mu \mathrm{in}$./in. Acrylonitrile specimens were removed from test after 1000 days under load with creep deformation of 28 to $117 \mu \mathrm{in}$./in. Chlorostyrene specimens were removed from test after 1000 days under load with a creep deformation of 31 to $69 \mu \mathrm{in}$./in. Tests of CP-7 (polyester-styrene) and CP-8 (CP-UA, MMA radiation-polymerized under water) specimens are continuing and show creep of $3 \mu \mathrm{in}$./ in. for CP-7 and $28 \mu \mathrm{in}$./in. for CP-8 specimens. Creep measurements on unimpregnated concrete after 1500 days under load show a deformation of $233 \mu \mathrm{in} . / \mathrm{in}$. on the control specimens, $97 \mu \mathrm{in}$./in. on radiation-treated concrete, and $58 \mu \mathrm{in}$./in. on thermally treated concrete.

After completion of the creep study, measurements of compressive strength were made on two specimens of each type of concrete that had been under the 800-psi sustained compressive load, and an unloaded control specimen of each type (Table 31). The compressive strengths of the loaded specimens were comparable to that of the corresponding unloaded control specimen. These results indicate no decrease in strength due to the 800-psi loading over periods of time ranging from 3 to $4 \frac{1}{2}$ years.

(b) HIGH-STRESS TensILE AND COMPRESSIVE CREeP. Results at about $2 \frac{1}{3}$ years under continuous loads from 345 psi tension to 7000 psi compression on PIC and unimpregnated concrete are presented in Table 32. Trends in these tests continue to be the same as those reported in Ref. 4. MMA and chlorostyrene specimens under tensile loads show negative creep (a contraction in length under tension) ranging from a unit deformation ( $\mu$ in./in. per psi) of 0.024 to one of 0.515 . Under the compressive loads, unit deformation of MMA and chlorostyrene specimens generally ranges from about 0.08 $\mu$ in./in.-psi under the low load of $690 \mathrm{psi}$ to about $0.05 \mu \mathrm{in}$./in.-psi under the high load of $7000 \mathrm{psi}$, or a decrease in unit deformation per psi with increasing load. The unit deformation per psi for unimpregnated concrete is nearly the same for the two loadings of 690 and 2313 psi used in this test, 
with possibly a slight increase at the higher loading. In comparing MMA and chlorostyrene specimens with unimpregnated specimens under the same load, the PIC specimens undergo about 5 times less creep at 690 psi and about 7 times less creep at $2313 \mathrm{psi}$. At the high load of $7000 \mathrm{psi}$, the PIC specimens have about 10 times less creep deformation per psi than unimpregnated concrete at 2313 psi.

Negative creep has been observed in PIC specimens only under low tensile and compressive loads and is not considered significant in the design of a structure.
5.1.2.4 flexural Strength of Partially Impreghated Concrete. The flexural strength of conventional concrete beams is limited by the amount of tensile stress that can be carried by the extreme tension fibers. A study was made to determine the effect of polymer impregnation of the extreme fibers on the flexural strength. Conventional concrete beams, $3 \times 5$ in. in cross section and 54 in. long, were partially impregnated with MMA and radiation-polymerized. The bottom surface of one set of bars was impregnated to a depth of $\approx 11 / 4$ in. to determine the effects of polymer impregnation of the tension fibers. Both the top and bottom surfaces of another

Table 30

800-psi Compressive Creep Tests

CP Test Series Specimens

\begin{tabular}{|c|c|c|c|c|c|c|c|c|c|c|}
\hline \multirow{3}{*}{$\begin{array}{l}\text { Sample } \\
\text { No., CP. }\end{array}$} & \multirow[b]{3}{*}{ Monomer } & \multirow{3}{*}{$\begin{array}{c}\text { Polymer } \\
\text { loading, } \\
\text { wt \% }\end{array}$} & \multirow{3}{*}{$\begin{array}{l}\text { Polymerization } \\
\text { method }^{b}\end{array}$} & \multicolumn{7}{|c|}{ Creep strain, $\mu$ in $/$ in. } \\
\hline & & & & \multicolumn{7}{|c|}{ Days under 800-psi compressive load } \\
\hline & & & & 6 & 30 & 90 & 270 & 360 & 1000 & 1500 \\
\hline $1 \mathrm{~A}-7 \mathbf{A}$ & MMA & 5.7 & $\mathbf{R}$ & $34^{\mathrm{c}}$ & $21^{\mathrm{c}}$ & $29 c$ & $3^{c}$ & $17^{\mathrm{c}}$ & 0 & $17^{c, d}$ \\
\hline $1 \mathrm{~A}-7 \mathrm{C}$ & MMA & 5.9 & $\mathbf{R}$ & $42^{c}$ & $54^{c}$ & $38^{\mathrm{c}}$ & $12^{\mathrm{c}}$ & $2^{\mathrm{c}}$ & $25^{c}$ & $33 \mathrm{c}, \mathrm{d}$ \\
\hline 1B-7A & MMA & 6.2 & $\mathbf{T}$ & $8^{c}$ & $25^{c}$ & $49 \mathrm{c}$ & $90^{c}$ & $67 \mathrm{c}$ & $75^{c}$ & $67^{c, d}$ \\
\hline 1B-7B & MMA & 6.2 & $\mathbf{T}$ & $50^{\mathrm{c}}$ & $86^{c}$ & $111^{\mathrm{c}}$ & $84^{\mathrm{e}}$ & $84^{c}$ & $58^{c}$ & $75^{\mathrm{e}, \mathrm{d}}$ \\
\hline $2 . \mathrm{A}-7 \mathrm{~A}$ & $\mathbf{S}$ & 5.6 & $\mathbf{R}$ & 0 & $101^{c}$ & $127^{c}$ & $90^{c}$ & $142^{\mathrm{c}}$ & $92^{c}$ & $183^{c, d}$ \\
\hline $2 A-7 B^{e}$ & $\mathbf{S}$ & 6.0 & $\mathbf{R}$ & 50 & $18 \mathrm{c}$ & 7 & 17 & 18 & 191 & $17^{r, d}$ \\
\hline $2 B-7 B^{e}$ & $\mathbf{S}$ & 5.1 & $\mathbf{T}$ & 66 & 51 & 68 & 156 & 160 & 200 & $267^{d}$ \\
\hline $2 B-7 X e$ & $\mathbf{S}$ & 3.5 & $\mathbf{T}$ & 8 & 43 & 52 & 135 & 148 & 184 & $233^{d}$ \\
\hline 4A-7A & MMA-TMPTMA & 6.2 & $\mathbf{R}$ & $27 \mathrm{e}$ & $\mathbf{0}$ & 12 & 17 & $0^{d}$ & - & - \\
\hline 4A-7B & MMA-TMPTMA & 6.2 & $\mathbf{R}$ & 2 & 32 & 17 & 37 & $32^{d}$ & - & - \\
\hline 5A-7A & $A N$ & 5.7 & $\mathbf{R}$ & 5 & 18 & 28 & 50 & 33 & $39 \mathrm{~d}$ & - \\
\hline 5A-7B & $A \mathbf{N}$ & 5.4 & $\mathbf{R}$ & 20 & 36 & 47 & 67 & 50 & $50 \mathrm{~d}$ & - \\
\hline $5 B-7 A$ & AN & 4.4 & $\mathrm{~T}$ & 0 & 0 & 0 & 66 & 49 & $117^{d}$ & - \\
\hline 5B-7B & $A N$ & 5.4 & $\mathbf{T}$ & 0 & 0 & 0 & 16 & 33 & $28^{d}$ & - \\
\hline $6 A-7 A$ & CS & 6.7 & $\mathbf{R}$ & 0 & 10 & 33 & 33 & 33 & $64^{d}$ & - \\
\hline $6 A-7 B$ & CS & 6.9 & $\mathbf{R}$ & $\mathbf{0}$ & 7 & 49 & 33 & 50 & $69 d$ & - \\
\hline 6B-7A & CS & 6.2 & $\mathbf{T}$ & 0 & 15 & 34 & 34 & 17 & $31^{d}$ & - \\
\hline 6B-7B & CS & 6.5 & $\mathbf{T}$ & 0 & 24 & 50 & 50 & 33 & $67^{d}$ & - \\
\hline $7-7 \mathrm{~A}, 7 \mathrm{~B}$ & S-P & 6.9 & $\mathbf{R}$ & 0 & 0 & 0 & 3 & & & \\
\hline UA-7A, 7B & MMA & 6.9 & $\mathbf{R}$ & 0 & 3 & 17 & 28 & & & \\
\hline $0-7 C, 7 B$ & - & - & - & 77 & 95 & 132 & 157 & 184 & 209 & $233^{d}$ \\
\hline 3A-7A, 7B & - & - & $\mathbf{R}$ & 40 & 64 & 87 & 87 & 91 & 101 & $97^{d}$ \\
\hline 3B-7A, 7B & - & - & $\mathbf{T}$ & 12 & 27 & 31 & 37 & 50 & 50 & $58^{d}$ \\
\hline \multicolumn{11}{|c|}{ 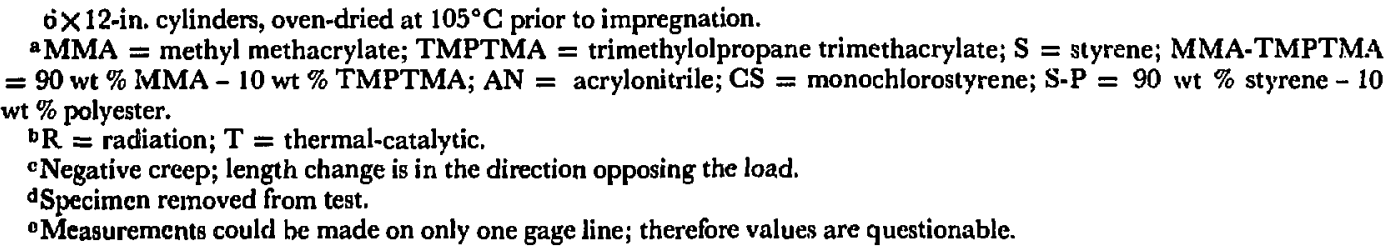 } \\
\hline
\end{tabular}


set of bars were impregnated to determine the effects of polymer impregnation on the tension and compression fibers. A set of unimpregnated bars was used as a control.

The test lrading was applied as shown in Figure 24. The test results indicate an average ultimate load of 1905 pounds for singly (tension fiher) impregnated beams, 1875 pounds for doubly (tension and compression fiber) impregnated beams, and 1610 pounds for unimpregnated beams (see Table 33). The results for doubly impregnated beams are inconclusive, since after the test most of the beams were found to be incompletely impregnated or polymerized. The reason for this is not known.

Tension and compression fiber strain measurements were made during the testing of each beam

Table 31

Compressive Strength of Creep Test Specimens

3 to $4 \frac{1}{2}$ Years Under 800-psi Sustained Compressive Load

\begin{tabular}{|c|c|c|c|c|c|c|}
\hline \multirow[b]{2}{*}{$\begin{array}{l}\text { Specimen } \\
\text { No., CP. }\end{array}$} & \multirow[b]{2}{*}{ Monomera } & \multirow{2}{*}{$\begin{array}{c}\text { Polymer } \\
\text { loading, } \\
\text { wt \% }\end{array}$} & \multirow[b]{2}{*}{$\begin{array}{l}\text { Polymerization } \\
\text { method }^{\mathbf{b}}\end{array}$} & \multirow[b]{2}{*}{$\begin{array}{c}\text { Time } \\
\text { under } \\
\text { load, yr }\end{array}$} & \multicolumn{2}{|c|}{ Compressive strength, psi } \\
\hline & & & & & Loaded specimens & $\begin{array}{c}\text { Unloaded } \\
\text { control specimens }\end{array}$ \\
\hline $1 \mathrm{~A}-7 \mathbf{A}$ & MMA & 5.7 & $\mathbf{R}$ & $41 / 2$ & 21,800 & - \\
\hline 2A-7C & MMA & 5.9 & $\mathbf{R}$ & $4^{1 / 2}$ & 22,800 & - \\
\hline 1A-7B & & 5.7 & $\mathbf{R}$ & & - & \\
\hline 1B-7A & MMA & 6.2 & $\mathbf{T}$ & $41 / 2$ & 19,600 & - \\
\hline 1B-7B & MMA & 6.2 & $T$ & $4^{1 / 2}$ & 19,700 & - \\
\hline $1 B-7 \mathrm{C}$ & MMA & 6.4 & $\mathbf{T}$ & 0 & - & 20,200 \\
\hline $2 A-7 A$ & $\mathbf{S}$ & 5.6 & $\mathbf{R}$ & $41 / 2$ & 17,400 & - \\
\hline $2 A-7 B$ & $\mathbf{S}$ & 6.0 & $\mathbf{R}$ & $41 / 2$ & 16,300 & - \\
\hline $2 A-7 C$ & $\mathbf{s}$ & & $\mathbf{R}$ & & - & 16,600 \\
\hline 2B-7B & $\mathbf{S}$ & 5.1 & $T$ & $4^{1 / 2}$ & 13,500 & - \\
\hline 2B-7X & $\mathbf{S}$ & 3.5 & $\mathbf{T}$ & $4^{1 / 2}$ & 10,800 & - \\
\hline 2B-7C & $\mathbf{s}$ & & $\mathbf{T}$ & & - & - \\
\hline $5 \mathbf{A}-7 \mathbf{A}$ & AN & 5.7 & $\mathbf{R}$ & 3 & 16,900 & - \\
\hline $5 \mathrm{~A}-7 \mathrm{~B}$ & AN & 5.4 & $\mathbf{R}$ & 3 & 18,100 & - \\
\hline $5 \mathrm{~A}-7 \mathrm{C}$ & AN & 4.9 & $\mathbf{R}$ & 0 & - & 16,300 \\
\hline $5 B-7 A$ & AN & 4.4 & $\mathrm{~T}$ & 3 & 7,100 & - \\
\hline 5B-7B & AN & 5.4 & $\mathbf{T}$ & 3 & 7,300 & - \\
\hline $5 B-7 \mathrm{C}$ & AN & 4.7 & $\mathbf{T}$ & 0 & - & 7,800 \\
\hline $6 \mathrm{~A} \cdot 7 \mathrm{~A}$ & CS & 6.7 & $\mathbf{R}$ & 3 & 19,700 & - \\
\hline $6 A-7 B$ & CS & 6.9 & $\mathbf{R}$ & 3 & 19,400 & - \\
\hline $6 \mathrm{~A}-7 \mathrm{C}$ & CS & 7.2 & $\mathbf{R}$ & $\mathbf{0}$ & - & 19,100 \\
\hline $6 \mathrm{~B}-7 \mathrm{~A}$ & CS & 6.2 & $\mathbf{T}$ & 3 & 15,400 & - \\
\hline 6B-7B & CS & 6.5 & $T$ & 3 & 15,600 & - \\
\hline 6B-7C & CS & 7.2 & $T$ & 0 & - & 14,900 \\
\hline $\begin{array}{ll}0 & -7 \mathrm{~B}\end{array}$ & - & - & - & $41 / 3$ & 6,600 & - \\
\hline $\begin{array}{lll}0 & -7 \mathrm{C}\end{array}$ & - & - & - & $4^{1 / 3}$ & 6,500 & - \\
\hline $0-7 A$ & - & - & - & 0 & - & 6,400 \\
\hline $3 \mathrm{~A}-7 \mathrm{~A}$ & - & - & $\mathbf{R}$ & $4^{1 / 3}$ & 6,400 & - \\
\hline 3A-7B & - & - & $\mathbf{R}$ & $41 / 3$ & 6,100 & - \\
\hline $3 \mathrm{~A}-7 \mathrm{C}$ & - & - & $\mathbf{R}$ & 0 & - & 6,000 \\
\hline 3B-7A & - & - & $\mathbf{T}$ & $41 / 3$ & 6,300 & - \\
\hline 3B-7B & - & - & $\mathrm{T}$ & $4^{1 / 3}$ & 5,400 & - \\
\hline 3B-7C & - & - & $\mathrm{T}$ & 0 & - & 6,000 \\
\hline
\end{tabular}

$6 \times 12$-in. cylinders, tested for compressive strength after completion of creep study.

Specimens oven-dried at $105^{\circ} \mathrm{C}$ prior to impregnation .

aMMA = methyl methacrylate; $\mathrm{S}=$ styrene; $\mathrm{AN}=$ acrylonitrile; $\mathrm{CS}=$ monochlorostyrene.

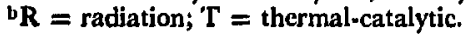


with use of 4-in. strain gages. The neutral axes of the beams were calculated from the strain measurements for each increment of load. The neutral axes of the control beams and the doubly impregnated beams started at the midpoint of the section because the compression and tension strains were equal. As the load increased the neutral axes moved $\approx 0.10$ in. toward the compression fiber. These calculations are based on the assumption that the strain varies linearly across the section. The neutral axes of singly impregnated beams started at a point $2.80 \mathrm{in}$. from the extreme compression fiber and remained in this position until failure. This proves that a transformed section does exist. The following ratios of the modulus of elasticity of impregnated concrete to that of concrete were computed.

\begin{tabular}{cc} 
Specimen No. & $n=E_{\operatorname{lmp}} / E_{\mathrm{g}}$ \\
\hline 1502 & 1.70 \\
1507 & 1.95 \\
1509 & 1.64 \\
1511 & 1.76 \\
1512 & 1.89
\end{tabular}

These ratios are comparable to results found in structural property testing of other materials.

5.1.2.5 Reimforced Polymer-Impreghated Concrete in flexure and SHEAR. Eleven $3 \times 5 \times 54$-in. reinforced concrete beams were tested in flexure. The reinforcing consisted of one No. 4 bar placed longitudinally in the center of the 3-in. dimension on the bottom side of the beam. The bar was placed to allow $1 / 2$ in. clear cover. Five of the beams were unimpregnated controls and six were impregnated with MMA and dipped in PMMA. Polymerization was

Table 32

High-Stress Tensile and Conpressive Creep

Polymer-Impregnated CP-Type Concrete

\begin{tabular}{|c|c|c|c|c|c|c|c|c|c|c|}
\hline \multirow[b]{3}{*}{ Monomera } & \multirow{3}{*}{$\begin{array}{l}\text { Cylinder } \\
\text { No., CP. }\end{array}$} & \multirow{3}{*}{$\begin{array}{c}\text { Polymer } \\
\text { loading, } \\
\text { wt } \%\end{array}$} & \multirow{3}{*}{$\begin{array}{l}\text { Sustained } \\
\text { load, psi }\end{array}$} & \multicolumn{7}{|c|}{ Creep deformation, $\mu$ in./in.-psi } \\
\hline & & & & \multicolumn{7}{|c|}{ Days under load } \\
\hline & & & & 8 & 31 & 70 & 261 & 562 & 744 & 836 \\
\hline \multirow{2}{*}{$\begin{array}{l}\text { Tensile creep } \\
\text { MMA }\end{array}$} & & & & & & & & & & \\
\hline & $\begin{array}{r}3 \\
13\end{array}$ & $\begin{array}{l}4.6 \\
4.6\end{array}$ & $\begin{array}{l}178 \\
345\end{array}$ & $\begin{array}{l}0.230^{b} \\
0.049^{b}\end{array}$ & $\begin{array}{l}0.051^{b} \\
0.023^{b}\end{array}$ & $\begin{array}{l}0.185^{b} \\
0.069^{b}\end{array}$ & $\begin{array}{l}0.191^{b} \\
0.049^{b}\end{array}$ & $\begin{array}{l}0.398^{b} \\
0.181^{b}\end{array}$ & $\begin{array}{l}0.421^{b} \\
0.205^{b}\end{array}$ & $\begin{array}{l}0.515^{b} \\
0.242^{b}\end{array}$ \\
\hline CS & $\begin{array}{l}4 \\
8\end{array}$ & $\begin{array}{l}6.1 \\
6.1\end{array}$ & $\begin{array}{l}178 \\
345\end{array}$ & $\begin{array}{l}0.090^{b} \\
0.003^{b}\end{array}$ & $\begin{array}{l}0.090^{b} \\
0\end{array}$ & $\begin{array}{l}0.191^{b} \\
0.052^{b}\end{array}$ & $\begin{array}{l}0.163^{b} \\
0.026^{b}\end{array}$ & $\begin{array}{l}0.234^{b} \\
0.024^{b}\end{array}$ & $\begin{array}{l}0.164^{b} \\
0.024^{b}\end{array}$ & $\begin{array}{l}0.257^{b} \\
0.024^{b}\end{array}$ \\
\hline Control & $\begin{array}{l}5 \\
6\end{array}$ & - & $\begin{array}{r}59 \\
178\end{array}$ & $\begin{array}{l}0.424 \\
0.051\end{array}$ & $\begin{array}{l}0.288 \\
0.191\end{array}$ & $\begin{array}{l}0.492 \\
0.258\end{array}$ & $\begin{array}{l}0.271 \\
0.331\end{array}$ & $\overline{0.257}$ & - & $\overline{0.164}$ \\
\hline $\begin{array}{l}\text { Compressive cre } \\
\text { MMA }\end{array}$ & $\begin{array}{l}11 \\
20 \\
31 \\
32 \\
37 \\
44\end{array}$ & $\begin{array}{l}5.4 \\
5.5 \\
5.4 \\
5.4 \\
5.4 \\
5.4\end{array}$ & $\begin{array}{r}690 \\
690 \\
2313 \\
2313 \\
7000 \\
7000\end{array}$ & $\begin{array}{l}0.006 \\
0 \\
0.015 \\
0.014 \\
0.019 \\
0.019\end{array}$ & $\begin{array}{l}0.011 \\
0.030 \\
0.023 \\
0.022 \\
0.025 \\
0.027\end{array}$ & $\begin{array}{l}0.039 \\
0.068 \\
0.036 \\
0.033 \\
0.035 \\
0.034\end{array}$ & $\begin{array}{l}0.029 \\
0.054 \\
0.038 \\
0.033 \\
0.041 \\
0.039\end{array}$ & $\begin{array}{l}0.066 \\
0.079 \\
0.049 \\
0.043 \\
0.049 \\
0.047\end{array}$ & $\begin{array}{l}0.072 \\
0.070 \\
0.054 \\
0.047 \\
0.051 \\
0.048\end{array}$ & $\begin{array}{l}0.085 \\
0.085 \\
0.058 \\
0.054 \\
0.054 \\
0.049\end{array}$ \\
\hline CS & $\begin{array}{l}12 \\
14 \\
15 \\
16 \\
17 \\
18\end{array}$ & $\begin{array}{l}6.1 \\
6.2 \\
6.2 \\
6.1 \\
6.5 \\
6.5\end{array}$ & $\begin{array}{r}690 \\
690 \\
2313 \\
2313 \\
7000 \\
7000\end{array}$ & $\begin{array}{l}0.049 \\
0.007 \\
0.010 \\
0.013 \\
0.014 \\
0.016\end{array}$ & $\begin{array}{l}0.074 \\
0.019 \\
0.022 \\
0.018 \\
0.020 \\
0.022\end{array}$ & $\begin{array}{l}0.074 \\
0.025 \\
0.024 \\
0.024 \\
0.022 \\
0.025\end{array}$ & $\begin{array}{l}0.055 \\
0.017 \\
0.032 \\
0.027 \\
0.030 \\
0.031\end{array}$ & $\begin{array}{l}0.127 \\
0.060 \\
0.047 \\
0.043 \\
0.041 \\
0.040\end{array}$ & $\begin{array}{l}0.121 \\
0.060 \\
0.050 \\
0.049 \\
0.045 \\
0.043\end{array}$ & $\begin{array}{l}0.163 \\
0.085 \\
0.067 \\
0.054 \\
0.049 \\
0.045\end{array}$ \\
\hline Control & $\begin{array}{l}22 \\
23 \\
25 \\
24\end{array}$ & $\begin{array}{l}- \\
- \\
-\end{array}$ & $\begin{array}{r}690 \\
690 \\
2313 \\
2313\end{array}$ & $\begin{array}{l}0.091 \\
0.084 \\
0.131 \\
0.134\end{array}$ & $\begin{array}{l}0.139 \\
0.127 \\
0.198 \\
0.198\end{array}$ & $\begin{array}{l}0.168 \\
0.155 \\
0.239 \\
0.243\end{array}$ & $\begin{array}{l}0.271 \\
0.258 \\
0.336 \\
0.336\end{array}$ & $\begin{array}{l}0.368 \\
0.356 \\
0.336 \\
0.400\end{array}$ & $\begin{array}{l}0.380 \\
0.405 \\
0.416 \\
0.425\end{array}$ & $\begin{array}{l}0.380 \\
0.423 \\
0.423 \\
0.432\end{array}$ \\
\hline
\end{tabular}

$4 \frac{1}{2} \times 12$-in. cylinders overı-dried at $150^{\circ} \mathrm{C}$ prior to impregnation.

Radiation polymerization.

- MMA = methyl methacrylate; CS = chlorostyrene.

vegative creep; length change is in direction opposing applied lcad. 


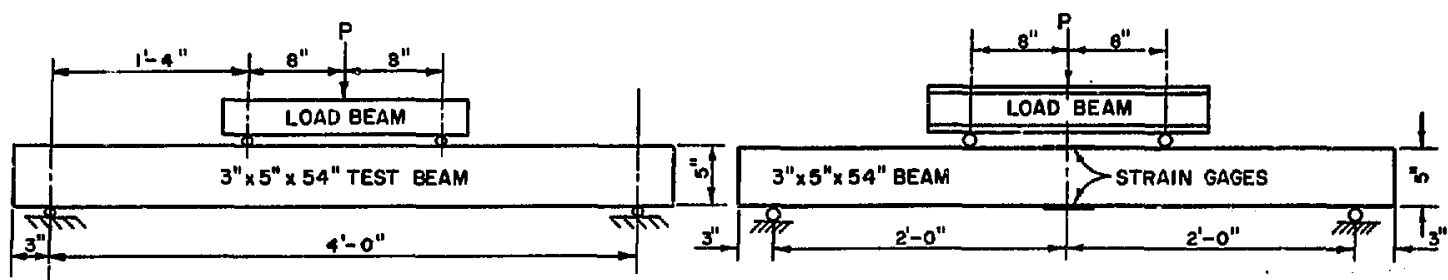

Figure 24. Schematic diagram of flexure test for partially impregnated $3 \times 5 \times 54$-in. beams.

Figure 25. Schematic diagram of flexure test for steel-reinforced $3 \times 5 \times 54$-in. beams.

Table 33

Partially Impregnated Concrete in Flexure

Ultimate Load

\begin{tabular}{|c|c|c|c|c|c|}
\hline \multicolumn{2}{|c|}{ Unimpregnated controls } & \multicolumn{2}{|c|}{$\begin{array}{l}\text { Singly impregnated } \\
\text { (tension fiber) }\end{array}$} & \multicolumn{2}{|c|}{$\begin{array}{l}\text { Doubly impregnated } \\
\text { (tension and compression fibers) }\end{array}$} \\
\hline $\begin{array}{l}\text { Specimen } \\
\text { No., 6.1.5. }\end{array}$ & $\begin{array}{l}\text { Ultimate } \\
\text { load, lb }\end{array}$ & $\begin{array}{l}\text { Specimen } \\
\text { No., 6.1.5- }\end{array}$ & $\begin{array}{l}\text { Ultimate } \\
\text { load, lb }\end{array}$ & $\begin{array}{l}\text { Specimen } \\
\text { No., 6.1.5. }\end{array}$ & $\begin{array}{l}\text { Ultimate } \\
\text { load, lb }\end{array}$ \\
\hline $\begin{array}{l}1513 \\
1514 \\
1515 \\
1516 \\
1517\end{array}$ & $\begin{array}{l}1100 \\
1230 \\
1095 \\
1135 \\
1250\end{array}$ & $\begin{array}{l}1502 \\
1507 \\
1509 \\
1511 \\
1512\end{array}$ & $\begin{array}{l}2135 \\
1750 \\
1935 \\
1945 \\
1755\end{array}$ & $\begin{array}{l}1503 \\
1504 \\
1505 \\
1508 \\
1510\end{array}$ & $\begin{array}{l}1240^{\mathrm{a}} \\
2000 \\
1110^{\mathrm{a}} \\
1580^{\mathrm{a}} \\
1750\end{array}$ \\
\hline Mean & 1160 & & 1905 & & 1875 \\
\hline
\end{tabular}

$3 \times 5 \times 54-i n$. beams partially impregnated with MMA, radiation polymerized. Specimens singly impregnated on bottom surfaces and doubly impregnated on top and bottom surfaces, to a depth of $1^{1 \frac{14}{4}}$ in.

-Beams incompletely impregnated or polymerized; excluded from mean.

Table 34

Reinforced Concrete Beams in Flexure

\begin{tabular}{|c|c|c|c|c|c|c|}
\hline $\begin{array}{c}\text { Specimen } \\
\text { No., 6.1.6- }\end{array}$ & $\begin{array}{c}\text { Polymer } \\
\text { loading, wt \% }\end{array}$ & $\begin{array}{l}\text { Ultimate } \\
\text { load, lb }\end{array}$ & $\begin{array}{c}\text { Ultimate } \\
\text { compressive } \\
\text { strain, in./in. }\end{array}$ & $\begin{array}{l}\text { Ultimate } \\
\text { monient, } \\
\text { in.-lb }\end{array}$ & $\begin{array}{c}\text { Modulus of } \\
\text { eiasticity } \\
\text { (from av strain), } \\
10^{6} \mathrm{psi}\end{array}$ & $\begin{array}{l}\text { Modulus of } \\
\text { rupture, psi }\end{array}$ \\
\hline $\begin{array}{l}1602 \\
1603 \\
1604 \\
1605 \\
1606 \\
1607\end{array}$ & $\begin{array}{l}6.7 \\
6.9 \\
7.0 \\
7.3 \\
7.4 \\
6.8\end{array}$ & $\begin{array}{l}6,600 \\
6,600 \\
7,320 \\
6,700 \\
6,750 \\
6,560\end{array}$ & $\begin{array}{l}0.0023 \\
0.0023 \\
0.0020 \\
0.0033 \\
0.0022 \\
0.0027\end{array}$ & $\begin{array}{l}52,80 i \\
52,800 \\
58,560 \\
53,600 \\
54,000 \\
52,480\end{array}$ & $\begin{array}{l}6.43 \\
6.62 \\
6.49 \\
6.43 \\
6.52 \\
6.49\end{array}$ & $\begin{array}{l}4,220 \\
4,220 \\
4,680 \\
4,290 \\
4,320 \\
4,200\end{array}$ \\
\hline Mean & 7.0 & 6,760 & 0.0025 & 54,040 & 6.50 & 4,320 \\
\hline $\begin{array}{l}1608 \\
1609 \\
1610 \\
1611 \\
1612\end{array}$ & $\begin{array}{l}\bar{z} \\
\bar{z} \\
\overline{-}\end{array}$ & $\begin{array}{l}5,650 \\
5,275 \\
5,430 \\
5,450 \\
5,550\end{array}$ & $\begin{array}{l}0.0023 \\
0.0042 \\
0.0029 \\
0.0034 \\
0.0020\end{array}$ & $\begin{array}{l}45,200 \\
42,200 \\
43,400 \\
43,600 \\
44,400\end{array}$ & $\begin{array}{l}2.28 \\
2.26 \\
2.26 \\
2.12 \\
2.02\end{array}$ & $\begin{array}{l}3,620 \\
3,380 \\
3,480 \\
3,490 \\
3,550\end{array}$ \\
\hline Mean & - & 5,470 & 0.0029 & 43,760 & 2.19 & 3,500 \\
\hline
\end{tabular}

Monomer, MMA with PMMA dip coat.

Radiation-induced polymerization.
Specinens, $3 \times 5 \times 54$-in. beams. Test temperature, $20^{\circ} \mathrm{C}$. 


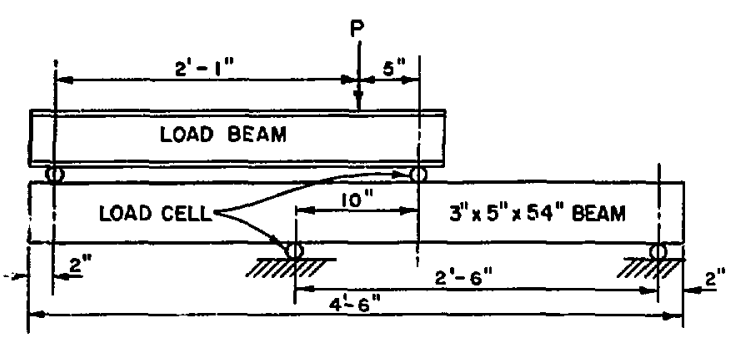

Figure 26. Schematic diagram of shear test for steel-reinforced $3 \times 5 \times 54$-in. beams. induced by radiation. The test loading was applied as shown in Figure 25. Four-in.-gage-length strain gages were placed longitudinally on the centerlines of the top and bottom surfaces to record strain. Results of the tests are shown in Table 34.

The ultimate moment of $3 \times 5 \times 54$-in. beams in flexure was checked in accordance with ACI Code 318-63. A measured yield strength for the steel reinforcement of $\mathbf{4 8} \mathrm{ksi}$ was used. From this check it was determined that the test beams were inadequately reinforced. Consequently the reinforcement rather than the concrete had been tested.

Table 35

Reinforced Concrete Beams in Shear

\begin{tabular}{|c|c|c|c|c|c|}
\hline $\begin{array}{l}\text { Specimen } \\
\text { No., } 6.1 .6\end{array}$ & $\begin{array}{c}\text { Polymer } \\
\text { loading, wt \% }\end{array}$ & $\begin{array}{l}\text { Ultimate } \\
\text { load, lb }\end{array}$ & $\begin{array}{l}\text { Ultimate } \\
\text { shear, lb }\end{array}$ & $\begin{array}{l}\text { Shear } \\
\text { stress, psi }\end{array}$ & $\begin{array}{l}\text { Ultimate } \\
\text { moment, in.-lb }\end{array}$ \\
\hline $\begin{array}{l}1621 \\
1622 \\
1623 \\
1626 \\
1627\end{array}$ & $\begin{array}{l}6.6 \\
6.7 \\
6.7 \\
6.6 \\
7.4\end{array}$ & $\begin{array}{l}15,860 \\
15,840 \\
16,480 \\
16,340 \\
15,200\end{array}$ & $\begin{array}{l}10,570 \\
10,560 \\
10,990 \\
10,890 \\
10,130\end{array}$ & $\begin{array}{l}830 \\
830 \\
860 \\
855 \\
795\end{array}$ & $\begin{array}{l}52,870 \\
52,800 \\
54,930 \\
54,470 \\
50,670\end{array}$ \\
\hline Mean & 6.8 & 15,940 & 10,630 & 835 & 53,150 \\
\hline $\begin{array}{l}1628 \\
1629 \\
1630 \\
1631 \\
1632\end{array}$ & $\begin{array}{l}- \\
- \\
- \\
-\end{array}$ & $\begin{array}{l}12,200 \\
10,500 \\
11,500 \\
10,220 \\
11,420\end{array}$ & $\begin{array}{l}8,130 \\
7,000 \\
7,670 \\
6,810 \\
7,610\end{array}$ & $\begin{array}{l}640 \\
550 \\
600 \\
535 \\
595\end{array}$ & $\begin{array}{l}40,670 \\
35,000 \\
38,330 \\
34,070 \\
33,070\end{array}$ \\
\hline Mean & - & 11,170 & 7,440 & & 37,230 \\
\hline \multicolumn{3}{|c|}{$\begin{array}{l}\text { Monomer, MMA with PMMA dip coat. } \\
\text { Radiation-induced polymerization. }\end{array}$} & & \multicolumn{2}{|c|}{$\begin{array}{l}\text { Specimens, } 3 \times 5 \times 54 \text {-in. beams. } \\
\text { Test temperature, } 20^{\circ} \mathrm{C} \text {. }\end{array}$} \\
\hline
\end{tabular}

Table 36

Flexure Tests

MMA-Impregnated Conurete

\begin{tabular}{ccccc}
\hline $\begin{array}{c}\text { Specimen } \\
\text { No., 6.1.6- }\end{array}$ & $\begin{array}{c}\text { Polymer } \\
\text { loading, wt \% }\end{array}$ & $\begin{array}{c}\text { Ultimate } \\
\text { load, lb }\end{array}$ & $\begin{array}{c}\text { Modulus of } \\
\text { rupture, psi }\end{array}$ & $\begin{array}{c}\text { Modulus of } \\
\text { elasticity, } \\
10^{6} \text { psi }\end{array}$ \\
\hline 1641 & 8.0 & 5830 & 2270 & 6.6 \\
1642 & 8.3 & 5325 & 2070 & 6.1 \\
1643 & 8.1 & 5165 & 2010 & 6.1 \\
1644 & 7.5 & 5230 & 2030 & 6.5 \\
Mean & 8.0 & 5390 & 2100 & 6.3 \\
1645 & - & 2155 & 840 & 4.2 \\
1646 & - & 2180 & 840 & 3.9 \\
Mean & & 2168 & 840 & 4.1 \\
\hline
\end{tabular}

Radiation-induced polymerization.

Specimens, $3 \times 3 \times 16$-in. beams.

Test temperature, $21^{\circ} \mathrm{C}$. 
Ten $3 \times 5 \times 54$-in. reinforced concrete beams were tested in shear. A No. 4 reinforcing rod was placed at the top and bottom of each beam. The steel reinforcement was placed to allow $1 / 2$ in. clear cover. MMA with a PMMA dip coat was used to impregnate five of the beams, and polymerization was induced by radiation. Five unimpregnated beams were used as controls. The test loading was applied as shown in Figure 26. As indicated in the figure, the shear load applied to the beam was determined by load cells. Test gesulis are given in Table 35. All the controls failed in shear. However, all the impregnated specimens failed in flexure. The loading setup will be revised in an attempt to produce shear failure in the impregnated specimens.

Additional specimens $-3 \times 3 \times 16$-in. unreinforced bars and $3 \times 6$-in. cylinders - were prepared to determine the basic properties of unreinforced concrete for comparison with the reinforced concrete. Four impregnated and two unimpregnated bars were tested (see Table 36). Six impregnated and six unimpregnated $3 \times 6$-in. companion cylinders were also tested. Three of each type were tested under compression and three under direct tension. Table 37 shows the results of these tests.

5.1.2.6 Fatigue TESTS. A fatigue-testing machine was installed, checked out, and put into operation. Fatigue tests were started on six $3 \times 5 \times 54$-in. concrete beams. Three of the beams were unimpregnatd controls and three were impregnated with MMA. Polymerization was induced by radiation. Results are not yet available.

5.1.3 Durability Properties of Parfially Impregnated Concrele. Partially impregnated concrete is under investigation as a less costly alternative to fully impregnated concrete in applications where durability rather than high strength is required. The monomer should effectively seal the surface and penetrate deeply enough to prevent separation of the impregnated layer and premature failure. Viscous monomer systems are used because penetration depths are more easily controlled, voids in the penetrated portion remain filled, and monomer losses due to evaporation and drainage during the time between impregnation and complete polymerization are lower.

The preparation of partially impregnated concrete has been discussed in Refs. 2 to 4 . The first series of partial impregnation tests utilized epoxyand polyester-styrene monomer mixtures. The specimens were impregnated to deptins of $1 / 16,1 / \%$, and $1 / 4 \mathrm{in}$. Difficulties were encountered in obtain- ing uniform penetrations within the desired closely spaced depths. Work on developing better systems for controlled penetration continued with a second series of tests using polyester-styrene monomer and PMMA prepolymer. A third series of tests was started to evaluate the effects that the use of highpressure steam-cured concrete and high-entrainedair concrete might have on the durability of partially impregnated concrete.

First Test Series. This series is nearing completion, with only the sulfate attack tests continuing. Freeze-thaw tests were completed and the results incorporated in the Fourth Topical Report.4

The test for resistance to $15 \% \mathrm{HCl}$ was concluded after 940 days of exposure to the acid (see Table 38). Specimens were removed from test and compressive strengths were determined. After 940 days of exposure, weight losses of partially impregnated specimens ranged from about 6 to $22 \%$ as compared with a weight loss of $>25 \%$ at 257 days for unimpregnated concrete. Although these specimens were exposed to acid for me re than $3 \frac{1 / 2}{2}$ times

Table 37

Compressive and Direct Tensile Strength Tests

MMA-Impregnated Concrete

\begin{tabular}{cccr}
\hline $\begin{array}{c}\text { Specimen } \\
\text { No., } \\
6.1 .6-\end{array}$ & $\begin{array}{c}\text { Polymer } \\
\text { loading, } \\
\text { wt } \%\end{array}$ & Test & $\begin{array}{c}\text { Strength, } \\
\text { psi }\end{array}$ \\
\hline 1651 & 7.3 & Tension & 1,170 \\
1653 & 7.6 & Tension & 1,310 \\
1656 & 7.5 & Tension & 1,130 \\
Mean & 7.5 & & 1,200 \\
1657 & - & Tension & 330 \\
1658 & - & Tension & 340 \\
1659 & - & Tension & 360 \\
Mean & & & 350 \\
1652 & 7.6 & Compression & 19,500 \\
1654 & 7.4 & Compression & 18,400 \\
1655 & 7.8 & Compression & 20,900 \\
Mean & 7.6 & & 19,600 \\
1660 & - & & \\
1661 & - & Compression & 4,580 \\
1662 & - & Compression & 4,810 \\
Mean & & & 4,500 \\
& & & 4,630 \\
\hline
\end{tabular}

Radiation-induced polymerization.

Specimens, 3-in.-diam $\times 6$-in.-long cylinders.

Test temperature, $21^{\circ} \mathrm{C}$. 
Table 38

Resistance to $15 \% \mathrm{HCl}$

Partially Impregnated Concrete - First Test Series

\begin{tabular}{|c|c|c|c|c|c|c|c|}
\hline $\begin{array}{l}\text { Specimen } \\
\text { No., } \\
\text { CP-DP- }\end{array}$ & Monomer & $\begin{array}{l}\text { Nominal depth } \\
\text { of penetration, } \\
\text { in. }\end{array}$ & $\begin{array}{l}\text { Polymer } \\
\text { loading, } \\
\text { wt \% }\end{array}$ & $\begin{array}{c}\text { Water } \\
\text { absorption, } \\
\text { wt \% }\end{array}$ & $\begin{array}{c}\text { Acid } \\
\text { exposure, } \\
\text { days }\end{array}$ & $\begin{array}{l}\text { Weight } \\
\text { loss, \% }\end{array}$ & $\begin{array}{c}\text { Compressive } \\
\text { strength, }^{\mathrm{a}} \\
\text { psi }^{-}\end{array}$ \\
\hline 53 & - & - & - & 6.8 & 259 & $27.3^{b}$ & - \\
\hline 43 & - & - & - & 6.9 & 259 & $35.2^{\mathrm{b}}$ & - \\
\hline $\begin{array}{r}6 \\
45\end{array}$ & $\begin{array}{l}\text { E-S } \\
\text { E-S }\end{array}$ & $\begin{array}{l}1 / 6 \\
3 / 66\end{array}$ & $\begin{array}{l}1.9 \\
2.0\end{array}$ & $\begin{array}{l}3.1 \\
3.2\end{array}$ & $\begin{array}{l}940 \\
940\end{array}$ & $\begin{array}{r}10.3 \\
9.5\end{array}$ & $\begin{array}{l}310 \\
300\end{array}$ \\
\hline $\begin{array}{l}38 \\
44\end{array}$ & $\begin{array}{l}\text { E-S } \\
\text { E-S }\end{array}$ & $\begin{array}{l}3 / 8 \\
3 / 6\end{array}$ & $\begin{array}{l}2.1 \\
2.1\end{array}$ & $\begin{array}{l}4.4 \\
4.5\end{array}$ & $\begin{array}{l}940 \\
940\end{array}$ & $\begin{array}{l}18.0 \\
18.4\end{array}$ & $\begin{array}{l}200 \\
210\end{array}$ \\
\hline $\begin{array}{l}33 \\
40\end{array}$ & $\begin{array}{l}\text { E-S } \\
\text { E-S }\end{array}$ & $\begin{array}{l}1 / 4 \\
1 / 4\end{array}$ & $\begin{array}{l}2.0 \\
2.0\end{array}$ & $\begin{array}{l}3.9 \\
4.8\end{array}$ & $\begin{array}{l}940 \\
940\end{array}$ & $\begin{array}{l}11.3 \\
22.4\end{array}$ & $\begin{array}{l}290 \\
180\end{array}$ \\
\hline $\begin{array}{r}1 \\
28\end{array}$ & $\begin{array}{l}\text { PE-S } \\
\text { PE-S }\end{array}$ & $\begin{array}{l}1 / 16 \\
1 / 66\end{array}$ & $\begin{array}{l}1.1 \\
1.5\end{array}$ & $\begin{array}{l}3.0 \\
3.7\end{array}$ & $\begin{array}{l}940 \\
940\end{array}$ & $\begin{array}{l}20.5 \\
14.9\end{array}$ & $\begin{array}{l}210 \\
230\end{array}$ \\
\hline $\begin{array}{r}8 \\
48\end{array}$ & $\begin{array}{l}\text { PE-S } \\
\text { PE-S }\end{array}$ & $\begin{array}{l}1 / 8 \\
1 / 8\end{array}$ & $\begin{array}{l}1.6 \\
1.7\end{array}$ & $\begin{array}{l}0.6 \\
1.7\end{array}$ & $\begin{array}{l}940 \\
940\end{array}$ & $\begin{array}{l}8.4 \\
9.2\end{array}$ & $\begin{array}{l}270 \\
250\end{array}$ \\
\hline $\begin{array}{l}29 \\
35\end{array}$ & $\begin{array}{l}\text { PE-S } \\
\text { PE-S }\end{array}$ & $\begin{array}{l}1 / 4 \\
1 / 4\end{array}$ & $\begin{array}{l}1.8 \\
1.9\end{array}$ & $\begin{array}{l}1.1 \\
0.3\end{array}$ & $\begin{array}{l}940 \\
940\end{array}$ & $\begin{array}{l}9.3 \\
6.5\end{array}$ & $\begin{array}{l}290 \\
320\end{array}$ \\
\hline $\begin{array}{l}3 \times 6 \text {-in. } \\
\text { Radiati } \\
\text { E-S }=0\end{array}$ & $\begin{array}{l}\text { ders oven- } \\
\text { itiated poly }\end{array}$ & $\begin{array}{l}\text { dization. } \\
\text { rizat }\end{array}$ & & \multicolumn{4}{|c|}{$\begin{array}{l}\text { a After exposure to } \mathrm{HCl} \text { for } 940 \text { days. } \\
\text { bFailed (weight loss }>25 \% \text { ), removed from test. }\end{array}$} \\
\hline
\end{tabular}

Table 39

Resistance to Sulfate Attack

Partially Impregnated Concrete - First Test Series

\begin{tabular}{lcccc}
\hline Specimen No. & Monomer & $\begin{array}{c}\text { Nominal depth } \\
\text { of penetration, in. }\end{array}$ & Test cycles, days & Net expansion, \% \\
\hline GP-DP-49 & - & - & 908 & 0.456 \\
CP-DP-50 & - & - & 908 & 0.450 \\
CP-DP-20 & E-S & $1 / 16$ & 908 & 0.162 \\
CP-DP-11 & E-S & $1 / 16$ & 908 & 0.166 \\
CP-DP-39 & E-S & $1 / 8$ & 908 & 0.126 \\
CP-DP-12 & E-S & $1 / 8$ & 908 & 0.098 \\
CP-DP-24 & E-S & $1 / 4$ & 908 & 0.498 \\
CP-DP-43 & E-S & $1 / 4$ & 908 & 0.204 \\
CP-DP-22 & PE-S & $1 / 16$ & 908 & 0.534 \\
CP-DP-15 & PE-S & $1 / 16$ & 908 & 0.340 \\
CP-DP-2 & PE-S & $1 / 6$ & 908 & 0.204 \\
CP-DP-34 & PE-S & $1 / 8$ & 908 & 0.084 \\
CP-DP-9 & PE-S & $1 / 4$ & 908 & 0.080 \\
CP-DP-26 & PE-S & $1 / 4$ & 908 & 0.074 \\
\hline
\end{tabular}

$3 \times 6$-in, specimens oven-dried at $150^{\circ} \mathrm{C}$ prior to impregnation.

Radiation-initiated polymerization.

E-S = epoxy styrene; PE-S = polyester-styrene. 
Table 40

Compressive Strength

Partially Impregnated Concrete - Second Test Series

\begin{tabular}{clccccc}
\hline $\begin{array}{c}\text { Specimen } \\
\text { No., } \\
\text { CP-DP- }\end{array}$ & Polymer & $\begin{array}{c}\text { Nominal depth } \\
\text { of penetration, } \\
\text { in. }\end{array}$ & $\begin{array}{c}\text { Polymer } \\
\text { loading, wt \% }\end{array}$ & $\begin{array}{c}\text { Water } \\
\text { absorption, \% }\end{array}$ & $\begin{array}{c}\text { Compressive } \\
\text { strength, psi }\end{array}$ & $\begin{array}{c}\text { Modulus of } \\
\text { elasticity, } \\
10^{6} \text { psi }\end{array}$ \\
\hline 121 & PE-S & $1 / 2$ & 5.4 & 0.2 & 13,900 & 5.4 \\
123 & PE-S & $1 / 2$ & 5.5 & 0.2 & 14,400 & 5.7 \\
111 & PE-S & $3 / 6$ & 3.4 & 0.4 & 8,600 & 4.3 \\
116 & PE-S & $3 / 8$ & 3.6 & 0.3 & 9,600 & 4.4 \\
114 & PE-S & $1 / 4$ & 2.8 & 0.6 & 7,300 & 4.1 \\
120 & PE-S & $1 / 4$ & 3.1 & 0.7 & 3,300 & 3.8 \\
117 & PMMA & $1 / 2$ & 5.0 & 0.2 & 13,500 & 5.7 \\
119 & PMMA & $1 / 2$ & 5.3 & 0.1 & 13,900 & 5.3 \\
105 & PMMA & $3 / 6$ & 5.1 & 0.3 & 10,700 & 4.7 \\
106 & PMMA & $3 / 4$ & 3.9 & 0.6 & 7,700 & 4.4 \\
103 & PMMA & $1 / 4$ & 4.5 & 0.1 & 10,400 & 5.1 \\
104 & PMMA & $1 / 4$ & 4.7 & 0.1 & 11,200 & 5.0 \\
112 & - & - & - & - & 4,600 & 3.0 \\
\hline
\end{tabular}

$3 \times 6$-in. specimens oven-dried at $105^{\circ} \mathrm{C}$.

$\mathrm{PE}-\mathrm{S}=50 \mathrm{wt} \%$ polyester (Plaskon) - $50 \mathrm{wt} \%$ styrene; viscosity, $\approx 70 \mathrm{cP}$.

$\mathbf{P M M A}=\mathbf{P M M A}$ prepolymer, produced by irradiating MMA to a viscosity of $\approx 70 \mathrm{cP}$.

Table 41

Resistance to Freezing and Thawing

Partially Impregnated Concrete - Second Test Series

\begin{tabular}{|c|c|c|c|c|c|c|}
\hline $\begin{array}{l}\text { Specimen } \\
\text { No., } \\
\text { CP-DP. }\end{array}$ & Polymer & $\begin{array}{l}\text { Nominal depth } \\
\text { of penetration, } \\
\text { in. }\end{array}$ & $\begin{array}{c}\text { Polymer } \\
\text { loading, wt \% }\end{array}$ & $\begin{array}{c}\text { Water } \\
\text { absorption, \% }\end{array}$ & $\begin{array}{l}\text { Number } \\
\text { of cycles }\end{array}$ & $\begin{array}{l}\text { Weight } \\
\text { loss, \% }\end{array}$ \\
\hline $\begin{array}{l}83 \\
95\end{array}$ & $\begin{array}{l}\text { PE-S } \\
\text { PE-S }\end{array}$ & $\begin{array}{l}1 / 2 \\
1 / 2\end{array}$ & $\begin{array}{l}5.3 \\
6.0\end{array}$ & $\begin{array}{l}0.2 \\
0.2\end{array}$ & $\begin{array}{l}1900 \\
1900\end{array}$ & $\begin{array}{l}1.5^{2} \\
0.5^{2}\end{array}$ \\
\hline $\begin{array}{l}79 \\
81\end{array}$ & $\begin{array}{l}\text { PE-S } \\
\text { PE-S }\end{array}$ & $\begin{array}{l}3 / 6 \\
3 / 6\end{array}$ & $\begin{array}{l}4.0 \\
3.5\end{array}$ & $\begin{array}{l}0.3 \\
0.4\end{array}$ & $\begin{array}{l}1900 \\
1900\end{array}$ & $\begin{array}{l}2.0^{n} \\
1.5^{n}\end{array}$ \\
\hline $\begin{array}{l}80 \\
93\end{array}$ & $\begin{array}{l}\text { PE-S } \\
\text { PE-S }\end{array}$ & $\begin{array}{l}1 / 4 \\
1 / 4\end{array}$ & $\begin{array}{l}3.0 \\
3.0\end{array}$ & $\begin{array}{l}0.4 \\
0.3\end{array}$ & $\begin{array}{l}1900 \\
1900\end{array}$ & $\begin{array}{l}3.0^{2} \\
1.0^{\circ}\end{array}$ \\
\hline $\begin{array}{r}91 \\
100\end{array}$ & $\begin{array}{l}\text { PMM. } \\
\text { PMMA }\end{array}$ & $\begin{array}{l}1 / 2 \\
1 / 2\end{array}$ & $\begin{array}{l}5.6 \\
4.9\end{array}$ & $\begin{array}{l}0.2 \\
0.3\end{array}$ & $\begin{array}{l}1900 \\
1900\end{array}$ & $\begin{array}{l}0 \\
1.5\end{array}$ \\
\hline $\begin{array}{l}74 \\
77\end{array}$ & $\begin{array}{l}\text { PMMA } \\
\text { PMMA }\end{array}$ & $\begin{array}{l}\text { 36 } \\
\text { 解 }\end{array}$ & $\begin{array}{l}5.3 \\
4.5\end{array}$ & $\begin{array}{l}0.2 \\
0.5\end{array}$ & $\begin{array}{l}1900^{\mathrm{b}} \\
1900^{\mathrm{b}}\end{array}$ & $\begin{array}{l}1.0 \\
7.0\end{array}$ \\
\hline $\begin{array}{l}75 \\
88\end{array}$ & $\begin{array}{l}\text { PMMA } \\
\text { PMMA }\end{array}$ & $\begin{array}{l}1 / 4 \\
1 / 4\end{array}$ & $\begin{array}{l}4.4 \\
4.3\end{array}$ & $\begin{array}{l}0.1 \\
0.1\end{array}$ & $\begin{array}{l}1900 \\
1900\end{array}$ & $\begin{array}{l}3.0^{2} \\
3.0^{n}\end{array}$ \\
\hline $\begin{array}{r}92 \\
101\end{array}$ & $\begin{array}{l}\text { Control } \\
\text { Control }\end{array}$ & - & - & & $\begin{array}{l}1900^{\circ} \\
1900\end{array}$ & $\begin{array}{l}15 \\
14\end{array}$ \\
\hline
\end{tabular}

$3 \times 6$-in. cylinders oven-dried at $105^{\circ} \mathrm{C}$ prior to impregnation.

Radiation-initiated polymerization.

PE-S = 50 wt \% polyester (Plaskon) - 50 wt \% styrene; viscosity, $\approx 70 \mathrm{cP}$.

PMMA = PMMA prepolymer, produced by irradiating MMA to a viscosity of $\approx 70 \mathrm{cP}$.

- Gain in weight.

-Outer shell scaling off.

-Top $1 / 2$ separated at $13 \%$ loss. 
Table 42

Resistance to $5 \% \mathrm{H}_{2} \mathrm{SO}_{4}$

Partially Impregnated Concrete - Second Test Series

\begin{tabular}{|c|c|c|c|c|c|c|}
\hline Monomer & $\begin{array}{c}\text { Specimen } \\
\text { No., } \\
\text { CP-DP. }\end{array}$ & $\begin{array}{l}\text { Nominal } \\
\text { penetration } \\
\text { depth, in. }\end{array}$ & $\begin{array}{c}\text { Polymer } \\
\text { loading, } \\
\text { wt \% }\end{array}$ & $\begin{array}{c}\text { Absorption, } \\
\text { wt \% }\end{array}$ & $\begin{array}{l}\text { Exposure, } \\
\text { days }\end{array}$ & $\begin{array}{l}\text { Weight } \\
\text { loss, \% }\end{array}$ \\
\hline \multirow[t]{3}{*}{ PE-S } & $\begin{array}{l}115 \\
118\end{array}$ & $\begin{array}{l}1 / 2 \\
1 / 2\end{array}$ & $\begin{array}{l}5.4 \\
5.0\end{array}$ & $\begin{array}{l}0.1 \\
0.2\end{array}$ & $\begin{array}{l}252 \\
252\end{array}$ & $\begin{array}{l}26.8^{\mathrm{a}} \\
24.9\end{array}$ \\
\hline & $\begin{array}{r}96 \\
110\end{array}$ & $\begin{array}{l}3 / 8 \\
3 / 6\end{array}$ & $\begin{array}{l}3.8 \\
3.9\end{array}$ & $\begin{array}{l}0.4 \\
0.4\end{array}$ & $\begin{array}{l}252 \\
252\end{array}$ & $\begin{array}{l}24.6 \\
24.6\end{array}$ \\
\hline & $\begin{array}{r}94 \\
108\end{array}$ & $\begin{array}{l}1 / 4 \\
1 / 4\end{array}$ & $\begin{array}{l}3.2 \\
3.0\end{array}$ & $\begin{array}{l}0.6 \\
0.5\end{array}$ & $\begin{array}{l}252 \\
252\end{array}$ & $\begin{array}{l}22.6 \\
20.4\end{array}$ \\
\hline \multirow[t]{3}{*}{ PMMA } & $\begin{array}{l}109 \\
113\end{array}$ & $\begin{array}{l}1 / 2 \\
1 / 2\end{array}$ & $\begin{array}{l}5.0 \\
5.2\end{array}$ & $\begin{array}{l}0.2 \\
0.2\end{array}$ & $\begin{array}{l}252 \\
252\end{array}$ & $\begin{array}{l}20.0 \\
22.3\end{array}$ \\
\hline & $\begin{array}{l}90 \\
97\end{array}$ & $\begin{array}{l}3 / 8 \\
3 / 8\end{array}$ & $\begin{array}{l}3.3 \\
4.5\end{array}$ & $\begin{array}{l}0.3 \\
0.4\end{array}$ & $\begin{array}{l}252 \\
252\end{array}$ & $\begin{array}{l}27.6^{\mathrm{a}} \\
28.3^{\mathrm{a}}\end{array}$ \\
\hline & $\begin{array}{l}89 \\
98\end{array}$ & $\begin{array}{l}1 / 4 \\
1 / 4\end{array}$ & $\begin{array}{l}4.1 \\
4.9\end{array}$ & $\begin{array}{l}0.1 \\
0.1\end{array}$ & $\begin{array}{l}252 \\
252\end{array}$ & $\begin{array}{l}20.9 \\
16.4\end{array}$ \\
\hline Unimpregnated & $\begin{array}{l}76 \\
82\end{array}$ & - & - & - & $\begin{array}{l}210 \\
210\end{array}$ & $\begin{array}{l}33.8^{\mathrm{a}} \\
32.4^{\mathrm{a}}\end{array}$ \\
\hline
\end{tabular}

$3 \times 6$-in. specimens oven-dried at $105^{\circ} \mathrm{C}$ prior to impregnation.

PE-S = 50 wt $\%$ polyester (Plaskon) - 50 wt \% styrene; viscosity, $\approx 70 \mathrm{cP}$.

PMMA $=$ methyl methacrylate prepolymer, produced by irradiating MMA to a viscosity of $\approx 70 \mathrm{cP}$.

Radiation polymerization.

- Failed (weight loss > 25\%).

Table 43

Resistance to Sulfate Attack

Partially Impregnated Concrete - Second Test Series

\begin{tabular}{clccccc}
\hline $\begin{array}{c}\text { Specimen } \\
\text { No., } \\
\text { CP-DP- }\end{array}$ & Polymer & $\begin{array}{c}\text { Nominal depth } \\
\text { of penetration, in. }\end{array}$ & $\begin{array}{c}\text { Polymer } \\
\text { loading, wt \% }\end{array}$ & Absorption, \% & $\begin{array}{c}\text { Test cycles, } \\
\text { days }\end{array}$ & $\begin{array}{c}\text { Net } \\
\text { expansion, \% }\end{array}$ \\
\hline 60 & PE-S & $1 / 2$ & 5.1 & 0.3 & 300 & 0.006 \\
72 & PE-S & $1 / 2$ & 5.2 & 0.2 & 300 & 0.008 \\
68 & PE-S & $1 / 3$ & 3.3 & 0.3 & 300 & 0.010 \\
69 & PE-S & $3 / 6$ & 3.4 & 0.6 & 300 & $0.054^{a}$ \\
59 & PE-S & $1 / 4$ & 3.1 & 0.6 & 300 & $0.066^{a}$ \\
70 & PE-S & $1 / 4$ & 2.6 & 0.8 & 300 & 0.056 \\
58 & PMMA & $1 / 2$ & 5.5 & 0.3 & 300 & 0.036 \\
62 & PMMA & $1 / 2$ & 6.1 & 0.2 & 300 & 0.016 \\
66 & PMMA & $1 / 6$ & 4.3 & 0.4 & 300 & 0.034 \\
73 & PMMA & $\$ / 6$ & 4.5 & 0.4 & 300 & 0.030 \\
57 & PMMA & $1 / 4$ & 4.6 & 0.2 & 300 & 0.014 \\
71 & PMMA & $1 / 4$ & 4.6 & 0.1 & 300 & 0.016 \\
63 & None & - & - & - & 300 & 0.076 \\
67 & None & - & - & - & 300 & 0.040 \\
\hline
\end{tabular}

$3 \times 6$-jn. specimens oven-dried at $105^{\circ} \mathrm{C}$.

PE-S = 50 wt $\%$ polyester (Plaskon) -50 wt $\%$ styrene; viscosity, $\approx 70 \mathrm{cP}$.

FMMA $=$ methyl methacrylate prepolymer, produced by irradiating MMA to a vis,osity of $\approx 70 \mathrm{cP}$.

Fine cracks appcared at 60 days. 
Table 44

Resistance to $5 \% \mathrm{H}_{2} \mathrm{SO}_{4}$

Partially Impregnated CP.Type Concrete - Third Test Series

\begin{tabular}{|c|c|c|c|c|c|c|}
\hline Monomer & $\begin{array}{c}\text { Specimen } \\
\text { No. }\end{array}$ & $\begin{array}{l}\text { Nominal } \\
\text { penetration } \\
\text { depth, in. }\end{array}$ & $\begin{array}{c}\text { Polymer } \\
\text { loading, } \\
\text { wt \% }\end{array}$ & $\begin{array}{c}\text { Absorption, } \\
\text { wt \% }\end{array}$ & $\begin{array}{l}\text { Exposure, } \\
\text { days }\end{array}$ & $\begin{array}{l}\text { Weight } \\
\text { loss, \% }\end{array}$ \\
\hline \multirow[t]{9}{*}{ PE-S } & $72.16-7$ & $3 / 4$ & 2.5 & 5.2 & 52 & 0.4 \\
\hline & 8 & $1 / 4$ & 2.3 & 5.5 & 52 & 0.9 \\
\hline & 9 & $1 / 4$ & 2.2 & 5.0 & 52 & 0.8 \\
\hline & 4 & $3 / 6$ & 4.9 & 2.6 & 52 & 1.2 \\
\hline & 5 & $3 / 8$ & 4.6 & 1.9 & 52 & 1.6 \\
\hline & 6 & $3 / 6$ & 4.7 & 2.5 & 52 & 1.3 \\
\hline & 1 & $1 / 2$ & 5.7 & 1.7 & 52 & 2.4 \\
\hline & 2 & $1 / 2$ & 5.2 & 2.1 & 52 & 2.0 \\
\hline & 3 & $1 / 2$ & 5.8 & 1.3 & 52 & 1.3 \\
\hline \multirow[t]{9}{*}{ PMMA } & 17 & $1 / 4$ & 2.3 & 5.2 & 52 & $0.6^{\mathrm{a}}$ \\
\hline & 19 & $1 / 4$ & 3.0 & 0.8 & 52 & $0.8^{\mathrm{a}}$ \\
\hline & 20 & $1 / 4$ & 2.6 & 3.0 & 52 & $0.2^{\mathrm{a}}$ \\
\hline & 11 & $3 / 8$ & 3.9 & 2.3 & 52 & 0.4 \\
\hline & 13 & $3 / 6$ & 3.3 & 1.7 & 52 & 1.4 \\
\hline & 15 & $3 / 8$ & 3.7 & 3.0 & 52 & 0.5 \\
\hline & 10 & $1 / 2$ & 4.1 & 1.1 & 52 & 0.9 \\
\hline & 12 & $3 / 2$ & 4.6 & 1.2 & 52 & 0.9 \\
\hline & 14 & $1 / 2$ & 4.5 & 2.1 & 52 & 1.5 \\
\hline \multirow[t]{6}{*}{ Unimpregnated } & $72.17-1$ & - & - & 6.6 & 52 & $2.6^{\mathrm{a}}$ \\
\hline & 2 & - & - & 6.9 & 52 & $4.8^{\mathrm{a}}$ \\
\hline & 3 & - & - & 6.7 & 52 & $4.3^{\mathrm{a}}$ \\
\hline & 4 & - & - & 6.3 & 52 & $1.1^{\mathrm{a}}$ \\
\hline & 5 & - & - & 6.9 & 52 & $4.8^{\mathrm{a}}$ \\
\hline & 6 & - & - & 6.3 & 52 & $1.0^{\mathrm{a}}$ \\
\hline
\end{tabular}

$3 \times 6$-in. specimens oven-dried at $110^{\circ} \mathrm{C}$.

Radiation-initiated polymerization.

PE-S $=50$ wt $\%$ polyester -50 wt \% styrene; viscosity, $\approx 40 \mathrm{cP}$.

PMMA $=20 \%$ solution of PMMA in methyl methacrylate; viscosity, $\approx 60 \mathrm{cP}$.

aain in weight.

as long as unimpregnated concrete, with about one-half as much weight loss, the compressive strength of the specimens after exposure was in the 200 to 300 -psi range. The acid slowly penetrates the specimens and attacks the cement paste.

Sulfate-attack test results are shown in Table 39. Specimens impregnated with epoxy-styrene are erratic in performance, ranging from about $0.10 \%$ to about $0.5 \%$ net expansion after 908 cycle-days, as compared with $0.45 \%$ expansion for unimpregnated concrete. Specimens impregnated with polyester-styrene had expansions ranging between $0.07 \%$ and $0.53 \%$. A correlation with depth of monomer penetration is apparent.
Second Test Series. Compressive strengths (Table 40) ranged from about 7700 psi to 14,400 psi and in general increased with polymer loading and depth of penetration for the polyester-styrene specimens and to a lesser extent with PMMA specimens.

Freeze-thaw tests show excellent durability after 1900 cycles (Table 41). All polyester-styiene specimens show a slight increase in weight which is due to absorption of water. The $3 / 6$-in.-depth PMMA specimens are showing some deterioration.

Results after 252 days of exposure to $5 \% \mathrm{H}_{2} \mathrm{SO}_{4}$ are given in Table 42. This is a severe test, and the specimens are deteriorating more rapidly than those in the first test series, which were exposed to 


\begin{tabular}{|c|c|c|c|c|c|c|}
\hline \multicolumn{7}{|c|}{$\begin{array}{c}\text { Table } 45 \\
\text { Resistance to } 5 \% \mathrm{H}_{2} \mathrm{SO}_{4}\end{array}$} \\
\hline \multicolumn{7}{|c|}{ Partially Impregnated High-Entrained-Air Concrete - Third Test Series } \\
\hline Monomer & $\begin{array}{c}\text { Specimen } \\
\text { No. }\end{array}$ & $\begin{array}{l}\text { Nominal } \\
\text { penetration } \\
\text { depth, in. }\end{array}$ & $\begin{array}{l}\text { Polymer } \\
\text { loading, } \\
\text { wt \% }\end{array}$ & $\begin{array}{c}\text { Absorption, } \\
\text { wt } \%\end{array}$ & $\begin{array}{l}\text { Exposure, } \\
\text { days }\end{array}$ & $\begin{array}{c}\text { Weight } \\
\text { loss, \% }\end{array}$ \\
\hline PE-S & $\begin{array}{r}72.45-5 \\
6 \\
7\end{array}$ & $\begin{array}{l}1 / 4 \\
1 / 4 \\
1 / 4\end{array}$ & $\begin{array}{l}4.6 \\
4.2 \\
4.7\end{array}$ & $\begin{array}{l}6.4 \\
6.0 \\
5.5\end{array}$ & $\begin{array}{l}52 \\
52 \\
52\end{array}$ & $\begin{array}{l}0.5 \\
0.3 \\
0.9\end{array}$ \\
\hline & $\begin{array}{l}1 \\
2 \\
4\end{array}$ & $\begin{array}{l}3 / 8 \\
3 / 8 \\
3 / 8\end{array}$ & $\begin{array}{l}5.1 \\
4.9 \\
5.1\end{array}$ & $\begin{array}{l}4.4 \\
5.3 \\
4.7\end{array}$ & $\begin{array}{l}52 \\
52 \\
52\end{array}$ & $\begin{array}{l}1.4 \\
1.4 \\
1.3\end{array}$ \\
\hline & $\begin{array}{r}8 \\
9 \\
10\end{array}$ & $\begin{array}{l}1 / 2 \\
1 / 2 \\
1 / 2\end{array}$ & $\begin{array}{l}7.7 \\
7.8 \\
8.0\end{array}$ & $\begin{array}{l}0.7 \\
0.6 \\
0.7\end{array}$ & $\begin{array}{l}52 \\
52 \\
52\end{array}$ & $\begin{array}{l}3.2 \\
3.2 \\
3.5\end{array}$ \\
\hline PMMA & $\begin{array}{l}20 \\
21 \\
24\end{array}$ & $\begin{array}{l}1 / 4 \\
1 / 4 \\
1 / 4\end{array}$ & $\begin{array}{l}3.7 \\
3.7 \\
3.9\end{array}$ & $\begin{array}{l}7.5 \\
8.2 \\
6.4\end{array}$ & $\begin{array}{l}52 \\
52 \\
52\end{array}$ & $\begin{array}{l}0.8^{\mathrm{a}} \\
1.1^{\mathrm{a}} \\
0.2^{\mathrm{a}}\end{array}$ \\
\hline & $\begin{array}{l}17 \\
18 \\
19\end{array}$ & $\begin{array}{l}3 / 8 \\
3 / 6 \\
3 / 8\end{array}$ & $\begin{array}{l}5.5 \\
5.7 \\
5.5\end{array}$ & $\begin{array}{l}1.3 \\
2.4 \\
2.4\end{array}$ & $\begin{array}{l}52 \\
52 \\
52\end{array}$ & $\begin{array}{l}1.0 \\
0.8^{a} \\
0.1^{a}\end{array}$ \\
\hline & $\begin{array}{l}12 \\
13 \\
15\end{array}$ & $\begin{array}{l}1 / 2 \\
1 / 2 \\
1 / 2\end{array}$ & $\begin{array}{l}7.8 \\
7.9 \\
8.0\end{array}$ & $\begin{array}{l}1.9 \\
1.4 \\
1.7\end{array}$ & $\begin{array}{l}52 \\
52 \\
52\end{array}$ & $\begin{array}{l}0.5^{\mathfrak{a}} \\
0.1 \\
0.5^{\mathfrak{a}}\end{array}$ \\
\hline Unimpregnated & $\begin{array}{r}72.46-1 \\
2 \\
3 \\
5 \\
6\end{array}$ & $\begin{array}{l}- \\
- \\
- \\
-\end{array}$ & $\begin{array}{l}- \\
- \\
- \\
-\end{array}$ & $\begin{array}{l}6.2 \\
5.7 \\
6.3 \\
6.4 \\
6.3\end{array}$ & $\begin{array}{l}52 \\
52 \\
52 \\
52 \\
52\end{array}$ & $\begin{array}{r}12.7 \\
11.6 \\
9.9 \\
13.2 \\
8.6\end{array}$ \\
\hline
\end{tabular}

High-entrained-air concrete, CP-type concrete mix adjusted to give $11.2 \%$ entrained air, $3 \times 6$-in. specimens ovendried at $110^{\circ} \mathrm{C}$.

Radiation-initiated polymerization.

PE-S $=50 \mathrm{wt} \%$ polyester $-50 \mathrm{wt} \%$ styrene; viscosity, $\approx 40 \mathrm{cP}$.

PMMA $=20 \%$ solution of PMMA in methyl methacrylate; viscosity, $\approx 60 \mathrm{cP}$.

Gain in weight.

HCl. Weight losses ranged from about $16 \%$ to $28 \%$ at 252 days for partially impregnated specimens. Both monomer systems gave similar results and no correlation with penetration depth was apparent. Unimpregnated specimens had $>30 \%$ weight loss at 210 days. An improved specimenpreparation technique, such as treatment with a seal coat to obtain an impermeable specimen, will be required to produce a material with high durability when exposed to sulfuric acid. This technique has been used successfully with sewer pipe (see Section 8.1.3).

Sulfate-attack tests (Table 43) show generally low expansions after 300 test cycies. This is not a sufficient exposure time to produce significant results.

Third Test Series. Partially impregnated specimens were prepared from the standard CP-mix concrete and from a CP mix adjusted to give a high entrained air content ( $11 \%$ vs $6 \%$ for standard CP mix). Both types of concrete were cured with high-pressure steam and then impregnated with polyester-styrene and PMMA solutions. Specimens in this series were tested only for absorption and resistance to $5 \% \mathrm{H}_{2} \mathrm{SO}_{4}$ (see Tables 44 and 45 ).

Partially impregnated specimens generally showed a decrease in absorption with increased depth of penetration; however, absorption was 
fairly high as compared with that found in previous tests of partially impregnated concrete. After 52 days of exposure to $5 \% \mathrm{H}_{2} \mathrm{SO}_{4}$, the partially impregnated specinens are deteriorating slightly, with several specimens showing weight gains due to absorption. The unimpregnated steam-cured CP-type concrete specimens are showing good durability, and the steam-cured high-air-content specimens are showing significant weight loss.

\subsection{Polymer-Impreonated Concrete ror Desalting Plant Applications at Temperatures UP to $143^{\circ} \mathrm{C}$}

5.2.1 Structural Properties and Design Criteria. Tests of structural priperties were conducted on unimpregnated CP-type concrete and on CP-type concrete impregnated with 60 wt $\%$ styrene, -40 wt \% TMPTMA and 70 wt \% MMA - 30 wt \% TMPTMA. The tests included compressive, tensile, flexural, and shear strengths, and were conducted at room temperature (taken here as $21^{\circ} \mathrm{C}$ ), $121^{\circ} \mathrm{C}$, and $143^{\circ} \mathrm{C}$. In addition, several tests of compressive and tensile strength were conducted at $-23^{\circ} \mathrm{C}$ and $177^{\circ} \mathrm{C}$. The long-term tests in progress on creep deformation and brine-loop exposure were continued.

Preliminary design values were calculated for compressive strength, Poisson's ratio, and modulus of elasticity of the MMA-TMPTMA impregnated concrete at $-23^{\circ}, 21^{\circ}, 121^{\circ}$, and $143^{\circ} \mathrm{C}$, and for unimpregnated concrete and the styrene-TMPTMA impregnated concrete at $177^{\circ} \mathrm{C}$. The design values are equal to the mean compressive strength minus the standard deviation and were obtained from compressive strength tests described in Section 5.2.1.1. These values are for short-term exposure at the various temperatures. Results are given in Table 46, which also contains a summary of design values for unimpregnated concrete and 60 wt \% styrene - 40 wt \% TMPTMA impregnated. concrete presented in Ref. 4. The design values for PIC show a downward trend with increasing temperature. The lowest value for compressive strength of the styrene-TMPTMA impregnated concrete is $13,700 \mathrm{psi}$ at $143^{\circ} \mathrm{C}$, and for the MMATMPTMA concrete the lowest value is 11,900 psi

Table 46

Ultimate Design Compressive Strength and Elastic Properties

Polymer-Impregnated Concrete for High-Temperature Applications

\begin{tabular}{|c|c|c|c|c|c|c|c|c|}
\hline \multirow[b]{2}{*}{ Type of material } & \multirow[b]{2}{*}{$\begin{array}{c}\text { Test } \\
\text { temperature, } \\
{ }^{\circ} \mathrm{C}\end{array}$} & \multirow[b]{2}{*}{$\begin{array}{c}\text { No. of } \\
\text { specimens }\end{array}$} & \multicolumn{3}{|c|}{ Design valuesb } & \multicolumn{3}{|c|}{ Average valuese } \\
\hline & & & $\begin{array}{c}\text { Compressive } \\
\text { strength } \\
\left(f^{\prime} c\right), \text { psi }\end{array}$ & $\begin{array}{l}\text { Poisson's } \\
\text { ratio }\end{array}$ & $\begin{array}{l}\text { Modulus of } \\
\text { elasticity, } \\
10^{6} \text { psi }\end{array}$ & $\begin{array}{c}\text { Polymer } \\
\text { loading, } \\
\text { wt \% }\end{array}$ & $\begin{array}{c}\text { Elastic } \\
\text { limit } \\
\text { stress, psi }\end{array}$ & $\begin{array}{l}\text { Ultimate } \\
\text { strain, } \\
\text { in./in. }\end{array}$ \\
\hline \multirow[t]{4}{*}{ Unimpregnated } & 21 & 10 & 4,700 & 0.14 & 3.4 & - & 1,200 & 0.0023 \\
\hline & 121 & 10 & 4,800 & 0.13 & 3.0 & - & 1,400 & 0.0024 \\
\hline & 143 & 15 & 4,500 & 0.12 & 2.9 & - & 1,3170 & 0.0025 \\
\hline & 177 & 10 & $4,8 C 0$ & 0.11 & 2.7 & - & 1,100 & 0.0026 \\
\hline \multirow[t]{4}{*}{ S-TMPTMA } & 21 & 12 & 15,300 & 0.20 & 6.1 & 5.7 & 10,500 & 0.0029 \\
\hline & 121 & 12 & 15,000 & 0.20 & 5.7 & 5.6 & 9,800 & 0.0030 \\
\hline & 143 & 12 & 13,700 & 0.17 & 5.5 & 5.5 & 8,200 & 0.0026 \\
\hline & 177 & 10 & 14,200 & 0.15 & 5.1 & 5.6 & 9,900 & 0.0030 \\
\hline \multirow[t]{4}{*}{ MMA-TMPTMA } & -23 & 10 & 17,200 & 0.17 & 5.7 & 6.4 & 13,600 & 0.0033 \\
\hline & 21 & 15 & 17,100 & 0.18 & 5.8 & 5.8 & 12,400 & 0.0032 \\
\hline & 121 & 25 & 12,500 & 0.16 & 4.8 & 5.8 & 9,200 & 0.0030 \\
\hline & 143 & 20 & 11,900 & 0.14 & 4.3 & 5.8 & 8,900 & 0.0030 \\
\hline
\end{tabular}

Compressive strength tests on $6 \times 12$-in. cylinders.

Thermal-catalytic polymerization.

'S-TMPTMA $=60$ wt $\%$ styrene - 40 wt \% TMPTMA; MMA-TMPTMA = 70 wt \% MMA - 30 wt $\%$ TMPTMA.

bDesign values = mean minus standard deviation.

cAverage values $=$ mean of 10 to 25 specimens. 
Table 47

Ultimate Design Direct Tensile Strength and Elastic Properties Polymer-Impregnated Concrete for High-Temperature Applications

\begin{tabular}{|c|c|c|c|c|c|c|}
\hline \multirow[b]{2}{*}{ Type of material } & \multirow[b]{2}{*}{$\begin{array}{c}\text { Test } \\
\text { temperature, } \\
{ }^{\circ} \mathrm{C}\end{array}$} & \multicolumn{2}{|c|}{ Design values } & \multicolumn{3}{|c|}{ Average values } \\
\hline & & $\begin{array}{c}\text { Tensile } \\
\text { strength, } \\
\text { psi }\end{array}$ & $\begin{array}{l}\text { Modulus of } \\
\text { elasticity, } \\
10^{6} \mathrm{psi}\end{array}$ & $\begin{array}{c}\text { Polymer } \\
\text { loading, } \\
\text { wt } \%\end{array}$ & $\begin{array}{l}\text { Ultimate } \\
\text { strain, } \\
\mu \text { in./in. }\end{array}$ & $\begin{array}{l}\text { Poisson's } \\
\text { ratio }\end{array}$ \\
\hline \multirow{3}{*}{ Unimpregnated } & 21 & 260 & 3.8 & - & 136 & 0.14 \\
\hline & 121 & 170 & 2.9 & - & 162 & 0.10 \\
\hline & 143 & 210 & 2.6 & - & 156 & - \\
\hline \multirow[t]{3}{*}{ S-TMPTMA } & 21 & 980 & 6.6 & 5.5 & 172 & 0.20 \\
\hline & 121 & 800 & 5.9 & 5.5 & 146 & 0.22 \\
\hline & 143 & 760 & 5.5 & 5.5 & 161 & 0.19 \\
\hline
\end{tabular}

Direct tension tests on $4^{1 / 2} \times 12^{1 / 2-i n}$. cylinders.

Average values $=$ mean of 4 or 5 specimens.

Design values $=$ mean minus standard deviation.

S-TMPTMA $=60 \mathrm{wt} \%$ styrene $-40 \mathrm{wt} \%$ TMPTMA.

Thermal-catalytic polymerization.

Table 48

Comparison of Tensile Strength Average and Design Values Deternined in Direct 'Tension and Tensile Splitting Tests

\begin{tabular}{|c|c|c|c|c|c|c|c|c|c|}
\hline \multirow[b]{3}{*}{$\begin{array}{l}\text { Type of } \\
\text { materiala }\end{array}$} & \multirow[b]{3}{*}{$\begin{array}{l}\text { Test } \\
\text { temper- } \\
\text { ature, } \\
{ }^{\circ} \mathrm{C}\end{array}$} & & & \multicolumn{6}{|c|}{ Average values from } \\
\hline & & \multicolumn{2}{|c|}{ Design values from } & \multicolumn{3}{|c|}{ Direct tension ${ }^{d}$} & \multicolumn{3}{|c|}{ Tensile splitting ${ }^{\circ}$} \\
\hline & & $\begin{array}{c}\text { Direct } \\
\text { tension, } \\
\text { psi }\end{array}$ & $\begin{array}{c}\text { Tensile } \\
\text { splitting, } \\
\text { psi }\end{array}$ & $\begin{array}{c}\text { No. of } \\
\text { specimens }\end{array}$ & $\begin{array}{c}\text { Tensile } \\
\text { strength, } \\
\text { psi }\end{array}$ & $\begin{array}{c}\text { Standard } \\
\text { deviation, } \\
\text { psi }\end{array}$ & $\begin{array}{c}\text { No. of } \\
\text { specimens }\end{array}$ & $\begin{array}{c}\text { T'ensile } \\
\text { strength. } \\
\text { psi }\end{array}$ & $\begin{array}{c}\text { Standard } \\
\text { deviation, } \\
\text { psi }\end{array}$ \\
\hline \multirow{4}{*}{ Unimpregnated } & 21 & 260 & 250 & 4 & 310 & 50 & 10 & 340 & 50 \\
\hline & 121 & 170 & 230 & 5 & 220 & 50 & 10 & 310 & 40 \\
\hline & 143 & 210 & 280 & 4 & 230 & 20 & 10 & 370 & 40 \\
\hline & 177 & - & 260 & & - & & 10 & 330 & 30 \\
\hline \multirow[t]{4}{*}{ S-TMPTMA } & 21 & 980 & 660 & 5 & 1090 & 110 & 10 & 890 & 110 \\
\hline & 121 & 800 & 650 & 5 & 890 & 90 & 10 & 880 & 110 \\
\hline & 143 & 760 & $620^{d}$ & 5 & 850 & 90 & 10 & 920 & 190 \\
\hline & 177 & - & $540^{d}$ & & - & & 10 & 790 & 150 \\
\hline MMA- & -23 & - & 820 & & - & & 10 & 1040 & 70 \\
\hline \multirow[t]{3}{*}{ TMPTMA } & 21 & - & 780 & & - & & 20 & 1000 & 80 \\
\hline & 121 & - & 780 & & - & & 20 & 990 & 70 \\
\hline & 143 & - & 640 & & - & & 20 & 870 & 110 \\
\hline
\end{tabular}

Direct tension tests on $4 \frac{1 / 2}{2} \times 12^{1 / 2}$-in. cylinders; tensile splitting tests on $6 \times 12$-in. cylinders.

Thermal-catalytic polymerization.

aS-TMPTMA $=60 \mathrm{wt} \%$ styrene $-40 \mathrm{wt} \%$ TMPTMA; MMA-TMPTMA $=70 \mathrm{wt} \%$ MMA - $30 \mathrm{wt} \%$ TMPTMA.

b Design values $=$ mean ininus standard deviation.

- Design values $=0.85$ (mean - standard deviation).

${ }^{\text {aCoefficient }}$ of variation was $>15 \%$. 
at $143^{\circ} \mathrm{C}$. On the basis of these tests, these values should be used as the upper limit of ultimate compressive strength design stresses.

Preliminary tensile strength design values for styrene-TMPTMA impregnated concrete tested in direct tension at $21^{\circ}, 121^{\circ}$, and $143^{\circ} \mathrm{C}$ are given in Table 47. Design values calculated from tensile splitting tests on styrene-TMPTMA and MMATMPTMA impregnated concrete, and a comparison of direct tension and tensile splitting strengths, are given in Table 48 . These data were obtained from tests discussed in Section 5.2.1.2 and from Ref. 4. Test temperatures ranged from $-23^{\circ} \mathrm{C}$ to $177^{\circ} \mathrm{C}$. Design values from direct tension tests are equal to the mean tensile strength minus the standard deviation; those from tensile splitting tests are calculated by multiplying the mean tensile splitting strength minus the standard deviation by an empirical factor of 0.85 (see discussion in Section 5.2.1.2).

The tensile strength design values for PIC, like those for compressive strength, generally show a decrease with increasing temperature. The lowest tensile strength design value for styrene-TMP. TMA impregnated concrete from direct tension tests was 760 psi at $143^{\circ} \mathrm{C}$. Such tests have not yet been performed on the MMA-TMPTMA impregnated concrete. The lowest tensile strength design values from tensile splitting tests were 620 psi at $143^{\circ} \mathrm{C}$ and $540 \mathrm{psi}$ at $177^{\circ} \mathrm{C}$ for the styreneTMPTMA impregnated concrete, and 640 psi at $143^{\circ} \mathrm{C}$ for the MMA-TMPTMA impregnated

Table 49

Compressive Strength of Unimpregnated and Styrene-TMPTMA Impregnated Concrete After Short-Term Exposure at $177^{\circ} \mathrm{C}$

\begin{tabular}{|c|c|c|c|c|c|c|}
\hline $\begin{array}{c}\text { Specimen } \\
\text { No. }\end{array}$ & $\begin{array}{l}\text { Polymer } \\
\text { loading, } \\
\text { wt \% }\end{array}$ & $\begin{array}{l}\text { Compressive } \\
\text { strength, } \\
\text { psi }\end{array}$ & $\begin{array}{l}\text { Poisson's } \\
\text { ratio }\end{array}$ & $\begin{array}{l}\text { Modulus of } \\
\text { elasticity, } \\
10^{6} \text { psi }\end{array}$ & $\begin{array}{c}\text { Elastic } \\
\text { limit stress, } \\
\text { psi }\end{array}$ & $\begin{array}{l}\text { Ultimate } \\
\text { strain, } \\
\mu \text { in./in. }\end{array}$ \\
\hline $72.3-1$ & 5.8 & 14,900 & 0.21 & 5.2 & 9,000 & 3,100 \\
\hline 2 & 5.9 & 14,600 & 0.17 & 5.1 & 10,000 & 2,900 \\
\hline 5 & 5.3 & 14,500 & 0.19 & 5.7 & 11,500 & 2,760 \\
\hline 6 & 5.9 & 14,000 & 0.22 & 5.2 & 9,500 & 2,800 \\
\hline 7 & 6.2 & 15,000 & 0.19 & 5.2 & 9,500 & 3,190 \\
\hline 8 & 5.0 & 14,800 & 0.19 & 5.3 & 10,000 & 3,050 \\
\hline 9 & 5.0 & 14,600 & 0.14 & 5.4 & 10,000 & 3,000 \\
\hline 10 & 5.7 & 14,700 & 0.15 & 5.3 & 9,500 & 2,960 \\
\hline 11 & 5.8 & 14,800 & 0.17 & 5.2 & 9,000 & 3,100 \\
\hline 12 & 5.3 & 14,000 & 0.15 & 5.1 & 11,000 & 2,600 \\
\hline & 5.6 & 14,600 & 0.18 & 5.3 & 9,900 & 2,950 \\
\hline & - & 300 & 0.03 & 0.2 & 810 & - \\
\hline $72.4-1$ & - & 5,200 & 0.08 & 2.8 & 1,150 & 2,700 \\
\hline 2 & - & 5,000 & 0.18 & 2.9 & 1,100 & 2,800 \\
\hline 3 & - & 5,100 & 0.21 & 3.1 & 1,100 & 2,700 \\
\hline 4 & - & 5,000 & 0.18 & 2.9 & 1,100 & 2,600 \\
\hline 5 & - & 5,000 & 0.12 & 2.8 & 1,150 & 2,600 \\
\hline 6 & - & 5,100 & 0.14 & 2.8 & 1,150 & 2,700 \\
\hline 7 & - & 4,600 & - & 2.5 & 1,100 & 2,700 \\
\hline 8 & - & 5,000 & 0.16 & 3.0 & 1,250 & 2,550 \\
\hline 9 & - & 5,100 & 0.08 & 2.9 & 1,100 & 2,550 \\
\hline 10 & - & 4,600 & 0.10 & 3.0 & 1,150 & 2,400 \\
\hline \multirow{2}{*}{\multicolumn{2}{|c|}{$\begin{array}{l}\text { Mean } \\
\text { S.D. }\end{array}$}} & 5,000 & 0.14 & 2.9 & 1,140 & 2,630 \\
\hline & & 200 & 0.05 & 0.2 & 50 & - \\
\hline
\end{tabular}

Specimens, 6-in.-diam $\times 12$-in.-long cylinders of CP-type concrete, oven-dried at $177^{\circ} \mathrm{C}$ prior to impregnation and thermal-catalytic polymerization.

Monomer, 60 wt \% styrene - 40 wt \% TMPTMA.

Test temperature, $177^{\circ} \mathrm{C}$. 
concrete. These values should be considered the upper limit of ultimate tensile strength stress for use as a preliminary design aid.

5.2.1.1 Compaessive STREnGTH. Compressive strength and elastic properties have been obtained for unimpregnated concrete and for concrete impreg- nated with 60 wt \% styrene - 40 wt \% TMPTMA and 70 wt \% MMA - 30 wt \% TMPTMA. Test temperatures ranged from $-23^{\circ} \mathrm{C}$ to $177^{\circ} \mathrm{C}$. Results at the various temperatures are considered to be short-term effects, since the specimens are exposed only long enough to obtain a uniform tem-

Table 50

Compressive Strength of MMA-TMPTMA Impregnated Concrete After Short-Term Exposure at $21^{\circ}, 121^{\circ}$, and $143^{\circ} \mathrm{C}$

\begin{tabular}{|c|c|c|c|c|c|c|c|}
\hline $\begin{array}{c}\text { Test } \\
\text { temperature, } \\
{ }^{\circ} \mathrm{C}\end{array}$ & $\begin{array}{c}\text { Specimen } \\
\text { No., } \\
72.93-\end{array}$ & $\begin{array}{l}\text { Polymer } \\
\text { loading, } \\
\text { wt \% }\end{array}$ & $\begin{array}{l}\text { Ultimate } \\
\text { strength, } \\
\text { psi }\end{array}$ & $\begin{array}{l}\text { Poisson's } \\
\text { ratio }\end{array}$ & $\begin{array}{l}\text { Modulus of } \\
\text { elasticity, } \\
10^{6} \mathrm{psi}\end{array}$ & $\begin{array}{c}\text { Elastic } \\
\text { limit stress, } \\
\text { psi }\end{array}$ & $\begin{array}{l}\text { Ultimate } \\
\text { strain, } \\
\mu \text { in./in. }\end{array}$ \\
\hline \multirow[t]{10}{*}{21} & 1 & 5.7 & 17,900 & 0.21 & 5.8 & 13,000 & 3,160 \\
\hline & 2 & 5.6 & 17,400 & 0.20 & 5.9 & 12,500 & 3,000 \\
\hline & 5 & 6.1 & 17,900 & 0.20 & 5.9 & 12,500 & 3,400 \\
\hline & 14 & 5.9 & 18,100 & 0.19 & 5.8 & 13,500 & 3,400 \\
\hline & 15 & 5.8 & 17,400 & 0.19 & 5.7 & 13,000 & 3,040 \\
\hline & 17 & 6.1 & 17,100 & 0.18 & 5.9 & 12,500 & 3,380 \\
\hline & 23 & 5.6 & 17,300 & 0.23 & 6.1 & 11,000 & 2,960 \\
\hline & 29 & 5.8 & 18,000 & 0.19 & 5.8 & 12,000 & 3,420 \\
\hline & 31 & 5.3 & 17,400 & 0.18 & 6.0 & 10,000 & 2,910 \\
\hline & 33 & 5.8 & 16,900 & 0.21 & 6.4 & 11,500 & 2,820 \\
\hline \multirow{2}{*}{\multicolumn{2}{|c|}{$\begin{array}{l}\text { Mean } \\
\text { S.D. }\end{array}$}} & 5.8 & 17,500 & 0.20 & 5.9 & 12,150 & 3,150 \\
\hline & & - & 400 & 0.02 & 0.2 & - & - \\
\hline \multirow[t]{10}{*}{121} & 4 & 5.9 & 13,100 & 0.13 & 4.9 & 8,500 & 3,190 \\
\hline & 7 & 5.6 & 14,800 & 0.17 & 4.9 & 10,000 & 3,460 \\
\hline & 13 & 6.1 & 13,000 & 0.18 & 4.6 & 10,000 & 3,400 \\
\hline & 16 & 5.8 & 13,600 & 0.19 & 4.9 & 9,500 & 3,030 \\
\hline & 20 & 6.1 & 13,800 & 0.21 & 5.2 & 8,500 & 3,370 \\
\hline & 21 & 5.8 & 12,800 & 0.16 & 4.3 & 10,000 & 3,220 \\
\hline & 25 & 5.7 & 14,600 & 0.20 & 5.3 & 9,500 & 3,030 \\
\hline & 27 & 5.6 & 13,500 & 0.20 & 4.9 & 9,000 & 3,020 \\
\hline & 30 & 5.8 & 13,400 & 0.17 & 5.3 & 9,000 & 3,030 \\
\hline & 35 & 5.4 & 14,000 & 0.17 & 5.6 & 9,500 & 2,700 \\
\hline \multirow{2}{*}{\multicolumn{2}{|c|}{$\begin{array}{l}\text { Mean } \\
\text { S.D. }\end{array}$}} & 5.8 & 13,700 & 0.18 & 5.0 & 9,350 & 3,150 \\
\hline & & - & 700 & 0.02 & 0.4 & - & - \\
\hline \multirow[t]{10}{*}{143} & 3 & 5.9 & 12,300 & 0.13 & 4.5 & 8,500 & 2,900 \\
\hline & 6 & 5.8 & 13,000 & 0.20 & 5.1 & 8,000 & 2,960 \\
\hline & 10 & 5.1 & 12,100 & 0.16 & 4.6 & 9,500 & 2,530 \\
\hline & 18 & 5.8 & 13,100 & 0.17 & 4.8 & 9,500 & 2,840 \\
\hline & 19 & 5.7 & 12,300 & 0.13 & 5.0 & 9,000 & 2,760 \\
\hline & 22 & 5.6 & 12,700 & 0.16 & 4.8 & 9,000 & 2,750 \\
\hline & 24 & 6.1 & 12,000 & 0.17 & 4.8 & 9,500 & 3,020 \\
\hline & 26 & 6.1 & 11,900 & 0.20 & 4.5 & 9,000 & 2,710 \\
\hline & 32 & 5.7 & 13,600 & 0.19 & 5.1 & 9,000 & 3,040 \\
\hline & 34 & 5.7 & 12,800 & 0.18 & 5.0 & 9,000 & 2,950 \\
\hline \multirow{2}{*}{\multicolumn{2}{|c|}{$\begin{array}{l}\text { Mean } \\
\text { S.D. }\end{array}$}} & 5.8 & 12,600 & 0.17 & 4.8 & 9,000 & 2,850 \\
\hline & & - & 500 & 0.03 & 0.2 & $\ldots$ & - \\
\hline
\end{tabular}

Specimens, $6 \times 12-\mathrm{in}$. cylinders of CP-type concrete, oven-dried at $177^{\circ} \mathrm{C}$ prior to impregnation and thermal-catalytic polymerization.

Monomer, 70 wt \% MMA - 30 wt \% TMPTMA. 
perature. The test specimens are $6 \times 12$-in. cylinders. Elastic properties are determined with use of electrical resistance strain gages bonded to the test cylinders, and three test runs are made. In the first two, PIC is stressed to 2000 psi and unimpregnated concrete is stressed to 1000 psi. Data from these runs are used to determine Poisson's ratio and modulus of elasticity. The third run is used to obtain stress-strain data to failure.

Compressive strength and elastic properties at $177^{\circ} \mathrm{C}$ of unimpregnated concrete and styreneTMPTMA impregnated concrete are given in Table 49. The unimpregnated concrete had an average compressive strength of 5000 psi and the

Table 51

Compressive Strength of MMA-TMPTMA Impregnated Concrete

Initial Tests for Long-Term Exposure Tests at $-23^{\circ}, 21^{\circ}, 121^{\circ}$, and $143^{\circ} \mathrm{C}$

\begin{tabular}{|c|c|c|c|c|c|c|c|}
\hline $\begin{array}{c}\text { Test } \\
\text { temperature, } \\
{ }^{\circ} \mathrm{C}\end{array}$ & $\begin{array}{c}\text { Specimen } \\
\text { No., } \\
72.194-\end{array}$ & $\begin{array}{l}\text { Polymer } \\
\text { loading, } \\
\text { wt \% }\end{array}$ & $\begin{array}{l}\text { Ultimate } \\
\text { strength, } \\
\text { psi }\end{array}$ & $\begin{array}{l}\text { Poisson's } \\
\text { ratio }\end{array}$ & $\begin{array}{l}\text { Modulus of } \\
\text { elasticity, } \\
10^{6} \mathrm{psi}\end{array}$ & $\begin{array}{c}\text { Elastic } \\
\text { limit stress, } \\
\text { psi }\end{array}$ & $\begin{array}{l}\text { Ultimate } \\
\text { strain, } \\
\mu \text { in./in. }\end{array}$ \\
\hline-23 & $\begin{array}{r}1 \\
6 \\
8 \\
11 \\
13 \\
15 \\
17 \\
19 \\
22 \\
24\end{array}$ & $\begin{array}{l}6.4 \\
6.4 \\
6.7 \\
6.3 \\
6.1 \\
7.2 \\
6.6 \\
6.7 \\
5.3 \\
6.6\end{array}$ & $\begin{array}{l}18,400 \\
18,200 \\
18,500 \\
17,500 \\
17,900 \\
17,000 \\
17,800 \\
18,700 \\
18,900 \\
18,000\end{array}$ & $\begin{array}{l}0.16 \\
0.21 \\
0.20 \\
0.19 \\
0.21 \\
0.22 \\
0.19 \\
0.18 \\
0.16 \\
0.18\end{array}$ & $\begin{array}{l}5.9 \\
5.7 \\
5.8 \\
5.9 \\
6.0 \\
5.6 \\
6.1 \\
6.1 \\
6.2 \\
6.1\end{array}$ & $\begin{array}{l}14,000 \\
14,000 \\
14,000 \\
13,000 \\
13,000 \\
13,000 \\
13,500 \\
14,000 \\
13,500 \\
14,000\end{array}$ & $\begin{array}{l}3,520 \\
3,620 \\
3,400 \\
3,260 \\
3,320 \\
3,380 \\
3,080 \\
3,150 \\
3,180 \\
3,080\end{array}$ \\
\hline & $\begin{array}{l}\text { Mean } \\
\text { S.D. }\end{array}$ & $\begin{array}{c}6.4 \\
-\end{array}$ & $\begin{array}{r}18,100 \\
600\end{array}$ & $\begin{array}{l}0.19 \\
0.02\end{array}$ & $\begin{array}{l}5.9 \\
0.2\end{array}$ & $\begin{array}{c}13,600 \\
-\end{array}$ & $\begin{array}{c}3,280 \\
-\end{array}$ \\
\hline 21 & $\begin{array}{r}5 \\
7 \\
9 \\
12 \\
21\end{array}$ & $\begin{array}{l}6.3 \\
6.4 \\
6.7 \\
6.6 \\
6.3\end{array}$ & $\begin{array}{l}18,000 \\
17,300 \\
17,900 \\
18,500 \\
18,000\end{array}$ & $\begin{array}{l}0.22 \\
0.22 \\
0.23 \\
0.24 \\
0.16\end{array}$ & $\begin{array}{l}5.9 \\
6.0 \\
6.1 \\
6.2 \\
6.4\end{array}$ & $\begin{array}{l}13,000 \\
13,000 \\
13,000 \\
13,000 \\
13,000\end{array}$ & $\begin{array}{l}3,480 \\
3,080 \\
3,300 \\
3,160 \\
3,100\end{array}$ \\
\hline & $\begin{array}{l}\text { Mean } \\
\text { S.D. }\end{array}$ & $\begin{array}{c}6.5 \\
-\end{array}$ & $\begin{array}{r}17,900 \\
500\end{array}$ & $\begin{array}{l}0.21 \\
0.03\end{array}$ & $\begin{array}{l}6.1 \\
0.2\end{array}$ & $\begin{array}{c}13,000 \\
-\end{array}$ & $\begin{array}{c}3,220 \\
-\end{array}$ \\
\hline 121 & $\begin{array}{r}2 \\
4 \\
8 \\
20 \\
26\end{array}$ & $\begin{array}{l}6.6 \\
6.3 \\
6.4 \\
5.6 \\
6.9\end{array}$ & $\begin{array}{l}11,100 \\
12,200 \\
13,500 \\
13,200 \\
14,100\end{array}$ & $\begin{array}{l}0.20 \\
0.20 \\
0.16 \\
0.16 \\
0.18\end{array}$ & $\begin{array}{l}5.2 \\
5.4 \\
4.9 \\
5.2 \\
5.1\end{array}$ & $\begin{array}{l}8,000 \\
8,000 \\
9,000 \\
9,000 \\
9,000\end{array}$ & $\begin{array}{l}2,400 \\
2,580 \\
3,200 \\
2,660 \\
3,680\end{array}$ \\
\hline & $\begin{array}{l}\text { Mean } \\
\text { S.D. }\end{array}$ & $\begin{array}{c}6.4 \\
-\end{array}$ & $\begin{array}{r}12,800 \\
1,200\end{array}$ & $\begin{array}{l}0.18 \\
0.02\end{array}$ & $\begin{array}{l}5.2 \\
0.2\end{array}$ & $\begin{array}{c}8,600 \\
-\end{array}$ & $\begin{array}{c}2,900 \\
-\end{array}$ \\
\hline 143 & $\begin{array}{r}3 \\
10 \\
14 \\
16 \\
25\end{array}$ & $\begin{array}{l}6.3 \\
6.6 \\
6.6 \\
6.1 \\
6.4\end{array}$ & $\begin{array}{l}12,500 \\
12,700 \\
12,200 \\
11,500 \\
12,400\end{array}$ & $\begin{array}{l}0.15 \\
0.12 \\
0.16 \\
0.16 \\
0.16\end{array}$ & $\begin{array}{l}4.6 \\
3.9 \\
4.7 \\
4.2 \\
4.1\end{array}$ & $\begin{array}{l}9,500 \\
9,000 \\
9,000 \\
8,500 \\
8,000\end{array}$ & $\begin{array}{l}3,400 \\
3,240 \\
3,200 \\
2,950 \\
3,180\end{array}$ \\
\hline & $\begin{array}{l}\text { Mean } \\
\text { S.D. }\end{array}$ & $\begin{array}{c}6.4 \\
-\end{array}$ & $\begin{array}{r}12,300 \\
400\end{array}$ & $\begin{array}{l}0.15 \\
0.02\end{array}$ & $\begin{array}{l}4.3 \\
0.4\end{array}$ & $\begin{array}{c}8,800 \\
-\end{array}$ & $\begin{array}{c}3,190 \\
-\end{array}$ \\
\hline
\end{tabular}

Specimens, $6 \times 12$-in. cylinders of CP-type concrete, oven-dried at $177^{\circ} \mathrm{C}$ prior to impregnation and thermal-catalytic polymerization.

Monomer, 70 wt \% MMA - 30 wt \% TMPTMA. 
Table 52

Compressive Strength of Unimpregnated and MMA-TMPTMA Impregnated Concrete

Initial Tests at $121^{\circ}$ and $143^{\circ} \mathrm{C}$ for Three-Phase Brine Loop Exposure

\begin{tabular}{|c|c|c|c|c|c|c|c|}
\hline $\begin{array}{c}\text { Test } \\
\text { temperature, } \\
{ }^{\circ} \mathbf{C}\end{array}$ & $\begin{array}{l}\text { Spocimen } \\
\text { No. }\end{array}$ & $\begin{array}{c}\text { Polymer } \\
\text { loading, } \\
\text { wt \% }\end{array}$ & $\begin{array}{l}\text { Ultimate } \\
\text { strength, } \\
\text { psi }\end{array}$ & $\begin{array}{l}\text { Poisson's } \\
\text { ratio }\end{array}$ & $\begin{array}{c}\text { Modulus of } \\
\text { elasticity, } \\
10^{6} \mathrm{psi}\end{array}$ & $\begin{array}{c}\text { Elastic } \\
\text { limit } \\
\text { stress, psi }\end{array}$ & $\begin{array}{l}\text { Ultimate } \\
\text { strain, } \\
\mu \text { in./in. }\end{array}$ \\
\hline \multirow[t]{12}{*}{121} & $72.189-1$ & 5.8 & 12,800 & 0.20 & 5.3 & 9,000 & 2,710 \\
\hline & 2 & 6.1 & 14,500 & 0.21 & 5.9 & 10,000 & 2,980 \\
\hline & 4 & 5.8 & 14,300 & 0.18 & 5.6 & 9,500 & 2,990 \\
\hline & 6 & 5.9 & 15,000 & 0.20 & 5.7 & 9,000 & 2,900 \\
\hline & 7 & 5.8 & 13,600 & 0.26 & 5.7 & 9,000 & 2,680 \\
\hline & $72.123-61 X$ & 5.5 & 13,300 & - & - & - & - \\
\hline & $62 \mathrm{~S}$ & 5.8 & 13,100 & - & - & - & - \\
\hline & $63 x$ & 6.1 & 15,400 & - & - & - & - \\
\hline & $64 X$ & 5.8 & 12,700 & - & - & - & - \\
\hline & $65 X$ & 6.1 & 11,500 & - & - & - & - \\
\hline & Mean & 5.9 & 13,600 & 0.21 & 5.6 & 9,300 & 2,850 \\
\hline & S.D. & - & 1,200 & 0.03 & 0.2 & 400 & 150 \\
\hline \multirow[t]{7}{*}{143} & $72.189-3$ & 5.9 & 12,900 & 0.21 & 5.1 & 8,500 & 3,220 \\
\hline & 5 & 6.0 & 12,900 & 0.16 & 5.0 & 9,000 & 2,750 \\
\hline & 8 & 6.1 & 12,900 & 0.21 & 5.2 & 9,000 & 3,230 \\
\hline & 9 & 5.9 & 12,900 & 0.21 & 4.6 & 8,000 & 5,120 \\
\hline & 10 & 6.3 & 11,400 & 0.20 & 4.8 & 8,500 & 2,680 \\
\hline & Mean & 6.0 & 12,600 & 0.20 & 5.0 & 8,600 & 3,000 \\
\hline & S.D. & - & 600 & 0.02 & 0.2 & 400 & 260 \\
\hline \multirow[t]{5}{*}{143} & $72,199-1$ & - & 4,500 & 0.17 & 3.3 & 1,400 & 1,660 \\
\hline & 2 & - & 4,600 & 0.19 & 3.0 & 1,500 & 2,560 \\
\hline & 3 & - & 4,500 & 0.12 & 3.2 & 1,600 & 1,810 \\
\hline & 4 & - & 4,900 & 0.16 & 3.3 & 1,600 & - \\
\hline & 5 & - & 4,400 & 0.15 & 3.3 & 1,600 & 2,340 \\
\hline & Mean & - & 4,600 & 0.16 & 3.2 & 1,500 & 2,090 \\
\hline & S.D. & - & 200 & 0.03 & 0.1 & 90 & 430 \\
\hline
\end{tabular}

Specimens, $6 \times 12$-in. cylinders of $\mathrm{CP}$-type concrete, oven-dried at $177^{\circ} \mathrm{C}$ prior to impregnation and thermal-catalytic polymerization.

Monomer, 70 wt \% MMA - 30 wt TMPTMA.

styrene-TMPTMA impregnated concrete averaged 14,600 psi.

Compressive strength and clastic properties of the MMA-TMPTMA impregnated concrete at $21^{\circ}, 121^{\circ}$, and $143^{\circ} \mathrm{C}$ are given in Table 50. Compressive strengths showed a decrease with increased temperature, averaging 17,500 psi at $21^{\circ} \mathrm{C}, 13,700$ psi at $121^{\circ} \mathrm{C}$, and $12,600 \mathrm{psi}$ at $143^{\circ} \mathrm{C}$.

Additional tests of compressive strength and elastic properties of MMA-TMPTMA impregnated concrete have been performed. Initial results from a series of tests to determine long-term effects of exposure at $-23^{\circ}, 21^{\circ}, 121^{\circ}$, and $143^{\circ} \mathrm{C}$ are given in Table 51. These specimens showed a similar decrease in compressive strength with increased temperature, averaging $18,100 \mathrm{psi}$ at $-23^{\circ} \mathrm{C}, 17,900$ psi ar $21^{\circ} \mathrm{C}, 12,800$ psi at $121^{\circ} \mathrm{C}$, and 12,300 psi at $143^{\circ} \mathrm{C}$. Initial results on specimens selected for long-term exposure in the threephase brine loops are given in Table 52. These specimens had an average compressive strength of $13,600 \mathrm{psi}$ at $121^{\circ} \mathrm{C}$, and $12,600 \mathrm{psi}$ at $143^{\circ} \mathrm{C}$.

A summary of average values for compressive strength and elastic properties for unimpregnated, styrene-TMPTMA impregnated, and MMATMPTMA impregnated concretes is given in Table 53. This table summarizes the data presented in Tables 49 to 52 and data on unimpregnated and 60 wt \% styrene - 40 wt \% TMPTMA impregnated concrete from Ref. 4 . 
Table 53

Average Values for Compressive Strength and Elastic Properties

Unimpregnated, Styrene-TMPTMA Impregnated, and MMA-TMPTMA Impregnated Concrete

\begin{tabular}{ccccccccc}
\hline $\begin{array}{c}\text { Concrete } \\
\text { type }\end{array}$ & $\begin{array}{c}\text { Polymer } \\
\text { loading, } \\
\text { wt \% }\end{array}$ & $\begin{array}{c}\text { Test } \\
\text { temperature, } \\
{ }^{\circ} \mathbf{C}\end{array}$ & $\begin{array}{c}\text { No. of } \\
\text { specimens }\end{array}$ & $\begin{array}{c}\text { Compressive } \\
\text { strength, psi }\end{array}$ & $\begin{array}{c}\text { Poisson's } \\
\text { ratio }\end{array}$ & $\begin{array}{c}\text { Modulus of } \\
\text { elasticity, } \\
10^{\boldsymbol{\theta}} \text { psi }\end{array}$ & $\begin{array}{c}\text { Elastic } \\
\text { limit } \\
\text { stress, psi }\end{array}$ & $\begin{array}{c}\text { Ultimate } \\
\text { strain, } \\
\mu \text { in./in. }\end{array}$ \\
\hline Unimpregnated & - & 21 & 10 & 5,000 & 0.16 & 3.5 & 1,200 & 2,320 \\
& - & 121 & 10 & 5,200 & 0.15 & 3.2 & 1,380 & 2,390 \\
& - & 143 & 15 & 4,900 & 0.15 & 3.1 & 1,290 & 2,450 \\
Styrene-TMPTMA & - & 177 & 10 & 5,000 & 0.14 & 2.9 & 1,140 & 2,630 \\
& 5.7 & 21 & 12 & 16,900 & 0.21 & 6.4 & 10,500 & 2,920 \\
& 5.6 & 121 & 12 & 16,100 & 0.21 & 6.0 & 9,800 & 2,960 \\
& 5.5 & 143 & 12 & 15,000 & 0.19 & 5.3 & 8,200 & 2,600 \\
MMA-TMPTMA & 5.6 & 177 & 10 & 14,600 & 0.18 & 5.3 & 9,900 & 2,950 \\
& 6.4 & -23 & 10 & 18,100 & 0.19 & 5.9 & 13,600 & 3,280 \\
& 6.0 & 21 & 15 & 17,700 & 0.20 & 6.0 & 12,400 & 3,170 \\
& 6.0 & 121 & 25 & 13,500 & 0.19 & 5.2 & 9,200 & 3,020 \\
& 6.0 & 143 & 20 & 12,500 & 0.17 & 4.7 & 8,900 & 2,970 \\
\hline
\end{tabular}

Specimens, $6 \times 12$-in. cylinders of CP-type concrete, oven-dried at $177^{\circ} \mathrm{C}$ prior to impregnation and thermal-catalytic polymerization.

Monomers, 60 wt \% styrene - 40 wt \% TMPTMA; 70 wt \% MMA - 30 wt \% TMPTMA.

Table 54

Direct Tensile Strength of Unimpregnated Concrete After Short-Term Exposure at $21^{\circ}, 121^{\circ}$, and $143^{\circ} \mathrm{C}$

\begin{tabular}{|c|c|c|c|c|c|c|}
\hline $\begin{array}{c}\text { Test } \\
\text { temperature, }{ }^{\circ} \mathbf{C}\end{array}$ & $\begin{array}{c}\text { Specimen No., } \\
6.2 .1-\end{array}$ & $\begin{array}{l}\text { Tensile } \\
\text { strength, psi }\end{array}$ & $\begin{array}{l}\text { Poisson's } \\
\text { ratio }\end{array}$ & $\begin{array}{l}\text { Modulus of } \\
\text { elasticity, } \\
10^{6} \mathrm{psi}\end{array}$ & 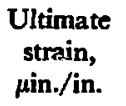 & $\begin{array}{l}\text { Type of } \\
\text { failure }\end{array}$ \\
\hline \multirow[t]{2}{*}{21} & $\begin{array}{l}4021 \\
4029 \\
4030 \\
4032\end{array}$ & $\begin{array}{l}320 \\
250 \\
300 \\
360\end{array}$ & $\begin{array}{l}- \\
0.14 \\
- \\
-\end{array}$ & $\begin{array}{l}3.9 \\
3.8 \\
4.5 \\
4.1\end{array}$ & $\begin{array}{r}148 \\
78 \\
162 \\
154\end{array}$ & $\begin{array}{l}\text { OF } \\
\text { MF } \\
\text { MF } \\
\text { MF }\end{array}$ \\
\hline & $\begin{array}{l}\text { Mean } \\
\text { S.D. }\end{array}$ & $\begin{array}{r}310 \\
50\end{array}$ & 0.14 & $\begin{array}{l}4.1 \\
0.3\end{array}$ & $\begin{array}{c}136 \\
-\end{array}$ & \\
\hline \multirow[t]{2}{*}{121} & $\begin{array}{l}4024 \\
4028 \\
n n^{2} 1 \\
4033\end{array}$ & $\begin{array}{l}280 \\
240 \\
150 \\
230\end{array}$ & $\begin{array}{c}- \\
\overline{0} 10 \\
-\end{array}$ & $\begin{array}{l}2.9 \\
3.2 \\
2.9 \\
3.0\end{array}$ & $\begin{array}{r}169 \\
184 \\
89 \\
205\end{array}$ & $\begin{array}{l}\text { MF } \\
\text { MF } \\
\text { GF } \\
\text { MF }\end{array}$ \\
\hline & $\begin{array}{l}\text { Mean } \\
\text { S.D. }\end{array}$ & $\begin{array}{r}220 \\
50\end{array}$ & $\begin{array}{c}0.10 \\
-\end{array}$ & $\begin{array}{l}3.0 \\
0.1\end{array}$ & $\begin{array}{c}162 \\
-\end{array}$ & \\
\hline \multirow[t]{2}{*}{143} & $\begin{array}{l}4022 \\
4023 \\
4025 \\
4026\end{array}$ & $\begin{array}{l}230 \\
230 \\
260 \\
200\end{array}$ & $\begin{array}{l}- \\
- \\
-\end{array}$ & $\begin{array}{l}2.5 \\
2.8 \\
3.0 \\
2.7\end{array}$ & $\begin{array}{l}152 \\
153 \\
177 \\
141\end{array}$ & $\begin{array}{l}\text { OF } \\
\text { MF } \\
\text { MF } \\
\text { MF }\end{array}$ \\
\hline & $\begin{array}{l}\text { Mean } \\
\text { S.D. }\end{array}$ & $\begin{array}{r}230 \\
20\end{array}$ & - & $\begin{array}{l}2.8 \\
0.2\end{array}$ & 156 & \\
\hline
\end{tabular}

\section{Direct tension test.}

Specimens, $41 / 6 \times 121 / 2-i n$. cylinders of CP-type concrete.

- MF = failed in middle of specimen; $O F=$ failed outside recessed portion of end plate. 
Table 55

Direct Tensile Strength of Styrene-TMPTMA Impregnated Concrete After Short-Term Exposure at $21^{\circ}, 121^{\circ}$, and $143^{\circ} \mathrm{C}$

\begin{tabular}{|c|c|c|c|c|c|c|c|}
\hline $\begin{array}{c}\text { Test } \\
\text { temperature, } \\
{ }^{\circ} \mathrm{C}\end{array}$ & $\begin{array}{c}\text { Specimen } \\
\text { No., } \\
6.2 .1-\end{array}$ & $\begin{array}{c}\text { Polymer } \\
\text { loading, } \\
\text { wt \% }\end{array}$ & $\begin{array}{c}\text { Tensile } \\
\text { strength, } \\
\text { psi }\end{array}$ & $\begin{array}{l}\text { Poisson's } \\
\text { ratio }\end{array}$ & $\begin{array}{c}\text { Madulus of } \\
\text { elasticity, } \\
10^{6} \mathrm{psi}\end{array}$ & $\begin{array}{l}\text { Ultimate } \\
\text { strain, } \\
\mu \text { in./in. }\end{array}$ & $\begin{array}{l}\text { Type of } \\
\text { failure }\end{array}$ \\
\hline 21 & $\begin{array}{l}4001 \\
4007 \\
4011 \\
4013 \\
4016\end{array}$ & $\begin{array}{l}5.4 \\
5.4 \\
5.4 \\
5.8 \\
5.4\end{array}$ & $\begin{array}{r}960 \\
1130 \\
1190 \\
1180 \\
990\end{array}$ & $\begin{array}{l}0.20 \\
- \\
- \\
- \\
-\end{array}$ & $\begin{array}{l}7.2 \\
6.7 \\
7.1 \\
6.8 \\
6.6\end{array}$ & $\begin{array}{l}159 \\
178 \\
184 \\
180 \\
159\end{array}$ & $\begin{array}{l}\text { OF } \\
\text { EF } \\
\text { OF } \\
\text { OF } \\
\text { OF }\end{array}$ \\
\hline & $\begin{array}{l}\text { Mean } \\
\text { S.D. }\end{array}$ & $\begin{array}{l}5.5 \\
-\end{array}$ & $\begin{array}{r}1090 \\
110\end{array}$ & $\begin{array}{c}0.20 \\
-\end{array}$ & $\begin{array}{l}6.9 \\
0.3\end{array}$ & $\begin{array}{c}172 \\
-\end{array}$ & \\
\hline 121 & $\begin{array}{l}4002 \\
4004 \\
4008 \\
4012 \\
4017\end{array}$ & $\begin{array}{l}5.8 \\
5.4 \\
5.4 \\
5.4 \\
5.4\end{array}$ & $\begin{array}{r}860 \\
880 \\
1040 \\
800 \\
890\end{array}$ & $\begin{array}{l}\overline{0} \\
- \\
- \\
-\end{array}$ & $\begin{array}{l}6.2 \\
6.4 \\
6.4 \\
5.8 \\
6.0\end{array}$ & $\begin{array}{l}144 \\
140 \\
129 \\
158 \\
158\end{array}$ & $\begin{array}{l}\mathbf{E F} \\
\text { OF } \\
\mathbf{E F} \\
\mathbf{M F} \\
\mathbf{E F}\end{array}$ \\
\hline & $\begin{array}{l}\text { Mean } \\
\text { S.D. }\end{array}$ & $\begin{array}{c}5.5 \\
-\end{array}$ & $\begin{array}{c}890 \\
90\end{array}$ & $\begin{array}{c}0.22 \\
-\end{array}$ & $\begin{array}{l}6.2 \\
0.3\end{array}$ & $\begin{array}{c}146 \\
-\end{array}$ & \\
\hline 143 & $\begin{array}{l}4005 \\
4006 \\
4010 \\
4015 \\
4019\end{array}$ & $\begin{array}{l}5.4 \\
5.8 \\
5.4 \\
5.4 \\
5.4\end{array}$ & $\begin{array}{l}800 \\
900 \\
970 \\
870 \\
730\end{array}$ & $\begin{array}{l}0.19 \\
- \\
- \\
- \\
-\end{array}$ & $\begin{array}{l}5.9 \\
5.9 \\
6.1 \\
5.7 \\
5.4\end{array}$ & $\begin{array}{l}152 \\
152 \\
178 \\
155 \\
157\end{array}$ & $\begin{array}{l}\mathbf{E F} \\
\mathbf{E F} \\
\mathbf{E F} \\
\mathbf{E F} \\
\mathbf{M F}\end{array}$ \\
\hline & $\begin{array}{l}\text { Mean } \\
\text { S.D. }\end{array}$ & $\begin{array}{l}5.5 \\
-\end{array}$ & $\begin{array}{r}850 \\
90\end{array}$ & $\begin{array}{c}0.19 \\
-\end{array}$ & $\begin{array}{l}5.8 \\
0.3\end{array}$ & $\begin{array}{c}161 \\
-\end{array}$ & \\
\hline
\end{tabular}

Direct tension test.

Specimens, $4^{1 / 2} \times 12 \frac{1}{2}$-in. cylinders of CP-type concrete, oven-dried at $177^{\circ} \mathrm{C}$ prior to impregnation and thermalcatalytic polymerization.

Monomer, 60 wt \% styrene - 40 wt \% TMPTMA.

-MF = failed in middle of specimen; $O F=$ failed outside recessed portion of end plate; $E F=$ failed inside end plate.

5.2.1.2 Tewste SThenorh. Tensile strengths from direct tension tests and tensile splitting tests have been obtained for PIC and unimpregnated concrete at various temperatures ranging from $-21^{\circ}$ to $177^{\circ} \mathrm{C}$. Test results at the various temperatures are considered to be short-term effects, since the specimens are exposed only long enough to obtain a uniform temperature. The direct tension tests are performed on $4 \frac{1}{2} \times 12^{1 / 3}$-in. cylinders, and the tensile splitting tests are performed on $6 \times 12$-in. cylinders. A summary of direct tensile and tensile splitting strengths, and design values obtained from these results, is given in Table 48 .

Tensile strength and elastic properties from direct tension tests of unimpregnated and $60 \mathrm{wt} \%$ styrene - 40 wt \% TMPTMA impregnated con- crete at $21^{\circ}, 121^{\circ}$ and $143^{\circ} \mathrm{C}$ are given in Tables 54 and 55 . Elastic properties were determined by electrical resistance strain gages bonded to the test cylinders, and three test runs were made on each cylinder. Data from the first two were used to determine Poisson's ratio and modulus of elasticity. Poisson's ratio was determined for only a few specimens because of the low strain level of direct tension tests. The third run was used to obtain stress-strain data to failure.

A cross-sectional view of the direct tension test and types of failure are shown in Figure 21. The end failures and failures within 4 -in. of the end plate were not considered significant, since the strengths of these specimens were not greatly different from those of specimens with middle failures. 
Table $56^{\circ}$

Comparison of Direct Tensile Strength With Tensile Splitting Strength, Unimpregnated and Styrene-TMPTMA Impregnated Concrete

\begin{tabular}{|c|c|c|c|c|}
\hline \multirow[b]{2}{*}{$\begin{array}{l}\text { Type of } \\
\text { concrete }\end{array}$} & \multirow[b]{2}{*}{$\begin{array}{c}\text { Test } \\
\text { temper- } \\
\text { ature, }{ }^{\circ} \mathrm{C}\end{array}$} & \multicolumn{3}{|c|}{ Tensile strength, ${ }^{\mathbf{a}}$ psi } \\
\hline & & $\begin{array}{l}\text { Tensile } \\
\text { splitting }\end{array}$ & $\begin{array}{c}85 \% \text { of } \\
\text { tensile } \\
\text { splittingb }\end{array}$ & $\begin{array}{l}\text { Direct } \\
\text { tension }\end{array}$ \\
\hline S-TMPTMAc & $\begin{array}{r}21 \\
121 \\
143\end{array}$ & $\begin{array}{l}890 \\
880 \\
920\end{array}$ & $\begin{array}{l}760 \\
750 \\
780\end{array}$ & $\begin{array}{r}1090 \\
890 \\
850\end{array}$ \\
\hline Unimpregnated & $\begin{array}{r}21 \\
121 \\
143\end{array}$ & $\begin{array}{l}340 \\
310 \\
370\end{array}$ & $\begin{array}{l}290 \\
260 \\
310\end{array}$ & $\begin{array}{l}310 \\
220 \\
230\end{array}$ \\
\hline
\end{tabular}

Specimens, $41 / 2 \times 121 / 2$-in. cylinders for direct tension tests; $6 \times 12$-in. cylinders for tensile splitting tests.

- Values are averages for 4 or 5 specimens for direct tension tests and 10 specimens for tensile splitting tests.

b Empirical factor sometimes used with unimpregnated concrete to approximate direct strength from tensile splitting tests.

c 60 wt \% styrene - 40 wt \% TMPTMA, thermal-catalytically polymerized.

The direct tension tests for unimpregnated concrete and the styrene-TMPTMA impregnated concrete show a loss of tensile strength and a lower modulus of elasticity with an increase in test temperature. Tensile strength of the impregnated concrete averaged $1090 \mathrm{psi}$ at $21^{\circ} \mathrm{C}, 890 \mathrm{psi}$ at $121^{\circ} \mathrm{C}$, and 850 psi at $143^{\circ} \mathrm{C}$. Tensile strength of unimpregnated concrete averaged $310 \mathrm{psi}$ at $21^{\circ} \mathrm{C}$, $220 \mathrm{psi}$ at $121^{\circ} \mathrm{C}$, and $230 \mathrm{psi}$ at $143^{\circ} \mathrm{C}$.

A comparison of the direct tension tests with previously reported 4 tensile splitting tests at $21^{\circ}$, $121^{\circ}$, and $143^{\circ} \mathrm{C}$ is given in Table 56 . Tensile splitting strengths for unimpregnated concrete run consistently higher than the direct tensile strengths. For the styrene-TMPTMA impregnated concrete, tensile splitting strengths showed no significant variation with temperature and were closely grouped at about $900 \mathrm{psi}$, whereas the direct tensile strengths ranged from 1090 psi at $21^{\circ} \mathrm{C}$ to 850 si at $143^{\circ} \mathrm{C}$. Table 56 also lists a computed value tor tensile strength determined by multiplying the tensile splitting strength by 0.85 , which is used to approximate the direct tensile strength of unimpregnated concrete from tensile splitting strength tests. These computed values for styrene-TMPTMA impregnated concrete are consistently low-
Table 57

Tensile Splitting Strength After Short-Term Exposure at $177^{\circ} \mathrm{C}$, Unimpregnated and Styrene-TMPTMA Impregnated CP-Type Concrete

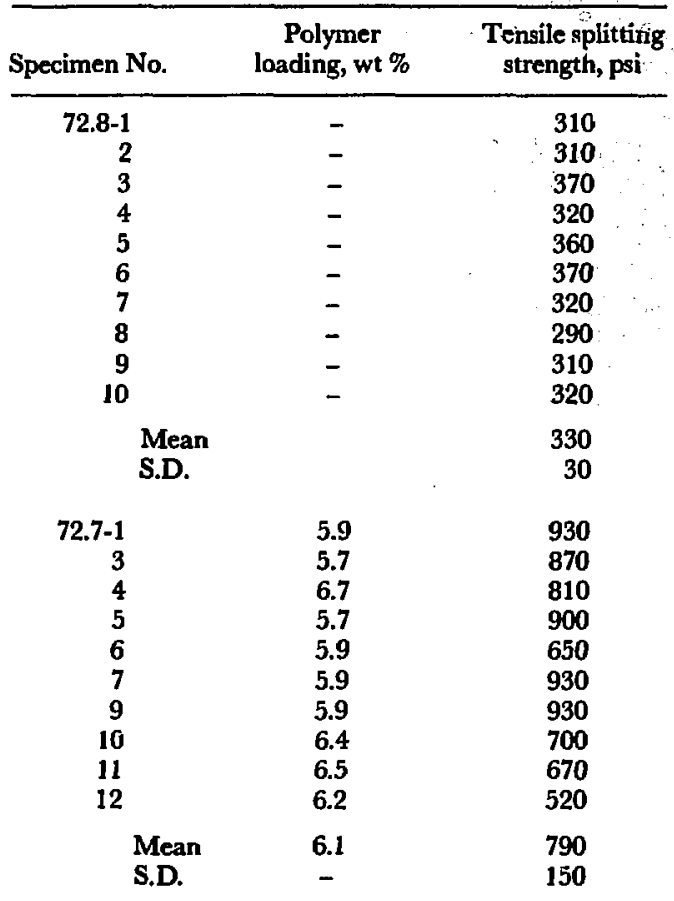

Specimens, $6 \times 12$-in. cylinders, oven-dried at $177^{\circ} \mathrm{C}$ prior to impregnation and thermal-catalytic polymerization.

Monomer, 60 wt \% styrene -40 wt \% TMPTMA.

er (by 70 to $330 \mathrm{psi}$ ) than comparable direct tensile strengths, and use of the $\mathbf{0 . 8 5}$ factor does not appear to be valid for PIC. Further test .. e required to determine whether a factor should be applied to approximate direct tensile strength from tensile splitting tests.

Tensile splitting test results at $177^{\circ} \mathrm{C}$ are shown in Table 57 for unimpregnated and styrene-TMP. TMA concrete. Tensile splitting strength averaged 790 psi for the impregnated concrete, and 330 psi for the unimpregnated.

Tensile splitting test results at $21^{\circ}, 121^{\circ}$, and $143^{\circ} \mathrm{C}$ for MMA-TMPTMA impregnated concrete are given in Table $\$ 3$. These tests show a decrease in tensile splitting strength with an increase in temperature, from 1030 psi at $21^{\circ} \mathrm{C}$, to $990 \mathrm{psi}$ at $121^{\circ} \mathrm{C}$, and $880 \mathrm{psi}$ at $143^{\circ} \mathrm{C}$.

Additional tensile splitting tests were performed at $-23^{\circ}, 21^{\circ}, 121^{\circ}$, and $143^{\circ} \mathrm{C}$ on another group 
of specimens also impregnated with MMA-TMPTMA (Table 59). These are initial tests on specimens selected for long-term exposire at these four temperatures. Tensile splitting strength averaged 1040 psi at $-23^{\circ} \mathrm{C}, 970$ psi at $21^{\circ} \mathrm{C}, 990 \mathrm{psi}$ at $121^{\circ} \mathrm{C}$, and 860 psi at $143^{\circ} \mathrm{C}$.

Table 58

Tensile Splitting Strength After Short-Term Exposure at Various Temperatures, MMA-TMPTMA Impregnated Concrete

\begin{tabular}{cccc}
$\begin{array}{c}\text { Test } \\
\text { temperature, } \\
{ }^{\circ} \mathbf{C}\end{array}$ & $\begin{array}{c}\text { Specimen } \\
\text { No., } \\
72.95-\end{array}$ & $\begin{array}{c}\text { Polymer } \\
\text { loading, wt \% }\end{array}$ & $\begin{array}{c}\text { Tensile } \\
\text { splitting } \\
\text { strength, psi }\end{array}$ \\
\hline 21 & 1 & 5.9 & 850 \\
& 2 & 6.1 & 1030 \\
& 4 & 6.4 & 1100 \\
& 5 & 5.9 & 1090 \\
& 10 & 5.9 & 1000 \\
& 11 & 5.9 & 1010 \\
& 12 & 5.8 & 1080 \\
& 15 & 6.4 & 940 \\
& 29 & 6.2 & 1020 \\
& 32 & 5.6 & 1120 \\
& Mean & 6.0 & 1030 \\
& S.D. & - & $9 \sqrt{7}$
\end{tabular}

121

\begin{tabular}{|c|c|c|}
\hline 6 & 6.2 & 960 \\
\hline 13 & 6.1 & 920 \\
\hline 17 & 5.9 & 1060 \\
\hline 18 & 6.1 & 970 \\
\hline 20 & 5.9 & 1100 \\
\hline 23 & 5.9 & 960 \\
\hline 24 & 6.4 & 970 \\
\hline 25 & 6.1 & 1050 \\
\hline 28 & 5.9 & 1030 \\
\hline 34 & 6.2 & 900 \\
\hline Mean & 6.1 & 990 \\
\hline S.D. & - & 60 \\
\hline
\end{tabular}

143

\begin{tabular}{|c|c|c|}
\hline $\begin{array}{r}7 \\
14 \\
16 \\
21 \\
26 \\
27 \\
30 \\
33 \\
35 \\
36\end{array}$ & $\begin{array}{l}6.1 \\
5.6 \\
6.1 \\
6.7 \\
5.9 \\
5.6 \\
5.6 \\
5.9 \\
5.9 \\
6.4\end{array}$ & $\begin{array}{r}950 \\
990 \\
970 \\
940 \\
710 \\
770 \\
990 \\
740 \\
770 \\
1020\end{array}$ \\
\hline $\begin{array}{l}\text { Mean } \\
\text { S.D. }\end{array}$ & $\begin{array}{c}6.0 \\
-\end{array}$ & $\begin{array}{l}880 \\
120\end{array}$ \\
\hline
\end{tabular}

Specimens, $6 \times 12$-in. cylinders of CP-type concrete, oven-dried at $177^{\circ} \mathrm{C}$ prior to impregnation and thermalcatalytic polymerization.

Monomer, 70 wt \% MMA - 30 wt \% TMPTMA.
Tensile Splitting Strength After Short-Term Exposure of MMA-TMPTMA Impregnated Concrete at Various Temperatures - Initial Tests for Long-Term Exposure

\begin{tabular}{|c|c|c|c|}
\hline $\begin{array}{c}\text { Test } \\
\text { temperature, } \\
{ }^{\circ} \mathrm{C}\end{array}$ & $\begin{array}{c}\text { Specimen } \\
\text { No., } \\
72.196-\end{array}$ & $\begin{array}{c}\text { Polymer } \\
\text { loading, wt \% }\end{array}$ & $\begin{array}{c}\text { Tensile } \\
\text { splitting } \\
\text { strength, psi }\end{array}$ \\
\hline-23 & $\begin{array}{r}3 \\
4 \\
6 \\
10 \\
18 \\
22 \\
26 \\
30 \\
31 \\
42\end{array}$ & $\begin{array}{l}5.8 \\
7.2 \\
6.3 \\
6.6 \\
6.6 \\
6.7 \\
6.1 \\
6.7 \\
6.3 \\
6.5\end{array}$ & $\begin{array}{r}950 \\
940 \\
1070 \\
1140 \\
1060 \\
1090 \\
1120 \\
1020 \\
970 \\
1030\end{array}$ \\
\hline & $\begin{array}{l}\text { Mean } \\
\text { S.D. }\end{array}$ & $\begin{array}{l}6.5 \\
-\end{array}$ & $\begin{array}{r}1040 \\
70\end{array}$ \\
\hline 21 & $\begin{array}{r}2 \\
5 \\
11 \\
12 \\
15 \\
19 \\
20 \\
28 \\
34 \\
37\end{array}$ & $\begin{array}{l}6.4 \\
6.6 \\
6.7 \\
6.3 \\
6.9 \\
6.6 \\
6.7 \\
6.3 \\
6.1 \\
6.6\end{array}$ & $\begin{array}{r}970 \\
1000 \\
940 \\
1090 \\
1010 \\
980 \\
950 \\
790 \\
1040 \\
970\end{array}$ \\
\hline & $\begin{array}{l}\text { Mean } \\
\text { S.D. }\end{array}$ & $\begin{array}{c}6.5 \\
-\end{array}$ & $\begin{array}{r}970 \\
80\end{array}$ \\
\hline
\end{tabular}

121

$\begin{array}{rcr}1 & 7.2 & 1080 \\ 7 & 6.4 & 1070 \\ 8 & 7.0 & 930 \\ 9 & 6.6 & 960 \\ 17 & 6.9 & 1050 \\ 21 & 6.6 & 1130 \\ 24 & 6.3 & 990 \\ 35 & 6.1 & 920 \\ 36 & 5.8 & 950 \\ 41 & 6.1 & 960 \\ \text { Mean } & 6.5 & 990 \\ \text { S.D. } & - & 90\end{array}$

143

$\begin{array}{llr}13 & 6.3 & 640 \\ 14 & 6.1 & 810 \\ 16 & 7.1 & 930 \\ 23 & 6.7 & 810 \\ 25 & 6.6 & 800 \\ 27 & 6.9 & 800 \\ 29 & 6.1 & 1020 \\ 32 & 6.0 & 990 \\ 33 & 6.3 & 890 \\ 40 & 6.9 & 860 \\ \text { Mean } & 6.5 & 860 \\ \text { S.D. } & - & 110\end{array}$

Specimens, $6 \times 12$-in. cylinders of CP-type concrete, oven-dried at $177^{\circ} \mathrm{C}$ prior to impregnation and thermalcatalytic polymerization.

Monomer, 70 wt \% MMA - 30 wt \% TMPTMA. 
Table 60)

Flexural Strength of Unimpregnated Concrete and Styrene-TMPTMA Impregnated Concrete at $21^{\circ} \mathrm{C}$

\begin{tabular}{ccccccc}
\hline $\begin{array}{c}\text { Specimen } \\
\text { No. }\end{array}$ & $\begin{array}{c}\text { Polymer } \\
\text { loading, wt } \%\end{array}$ & $\begin{array}{c}\text { Ultimatc } \\
\text { load, } \mathbf{l b}\end{array}$ & $\begin{array}{c}\text { Modulus of } \\
\text { rupture, psi }\end{array}$ & $\begin{array}{c}\text { Modulus of } \\
\text { elasticity, } 10^{8} \text { psi }\end{array}$ & Shear, lb & $\begin{array}{c}\text { Nominal shear } \\
\text { stress, psi }\end{array}$ \\
\hline $72.27-1$ & - & 3960 & 745 & 4.39 & 1980 & 124 \\
2 & - & 3580 & 675 & 4.25 & 1790 & 112 \\
3 & - & 3820 & 720 & 4.40 & 1910 & 119 \\
4 & - & 3550 & 665 & 3.99 & 1775 & 111 \\
5 & - & 3960 & 745 & 4.63 & 1980 & 124 \\
Mean & - & 3775 & 710 & 4.33 & 1888 & 6 \\
$72.26-1$ & 5.9 & 8980 & 1690 & 6.24 & 4490 & 281 \\
5 & 6.2 & 8400 & 1580 & 6.36 & 4200 & 262 \\
8 & 7.0 & 6900 & 1300 & 6.22 & 3450 & 216 \\
10 & 7.0 & 6800 & 1280 & 6.36 & 3400 & 212 \\
16 & 5.8 & 8060 & 1515 & 5.95 & 4030 & 252 \\
Mean & 6.4 & 7830 & 1475 & 6.23 & 3915 & 245 \\
\hline
\end{tabular}

Specimens, $4 \times 4 \times 30$-in. bars of CP-type concrete, oven-dried at $177^{\circ} \mathrm{C}$ prior to impregnation and thermal-catalytic polymerization.

Monomer, 60 wt \% styrene - 40 wt \% TMPTMA.

Table 61

Flexural Strength of Unimpregnated Concrete and Styrene-TMPTMA Impregnated Concrete After Short-Term Exposure at $121^{\circ} \mathrm{C}$

\begin{tabular}{crrrrrr}
\hline $72.27-6$ & - & 3210 & 605 & 3.26 & 1605 & 100 \\
7 & - & 1985 & 375 & 2.88 & 993 & 62 \\
8 & - & 3370 & 635 & 3.38 & 1685 & 105 \\
9 & - & 3280 & 615 & 3.11 & 1640 & 103 \\
10 & - & 2895 & 545 & 3.28 & 1448 & 91 \\
Nean & - & 2950 & 555 & 3.18 & 1474 & 92 \\
$72.26-2$ & 6.6 & 5920 & 1115 & 4.84 & 2960 & 185 \\
4 & 6.3 & 7080 & 1130 & 4.81 & 3540 & 221 \\
6 & 5.9 & 7020 & 1320 & 5.52 & 3510 & 219 \\
11 & 6.5 & 5300 & 995 & 5.40 & 2650 & 166 \\
13 & 6.5 & 6000 & 1130 & 5.48 & 3000 & 188 \\
Mean & 6.4 & 6265 & 1180 & 5.21 & 3132 & 196
\end{tabular}

Specimens, $4 \times 4 \times 30$-in. bars of CP-type concrete, oven-dried at $177^{\circ} \mathrm{C}$ prior to impregnation and thermal-catalytic polymerization.

Monomer, 60 wt \% styrene - 40 wt \% TMPTMA.

Test temperature, $121^{\circ} \mathrm{C}$.

Table 62

Flexural Strength of Unimpregnated Concrete and Styrene-TMPTMA

Impregnated Concrete After Short-Term Exposure at $143^{\circ} \mathrm{C}$

\begin{tabular}{|c|c|c|c|c|c|c|}
\hline $72.27-11$ & - & 3815 & 715 & 3.42 & 1908 & 119 \\
\hline 12 & - & 3130 & 590 & 3.29 & 1565 & 98 \\
\hline $\mathbf{x}$ & - & 3570 & 670 & 3.21 & 1785 & 112 \\
\hline 14 & - & 3250 & 610 & 3.13 & 1625 & 102 \\
\hline 15 & - & 3510 & 660 & 3.43 & 1755 & 110. \\
\hline Mean & - & 3455 & 650 & 3.30 & 1728 & 108 \\
\hline $\begin{array}{r}72.26-7 \\
9 \\
12 \\
14 \\
15\end{array}$ & $\begin{array}{l}6.8 \\
6.4 \\
6.4 \\
6.3 \\
6.0\end{array}$ & $\begin{array}{l}6760 \\
7060 \\
5920 \\
6320- \\
7080\end{array}$ & $\begin{array}{l}1270 \\
1330 \\
1115 \\
1190 \\
1330\end{array}$ & $\begin{array}{l}5.21 \\
5.05 \\
5.72 \\
5.38 \\
5.13\end{array}$ & $\begin{array}{l}3380 \\
3530 \\
2960 \\
3160 \\
3540\end{array}$ & $\begin{array}{l}211 \\
221 \\
185 \\
198 \\
221\end{array}$ \\
\hline Mean & 6.4 & 6630 & 1245 & 5.30 & 3315 & 207 \\
\hline
\end{tabular}

Specimens, $4 \times 4 \times 30$-in. bars of CP-type concrete, oven-dried a $177^{\circ} \mathrm{C}$ prior to impregnation and thermaliotitalytic polymerization.

Monomer, $j 0 \mathrm{wt} \%$ styrene - $40 \mathrm{wt} \%$ TMPTMA.

Tent temperature, $143^{\circ} \mathrm{C}$. 


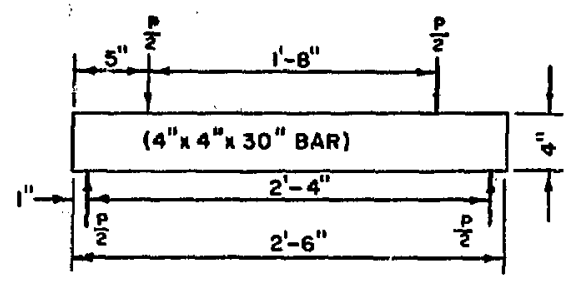

Figure 27. Flexure test of $4 \times 4 \times 30$-in. bars of unimpregnated and 60 wt \% styrene -40 wt \%.TMPTMA impregnated CP-type concrete.

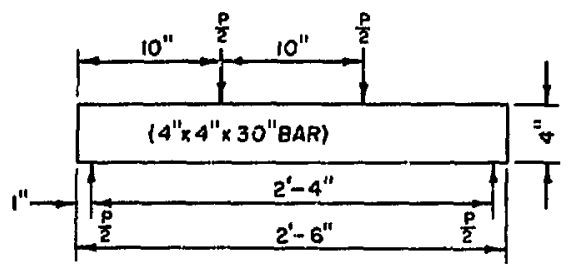

Figure 28. Flexure test of $4 \times 4 \times 30$-in. bars of $70 \mathrm{wt} \%$ MMA - 30 wt \% TMPTMA impregnated CP-type concrete.

Table 63

Flexural Strength of MMA-TMPTMA Impregnated Concrete at $21^{\circ} \mathrm{C}$

\begin{tabular}{|c|c|c|c|c|c|c|}
\hline $\begin{array}{c}\text { Specimen No. } \\
72.110\end{array}$ & $\begin{array}{c}\text { Polymer } \\
\text { loading, wt \% }\end{array}$ & $\begin{array}{l}\text { Ultimate } \\
\text { load, lb }\end{array}$ & $\begin{array}{l}\text { Modulus of } \\
\text { rupture, psi }\end{array}$ & $\begin{array}{l}\text { Modulus of } \\
\text { elasticity, } 10^{6} \mathrm{psi}\end{array}$ & Shear, lb & $\begin{array}{l}\text { Nominal shear } \\
\text { stress, psi }\end{array}$ \\
\hline 1 & 6.1 & $a$ & - & 6.34 & - & - \\
\hline 2 & 6.3 & 3900 & 1650 & 5.64 & 1950 & 122 \\
\hline 3 & 6.2 & 3765 & 1590 & 5.81 & 1880 & 118 \\
\hline 4 & 6.9 & 4255 & 1800 & 6.39 & 2130 & 133 \\
\hline 14 & 6.0 & 4175 & 1760 & 5.41 & 2090 & 131 \\
\hline Mean & 6.3 & 4020 & 1700 & 5.92 & 2010 & 126 \\
\hline
\end{tabular}

Specimers, $4 \times 4 \times 30$-in. bars of CP-type concrete, oven-dried at $177^{\circ} \mathrm{C}$ prior to impregnation and thermal-catalytic polymerization.

Monomer, 70 wt \% MMA - 30 wt \% TMPTMA.

Accidentally failed.

Table 64

Flexural Strength of MMA-TMPTMA Impregnated Concrete

After Short-Term Exposure at $121^{\circ} \mathrm{C}$

\begin{tabular}{ccccccc}
\hline 6 & 6.7 & 2850 & 1200 & 4.35 & 1425 & 89 \\
7 & 6.5 & 2630 & 1110 & 4.74 & 1315 & 82 \\
8 & 6.5 & 2715 & 1150 & 4.76 & 1360 & 85 \\
9 & 6.5 & 2810 & 1190 & 4.89 & 1405 & 88 \\
10 & 5.2 & 2550 & 1080 & 4.61 & 1280 & 80 \\
Mean & 6.3 & 2710 & 1150 & 4.67 & 1360 & 85 \\
\hline
\end{tabular}

Specimens, $4 \times 4 \times 30$-in. bars of CP-type concrete, oven-dried at $177^{\circ} \mathrm{C}$ prior to impregnation and thermal-catalytic polymerization.

Monomer, 70 wt \% MMA - 30 wt \% TMPTMA.

Test temperature, $121^{\circ} \mathrm{C}$.

Table 65

Flexural Strength of MMA-TMPTMA Impregnated Concrete After Short-Term Exposure at $143^{\circ} \mathrm{C}$

\begin{tabular}{ccccccc}
\hline 5 & 6.6 & 2225 & 940 & 4.35 & 1110 & 69 \\
11 & 6.0 & 2810 & 1190 & 4.52 & 1405 & 88 \\
12 & 6.8 & 2720 & 1150 & 4.52 & 1360 & 85 \\
13 & 6.3 & 2900 & 1220 & 4.84 & 1450 & 91 \\
15 & 5.8 & 2805 & 1180 & 4.80 & 1400 & 88 \\
Mean & 6.3 & 2690 & 1140 & 4.61 & 1345 & 84 \\
\hline
\end{tabular}

Specimens, $4 \times 4 \times 30$-in. bars of CP-type concrete, oven-dried at $177^{\circ} \mathrm{C}$ prior to impregnation and thermal-catalytic polymerization.

Monomer, 70 wt \% MMA - 30 wt \% TMPTMA.

Test temperature, $143^{\circ} \mathrm{C}$. 
Table 66

Average Values for Strength and Modulus of Elasticity as Determined From Flexure Tests

\begin{tabular}{|c|c|c|c|c|c|c|c|c|}
\hline \multirow[b]{2}{*}{$\begin{array}{l}\text { Type of } \\
\text { material }\end{array}$} & \multirow[b]{2}{*}{$\begin{array}{c}\text { Test } \\
\text { temperature, } \\
{ }^{\circ} \mathrm{C}\end{array}$} & \multicolumn{4}{|c|}{ Flexure tests } & \multicolumn{3}{|c|}{ Compressive tests } \\
\hline & & $\begin{array}{c}\text { Polymer } \\
\text { loading, } \\
\text { wt \% }\end{array}$ & $\begin{array}{c}\text { No. of } \\
\text { specimens }\end{array}$ & $\begin{array}{l}\text { Modulus of } \\
\text { rupture, } \\
\text { psi }\end{array}$ & $\begin{array}{c}\text { Modulus of } \\
\text { elasticity, } \\
10^{6} \mathrm{psi}\end{array}$ & $\begin{array}{c}\text { Polymer } \\
\text { loading, } \\
\text { wt \% }\end{array}$ & $\begin{array}{c}\text { No. of } \\
\text { specimens }\end{array}$ & $\begin{array}{l}\text { Modulus of } \\
\text { elasticity, } \\
10^{6} \mathrm{psi}\end{array}$ \\
\hline Control & $\begin{array}{r}21 \\
121 \\
143\end{array}$ & $\begin{array}{l}- \\
-\end{array}$ & $\begin{array}{l}5 \\
5 \\
5\end{array}$ & $\begin{array}{l}710 \\
555 \\
650\end{array}$ & $\begin{array}{l}4.3 \\
3.2 \\
3.3\end{array}$ & $\begin{array}{l}- \\
-\end{array}$ & $\begin{array}{l}10 \\
10 \\
10\end{array}$ & $\begin{array}{l}3.5 \\
3.2 \\
3.0\end{array}$ \\
\hline S-TMPTMAa & $\begin{array}{r}21 \\
121 \\
143\end{array}$ & $\begin{array}{l}6.4 \\
6.4 \\
6.4\end{array}$ & $\begin{array}{l}5 \\
5 \\
5\end{array}$ & $\begin{array}{l}1475 \\
1180 \\
1245\end{array}$ & $\begin{array}{l}6.3 \\
5.2 \\
5.3\end{array}$ & $\begin{array}{l}5.7 \\
5.6 \\
5.5\end{array}$ & $\begin{array}{l}12 \\
12 \\
12\end{array}$ & $\begin{array}{l}6.4 \\
6.0 \\
5.3\end{array}$ \\
\hline MMA-TMPTMA' & $\begin{array}{r}21 \\
121 \\
143\end{array}$ & $\begin{array}{l}6.3 \\
6.3 \\
6.3\end{array}$ & $\begin{array}{l}5 \\
5 \\
5\end{array}$ & $\begin{array}{l}1700 \\
1150 \\
1140\end{array}$ & $\begin{array}{l}5.9 \\
4.7 \\
4.6\end{array}$ & $\begin{array}{l}6.0 \\
6.0 \\
6.0\end{array}$ & $\begin{array}{l}15 \\
15 \\
15\end{array}$ & $\begin{array}{l}6.0 \\
5.1 \\
4.6\end{array}$ \\
\hline
\end{tabular}

Specimens, $4 \times 4 \times 30$-in. bars of CP-type concrete, oven-dried at $177^{\circ} \mathrm{G}$ prior to impregnation and thermal-catalytic polymerization.

$a_{60}$ wt \% styrene - 40 wt \% TMPTMA.

b 70 wt \% MMA - 30 wt \% TMPTMA.

5.2.1.3 Flexural StRength. Flexure tests were performed at $21^{\circ}, 121^{\circ}$, and $143^{\circ} \mathrm{C}$ on $4 \times 4 \times 30$-in. bars to obtain the modulus of rupture (extreme tension fiber stress at failure) and the modulus of elasticity for unimpregnated concrete and concrete impregnated with $60 \mathrm{wt} \%$ styrene - $40 \mathrm{wt} \%$ TMPTMA (see Tables 60 to 62). All elevated-temperature testing is considered as short-term temperature exposure because the specimens are heated only long enough to obtain a uniform temperature. Figure 27 shows the test arrangement and loading locations.

The modulus of elasticity was determined from electrical resistance strain gages bonded to the top and bottom surfaces of the bars at midspan. Given the strain and moment, the modulus can be calculated. A comparison betwreen the modulus of elasticity as determined from the deflection and that determined from strain measurements was made for the bars tested at $21^{\circ} \mathrm{C}$. The values of modulus of elasticity were essentially the same, and therefore the strain method was adopted as a standard method.

Test results for concrete impregnated with 70 wt \% MMA - 30 wi \% TMPTMA are summarized in Tables 63 to 65. Data for three temperatures, $21^{\circ}, 121^{\circ}$, and $143^{\circ} \mathrm{C}$, are listed. A comparison of average values of modulus of rupture and modulus of elasticity and a comparison of modulus of elasticity obtained from compressive strength testing has been made. These results are summarized in Table 66. The loading arrangement is shown in Figure 28.

5.2.1.4 Shear Strength. Shear strengths have been obtained for unimpregnated concrete and concrete impregnated with $60 \mathrm{wt} \%$ styrene $-40 \mathrm{wt} \%$ TMPTMA and 70 wt \% MMA - 30 wt \% TMP. TMA, both thermal-catalytically polymerized. The tests were performed in accordance with the USBR standard single-shear method on 2-in.-diam $\times$ 4-in.-long cylinders at $21^{\circ} \mathrm{C}$. Section 5.1.2.2 contains an illustration and discussion of singleshear as well as double-shear methods. Examination of the test results summarized in Tables 67 to 69 indicates that both types of impregnated concrete produced a shear strength 3 times as great as that of unimpregnated concrete.

The shear strength of unimpregnated control specimens averaged $940 \mathrm{psi}$, which is slightly lower but generally comparable with that of unimpregnated control specimens in the study of normaltemperature applications discussed in Section 5.1.2.2. Shear strengths averaged 2880 psi for styrene-TMPTMA specimens and 2510 psi for MMA-TMPTMA specimens. These strengths were somewhat lower than the 3760 psi obtained 
Table 67

Shear Strength of Unimpregnated Concrete Single-Shear Test Method

\begin{tabular}{|c|c|c|}
\hline Specimen No., 72.29- & Load, lb & Shear stress, psi \\
\hline 3 & 3420 & 980 \\
\hline 4 & 3260 & 930 \\
\hline 5 & 2550 & 720 \\
\hline 6 & 3570 & 1020 \\
\hline 7 & 3420 & 980 \\
\hline 8 & 3240 & 920 \\
\hline 9 & 2890 & 830 \\
\hline 10 & 3370 & 960 \\
\hline 11 & 3620 & 1030 \\
\hline \multirow[b]{2}{*}{ Mean } & 3440 & 980 \\
\hline & 3280 & 940 \\
\hline
\end{tabular}

Specimens, 2-in.-diam $\times 4$-in.-long cylinders of GPtype concrete.

Test temperature, $21^{\circ} \mathrm{C}$ (room temperature).

Table 69

\section{Shear Strength of MMA-TMPTMA}

Impregnated Concrete

Single-Shear Test Method

\begin{tabular}{|c|c|c|c|}
\hline $\begin{array}{c}\text { Specimen No., } \\
72.111 \text {. }\end{array}$ & $\begin{array}{c}\text { Polymer } \\
\text { loading, wt \% }\end{array}$ & Load, lb & $\begin{array}{c}\text { Shear stress, } \\
\text { psi }\end{array}$ \\
\hline 2 & 7.4 & 9,740 & 2,780 \\
\hline 3 & 7.4 & 7,960 & 2,270 \\
\hline 5 & 7.2 & 7,600 & 2,160 \\
\hline 6 & 7.0 & 10,400 & 2,960 \\
\hline 7 & 7.0 & 10,440 & 2,990 \\
\hline 8 & 7.2 & 9,480 & 2,720 \\
\hline 9 & 7.0 & 8,840 & 2,550 \\
\hline 10 & 7.2 & 7,800 & 2,240 \\
\hline 11 & 7.1 & 8,040 & 2,280 \\
\hline 12 & 7.0 & 7,600 & 2,170 \\
\hline \multicolumn{2}{|c|}{ Mean } & 8,790 & 2,510 \\
\hline
\end{tabular}

Specimens, 2-in.-diam $\times 4$-in.-long cylinders of CP. type concrete, oven-dried at $177^{\circ} \mathrm{C}$ prior to impregnation and thermal-catalytic polymerization.

Monomer, 70 wt \% MMA - 30 wt \% TMPTMA.

Test temperature, $21^{\circ} \mathrm{C}$.

with MMA-impregnated specimens in the singleshear test (Section 5.1.2.2). A comparison of all shear tests is given in Table 70.

5.2.1.5 High-Temperature Caeep. Two series of tests have been conducted at elevated ternperatures: (1) an earlier test series with OSW-type concrete impregnated with $60 \mathrm{wt} \%$ styrene $-40 \mathrm{wt} \% \mathrm{TMP}$ TMA and 90 wt \% DAP - 10 wt \% MMA (the
Table 68

Shear Strength of Styrene-TMPTMA Impregnated Concrete

Single-Shear Test Method

\begin{tabular}{|c|c|c|c|}
\hline $\begin{array}{c}\text { Specimen No., } \\
72.28-\end{array}$ & $\begin{array}{c}\text { Polymer } \\
\text { loading, wt \% }\end{array}$ & Load, lb & $\begin{array}{c}\text { Shear stress, } \\
\text { psi }\end{array}$ \\
\hline 2 & 7.7 & 11,180 & 3,180 \\
\hline 3 & 8.3 & 9,330 & 2,650 \\
\hline 4 & 7.6 & 10,960 & 3,130 \\
\hline 5 & 7.6 & 9,180 & 2,630 \\
\hline 6 & 7.6 & 12,160 & 3,460 \\
\hline 7 & 7.6 & 7,140 & 2,040 \\
\hline 8 & 7.8 & 8,830 & 2,510 \\
\hline 9 & 7.8 & 9,920 & 2,810 \\
\hline 10 & 7.8 & 12,020 & 3,410 \\
\hline \multirow[t]{2}{*}{12} & 7.6 & 10,460 & 2,980 \\
\hline & 7.7 & 10,120 & 2,880 \\
\hline
\end{tabular}

Specimens, 2-in.-diam $\times 4$-in.-long cylinders of CP. type concrete, oven-dried at $177^{\circ} \mathrm{C}$ prior to impregnation and thermal-catalytic polylmerization.

Monomer, 60 wt \% styrene - 40 wt \% TMPTMA.

Test temperature, $21^{\circ} \mathrm{C}$.

Table 70

Comparison of Shear Test Results

Single-Shear and Double-Shear Methods

\begin{tabular}{llc}
\hline \multicolumn{1}{c}{ Specimen } & Test method & Shear stress, psi \\
\hline Unimpregnated & Single shear & 940 \\
Styrene-TMPTMA $^{a}$ & Single shear & 2880 \\
MMA-TMPTMA $^{b}$ & Single shear & 2540 \\
Unimpregnated & Single shear & 1140 \\
MMA & Single shear & 3760 \\
Unimpregnated & Double shear & 1730 \\
MMA & Double shear & 3670
\end{tabular}

Specimens, 2-in.-diam $\times$ 4-in.-long cylinders of CPtype concrete, oven-dried at $177^{\circ} \mathrm{C}$ prior to impregnation and thermal-catalytic polymerization.

Test temperature, $21^{\circ} \mathrm{C}$.

a60 wt \% styrene - 40 wt \% TMPTMA.

b 70 wt \% MMA - 30 wt \% TMPTMA.

DAP-MMA test results are given; however, the system is no longer being considered for desalting plant applications ${ }^{4}$ ), and (2) a test series with $\mathrm{CP}$. type concrete impregnated with 60 wt $\%$ styrene 40 wt \% TMPTMA and 70 wt \% MMA - 30 wt \% TMPTMA.

(a) OSW-TYPE CONCRETE. Compressive creep tests on OSW-type concrete at $143^{\circ} \mathrm{C}$ have been termi- 
Table 71

High-Temperature High-Stress Creep

Polymer-Impregnated OSW-Type Concrete

\begin{tabular}{|c|c|c|c|c|c|c|}
\hline \multirow{3}{*}{$\begin{array}{l}\text { Time under } \\
\text { load, days }\end{array}$} & \multicolumn{6}{|c|}{ Creep strain, $\mu$ in $/$ in.-psi at $143^{\circ} \mathrm{C}$} \\
\hline & \multicolumn{2}{|c|}{ S-TMPTMA ${ }^{a}$} & \multicolumn{2}{|c|}{ DAP-MMA' } & \multicolumn{2}{|c|}{ Unimpregnated } \\
\hline & Spec. $5^{e}$ & Spec. $2^{d}$ & Spec. 19c & Spec. $6^{\mathrm{d}}$ & Spec. $7 \mathrm{c}$ & Spec. $8^{d}$ \\
\hline 1 & 0.026 & 0 & 0.026 & 0 & 0.454 & o \\
\hline 5 & 0.062 & 0.020 & 0.061 & 0.029 & 0.630 & 0.178 \\
\hline 30 & 0.074 & 0.030 & 0.081 & 0.049 & 0.735 & 0.304 \\
\hline 55 & 0.076 & 0.032 & 0.094 & 0.058 & 0.751 & 0.328 \\
\hline 121 & 0.084 & 0.042 & 0.111 & 0.080 & 0.778 & 0.351 \\
\hline 184 & 0.089 & 0.043 & 0.124 & 0.092 & 0.782 & 0.353 \\
\hline 348 & 0.082 & 0.035 & 0.120 & 0.093 & 0.811 & 0.389 \\
\hline 498 & 0.091 & 0.048 & 0.158 & 0.129 & 0.816 & 0.402 \\
\hline 694 & 0.096 & 0.048 & 0.242 & 0.149 & 0.827 & 0.418 \\
\hline 798 & 0.104 & 0.051 & 0.248 & 0.161 & 0.832 & 0.425 \\
\hline 889 & 0.092 & 0.042 & 0.252 & 0.157 & 0.814 & 0.413 \\
\hline
\end{tabular}
$143^{\circ} \mathrm{C}$

$41 / 2 \times 12$-in. cylinders loaded to $\approx 37 \%$ of ultimate strength.

Impregnated concrete under 7000 psi and unimpregnated concrete under 2313 psi sustained compressive load at

aS-TMPTMA $=60 \mathrm{wt} \%$ styrene $-40 \mathrm{wt} \%$ TMPTMA; specimens have polymer loading of $4.7 \mathrm{wt} \%$.

bDAP-MMA $=90 \mathrm{wt} \%$ DAP - $10 \mathrm{wt} \%$ MMA; specimens have polymer loading of $5.4 \mathrm{wt} \%$.

cSpecimen loaded at $24^{\circ} \mathrm{C}$, then heated to $143^{\circ} \mathrm{C}$.

dSpecimen heated to $143^{\circ} \mathrm{C}$ before loading.

nated after nearly $2 \frac{1}{2}$ years (Table 71 ). The compressive loads are 7000 psi for PIC specimens and 2313 psi for unimpregnated specimens. These loadings were estimated to be about $37 \%$ of the ultimate strength at room temperature for each type of concrete. Initially specimens were either loaded at room temperature and then heated to $143^{\circ} \mathrm{C}$ for testing, or heated to $143^{\circ} \mathrm{C}$ and then loaded. PIC and unimpregnated specimens loaded at $143^{\circ} \mathrm{C}$ have about one-half the deformation of companion specimens loaded at room temperature and then heated to $143^{\circ} \mathrm{C}$. The styrene-TMPTMA specimens have about one-tenth the unit deformation per psi shown by comparable unimpregnated specimens. After 889 days under load, the styrene-TMPTMA specimen loaded at $143^{\circ} \mathrm{C}$ had a deformation of $0.043 \mu \mathrm{in} . / \mathrm{in}$.-psi, and the specimen loaded at room temperature and then heated to $143^{\circ} \mathrm{C}$ had a deformation of $0.092 \mu \mathrm{in}$./ in.-psi. Most of the deformation of the styreneTMPTMA and unimpregnated specimens occurred soon after loading. After about 1 month under load there was very little additional movement aside from minor fluctuations. The DAP-MMA specimens showed continued movement throughout the test. After completion of the test, the compressive strength and modulus of elasticity of all specimens was determined (Table 72). For both styrene-TMPTMA and unimpregnated specimens, no loss in strength due to exposure at $143^{\circ} \mathrm{C}$ or sustained compressive loading at $143^{\circ} \mathrm{C}$ was noted, although there was some decrease in modulus of elasticity.

(b) CP-TYPE COHCRETE. Compressive creep tests at $121^{\circ}$ and $143^{\circ} \mathrm{C}$ are in progress on 60 wt \% styrene -40 wt \% TMPTMA, 70 wt \% MMA -- 30 wt \% TMPTMA, and unimpregnated CP-type concrete (Table 73). PIC specimens are under compressive loads of 2313 and 7000 psi, and unimpregnated concrete is under compressive loads of 800 and 2313 psi. All specimens were heated to the test temperature before the load was applied. StyreneTMPTMA and the unimpregnated specimens have been under load for 400 days. The MMATMPTMA specimens were started at a later date and have been under load for only 46 days.

The styrene-TMPTMA specimens show that most of the deformation occurs during the first $\mathbf{1 2 0}$ 
Table 72

High-Temperature Strength of Creep Test Specimens

Polymer-Impregnated OSW-Type Concrete

\begin{tabular}{|c|c|c|c|c|c|}
\hline $\begin{array}{l}\text { Specimen } \\
\text { No., } \\
\text { OSW-10. }\end{array}$ & Polymer & $\begin{array}{c}\text { Polymer } \\
\text { loading, } \\
\text { wt \% }\end{array}$ & $\begin{array}{c}\text { Temperature } \\
\text { exposure } \\
\text { time, days }\end{array}$ & $\begin{array}{l}\text { Compressive } \\
\text { strength, } \\
\text { psi }\end{array}$ & $\begin{array}{l}\text { Modulus of } \\
\text { elasticity, } \\
10^{6} \mathrm{psi}\end{array}$ \\
\hline 28 & - & - & 1 & 6,000 & 4.3 \\
\hline 29 & - & - & 1 & 6,400 & 4.1 \\
\hline 30 & - & - & 7 & 6,200 & 3.5 \\
\hline 31 & - & - & 7 & 6,900 & 3.3 \\
\hline 32 & - & - & 70 & 6,200 & 4.2 \\
\hline 33 & - & - & 70 & 6,300 & 3.3 \\
\hline 34 & - & - & 457 & 4,400 & 2.2 \\
\hline 35 & - & - & 457 & 3,800 & 2.4 \\
\hline 9 & - & - & 890 & 6,600 & - \\
\hline $7^{b}$ & - & - & 890 & 6,100 & - \\
\hline $\mathrm{B}^{\mathrm{b}}$ & - & - & 890 & 6,000 & - \\
\hline $4^{n}$ & S+TMPTMA & 4.3 & 1 & 20,400 & 8.0 \\
\hline 1 & S + TMPTMA & 5.1 & 1 & 14,200 & 6.7 \\
\hline 11 & S+TMPTMA & 4.6 & 7 & 16,200 & 6.6 \\
\hline 14 & S+TMPTMA & 5.1 & 7 & 15,300 & 6.7 \\
\hline 16 & S+TMPTMA & 4.7 & 70 & 15,300 & 6.8 \\
\hline 20 & S+TMPTMA & 5.0 & 70 & 15,600 & 7.9 \\
\hline 12 & S+TMPTMA & 4.6 & 457 & 12,300 & 3.4 \\
\hline 21 & S+TMPTMA & 4.6 & 457 & 14,200 & 5.0 \\
\hline 26 & S+TMPTMA & 5.1 & 457 & 15,000 & 6.4 \\
\hline 27 & S+TMPTMA & 5.1 & 457 & 16,500 & 5.4 \\
\hline 12 & S + TMPTMA & 4.6 & 890 & 16,700 & - \\
\hline $5 d$ & $S+T M P T M A$ & 4.7 & 890 & 15,900 & - \\
\hline $2^{d}$ & S+TMPTMA & 4.7 & 890 & 16,000 & - \\
\hline $13=$ & $\mathbf{D A P}+\mathbf{M M A}^{\mathbf{E}}$ & 5.4 & 1 & 17,200 & 6.8 \\
\hline 15 & DAP+MMA & 4.9 & 1 & 13,000 & 6.0 \\
\hline 17 & DAP + MMA & 5.0 & 7 & 11,400 & 6.0 \\
\hline 18 & DAP + MMA & 5.0 & 7 & 14,900 & 6.2 \\
\hline 3 & DAP+MMA & 5.0 & 70 & 14,700 & 5.9 \\
\hline 22 & $\mathbf{D A P}+\mathbf{M M A}$ & 5.4 & 70 & 14,300 & 6.0 \\
\hline 23 & DAP+MMA & 5.4 & 457 & 13,700 & 4.0 \\
\hline 24 & DAP + MMA & 5.4 & 457 & 13,500 & 5.2 \\
\hline 25 & DAP + MMA & 5.0 & 457 & 10,400 & 4.1 \\
\hline 10 & DAP+MMA & 5.4 & 890 & 12,300 & 3.4 \\
\hline $19^{d}$ & DAP+MMA & 5.4 & 890 & 11,800 & - \\
\hline $6^{d}$ & DAP + MMA & 5.4 & 890 & 14,400 & - \\
\hline
\end{tabular}

$41 / 2 \times 12 \frac{1}{2}$-in. specimens $(L / d=2.8)$; compressive strengths have been corrected to approximate a cylinder of $L / d=2$. Specimens exposed to a temperature of $143^{\circ} \mathrm{C}$ and tested at $143^{\circ} \mathrm{C}$, except as noted.

-Specimen tested at room temperature $\left(24^{\circ} \mathrm{C}\right)$.

bSpecimen under 2313 psi compressive load at $143^{\circ} \mathrm{C}$ for 890 days.

eS + TMPTMA = 60 wt \% styrene - 40 wt \% TMPTMA; catalyst, 1 wt \% benzoyl peroxide.

¿Specimen under 7000 psi compressive load at $143^{\circ} \mathrm{C}$ for 890 days.

-DAP + MMA = $90 \mathrm{wt} \%$ diallyl phthalate $-10 \mathrm{wt} \% \mathrm{MMA}$; catalyst, $5 \mathrm{wt} \%$ tert.-butyl perbenzoate; thermal-catalytic polymerization. 
Table 73

High-Temperature High-Stres Creep

Polymer-Impregnated CP-Type Concrete

\begin{tabular}{|c|c|c|c|c|c|c|c|c|c|c|c|c|}
\hline \multirow[b]{4}{*}{$\begin{array}{c}\text { Time under load, } \\
\text { days }\end{array}$} & \multicolumn{12}{|c|}{ Avcrage creep strain, $\mu \mathrm{in} . / \mathrm{in}$.-pai } \\
\hline & \multicolumn{4}{|c|}{ S-TMPTMA } & \multicolumn{4}{|c|}{ Unimpregnated } & \multicolumn{4}{|c|}{ MMA-TMPTMA } \\
\hline & \multicolumn{2}{|c|}{$121^{\circ} \mathrm{C}$} & \multicolumn{2}{|c|}{$143^{\circ} \mathrm{C}$} & \multicolumn{2}{|c|}{$121^{\circ} \mathrm{C}$} & \multicolumn{2}{|c|}{$143^{\circ} \mathrm{C}$} & \multicolumn{2}{|c|}{$121^{\circ} \mathrm{C}$} & \multicolumn{2}{|c|}{$143^{\circ} \mathrm{C}$} \\
\hline & $\begin{array}{l}2313 \\
\text { psi }\end{array}$ & $\begin{array}{l}7000 \\
\mathrm{psi}\end{array}$ & $\begin{array}{l}2313 \\
\text { psi }\end{array}$ & $\begin{array}{l}7000 \\
\mathrm{psi}\end{array}$ & $\begin{array}{l}800 \\
\text { psi }\end{array}$ & $\begin{array}{c}2313 \\
\mathrm{poi}\end{array}$ & $\begin{array}{l}800 \\
p a i\end{array}$ & $\begin{array}{l}2313 \\
\text { pai }\end{array}$ & $\begin{array}{c}2313 \\
\text { pai }\end{array}$ & $\begin{array}{l}7000 \\
\text { pei }\end{array}$ & $\begin{array}{c}2313 \\
\text { pai }\end{array}$ & $\begin{array}{c}7000 \\
\text { pai }\end{array}$ \\
\hline 2 & 0.028 & 0.044 & 0.053 & 0.068 & 0.174 & 0.104 & 0.224 & 0.179 & 0.113 & 0.078 & 0.125 & 0.087 \\
\hline 4 & - & - & - & - & - & - & - & - & 0.132 & 0.099 & 0.154 & 0.114 \\
\hline 6 & 0.033 & 0.045 & 0.064 & 0.079 & 0.164 & 0.115 & 0.258 & 0.237 & 0.128 & 0.098 & 0.165 & 0.120 \\
\hline 46 & - & - & - & - & - & - & - & - & 0.173 & 0.138 & 0.192 & $0.1 \%$ \\
\hline 62 & 0.070 & 0.082 & 0.125 & 0.139 & 0.240 & 0.197 & 0.417 & 0.357 & & & & \\
\hline 126 & 0.102 & 0.099 & 0.151 & 0.155 & 0.294 & 0.217 & 0.508 & 0.408 & & & & \\
\hline 204 & 0.102 & 0.100 & 0.151 & 0.153 & 0.320 & 0.230 & 0.570 & 0.436 & & & & \\
\hline 308 & 0.104 & 0.101 & 0.195 & 0.174 & 0.375 & 0.270 & 0.570 & 0.454 & & & & \\
\hline 348 & 0.113 & 0.114 & 0.192 & 0.184 & 0.388 & 0.291 & 0.602 & 0.476 & & & & \\
\hline 400 & 0.105 & 0.100 & 0.173 & 0.174 & 0.370 & 0.262 & 0.622 & 0.467 & & & & \\
\hline
\end{tabular}

Values are average creep strain of two 4 th $\times 12$-in. cylindrical specimens.

Specimens heated to test temperatures of $121^{\circ}$ and $143^{\circ} \mathrm{C}$ prior to loading. Impregnated specimens subjected to 2313 and 7000 pei susteined com. pressive load; unimpregnated specimens subjected to 800 and 2313 psi sustained comprestive load. MMA-TMPTMA specimenu have been under load for only 46 days.

S-TMPTMA $=60$ wt $\%$ styrene -40 wt $\%$ TMPTMA.

MMA-TMPTMA = 70 wt \% MMA - 30 wt $\%$ TMPTMA.

Table 74

High-Temperature Strength of Companion Specimens for Creep Test

Polymer-Impregnated CP-Type Concrete

\begin{tabular}{|c|c|c|c|c|c|c|c|c|c|c|c|}
\hline \multirow[b]{2}{*}{$\begin{array}{c}\text { Test } \\
\text { temperature, } \\
{ }^{\circ} \mathbf{C}\end{array}$} & \multicolumn{4}{|c|}{ Styrene-TMPTMA: } & \multicolumn{4}{|c|}{ MMA-TMPTMA' } & \multicolumn{3}{|c|}{ Unimpregnated } \\
\hline & $\begin{array}{l}\text { Specimen } \\
\text { No. }\end{array}$ & $\begin{array}{c}\text { Polymer } \\
\text { loading, } \\
\text { wi } \%\end{array}$ & $\begin{array}{c}\text { Compressive } \\
\text { strength, } \\
\text { psi }\end{array}$ & $\begin{array}{l}\text { Modulus of } \\
\text { elasticity, } \\
10^{8} \mathrm{psi}^{-}\end{array}$ & $\begin{array}{l}\text { Specimen } \\
\text { No. }\end{array}$ & $\begin{array}{c}\text { Polymer } \\
\text { loading, } \\
\text { wt } \%\end{array}$ & $\begin{array}{c}\text { Compresive } \\
\text { trength, } \\
\text { pei }\end{array}$ & $\begin{array}{l}\text { Modulus of } \\
\text { elanticity, } \\
10^{6} \mathrm{pai}\end{array}$ & $\begin{array}{l}\text { Specimen } \\
\text { No. }\end{array}$ & $\begin{array}{l}\text { Compresive } \\
\text { trength, } \\
\text { pii }\end{array}$ & $\begin{array}{c}\text { Modulus of } \\
\text { elanticity, } \\
10^{6} \mathrm{pei}\end{array}$ \\
\hline \multicolumn{12}{|c|}{ Initial Tests } \\
\hline \multirow[t]{2}{*}{23} & $\begin{array}{l}14 \\
57 \\
56\end{array}$ & $\begin{array}{l}6.3 \\
5.8 \\
5.8\end{array}$ & $\begin{array}{l}18,500 \\
18,400 \\
17,400\end{array}$ & $\begin{array}{l}6.2 \\
6.4 \\
6.6\end{array}$ & $\begin{array}{l}12 \\
13 \\
14\end{array}$ & $\begin{array}{l}5.0 \\
5.2 \\
5.0\end{array}$ & $\begin{array}{l}17.000 \\
19,800 \\
18,500\end{array}$ & $\begin{array}{l}5.5 \\
6.4 \\
6.5\end{array}$ & $\begin{array}{r}3 \\
50 \\
52\end{array}$ & $\begin{array}{l}5,000 \\
5,300 \\
5,500\end{array}$ & $\begin{array}{l}3.6 \\
3.6 \\
3.6\end{array}$ \\
\hline & Av & & 18,100 & 6.4 & Av & 5.1 & 18,500 & 6.2 & & 5,300 & 3.6 \\
\hline \multirow[t]{2}{*}{121} & $\begin{array}{l}4 \\
97 \\
87\end{array}$ & $\begin{array}{l}6.3 \\
5.4 \\
5.8\end{array}$ & $\begin{array}{r}16,700 \\
17,600 \\
16,500\end{array}$ & $\begin{array}{l}6.6 \\
6.2 \\
6.4\end{array}$ & $\begin{array}{l}15 \\
16 \\
18 \\
41 \\
42\end{array}$ & $\begin{array}{l}5.3 \\
4.5 \\
4.9 \\
4.5 \\
4.5\end{array}$ & $\begin{array}{c}- \\
13,600 \\
- \\
14, \overline{7} 00 \\
13,400\end{array}$ & $\begin{array}{c}\mathbf{5 . 0} \\
5.1 \\
5.0 \\
- \\
-\end{array}$ & $\begin{array}{l}15 \\
32 \\
84\end{array}$ & $\begin{array}{l}4,900 \\
4,900 \\
5,700\end{array}$ & $\begin{array}{l}3.1 \\
3.1 \\
3.0\end{array}$ \\
\hline & Av & & 17,000 & 6.4 & Av & 5.6 & 13,900 & - & Av & 5,200 & 3.1 \\
\hline \multirow[t]{3}{*}{143} & $\begin{array}{r}29 \\
6 \\
68\end{array}$ & $\begin{array}{l}6.3 \\
5.8 \\
5.8\end{array}$ & $\begin{array}{l}14,800 \\
16,800 \\
14,600\end{array}$ & $\begin{array}{l}5.2 \\
5.5 \\
5.0\end{array}$ & $\begin{array}{l}19 \\
20 \\
21\end{array}$ & $\begin{array}{c}4.9 \\
4.6 \\
5.3\end{array}$ & $\begin{array}{r}11,100 \\
17,600 \\
\quad 11,600\end{array}$ & $\begin{array}{l}3.9 \\
4.2 \\
4.0\end{array}$ & $\begin{array}{r}46 \\
18 \\
101\end{array}$ & $\begin{array}{l}5,800 \\
4,500 \\
5,100\end{array}$ & $\begin{array}{l}3.2 \\
2.9 \\
2.6\end{array}$ \\
\hline & Av & & 15,400 & 5.2 & Av & 4.9 & 11,900 & 4.0 & Av & 5,500 & 2.9 \\
\hline & & & & Teats After 1 & 1-Year Expor & nure at Ted & it Temperature & & & & \\
\hline \multirow[t]{2}{*}{23} & $\begin{array}{r}61 \\
102\end{array}$ & $\begin{array}{l}5.8 \\
5.8\end{array}$ & $\begin{array}{l}18,900 \\
19,300\end{array}$ & $\begin{array}{l}6.1 \\
7.0\end{array}$ & & & & & $\begin{array}{l}30 \\
34\end{array}$ & $\begin{array}{l}5,700 \\
5,500\end{array}$ & $\begin{array}{l}3.7 \\
3.9\end{array}$ \\
\hline & Av & & 19,000 & 6.5 & & & & & Av & 5,600 & 3.8 \\
\hline \multirow[t]{2}{*}{121} & $\begin{array}{r}21 \\
2 \\
5\end{array}$ & $\begin{array}{l}6.3 \\
5.8 \\
5.8\end{array}$ & $\begin{array}{l}71,000 \\
15,400 \\
16,100\end{array}$ & $\begin{array}{l}5.7 \\
5.8 \\
5.4\end{array}$ & & & & & $\begin{array}{l}45 \\
46 \\
96\end{array}$ & $\begin{array}{l}4,900 \\
5,300 \\
5,400\end{array}$ & $\begin{array}{l}3.0 \\
3.0 \\
2.4\end{array}$ \\
\hline & Av & & 16,100 & 5.7 & & & & & Av & 5,200 & 2.8 \\
\hline \multirow[t]{2}{*}{143} & $\begin{array}{l}69 \\
73 \\
37\end{array}$ & $\begin{array}{l}6.3 \\
5.8 \\
5.8\end{array}$ & $\begin{array}{l}15,700 \\
15,100 \\
15,200\end{array}$ & $\begin{array}{l}4.9 \\
4.9 \\
5.1\end{array}$ & & & & & $\begin{array}{r}7 \\
38 \\
83\end{array}$ & $\begin{array}{l}5,2100 \\
5,000 \\
5,700\end{array}$ & $\begin{array}{l}2.6 \\
2.8 \\
2.7\end{array}$ \\
\hline & Av & & 15,300 & 5.0 & & & & & Av & 5,300 & 2.7 \\
\hline
\end{tabular}

$41 / 2 \times 12 \frac{1}{2}$-in, cylinden, $L / d=2,8$, Compremive atrengths have been corrected to approximate the atrength of a cylinder of $L / d=2$.

-Styrene-TMPTMA = 60 wt \% alyrene -40 wt \% TMPTMA.

-MMA-TMPTMA $=70$ w1\% MMA -30 wI $\%$ TMPTMA.

-MMA-TMPTMA specimenn have not been exposed long enough for 1-year teats. 
Table 75

Flexural Strength of Reinforced Concrete and Reinforced

Impregnated Concrete After Short-Term Exposure at $143^{\circ} \mathrm{C}$

\begin{tabular}{ccccccc}
\hline $\begin{array}{c}\text { Specimen } \\
\begin{array}{c}\text { No., } \\
6.2 .6-\end{array}\end{array}$ & $\begin{array}{c}\text { Polymer } \\
\text { loading, wt } \%\end{array}$ & $\begin{array}{c}\text { Ultimate } \\
\text { load, lb }\end{array}$ & $\begin{array}{c}\text { Ultimate } \\
\text { moment, in.-lb }\end{array}$ & $\begin{array}{c}\text { Ultimate } \\
\text { compressive } \\
\text { strain, in./in. }\end{array}$ & $\begin{array}{c}\text { Shear at } \\
\text { ultimate } \\
\text { load, lb }\end{array}$ & $\begin{array}{c}\text { Nominal } \\
\text { shear } \\
\text { stress, }{ }^{\mathrm{a}} \text { psi }\end{array}$ \\
\hline 10028 & - & 4,770 & 38,160 & 0.0014 & 2,385 & 187 \\
10029 & - & 4,700 & 37,600 & 0.0012 & 2,350 & 184 \\
10030 & - & 4,600 & 36,800 & 0.0020 & 2,300 & 180 \\
10031 & - & 4,825 & 38,600 & 0.0014 & 2,410 & 189 \\
10032 & - & 4,625 & 37,000 & 0.0014 & 2,310 & 181 \\
Mean & - & 4,700 & 37,630 & 0.0015 & 2,350 & 184 \\
10022 & & & & & & \\
10023 & 6.6 & 4,775 & 38,200 & 0.0008 & 2,390 & 187 \\
10024 & 6.5 & 4,590 & 36,720 & 0.0009 & 2,295 & 180 \\
10025 & 6.7 & 4,970 & 39,760 & 0.0009 & 2,485 & 195 \\
10026 & 6.9 & 4,940 & 39,520 & 0.0014 & 2,470 & 194 \\
\multicolumn{1}{c}{ Mean } & 6.7 & 4,630 & 37,040 & 0.0010 & 2,315 & 182 \\
\hline
\end{tabular}

Specimens, $3 \times 5 \times 54$-in. beams of CP-type concrete, reinforced with a single No. 4 deformed bar in tension area and oven-dried at $177^{\circ} \mathrm{C}$ prios to impregnation and thermal-catalytic polymerization.

Monomer, 60 wt \% styrene - 40 wt \% TMPTMA.

Test temperature, $143^{\circ} \mathrm{C}$.

- Nominal shear stress $=$ shear $/ 3 \times 4.25$.

Table 76

Shear Strength of Reinforced Concrete and Reinforced Impregnated Concrete After Short-Term Exposure at $143^{\circ} \mathrm{C}$

\begin{tabular}{|c|c|c|c|c|c|c|}
\hline $\begin{array}{c}\text { Specimen } \\
\text { No., } \\
6.2 .6-\end{array}$ & $\begin{array}{c}\text { Polymer } \\
\text { loading, wt \% }\end{array}$ & $\begin{array}{l}\text { Ultimate } \\
\text { load, 1b }\end{array}$ & $\begin{array}{l}\text { Ultimate } \\
\text { shear, lb }\end{array}$ & $\begin{array}{l}\text { Nominal } \\
\text { shear } \\
\text { stress, }{ }^{2} \text { psi }\end{array}$ & $\begin{array}{l}\text { Moment at } \\
\text { ultimate } \\
\text { load, in.-lb }\end{array}$ & $\begin{array}{l}\text { Type of } \\
\text { failure }\end{array}$ \\
\hline 10048 & - & 9,200 & 6,130 & 481 & 30,670 & Shear \\
\hline 10049 & - & 10,750 & 7,170 & 562 & 35,830 & $"$ \\
\hline 10050 & - & 11,200 & 7,470 & 586 & 37,330 & $"$ \\
\hline 10051 & - & 10,400 & 6,930 & 544 & 34,670 & $"$ \\
\hline 10052 & - & $\vdots 0,240$ & 6,830 & 536 & 34,130 & $"$ \\
\hline Mean & - & 10,360 & 6,910 & 542 & 34,530 & \\
\hline 10041 & 7.1 & 15,200 & 10,130 & 795 & 50,670 & Flexure \\
\hline 10042 & 6.9 & 14,500 & 9,670 & 758 & 48,330 & " \\
\hline 10043 & 6.6 & 16,620 & 11,080 & 869 & 55,400 & $"$ \\
\hline 10045 & 6.9 & 16,400 & 10,930 & 857 & 54,670 & Shear \\
\hline 10046 & 6.6 & 16,700 & 11,130 & 873 & 55,670 & Flexure \\
\hline Mean & 6.8 & 15,880 & 10,590 & 830 & 52,950 & \\
\hline
\end{tabular}

Specimens, $3 \times 5 \times 54$-in. beams of CP-type concrete, reinforced with two No. 4 deformed bars and oven-dried at $177^{\circ} \mathrm{C}$ prior to impregnation and thermal-catalytic polymerization.

Monomer, 60 wt \% styrene - 40 wt \% TMPTMA.

Test temperature, $143^{\circ} \mathrm{C}$.

Nominal shear streas $=$ shear $/ 3 \times 4.25$. 
days under load and that specimens under 2313 and 7000 psi load have about the same creep deformation per psi. Styrene-TMPTMA specimens tested at $121^{\circ} \mathrm{C}$ for 400 days have a creep deformation of about $0.10 \mu \mathrm{in}$./in.-psi; specimens tested at $143^{\circ} \mathrm{C}$ have a somewhat greater creep deformation, about $0.17 \mu \mathrm{in}$./in.-psi. The unimpregnated specimens show about 3 to 6 times more creep strain per psi than comparable styrene-TMPTMA specimens. The unimpregnated specimens under 800 psi load show about one-third more creep strain per psi than comparable specimens under $2313 \mathrm{psi}$, and specimens tested at $143^{\circ} \mathrm{C}$ have about one-half more creep strain per psi than specimens tested at $121^{\circ} \mathrm{C}$. The CP-type concrete creeps slightly more than the OSW type. At about 400 days under 7000 psi at $143^{\circ} \mathrm{C}$, styrene-TMPTMA CP-type concrete has a creep strain of 0.17 $\mu$ in./in.-psi, as compared with 0.04 for styreneTMPTMA OSW-type concrete (Table 71). Compressive strengths of companion specimens at room temperature and at the elevated temperatures are given in Table 74. Styrene-TMPTMA and unimpregnated specimens show no decrease in strength after exposure to high temperature for 1 year. The styrene-TMPTMA specimens show some decrease in strength with increasing exposure temperature, averaging about $19,000 \mathrm{psi}$ at room temperature, $16,100 \mathrm{psi}$ at $121^{\circ} \mathrm{C}$, and 15,300 psi at $143^{\circ} \mathrm{C}$. The initial strengths of MMA-TMPTMA specimens were slightly lower at the high temperatures; they averaged $18,500 \mathrm{psi}$ at room temperature, 13,900 psi at $121^{\circ} \mathrm{C}$, and 11,900 psi at $143^{\circ} \mathrm{C}$.

5.2.1.6 FleXURAL AND SHEAR STREMGTHS OF Reimfonced BEAMS. Flexural strengths and shear strengths were obtained for reinforced unimpregnated concrete and reinforced concrete impregnated with $60 \mathrm{wt} \%$ styrene -40 wt \% TMPTMA, thermal-catalytically polymerized. These tests were conducted at $143^{\circ} \mathrm{C}$ on $3 \times 5 \times 54$-in. beams each having one No. 4 deformed reinforcement bar in the tension area. Figures 25 and 26 show the flexure and shear test configurations, and the test results are summarized in Tables 75 and 76. None of the beams that failed in flexure failed because of a compression failure; this indicates that all beams were underreinforced.

The ultimate load was taken as the amount of load that the beam could support without failing. Comparison of Tables 75 and 76 shows that the shear specimens achieved higher moments at ultimate load. This is because the shear beams were doubly reinforced and the arrangement did not
Table 77

Flexural Strength of Unreinforced and Polymer-Impregnated Concrete

After Short-Term Exposure at $143^{\circ} \mathrm{C}$

\begin{tabular}{ccccc}
\hline $\begin{array}{c}\text { Specimen } \\
\text { No., } \\
6.2 .6-\end{array}$ & $\begin{array}{c}\text { Polymer } \\
\text { loading, } \\
\text { wt \% }\end{array}$ & $\begin{array}{c}\text { Ultimate } \\
\text { load, } \\
\text { lb }\end{array}$ & $\begin{array}{c}\text { Modulus } \\
\text { of rupture, } \\
\text { psi }\end{array}$ & $\begin{array}{c}\text { Modulus } \\
\text { of elasticity, } \\
10^{6} \text { psi }\end{array}$ \\
\hline 10065 & - & 1770 & 690 & 3.03 \\
10066 & - & 1760 & 680 & 3.20 \\
Mean & - & 1765 & 685 & 3.12 \\
10061 & 7.0 & 3660 & 1420 & 5.56 \\
10062 & 7.1 & 3860 & 1500 & 5.26 \\
10063 & 6.9 & 3620 & 1410 & 5.58 \\
10064 & 7.1 & 3240 & 1260 & 5.28 \\
Mean & 7.0 & 3595 & 1400 & 5.42 \\
\hline
\end{tabular}

Specimens, $3 \times 3 \times 16$-in. bars of CP-type concrete, oven-dried at $177^{\circ} \mathrm{C}$ prior to impregnation and thermalcatalytic polymerization.

Monomer, 60 wt \% styrene - 40 wt \% TMPTMA.

Test temperature, $143^{\circ} \mathrm{C}$.

allow a large deflection, such as was obtained in the flexure arrangement. Only one impregnated beam in the shear arrangement developed an actual shear failure. Even though the majority of the shear beams failed in flexure, the increase in the nominal shear stress is evident from the test results.

The flexural strengths of unreinforced unimpregnated bars and concrete impregnated with 60 wt \% styrene - 40 wt \% TMPTMA were obtained at $143^{\circ} \mathrm{C}$ (see Table 77). These bars were tested on a 14-in. span with a two-point loading of 4 in. between load points centered on the bar. A correlation between modulus of rupture and appearance of the first crack in the $3 \times 5 \times 54$-in. beams could not be made, since the beams were covered with insulation to maintain the test temperature.

Compressive and tensile strengths for unimpregnated concrete and concrete impregnated with 60 wt \% styrene - 40 wt \% TMPTMA were obtained at $143^{\circ} \mathrm{C}$. The data are summarized in Table 78. These values are higher than those obtained for $6 \times 12$-in. cylinders, probably because the aggregate used in a $3 \times 6$-in. cylinder has a smaller maximum size.

5.2.1.7 High-Tempenhtune LoOP Tests. Long-term loop tests are conducted to evaluate the behavior of PIC under exposure to simulated desalting plant conditions. The test results discussed in this 
Table 78

Compressive and Tensile Strengths of Unimpregnated and Styrene-TMPTMA Impregnated Concrete After Short-Term Exposure at $143^{\circ} \mathrm{C}$

\begin{tabular}{ccccc}
\hline $\begin{array}{c}\text { Specimen } \\
\text { No., } \\
6.2 .6\end{array}$ & $\begin{array}{c}\text { Polymer } \\
\text { loading, } \\
\text { wt \% }\end{array}$ & Test & $\begin{array}{c}\text { Ultimate } \\
\text { load, lb }\end{array}$ & $\begin{array}{c}\text { Strength, } \\
\text { psi }\end{array}$ \\
\hline 10077 & - & Tensile & 2,400 & 340 \\
10078 & - & & 2,600 & 370 \\
10079 & - & & 2,200 & 310 \\
Mean & & & 2,400 & 340 \\
10074 & 7.0 & Tensile & 8,300 & 1,173 \\
10076 & 7.0 & & 7,140 & 1,010 \\
Mean & 7.0 & & 7,720 & 1,090 \\
10080 & - & Compressive & 32,300 & 4,570 \\
10081 & - & & 42,100 & 5,950 \\
10082 & - & & 42,000 & 5,940 \\
Mean & & & 38,800 & 5,490 \\
10071 & 6.9 & Compressive & 129,000 & 18,250 \\
10073 & 7.2 & & 119,000 & 16,830 \\
10075 & 7.2 & & 100,000 & 14,140 \\
Mean & 7.1 & & 116,000 & 16,410 \\
\hline
\end{tabular}

Specimens, 3-in.-diam $\times 6$-in.-long cylinders of CP. type concrete, oven-dried at $177^{\circ} \mathrm{C}$ prior to impregnation and thermal-catalytic polymerization.

Monomer, 60 wt \% styrene - 40 wt \% TMPTMA.

Test temperature, $143^{\circ} \mathrm{C}$.

section pertain to structural properties. A discussion of test results pertaining to durability, as well as a description of the loop tests, is given in Section 5.2.2.3.

(a) SINGLE-PHASE Loops. Compressive strength tests were performed on three $60 \mathrm{wt} \%$ styrene $-40 \mathrm{wt}$ \% TMPTMA impregnated $6 \times 12$-in. cylinders after 2 years of exposure in the $121^{\circ} \mathrm{C}$ brine loop. Two companion cylinders that had been exposed to air at $23^{\circ} \mathrm{C}$ and $50 \%$ relative humidity during this period were also tested after being heated to $121^{\circ} \mathrm{C}$. As shown in Table 79, the specimens not exposed to the brine had both a greater strength and a higher modulus of elaiticity than those exposed to the brine.

The effect of exposure time in the $121^{\circ} \mathrm{C}$ brine loop is shown in Table 88 in Section 5.2.2.3. Tests on brine-exposed specimens indicated a gradual loss in strength from an average of 16,200 psi after 215 days of exposure to 13,300 psi after
2 years. A reduction in the modulus of elasticity from $5.7 \times 10^{6}$ to $5.0 \times 10^{8} \mathrm{psi}$ was noted in this time interval. A fairly consistent increase in unit length was observed from an initial 0 to 0.001272 in./in. in 2 years. No definite trend in length change is evident in the specimens exposed to air at $23^{\circ} \mathrm{C}$ and $50 \%$ relative humidity.

Test results on $6 \times 12$-in. cylinders and $4 \times 4 \times 30$ in. bars after 2 years of exposure in $143^{\circ} \mathrm{C}$ brine are summarized in Table 80 and in Table 88 in Section 5.2.2.3. Compared with initial and 6month measurements, some decrease in compressive strength and modulus of elasticity and an increase in length were noted. Three additional cylinders were removed from the loops and tested after 15 months to verify these changes. The same trend was noted for modulus of elasticity and change in unit length, but the compressive strength was not significantly different.

Tests were conducted on impregnated $6 \times 12$-in. specimens after 2 years of exposure in $143^{\circ} \mathrm{C}$ brine. Companion specimens that had been stored at $21^{\circ} \mathrm{C}$ and $50 \%$ relative humidity were also tested after being heated to $143^{\circ} \mathrm{C}$. The strength and modulus of elasticity of the brine-exposed specimens were only about $65 \%$ of the values for specimens not exposed. An analysis was made to determine the effect of exposure time in $143^{\circ} \mathrm{C}$ brine. A definite loss of strength was noted for both unimpregnated and styrene-TMPTMA impregnated concrete. This loss appears to continue with increased exposure time.

(b) ThreE-Phase Brine Loops. Tests were made on unimpregnated and $60 \mathrm{wt} \%$ styrene $-40 \mathrm{wt} \% \mathrm{TMP}$ TMA impregnated CP-type concrete after exposure for 6 months and 1 year in the $121^{\circ} \mathrm{C}$ threephase loops (see Table 89 in Section 5.2.2.3). Compressive strengths of the impregnated specimens were not significantly different for any environment. After 1 year's exposure, compressive strengths averaged 14,700 psi for both vapor and brine-vapor interface exposures and 15,300 psi for brine exposures. The average for all three environments was 14,900 psi, the same as that obtained for the impregnated OSW-type concrete specimens after 1 year of exposure in the single-phase brine loop at the same temperature. The average compressive strength of all impregnated specimens in the three-phase loops after 6 months' exposure was about 15,250 . The difference between results for 1 year and 6 months are not significant enough to arrive at any definite conclusion. Examination 
Table 79

Compressive Strength and Elasticity of Styrene-TMPTMA Impregnated Concrete After Two-Year Exposure to Brine at $121^{\circ} \mathrm{C}$

\begin{tabular}{ccccccc}
\hline $\begin{array}{c}\text { Specimen } \\
\text { No. }\end{array}$ & $\begin{array}{c}\text { Polymer } \\
\text { loading, wt \% }\end{array}$ & $\begin{array}{c}\text { Ultimate } \\
\text { strength, psi }\end{array}$ & $\begin{array}{c}\text { Modulus of } \\
\text { elasticity, 106 psi }\end{array}$ & $\begin{array}{c}\text { Poisson's } \\
\text { ratio }\end{array}$ & $\begin{array}{c}\text { Elastic limit } \\
\text { stress, psi }\end{array}$ & $\begin{array}{c}\text { Ultimate } \\
\text { strain, } \mu \text { in./in. }\end{array}$ \\
\hline OSW-8-1 & 4.6 & 13,210 & 4.66 & 0.08 & 12,000 & 2,660 \\
10 & 4.7 & 13,360 & 5.32 & 0.08 & 9,500 & 2,600 \\
8 & 4.4 & 13,300 & 5.08 & 0.13 & 10,000 & 3,000 \\
Mean & 4.6 & 13,290 & 5.02 & 0.10 & 10,500 & 2,730 \\
OSW-10-5 & 5.1 & 17,610 & 6.78 & 0.23 & 12,000 & 2,860 \\
36 & 4.6 & 14,180 & 7.47 & 0.22 & 10,000 & 2,040 \\
Mean & 4.9 & 15,900 & 7.13 & 0.23 & 11,000 & 2,450 \\
\hline
\end{tabular}

Specimens, 6-in.-diam $\times 12$-in.-long cylinders of OSW-type concrete, oven-dried at $150^{\circ} \mathrm{C}$ prior to impregnation and thermal-catalytic polymerization.

Monomer, 60 wt \% styrene - 40 wt \% TMPTMA.

OSW-8 specimens exposed to brine at $121^{\circ} \mathrm{C}$ for 2 years.

OSW-10 specimens exposed to air at $23^{\circ} \mathrm{C}$ and $50 \%$ relative humidity for 2 years.

Test temperature, $121^{\circ} \mathrm{C}$.

Table 80

Compressive Strength and Elasticity of Styrene-TMPTMA Impregnated Concrete

After Two-Year Exposure to Brine at $143^{\circ} \mathrm{C}$

\begin{tabular}{ccccccc}
\hline $\begin{array}{c}\text { Specimen } \\
\text { No. }\end{array}$ & $\begin{array}{c}\text { Polymer } \\
\text { loading, wt \% }\end{array}$ & $\begin{array}{c}\text { Ultimate } \\
\text { strength, psi }\end{array}$ & $\begin{array}{c}\text { Modulus of } \\
\text { elasticity, } 10^{8} \text { psi }\end{array}$ & $\begin{array}{c}\text { Poisson's } \\
\text { ratio }\end{array}$ & $\begin{array}{c}\text { Elastic limit } \\
\text { stress, psi }\end{array}$ & $\begin{array}{c}\text { Ultimate } \\
\text { strain, } \mu \text { in./in. }\end{array}$ \\
\hline OSW-9-8 & 4.6 & 10,500 & 4.35 & 0.13 & 7,500 & 2,580 \\
15 & 4.4 & 9,390 & 4.10 & 0.14 & 7,000 & 2,740 \\
25 & 4.8 & 11,100 & 4.84 & 0.17 & 7,500 & 2.800 \\
Mean & 4.6 & 10,330 & 4.43 & 0.15 & 7,330 & 2,710 \\
OSW-10-17 & 4.8 & 16,320 & 6.98 & 0.22 & 11,000 & 2,560 \\
24 & 5.0 & 15,570 & 6.75 & 0.19 & 11,000 & 2,700 \\
Mean & 4.9 & 15,950 & 6.86 & 0.20 & 11,000 & 2,630 \\
\hline
\end{tabular}

Specimens, 6-in.-diam $\times 12$-in.-long cylinders of $\mathrm{OSW}$-type concrete, oven-dried at $150^{\circ} \mathrm{C}$ prior to impregnation and thermal-catalytic polymerization.

Monomer, 60 wt \% styrene - 40 wt \% TMPTMA.

OSW-9 specimens expoeed to brine at $143^{\circ} \mathrm{C}$ for 2 years.

OSW-10 specimens exposed to air at $23^{\circ} \mathrm{C}$ and $50 \%$ relative humidity for 2 years.

Tett temperature, $143^{\circ} \mathrm{C}$.

of unit length change at 6 months and 1 year does indicate a trend to greater expansion with increased exposure time.

Results after 6 months and 1 year of exposure in the $143^{\circ} \mathrm{C}$ three-phase loops show more pronounced effects of exposure. (See Tables 81 and 82 and Table 89 in Section 5.2.2.3.) Compressive strengths of impregnated concrete ranged from
$11,700 \mathrm{psi}$ for the vapor-exposure specimens to 13,000 psi for the brine-exposure specimens. The average compressive strength of all impregnated CP-type concrete specimens tested in the threephase loops at $143^{\circ} \mathrm{C}$ is 12,400 psi, compared with 14,900 psi for $121^{\circ} \mathrm{C}$ three-phase specimens and 11,100 psi for impregnated OSW-type concrete in the $143^{\circ} \mathrm{C}$ single-phase loops. Unit length 
Table 81

Compressive Strength and Elasticity of Styrene-TMPTMA Impregnated Concrete After One-Year Exposure at $143^{\circ} \mathrm{C}$ in Three-Phase Test Loops

\begin{tabular}{|c|c|c|c|c|c|c|c|}
\hline $\begin{array}{c}\text { Specimen } \\
\text { No., } \\
72.174-\end{array}$ & Exposure & $\begin{array}{c}\text { Polymer } \\
\text { loading, wt \% }\end{array}$ & $\begin{array}{l}\text { Ultimate } \\
\text { strength, psi }\end{array}$ & $\begin{array}{l}\text { Modulus of } \\
\text { elasticity, } 10^{6} \mathrm{psi}\end{array}$ & $\begin{array}{l}\text { Poisson's } \\
\text { ratio }\end{array}$ & $\begin{array}{c}\text { Elastic } \\
\text { limit, psi }\end{array}$ & $\begin{array}{c}\text { Ultimate } \\
\text { strain, } \mu \text { in./in. }\end{array}$ \\
\hline 357 & $\mathbf{V}$ & 6.9 & 9,890 & 4.17 & 0.19 & 9,000 & 2,640 \\
\hline 279 & V & 5.9 & 12,460 & 4.55 & 0.12 & 10,000 & 3,100 \\
\hline 350 & V & 5.6 & 12,880 & 4.13 & 0.11 & 11,000 & 3,100 \\
\hline \multicolumn{2}{|c|}{ Mean } & 6.1 & 11,740 & 4.28 & 0.14 & 10,000 & 2,950 \\
\hline 234 & BV & 6.4 & 12,710 & 4.21 & 0.15 & 11,000 & 3,300 \\
\hline 341 & BV & 5.7 & 12,780 & 5.00 & 0.14 & 11,000 & 2,840 \\
\hline 261 & BV & 5.4 & 12,360 & 4.89 & 0.15 & 10,500 & 2,330 \\
\hline \multicolumn{2}{|c|}{ Mean } & 5.7 & 12,620 & 4.70 & 0.14 & 10,830 & 2,990 \\
\hline 349 & B & 6.2 & 13,110 & 3.89 & 0.15 & 11,000 & 3,420 \\
\hline 366 & B & 5.7 & 12,910 & 4.67 & 0.14 & $11,0,050$ & 2,840 \\
\hline 252 & B & 5.6 & 13,000 & 4.52 & 0.18 & 11,000 & 3,100 \\
\hline \multicolumn{2}{|c|}{ Mean } & 5.8 & 13,010 & 4.36 & 0.16 & 11,000 & 3,120 \\
\hline
\end{tabular}

Specimens, 6-in.-diam $\times 12$-in.-long cylinders of GP-type concrete, oven-dried at $150^{\circ} \mathrm{C}$ prior to impregnation and thermal-catalytic polymerization.

Monomer, $60 \mathrm{wt} \%$ styrene - $40 \mathrm{wt} \%$ TMPTMA.

Test temperature, $143^{\circ} \mathrm{C}$.

$-\mathrm{B}$, exposure to brine; $\mathrm{V}$, in vapor; $\mathrm{BV}$, at brine-vapor interface.

\section{Table 82}

Compressive Strength and Elasticity of Unimpregnated Concrete

After One-Year Exposure at $143^{\circ} \mathrm{C}$ in Three-Phase Test Loops

\begin{tabular}{|c|c|c|c|c|c|c|}
\hline $\begin{array}{c}\text { Specimen } \\
\text { No., } \\
\text { 72.175- }\end{array}$ & Exposurea & $\begin{array}{l}\text { Ultimate } \\
\text { strength, psi }\end{array}$ & $\begin{array}{l}\text { Modulus of } \\
\text { elasticity, } 10^{6} \mathrm{Fsi}\end{array}$ & $\begin{array}{l}\text { Poisson's } \\
\text { ratio }\end{array}$ & $\begin{array}{c}\text { Elastic } \\
\text { limit, psi }\end{array}$ & $\begin{array}{c}\text { Ultimate } \\
\text { strain, } \mu \text { in./in. }\end{array}$ \\
\hline $\begin{array}{l}403 \\
409 \\
333\end{array}$ & $\begin{array}{l}\mathrm{V} \\
\mathrm{V} \\
\mathrm{V}\end{array}$ & $\begin{array}{r}9,540 \\
9,540 \\
10,920\end{array}$ & $\begin{array}{l}4.56 \\
4.50 \\
4.94\end{array}$ & $\begin{array}{l}0.11 \\
0.12 \\
0.16\end{array}$ & $\begin{array}{l}7,000 \\
7,000 \\
6,500\end{array}$ & $\begin{array}{l}2,330 \\
2,300 \\
2,460\end{array}$ \\
\hline Mean & & 10,000 & 4.67 & 0.13 & 6,830 & 2,360 \\
\hline $\begin{array}{l}318 \\
393 \\
379\end{array}$ & $\begin{array}{l}\text { BV } \\
\text { BV } \\
\text { BV }\end{array}$ & $\begin{array}{l}7,460 \\
8,040 \\
9,210\end{array}$ & $\begin{array}{l}4.31 \\
4.47 \\
4.59\end{array}$ & $\begin{array}{l}0.18 \\
0.18 \\
0.16\end{array}$ & $\begin{array}{l}4,500 \\
5,500 \\
6,000\end{array}$ & $\begin{array}{l}\because, 280 \\
2,670 \\
2,720\end{array}$ \\
\hline Mean & & 8,240 & 4.46 & 0.17 & 5,330 & 2,560 \\
\hline $\begin{array}{l}310 \\
402 \\
387\end{array}$ & $\begin{array}{l}\text { B } \\
\text { B } \\
\text { B }\end{array}$ & $\begin{array}{l}8,710 \\
8,320 \\
7,790\end{array}$ & $\begin{array}{l}4.20 \\
4.57 \\
4.42\end{array}$ & $\begin{array}{l}0.20 \\
0.20 \\
0.18\end{array}$ & $\begin{array}{l}\mathbf{5 , 0 0 0} \\
\mathbf{5 , 5 0 0} \\
\mathbf{5 , 5 0 0}\end{array}$ & $\begin{array}{l}3,340 \\
2,280 \\
2,440\end{array}$ \\
\hline Mean & & 8,270 & 4.40 & 0.19 & 5,330 & 2,690 \\
\hline
\end{tabular}

Specimens, 6-in.-diam $\times$ 12-in.-long cylinders of CP-type concrete.

Test temperature, $143^{\circ} \mathrm{C}$.

-B, exponure to brine; $\mathrm{V}$, in vapor; BV, at brine-vapor interface. 
Table 83

Effect of Length of Exposure in Three-Phase Loops at $143^{\circ} \mathrm{C}$ on the Compressive Strength of Unimpregnated and Styrene-TMPTMA Impregnated Concrete

\begin{tabular}{rccrr}
\hline $\begin{array}{c}\text { Exposure } \\
\text { time, } \\
\text { mo }\end{array}$ & $\begin{array}{c}\text { Exposure } \\
\text { environment }^{8}\end{array}$ & $\begin{array}{c}\text { Polymer } \\
\text { loading, } \\
\text { wt \% }\end{array}$ & $\begin{array}{c}\text { Ultimate } \\
\text { strength, } \\
\text { psi }\end{array}$ & $\begin{array}{r}\text { Elastic } \\
\text { modulus, } \\
10^{6} \text { psi }\end{array}$ \\
\hline 6 & B & 6.0 & 12,640 & 4.30 \\
12 & B & 5.8 & 13,010 & 4.36 \\
6 & BV & 5.8 & 14,810 & 4.50 \\
12 & BV & 5.7 & 12,620 & 4.70 \\
6 & V & 5.8 & 13,417 & 4.40 \\
12 & V & 6.1 & 11,740 & 4.28 \\
6 & B & - & 7,080 & 4.67 \\
12 & B & - & 8,270 & 4.40 \\
6 & BV & - & 6,810 & 4.33 \\
12 & BV & - & 8,240 & 4.46 \\
6 & V & - & 8,180 & 4.67 \\
12 & V & - & 10,000 & 4.67 \\
\hline
\end{tabular}

Specimens, 6-in.-diam $\times 12$-in.-long cylinders of CP. type concrete, oven-dried at $150^{\circ} \mathrm{C}$ prior to impregnation and thermal-catalytic polymerization.

Monomer, 60 wt \% styrene - 40 wt \% TMPTMA.

Test temperature, $143^{\circ} \mathrm{C}$.

$\mathrm{B}$, exposure to brine; $\mathrm{V}$, in vapor; $\mathrm{BV}$, at brine-vapor interface.

change is nearly $\mathbf{2 . 5}$ times as great in these tests as it was after the same length of time in the $121^{\circ} \mathrm{C}$ three-phase loops. The reason for the extremely high compressive strengths observed for unimpregnated concrete is not known. However, a comparison of results of tests at 6 months and 1 year (see Table 83) does show a tendency for unimpregnated concrete to increase in strength with time in all three environments.

A series of 70 wt \% MMA - 30 wt \% TMPTMA specinens is being prepared for testing in the threephase loops.

5.2.1. Thermal Propeaties. Measurements of the thermal coefficient of expansion of $60 \mathrm{wt} \%$ styrene $40 \mathrm{wt} \%$ TMPTMA impregnated CP-type concrete are given in Table 84 . An increase in the linear coefficient of expansion was observed with an increase in the temperature range. The coefficient of expansion varied from $9.7 \mu \mathrm{in} . / \mathrm{in.} \cdot{ }^{\circ} \mathrm{C}$ in the temperature range $24^{\circ}$ to $66^{\circ} \mathrm{C}$ to $10.4 \mu \mathrm{in} . /$ in.- ${ }^{\circ} \mathrm{C}$ in the range $24^{\circ}$ to $127^{\circ} \mathrm{C}$, and $11 \mu \mathrm{in}$./in.${ }^{\circ} \mathrm{C}$ in the range $24^{\circ}$ to $178^{\circ} \mathrm{C}$.

The thermal diffusivity of 60 wt \% styrene 40 wt \% TMPTMA impregnated OSW-type concrete at temperaturcs of $21^{\circ}, 66^{\circ}$, and $149^{\circ} \mathrm{C}$ is
Table 84

Thermal Coefficient of Exparision of Styrene-TMPTMA Impregnated CP Type Concrete

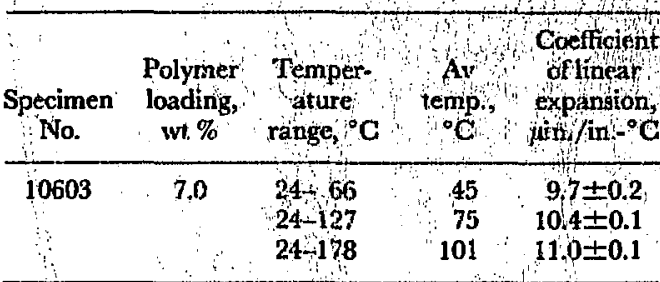

Monomer, 60 wt \% styrene -40 wt \% TMPTMA.

Specimen oven-dried at $177^{\circ} \mathrm{C}$ prior to impregnation and thermal-catalytic polymerization.

Tatile 85

High-Temperature Thermal Properties of Unimpregnated and Styrene-TMPTMA Impregnated OSW-Type Concrete

\begin{tabular}{|c|c|c|c|}
\hline \multirow{2}{*}{ Samples } & \multicolumn{3}{|c|}{$\begin{array}{l}\text { Average thermal } \\
\text { diffiusivity, } \mathrm{ft}^{2} / \mathrm{hr} \text {, at }\end{array}$} \\
\hline & $21^{\circ} \mathrm{C}$ & $66^{\circ} \mathrm{C}$ & $149^{\circ} \mathrm{C}$ \\
\hline $\begin{array}{l}\text { Impregnated concrete } \\
\text { Three } 8 \times 16 \text {-in. cylinders } \\
\text { Two } 6 \times 12 \text {-in, cylinders }\end{array}$ & 0.044 & $\begin{array}{c}0.041 \\
-\end{array}$ & $\begin{array}{l}0.035^{a} \\
0.024\end{array}$ \\
\hline $\begin{array}{l}\text { Unimpregnated concrete } \\
\text { Two } 8 \times 16 \text {.in. cylinders } \\
\text { One } 6 \times 12 \text {-in. cylinder }\end{array}$ & $\begin{array}{c}0.044 \\
-\end{array}$ & $\begin{array}{c}0.042 \\
-\end{array}$ & $\begin{array}{l}0.039^{2} \\
0.021\end{array}$ \\
\hline $\begin{array}{l}\text { Monomer, } 60 \text { wt \% styre } \\
\text { Specimens oven-dried at } \\
\text { and thermal-catalytic polyn } \\
\text { Extrapolated value. }\end{array}$ & $\begin{array}{l}\text { wt \% } \\
\text { prior } \\
\text { on. }\end{array}$ & imp & $\begin{array}{l}\text { A. } \\
\text { gnation }\end{array}$ \\
\hline
\end{tabular}

essentially the same as that of unimpregnated concrete (see Table 85 ). The impregnated and unimpregnated concrete specimens exhibit some reduction in diffusivity with increasing temperature.

\subsubsection{Durability and Resistance to Chenical} Aftack by Hot Brine and Distilled Water. Durability testing at the USBR and BNL of PIC for desalting plant applications includes exposure to brine and distilled water at elevated temperatures and environmental testing. At the USBR, exposure to brine is conducted in a series of enclosed recirculating loops maintained at $121^{\circ} \mathrm{C}$ and $143^{\circ} \mathrm{C}$, and exposure to distilled water is conducted at $143^{\circ} \mathrm{C}$ in a closed autoclave system through which deionized water is circulated. At BNL, hotbrine and distilled-water exposures are conducted 
in autoclaves modified to provide for testing specimens under water, in vapor, at the water-vapor interface, and when subjected to a dripping condensate. The BNL autoclave tests, USBR brineloop tests, and exposure tests in different environments are described in the following sections.

5.2.2.1 AutocLave TESTS. The autoclave tests at BNL are intended to provide rapid evaluation of the resistance of concrete and concrete-polymer materials to attack by hot brine and distilled water. The facility has been described in detail in previous topical reports. ${ }^{3,4}$ Briefly, it consists of 12 steel pressure vessels lined with a baked phenolic coating. The vessels are capable of operation at a steam pressure of up to $350 \mathrm{psi}\left(220^{\circ} \mathrm{C}\right)$. Sample holders in the vessels are designed to hold eighteen 11/2-in.diam $\times 3$-in.-long concrete cylinders. The cylinders may be in water, at the water-vapor interface, or in the vapor phase. In addition, the vessels contain condensers that permit the condensate to drip on the surface of short concrete specimens. The pressure vessels usually run at three temperatures, $121^{\circ}, 143^{\circ}$, and $177^{\circ} \mathrm{C}$.

An extensive screening program was completed this year to find a suitable polymer system to replace the 90 wt \% DAP - 10 wt \% MMA system, which had failed. The DAP-MMA system was a backup s'stem for the primary 60 wt \% styrene $40 \mathrm{wt} \%$ i MPTMA system. Failure of the DAPMMA system was indicated by rapid loss of material when exposed to condensate drip and by loss of strength at $143^{\circ} \mathrm{C}$.

Three candidate PIC systems were evaluated for 87 days in $143^{\circ} \mathrm{C}$ brine: isodiallyl phthalate (ISODAP), 50 wt \% ethylene glycol dimethacrylate -50 wt $\%$ MMA, and 70 wt \% MMA - 30 wt \% TMPTMA. The MMA-TMPTMA system was chosen for further evaluation, on the basis of compressive strength and weight loss after exposure to condensate drip. PIC was prepared with this polymer for further long-term evaluation in the pressure vessels at $121^{\circ}, 143^{\circ}$, and $177^{\circ} \mathrm{C}$.

Continued observations of the PIC condensate drip sample of the MMA-TMPTMA system were made. After 270 days in the pressure vessel (90 days under condensate) at $143^{\circ} \mathrm{C}$, the sample disintegrated completely. At $177^{\circ} \mathrm{C}$ the larger $1 \frac{1 / 2}{2}$ $\times 3$-in.-long samples started to disintegrate after 83 days. This system is still under evaluation at $121^{\circ} \mathrm{C}$. It should be noted that the types of failure exhibited by the condensate drip samples containing 90 wt \% DAP - 10 wc \% MMA and those con-

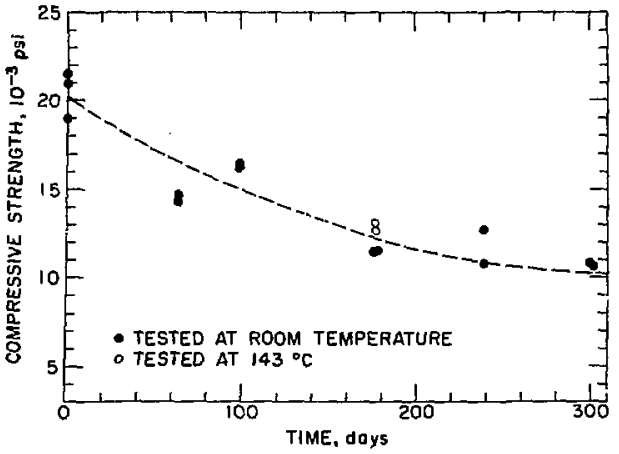

Figure 29. Compressive strength of PIC containing $60 \mathrm{wt}$ \% styrene -40 wt \% TMPTMA after immersion in brine at $143^{\circ} \mathrm{C}$.

taining 70 wt \% MMA - 30 wt \% TMPTMA are entirely different. The former fail by continuous erosion of the mortar phase. The latter exhibit a sound appearing surface until they start disintegrating. Once started, disintegration continues even at room temperature.

The main test program now consists of evaluating PIC prepared with $60 \mathrm{wt} \%$ styrene - $40 \mathrm{wt} \%$ TMPTMA. Weight and length changes are being measured at $121^{\circ}, 143^{\circ}$, and $177^{\circ} \mathrm{C}$, and compressive strength measurements are made periodically at $143^{\circ} \mathrm{C}$. The compressive strengths as a function of time are shown in Figure 29. Although the polymer in this system is the must stable used so far, the PIC has undergone a strength decrease of nearly $50 \%$. After about 180 days, the decrease in strength has almost stopped. In Table 86 the changes in weight and length are tabulated for samples immersed in brine at the three test temperatures. The changes in both weight and length are positive, an indication of absorption and swelling. The rates of weight and length change after exposure for 1 year are positive, although the standard deviations of the measurements are large.

Because the concrete being tested is water- or fog-culed, exposure to high-pressure steam or water, even after polymer impregnation, can result in changes in its pore structure (as reported previously ${ }^{3}$ and discussed in Section 6 of this report). Since these changes in the cement microstructure may be detrimental to the strength of the system, it was decided to try to avoid them by steam-curing the concrete prior to impregnation. Some preliminary tests were made using $60 \mathrm{wt} \%$ 
Table 86

Dimensional and Weight Changes in Polymer-Impregnated Concrete After Exposure to Hot Brine

\begin{tabular}{ccccc}
\hline $\begin{array}{c}\text { Temperature, } \\
{ }^{\circ} \mathrm{C}\end{array}$ & $\begin{array}{c}\text { Weight } \\
\text { change, }{ }^{\mathrm{a}} \%\end{array}$ & $\begin{array}{c}\text { Rate of weight } \\
\text { change, } \mathrm{b} \% / \mathrm{yr}\end{array}$ & $\begin{array}{c}\text { Length } \\
\text { change, } \mathrm{a} \%\end{array}$ & $\begin{array}{c}\text { Rate of length } \\
\text { change, } \mathrm{b} \% / \mathrm{yr}\end{array}$ \\
\hline 121 & $+2.3 \pm 0.0 \mathrm{c}^{\mathrm{c}}$ & $0.4 \pm 0.4$ & $+0.31 \pm 0.05$ & $0.4 \pm 0.6$ \\
143 & $+2.8 \pm 0.2$ & $0.6 \pm 1.7$ & $+0.57 \pm 0.08$ & $0.7 \pm 0.8$ \\
177 & $+3.1 \pm 0.2$ & $1.2 \pm 1.7$ & $+0.89 \pm 0.09$ & $0 \pm 0.2$ \\
\hline
\end{tabular}

Specimens, 1.5-in.-diam $\times$ 3-in.-long cylinders.

Monomer, 60 wt \% styrene - 40 wt \% TMPTMA.

${ }^{a}$ Change at temperature less change of controls in brine at room temperature, after about one year.

based on the last 70 days.

c Estimated standard deviation based on two samples.

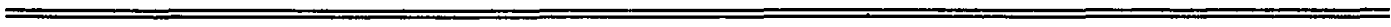

Table 87

Compressive Strength and Weight Loss

Polymer-Impregnated Concrete Exposed to Deionized Water at $143^{\circ} \mathrm{C}$

\begin{tabular}{|c|c|c|c|c|c|}
\hline $\begin{array}{l}\text { Specimen } \\
\text { No. }\end{array}$ & $\begin{array}{c}\text { Polymer } \\
\text { loading, wt \% }\end{array}$ & $\begin{array}{l}\text { Exposure } \\
\text { time, months }\end{array}$ & $\begin{array}{l}\text { Weight } \\
\text { change, \% }\end{array}$ & $\begin{array}{l}\text { Compressive } \\
\text { strength, psi }\end{array}$ & Remarks \\
\hline \multicolumn{6}{|c|}{ Unimpregnated concrete } \\
\hline $\begin{array}{l}41 \\
42 \\
43\end{array}$ & $\begin{array}{l}- \\
- \\
-\end{array}$ & $\begin{array}{l}6 \\
6 \\
6\end{array}$ & $\begin{array}{l}-0.55 \\
-0.52 \\
-0.38\end{array}$ & $\begin{array}{l}5,700 \\
5,500 \\
5,200\end{array}$ & \multirow[t]{2}{*}{$\begin{array}{l}\text { Concrete appears to be in good con- } \\
\text { dition. No signs of deterioration. }\end{array}$} \\
\hline & - & & -0.48 & 5,500 & \\
\hline $\begin{array}{l}44 \\
45 \\
46\end{array}$ & $\begin{array}{l}- \\
-\end{array}$ & $\begin{array}{l}12 \\
12 \\
12\end{array}$ & $\begin{array}{r}-3.98 \\
-13.96 \\
-2.12\end{array}$ & $\begin{array}{l}4,000 \\
3,700 \\
6,500\end{array}$ & \multirow[t]{2}{*}{$\begin{array}{l}\text { Concretc appears to be very unsound. } \\
\text { Surface spalling to depth of } 3 / 4 \text { in. } \\
\text { on No. } 45 \text {. }\end{array}$} \\
\hline & - & & -6.69 & 4,700 & \\
\hline
\end{tabular}

$60 \mathrm{wt} \%$ styrene $-40 \mathrm{wt} \%$ TMPTMA impregnated concrete

\begin{tabular}{|c|c|c|c|c|c|}
\hline $\begin{array}{r}2 \\
11 \\
28\end{array}$ & $\begin{array}{l}7.7 \\
8.0 \\
7.6\end{array}$ & $\begin{array}{l}6 \\
6 \\
6\end{array}$ & $\begin{array}{l}+0.58 \\
+0.47 \\
+0.36\end{array}$ & $\begin{array}{l}12,900 \\
12,200 \\
11,800\end{array}$ & \multirow[t]{2}{*}{$\begin{array}{l}\text { Concrete appears to be in good con- } \\
\text { dition. No signs of deterioration. }\end{array}$} \\
\hline Av & 7.8 & & +0.47 & 12,300 & \\
\hline $\begin{array}{l}12 \\
21 \\
26\end{array}$ & $\begin{array}{l}7.5 \\
7.6 \\
7.6\end{array}$ & $\begin{array}{l}12 \\
12 \\
12\end{array}$ & $\begin{array}{l}+0.19 \\
+0.32 \\
+0.55\end{array}$ & $\begin{array}{r}20,500 \\
10,500 \\
9,800\end{array}$ & $\begin{array}{l}\text { Concrete appears to be in good con- } \\
\text { dition. No signs of deterioration. }\end{array}$ \\
\hline Av & 7.6 & & +0.35 & I, 300 & \\
\hline
\end{tabular}

70 wt \% MMA - 30 wt \% TMP? wa impregnated concrete

\begin{tabular}{|c|c|c|c|c|c|}
\hline & \multirow[b]{2}{*}{7.3} & & & & \multirow{3}{*}{$\begin{array}{l}\text { Concrete appears to be in good con- } \\
\text { dition. No signs of deterioration. }\end{array}$} \\
\hline & & $\begin{array}{l}6 \\
6\end{array}$ & $\begin{array}{l}+0.78 \\
+1.21\end{array}$ & $\begin{array}{l}11,300 \\
13,000\end{array}$ & \\
\hline 5 & 7.0 & 6 & +1.95 & 13,000 & \\
\hline Av & 7.1 & & +1.31 & 12,400 & \\
\hline
\end{tabular}

$3 \times 6$-in. CP-type concrete cylinders oven-dried at $177^{\circ} \mathrm{C}$ prior to impregnation.

Thermal-catalytic polymerization. 
styrene $-40 \mathrm{wt} \%$ TMPTMA impregnated steamcured concrete. Initial results showed that the rate of decrease in strength was less for the steam-cured concrete than for the water-cured. A more extensive testing program with steam-cured concretes is in progress.

5.2.2.2 Delonized Waten Tests. Unimpregnated and PIC specimens are tested for resistance to deionized water at $149^{\circ} \mathrm{C}$ in a closed recirculating autoclave system. Specimens are removed periodically, visually examined, and tested for weight change and compressive strength. Unimpregnated and 60 wt \% styrene-40 wt \% TMPTMA impregnated concretes have been tested after 6 months and 1 year of exposure, and 70 wt \% MMA - $30 \mathrm{wt} \%$ TMPTMA impregnated concrete has been tested after 6 months' exposure. Test results are given in Table 87.

Unimpregnated concrete showed little deterioration after 6 months' exposure and had a compressive strength of 5500 psi. After 12 months' exposure, specimens appeared unsound, with some surface disintegration, and averaged about $7 \%$ weight loss; however, compressive strengths showed only a small decrease and averaged 4700 psi. The styrene-TMPTMA specimens appear to be in good condition after 12 months' exposure, showing only a slight weight increase. Compressive strengths seem to be declining, from an average of 12,300 psi after 6 months' exposure to 10,300 psi after 12 months. The MMA-TMPTMA specimens appear to be in good condition after 6 months' exposure. Compressive strengths after 6 months were comparable to those for the styrene-TMPTMA specimens (12,400 vs 12,300 psi). The MMA-TMPTMA specimens are showing a small weight gain of $1.3 \%$, which suggests that these specimens are a little more absorptive than the styrene-TMPTMA specimens.

5.2.2.3 Loop TEsTs. Loop-test specimens are exposed to concentrated synthetic seawater at high temperatures in enclosed recirculating systems. Two series of loop tests are in progress: the first is a single-phase test in which polymer impregnated OSW-type concrete is exposed to brine at $121^{\circ}$ and $143^{\circ} \mathrm{C}$; the second is a three-phase system in which polymer-impregnated CP-type concrete is exposed to brine, to the brine-vapor interface, and to vapor at $121^{\circ}$ and $143^{\circ} \mathrm{C}$. The brine in the $121^{\circ} \mathrm{C}$ loops is concentrated synthetic seawater containing $73,000 \mathrm{ppm}$ dissolved salt, and the brine in the $143^{\circ} \mathrm{C}$ loops contains 38,400 ppm dis- solved salt. The loop exposures are long-term tests; the single-phase system has been in test for 2 years, and the three-phase system, for 1 year. Early failures aside, the final observations on durability will await completion of the test. Measurements are made on specimens prior to exposure and periodically during the test.

Compressive strength, modulus of elasticity, Poisson's ratio, specific gravity, and ultrasonic pulse velocity are determined on 6 -in.-diam $\times 12$ in.-long cylinders. Resonant frequency and length and weight changes are measured on $4 \times 4 \times 30$-in. bars. Corrosion measurements are also made on $4 \times 4 \times 30$-in. bars containing reinforcing steel. A more detailed discussion of structural properties of loop-test specimens is given in Section 5.2.1.7.

(a) SINGLE-PHASE BRINE-LOOP IESTS. The single-phase brine loops are being used to test OSW-type concrete impregnated with 60 wt $\%$ styrene $-40 \mathrm{wt} \%$ TMPTMA, thermal-catalytically polymerized. Tests have been in progress for more than 2 years and results are summarized in Table 88.

Previous investigations ${ }^{4}$ have shown that concrete impregnated with 90 wt \% DAP - 10 wt \% MMA deteriorates when exposed to hot brine and distilled water.

Styrene-TMPTMA specimens exposed to brine at $121^{\circ}$ and $143^{\circ} \mathrm{C}$ show a trend toward lower compressive strengths with an increase in exposure time and temperature. Compressive strengths ranged from $16,200 \mathrm{psi}$ at $121^{\circ} \mathrm{C}$ for specimens exposed for 215 days in $121^{\circ} \mathrm{C}$ brine to 10,300 psi for specimens exposed for 2 years in $143^{\circ} \mathrm{C}$ brine. The modulus of elasticity shows a similar decrease, from $5.7 \times 10^{8}$ psi for a 215 -day exposure in $121^{\circ} \mathrm{C}$ brine to $4.4 \times 10^{6}$ psi for 2 years of exposure in $143^{\circ} \mathrm{C}$ brine. Length change measurements show a progressive expansion with an increase in exposure time and temperature, ranging from $593 \mu \mathrm{in} . /$ in. for 215 days of exposure at $121^{\circ} \mathrm{C}$ to $1704 \mu \mathrm{in} . /$ in. for 2 years of exposure at $143^{\circ} \mathrm{C}$. Tests of other properties show less definite changes with exposure time and temperature. Ultrasonic pulse velocity measurements show a decrease from about $18,000 \mathrm{ft} / \mathrm{sec}$ to about 14,000 to $16,000 \mathrm{ft} / \mathrm{sec}$ after exposure to brine, but the decrease in velocity does not appear to be a function of brine exposure time or temperature. Weight changes are minor and show an increase of about $2 \%$, due to moisture absorption. Resonant frequency measurements (resonant frequency squared) show an initial increase of $9.8 \%$ for specimens exposed in $121^{\circ} \mathrm{C}$ 
brine for $\mathbf{2 1 5}$ days, followed by a gradual decrease with exposure time to a $5.3 \%$ increase at 2 years. Specimens exposed in $143^{\circ} \mathrm{C}$ brine show decreases in resonant frequency of $3.4 \%$ at 180 days, $10.8 \%$ at 1 year, and $5.7 \%$ at 2 years.

The results of brine exposure tests on unimpregnated concrete in Table $\mathbf{8 8}$ are from a previous test ${ }^{16}$ and are included for a general comparison of the behavior of unimpregnated concrete. Some of the test conditions varied somewhat, chiefly in that the concrete was allowed to dry in air for up to $1 \frac{1 / 2}{2}$ years before exposure in brine and compressive strengths were determined at room temperature. The general conclusions from this study 16 were that $2 \frac{1 / 2}{2}$ years of exposure in $121^{\circ} \mathrm{C}$ brine does not detrimentally affect concrete, although minor surface alteration has occurred. Exposure in $143^{\circ} \mathrm{C}$ brine for 40 months produced loss of strength and deterioration in the surface of the concrete to an average depth of $15 \mathrm{~mm}$. Examination of $143^{\circ} \mathrm{C}$ test specimens revealed chemical alteration and microfracturing in the deteriorated zone. However, the interior of the concrete appeared sound. On the basis of these tests, the report recommended that unimpregnated concrete should not be used in contact with $143^{\circ} \mathrm{C}$ brine.

(b) Trane-Puss loors. Unimpregnated and $60 \mathrm{wt} \%$ styrene - 40 wt \% TMPTMA impregnated CP. type concretes have been in test at $121^{\circ}$ and $143^{\circ} \mathrm{C}$. in the three-phase brine loops for 1 year. A number of observations on test results have been made, but these tests have not been in progress long enough for definite concluaions to be made on the suitability of the materials. Test results are given in Table 89. A 70 wt \% MMA - 30 wt \% TMP. TMA monomer system has been selected as a second system for high-temperature applications, and testing has begun. 'To date the teat has not bien in progres long enough to give meaningful reaule.

Styrene-TMPTMA impregnated specimens show little difference in compresive strength after 6 months and I year of exposure to brine, the brine-vapor interface, and vapor at $121^{\circ} \mathrm{C}$. Compremive atrengths averaged about 15,000 pai and are comparable to the strength of styrene-TMP. TMA impregnated OSW-type concrete specimens exponed in the $121^{\circ} \mathrm{C}$ single-phase brine loops for 1 year. The compreasive strengths of styreneTMPTMA CP-type specimens in the $143^{\circ} \mathrm{C}$ three-phase system were a little lower and indicate a trend toward lower strengths with increased exposure time; small differences among specimens from the three test environments in the $143^{\circ} \mathrm{C}$ system were also apparent. Specimens exposed to $143^{\circ} \mathrm{C}$ brine for 1 year had an average compres. sive strength of $13,000 \mathrm{psi}$, brine-vapor interface specimens averaged $12,600 \mathrm{psi}$, and vapor specimens averaged 11,700 psi. Modulus of elasticity values were comparable to previous results with styrene-TMPTMA impregnated OSW-type concrete in the single-phase brine loops; specimens exposed at $121^{\circ} \mathrm{C}$ in the three-phase loops ranged from 5.1 to $5.6 \times 10^{6}$ psi and from 4.1 to $5.1 \times 10^{6}$ psi in the $143^{\circ} \mathrm{C}$ three-phase loops.

Measurements of length change and resonant frequency indicate some changes within the specimens. These measurements have not been correlated with other physical and mechanical properties of PIC but are useful as indications of reductions in the quality of the materials. Length change measurements show a gradual expansion with time and temperatuse in all three phases. Expansions were not as large for the styrene-TMPTMA impregnated OSW-type concrete specimens in the single-phase loops, and at one year were $486 \mu \mathrm{in} . /$ in. in the $121^{\circ} \mathrm{C}$ brine exposure and $1296 \mu \mathrm{in.} / \mathrm{in}$. in the $143^{\circ} \mathrm{C}$ brine exposure. Resonant frequency measurements (resonant frequency squared) showed sr.uall loseses of $5 \%$ and $6 \%$ at 1 year for specimens in the $121^{\circ} \mathrm{C}$ brine and vapor exposures, respectivcly, and a $20 \%$ loss in the brinevapor interface exposure. In the $143^{\circ} \mathrm{C}$ loope, lowses were about $18 \%$ after I year for all three exposures. The initial resonant frequency measurements for the $143^{\circ} \mathrm{C}$ impregnated specimens are roughly $10 \%$ higher than those usually obtained with impregnaicd specimens, but the readings after 1 year's exposure are roughly similar to 1-year measurements on $143^{\circ} \mathrm{C}$ single-phase loop specimera.

The reasons for the expansion in length and decrease in resonant frequency, as well as loss in compreasive strength, are not known. Although it would be speculative to try to evaluate the pomible cause in view of the fimited data and relatively short exposures, moisture in the specimens may be a contributing factor. Absorption of moisture is evident from the amall increase in weight and has also been observed in some compressive strength speximens. Several such specimens have emitted a smxll amount of vapor on fracturing, which in some tases condensed in small droplets of water on the test machines' land plates. 


\begin{tabular}{|c|c|c|c|c|c|c|c|c|c|c|c|c|c|c|c|}
\hline \multirow[b]{2}{*}{ Expofure } & \multicolumn{5}{|c|}{ Initial meacurements } & \multirow[b]{2}{*}{$\begin{array}{l}\text { Exposure } \\
\text { time }\end{array}$} & \multicolumn{9}{|c|}{ Measurements after expouure } \\
\hline & $\begin{array}{c}\text { Polymer } \\
\text { loading, wt \% }\end{array}$ & $\begin{array}{l}\text { Specific } \\
\text { gravity }\end{array}$ & $\begin{array}{l}\text { Unit } \\
\text { weight, } \\
\text { lb/cu ft }\end{array}$ & $\begin{array}{c}\text { Resonant } \\
\text { frequency } \\
\text { squared, } 10^{3} \mathrm{cP}\end{array}$ & $\begin{array}{l}\text { Pulse } \\
\text { velocity, ft/sec }\end{array}$ & & $\begin{array}{l}\text { Specific } \\
\text { gravityc }\end{array}$ & $\begin{array}{l}\text { Unit } \\
\text { weight } \\
\text { lb/cu ft }\end{array}$ & $\begin{array}{l}\text { Resonant } \\
\text { frequency, } \\
\% \text { change }\end{array}$ & $\begin{array}{l}\text { Pulse } \\
\text { velocity, } \\
\text { ft/sex }\end{array}$ & $\begin{array}{c}\text { Weight } \\
\text { change,d } \\
\%\end{array}$ & $\begin{array}{l}\text { Unit } \\
\text { length } \\
\text { change,d } \\
\mu \text { in./in. }\end{array}$ & $\begin{array}{l}\text { Strength } \\
\text { test } \\
\text { tempera. } \\
\text { ture, }{ }^{\circ} \mathrm{C}\end{array}$ & $\begin{array}{l}\text { Compreaive } \\
\text { strength, } \\
\text { psi }\end{array}$ & $\begin{array}{c}\text { Modulus of } \\
\text { elasticity, } \\
10^{5} \mathrm{pui}\end{array}$ \\
\hline \multicolumn{16}{|c|}{ Impregnated concrete } \\
\hline $121^{\circ} \mathrm{C}$ brine & $\begin{array}{l}4.5 \\
4.5 \\
4.6\end{array}$ & $\begin{array}{l}2.53 \\
2.57 \\
2.53\end{array}$ & $\begin{array}{l}157.8 \\
160.0 \\
157.7\end{array}$ & $\begin{array}{l}551 \\
551 \\
551\end{array}$ & $\begin{array}{l}18,300 \\
17,900 \\
17,500\end{array}$ & $\begin{array}{c}215 \text { days } \\
1 \text { yr } \\
2 \text { yr }\end{array}$ & $\begin{array}{l}2.55 \\
2.57 \\
2.56\end{array}$ & $\begin{array}{l}159.0 \\
160.1 \\
159.5\end{array}$ & $\begin{array}{l}+9.8 \\
+7.0 \\
+5.3\end{array}$ & $\begin{array}{l}16,400 \\
16,000 \\
15,900\end{array}$ & $\begin{array}{l}+1.4 \\
+1.8 \\
+2.0\end{array}$ & $\begin{array}{r}+593 \\
+955 \\
+1,272\end{array}$ & $\begin{array}{l}121 \\
121 \\
121\end{array}$ & $\begin{array}{l}16,200 \\
14,900 \\
13,300\end{array}$ & $\begin{array}{l}5.7 \\
5.3 \\
5.0\end{array}$ \\
\hline $143^{\circ} \mathrm{C}$ brine & $\begin{array}{l}4.6 \\
4.6 \\
4.6 \\
4.6\end{array}$ & $\begin{array}{l}2.57 \\
2.56 \\
2.55 \\
2.56\end{array}$ & $\begin{array}{c}159.7 \\
159.3 \\
- \\
159.2\end{array}$ & $\begin{array}{c}585 \\
585 \\
- \\
585\end{array}$ & $\begin{array}{l}18,300 \\
17,700 \\
18,300 \\
17,700\end{array}$ & $\begin{array}{c}180 \text { days } \\
1 \mathrm{yr} \\
11 / 4 \mathrm{yr} \\
2 \mathrm{yr}\end{array}$ & $\begin{array}{l}2.59 \\
2.56 \\
2.57 \\
2.59\end{array}$ & $\begin{array}{c}161.5 \\
159.5 \\
- \\
161.0\end{array}$ & $\begin{array}{c}-3.4 \\
-10.8 \\
- \\
-5.7\end{array}$ & $\begin{array}{l}15,600 \\
13,800 \\
16,400 \\
16,700\end{array}$ & $\begin{array}{c}+2.1 \\
+1.1 \\
- \\
+2.2\end{array}$ & $\begin{array}{c}+1,141 \\
+1,451 \\
-\overline{1} \\
+1,704\end{array}$ & $\begin{array}{l}143 \\
143 \\
143 \\
143\end{array}$ & $\begin{array}{l}12,900 \\
11,100 \\
11,400 \\
10,300\end{array}$ & $\begin{array}{l}4.7 \\
4.4 \\
4.1 \\
4.4\end{array}$ \\
\hline \multicolumn{16}{|c|}{ PIC control specimens } \\
\hline $23^{\circ} \mathrm{C}$ air (50\% R.H.) & $\begin{array}{l}4.9 \\
4.9 \\
4.9 \\
4.9\end{array}$ & $\begin{array}{l}2.54 \\
2.55 \\
2.53 \\
2.54\end{array}$ & $\begin{array}{l}158.6 \\
158.8 \\
157.7 \\
157.9\end{array}$ & $\begin{array}{c}608 \\
608 \\
- \\
-\end{array}$ & $\begin{array}{l}18,200 \\
17,900 \\
18,100 \\
17,500\end{array}$ & $\begin{array}{l}1 \mathrm{yr} \\
2 \mathrm{yr} \\
1 \mathrm{yr} \\
2 \mathrm{yr}\end{array}$ & $\begin{array}{c}- \\
2.55 \\
- \\
2.54\end{array}$ & $\begin{array}{c}- \\
158.7 \\
- \\
15 \overline{7} .9\end{array}$ & $\begin{array}{c}+1.3 \\
+1.9 \\
- \\
-\end{array}$ & $\begin{array}{l}18,200 \\
17,600 \\
17,800 \\
17,600\end{array}$ & $\begin{array}{c}+0.1 \\
-0.4 \\
- \\
-\end{array}$ & $\begin{array}{c}+94 \\
+107 \\
- \\
-\end{array}$ & $\begin{array}{l}121 \\
121 \\
143 \\
143\end{array}$ & $\begin{array}{l}17,200 \\
15,900 \\
14,600 \\
15,900\end{array}$ & $\begin{array}{r}7.2 \\
7.1 \\
6.6 \\
-\quad 6.9\end{array}$ \\
\hline \multicolumn{16}{|c|}{ Unimpregnated concrete } \\
\hline $121^{\circ} \mathrm{C}$ brine & $\begin{array}{l}- \\
- \\
- \\
- \\
- \\
- \\
-\end{array}$ & $\begin{array}{l}- \\
- \\
- \\
- \\
- \\
- \\
-\end{array}$ & $\begin{array}{c}155.3 \\
- \\
- \\
- \\
- \\
- \\
-\end{array}$ & $\begin{array}{c}449 \\
449 \\
449 \\
449 \\
449 \\
449 \\
- \\
-\end{array}$ & $\begin{array}{c}15,800 \\
- \\
- \\
- \\
- \\
- \\
- \\
-\end{array}$ & $\begin{array}{c}- \\
180 \text { days } \\
1 \mathrm{yr} \\
1 \frac{1}{2} \mathrm{yr} \\
2 \mathrm{yr} \\
21 / 2 \mathrm{yr} \\
3 \mathrm{yr} \\
31 / 6 \mathrm{yr}\end{array}$ & $\begin{array}{l}- \\
- \\
- \\
- \\
- \\
- \\
-\end{array}$ & $\begin{array}{l}155.3 \\
159.5 \\
159.1 \\
155.5 \\
157.4 \\
158.6 \\
158.3 \\
157.2\end{array}$ & $\begin{array}{r}- \\
+12.2 \\
+12.9 \\
+6.0 \\
+12.7 \\
+9.1 \\
+19.1 \\
+8.6\end{array}$ & $\begin{array}{l}15,800 \\
16,100 \\
16,500 \\
15,600 \\
16,000 \\
16,100 \\
15,200 \\
16,400\end{array}$ & $\begin{array}{r}- \\
+2.4 \\
+2.6 \\
+3.2 \\
+3.7 \\
+4.3 \\
+4.7 \\
+5.5\end{array}$ & $\begin{array}{l}- \\
+412 \\
+408 \\
+510 \\
+578 \\
+573 \\
+702 \\
+717\end{array}$ & $\begin{array}{l}\text { Room } \\
\text { Room } \\
\text { Room } \\
\text { Room } \\
\text { Room } \\
\text { Room } \\
\text { Room } \\
\text { Room }\end{array}$ & $\begin{array}{l}8,300 \\
7,900 \\
8,500 \\
8,600 \\
8,000 \\
7,600 \\
7,300 \\
7,400\end{array}$ & $\begin{array}{l}4.9 \\
5.7 \\
5.9 \\
6.3 \\
6.2 \\
6.1 \\
6.2 \\
5.6\end{array}$ \\
\hline $143^{\circ} \mathrm{C}$ brine & $\begin{array}{l}- \\
- \\
- \\
- \\
- \\
-\end{array}$ & $\begin{array}{l}- \\
- \\
- \\
- \\
- \\
-\end{array}$ & $\begin{array}{c}156.2 \\
- \\
- \\
- \\
- \\
- \\
-\end{array}$ & $\begin{array}{l}445 \\
445 \\
445 \\
445 \\
445 \\
445 \\
445\end{array}$ & $\begin{array}{c}15,600 \\
- \\
- \\
- \\
- \\
- \\
-\end{array}$ & $\begin{array}{c}- \\
180 \text { days } \\
1 \text { yr } \\
11 / 2 \mathrm{yr} \\
2 \mathrm{yr} \\
21 / 2 \mathrm{yr} \\
3 \mathrm{yr}\end{array}$ & $\begin{array}{l}- \\
- \\
- \\
- \\
- \\
-\end{array}$ & $\begin{array}{c}156.2 \\
159.9 \\
162.2 \\
161.5 \\
- \\
156.9 \\
-\end{array}$ & $\begin{array}{r}- \\
+3.8 \\
-3.6 \\
-6.5 \\
-13.0 \\
-19.6 \\
-34.4\end{array}$ & $\begin{array}{c}15,600 \\
16,800 \\
15,700 \\
15,700 \\
- \\
14,900 \\
-\end{array}$ & $\begin{array}{c}- \\
+2.6 \\
+4.5 \\
+5.4 \\
+6.2 \\
+7.1 \\
-\end{array}$ & $\begin{array}{r}- \\
+471 \\
+626 \\
+826 \\
+855 \\
+924 \\
+987\end{array}$ & $\begin{array}{l}\text { Room } \\
\text { Room } \\
\text { Room } \\
\text { Room } \\
\text { Room } \\
\text { Room } \\
\text { Room }\end{array}$ & $\begin{array}{c}7,900 \\
7,200 \\
5,400 \\
6,200 \\
- \\
4,900 \\
-\end{array}$ & $\begin{array}{c}4.4 \\
5.6 \\
4.8 \\
4.5 \\
- \\
3.2 \\
-\end{array}$ \\
\hline
\end{tabular}

*60 wt \% styrene - 40 wt \% TMPTMA, thermal-catalytically polymerized.

bynthetic seawater concentrated to $73,000 \mathrm{ppm}$ tds for $143^{\circ} \mathrm{C}$ expcsure and $38,400 \mathrm{ppm}$ tds for $121^{\circ} \mathrm{C}$ exposure.

- Values are averages for three $6 \times 12$-in. cylinders.

Values are averages for two $4 \times 4 \times 30$-in. prisms.

e Rcoults for unimpregnated concrete are from a previous study. ${ }^{16}$ 
Properties of Styrene-TMPTMAa Impregnated CP-Type Concrete Exposed to Brine,

Vapor, and Brine-Vapor Interface at Elevated Temperatures

\begin{tabular}{|c|c|c|c|c|c|c|c|c|c|c|c|c|c|c|}
\hline \multirow[b]{2}{*}{ Exposure } & \multicolumn{5}{|c|}{ Initial measurements } & \multirow[b]{2}{*}{$\begin{array}{l}\text { Exposure } \\
\text { time }\end{array}$} & \multicolumn{8}{|c|}{ Measurements after exposure } \\
\hline & $\begin{array}{l}\text { Polymer } \\
\text { losding, } \\
\text { wt \% }\end{array}$ & $\begin{array}{l}\text { Specific } \\
\text { gravity }\end{array}$ & $\begin{array}{c}\text { Unit } \\
\text { weight, } \\
\text { lb/cu ft }\end{array}$ & $\begin{array}{l}\text { Resonant } \\
\text { frequency } \\
\text { squared, } \\
10^{3} \mathrm{cP}\end{array}$ & $\begin{array}{c}\text { Pulse } \\
\text { velocity, } \\
\text { ft/sec }\end{array}$ & & $\begin{array}{l}\text { Specific } \\
\text { gravityc }\end{array}$ & $\begin{array}{c}\text { Unit } \\
\text { weight, } \\
\text { lb/cu ft }\end{array}$ & $\begin{array}{l}\text { Resonant } \\
\text { frequency, } \\
\text { \% change }\end{array}$ & $\begin{array}{l}\text { Pulse } \\
\text { velocity, } \\
\text { ft } / \sec \end{array}$ & $\begin{array}{c}\text { Weight } \\
\text { change, } \\
\%\end{array}$ & 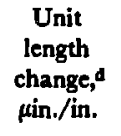 & $\begin{array}{c}\text { Compressive } \\
\text { strength,e,e } \\
\text { psi }\end{array}$ & $\begin{array}{l}\text { Modulus of } \\
\text { elasticity } \\
10^{\theta} \mathrm{psi}\end{array}$ \\
\hline \multicolumn{15}{|c|}{ Impregnated concrete } \\
\hline $121^{\circ} \mathrm{C}$ brine & $\begin{array}{l}6.3 \\
6.7\end{array}$ & $\begin{array}{l}2.38 \\
2.37\end{array}$ & $\begin{array}{l}148.3 \\
147.8\end{array}$ & $\begin{array}{l}570 \\
570\end{array}$ & $\begin{array}{l}16,800 \\
17,000\end{array}$ & $\begin{array}{l}6 \mathrm{mo} \\
1 \mathrm{yr}\end{array}$ & $\begin{array}{l}2.40 \\
2.28\end{array}$ & $\begin{array}{l}149.2 \\
148.4\end{array}$ & $\begin{array}{l}-1.3 \\
-6.4\end{array}$ & $\begin{array}{l}15,900 \\
15,300\end{array}$ & $\begin{array}{l}+0.3 \\
+0.4\end{array}$ & $\begin{array}{l}+280 \\
+486\end{array}$ & $\begin{array}{l}14,600 \\
15,300\end{array}$ & $\begin{array}{l}5.5 \\
5.5\end{array}$ \\
\hline $121^{\circ} \mathrm{C}$ brine/vapor & $\begin{array}{l}6.0 \\
6.2\end{array}$ & $\begin{array}{l}2.40 \\
2.37\end{array}$ & $\begin{array}{l}150.0 \\
148.1\end{array}$ & $\begin{array}{l}574 \\
574\end{array}$ & $\begin{array}{l}17,300 \\
17,200\end{array}$ & $\begin{array}{l}6 \mathrm{mo} \\
1 \mathrm{yr}\end{array}$ & $\begin{array}{l}2.40 \\
2.38\end{array}$ & $\begin{array}{l}149.5 \\
148.7\end{array}$ & $\begin{array}{r}-7.3 \\
-20.2\end{array}$ & $\begin{array}{l}15,900 \\
15,700\end{array}$ & $\begin{array}{l}+1.0 \\
+0.8\end{array}$ & $\begin{array}{l}+407 \\
+522\end{array}$ & $\begin{array}{l}15,200 \\
14,700\end{array}$ & $\begin{array}{l}5.6 \\
5.5\end{array}$ \\
\hline $121^{\circ} \mathrm{C}$ vapor & $\begin{array}{l}6.2 \\
6.5\end{array}$ & $\begin{array}{l}2.39 \\
2.37\end{array}$ & $\begin{array}{l}148.8 \\
147.7\end{array}$ & $\begin{array}{l}\mathbf{5 7 0} \\
\mathbf{5 7 0}\end{array}$ & $\begin{array}{l}17,300 \\
17,200\end{array}$ & $\begin{array}{l}6 \mathrm{mo} \\
1 \mathrm{yr}\end{array}$ & $\begin{array}{l}2.39 \\
2.39\end{array}$ & $\begin{array}{l}149.0 \\
148.4\end{array}$ & $\begin{array}{l}-1.2 \\
-5.2\end{array}$ & $\begin{array}{l}16,400 \\
15,800\end{array}$ & $\begin{array}{l}+0.8 \\
+1.1\end{array}$ & $\begin{array}{l}+291 \\
+436\end{array}$ & $\begin{array}{l}15,900 \\
14,700\end{array}$ & $\begin{array}{l}5.4 \\
5.1\end{array}$ \\
\hline $143^{\circ} \mathrm{C}$ brine & $\begin{array}{l}6.0 \\
5.8\end{array}$ & $\begin{array}{l}2.39 \\
2.40\end{array}$ & $\begin{array}{l}148.6 \\
149.9\end{array}$ & $\begin{array}{l}656 \\
656\end{array}$ & $\begin{array}{l}17,100 \\
16,500\end{array}$ & $\begin{array}{l}6 \mathrm{mo} \\
1 \mathrm{yr}\end{array}$ & $\begin{array}{c}2.39 \\
-\end{array}$ & $\begin{array}{c}149.1 \\
-\end{array}$ & $\begin{array}{l}-13.8 \\
-18.8\end{array}$ & $\begin{array}{c}15,300 \\
-\end{array}$ & $\begin{array}{l}+1.2 \\
+0.3\end{array}$ & $\begin{array}{r}+800 \\
+1296\end{array}$ & $\begin{array}{l}13,200 \\
13,000\end{array}$ & $\begin{array}{l}4.1 \\
4.4\end{array}$ \\
\hline $143^{\circ} \mathrm{C}$ brine/vapor & $\begin{array}{l}5.8 \\
5.7\end{array}$ & $\begin{array}{l}2.39 \\
2.40\end{array}$ & $\begin{array}{l}148.9 \\
149.1\end{array}$ & $\begin{array}{l}620 \\
620\end{array}$ & $\begin{array}{l}16,900 \\
16,900\end{array}$ & $\begin{array}{l}6 \mathrm{mo} \\
1 \mathrm{yr}\end{array}$ & $\begin{array}{c}2.39 \\
-\end{array}$ & $\begin{array}{c}149.1 \\
-\end{array}$ & $\begin{array}{l}-12.8 \\
-18.6\end{array}$ & $\begin{array}{c}15,400 \\
-\end{array}$ & $\begin{array}{l}+1.4 \\
+1.4\end{array}$ & $\begin{array}{r}+703 \\
+1264\end{array}$ & $\begin{array}{l}14,800 \\
12,600\end{array}$ & $\begin{array}{l}4.5 \\
4.7\end{array}$ \\
\hline $143^{\circ} \mathrm{C}$ vapor & $\begin{array}{l}5.8 \\
6.1\end{array}$ & $\begin{array}{l}2.38 \\
2.38\end{array}$ & $\begin{array}{l}148.5 \\
148.4\end{array}$ & $\begin{array}{l}632 \\
632\end{array}$ & $\begin{array}{l}16,800 \\
16,300\end{array}$ & $\begin{array}{l}6 \mathrm{mo} \\
1 \mathrm{yr}\end{array}$ & $\begin{array}{c}2.39 \\
-\end{array}$ & $\begin{array}{c}149.1 \\
-\end{array}$ & $\begin{array}{l}-13.4 \\
-18.0\end{array}$ & $\begin{array}{c}15,800 \\
-\end{array}$ & $\begin{array}{l}+1.6 \\
+1.7\end{array}$ & $\begin{array}{r}+728 \\
+1275\end{array}$ & $\begin{array}{l}13,400 \\
11,700\end{array}$ & $\begin{array}{l}4.4 \\
4.3\end{array}$ \\
\hline \multicolumn{15}{|c|}{ Unimpregnated concrete } \\
\hline $121^{\circ} \mathrm{C}$ brine & - & $\begin{array}{l}2.33 \\
2.31\end{array}$ & $\begin{array}{l}145.4 \\
143.9\end{array}$ & $\begin{array}{l}397 \\
397\end{array}$ & $\begin{array}{l}14,300 \\
14,300\end{array}$ & $\begin{array}{l}6 \mathrm{mo} \\
1 \mathrm{yr}\end{array}$ & $\begin{array}{l}2.38 \\
2.36\end{array}$ & $\begin{array}{l}148.4 \\
147.2\end{array}$ & $\begin{array}{l}-4.7 \\
-3.7\end{array}$ & $\begin{array}{l}13,300 \\
13,400\end{array}$ & $\begin{array}{l}+2.3 \\
+1.9\end{array}$ & $\begin{array}{l}+717 \\
+623\end{array}$ & $\begin{array}{l}5,700 \\
6,100\end{array}$ & $\begin{array}{l}4.2 \\
4.7\end{array}$ \\
\hline $121^{\circ} \mathrm{C}$ brine/vapor & - & $\begin{array}{l}2.32 \\
2.33\end{array}$ & $\begin{array}{l}144.6 \\
145.2\end{array}$ & $\begin{array}{l}403 \\
403\end{array}$ & $\begin{array}{l}14,400 \\
14,000\end{array}$ & $\begin{array}{l}6 \mathrm{mo} \\
1 \mathrm{yr}\end{array}$ & $\begin{array}{l}2.37 \\
2.37\end{array}$ & $\begin{array}{l}148.1 \\
147.4\end{array}$ & $\begin{array}{l}-4.4 \\
-4.7\end{array}$ & $\begin{array}{l}13,700 \\
13,500\end{array}$ & $\begin{array}{l}+2.8 \\
+1.8\end{array}$ & $\begin{array}{l}+707 \\
+486\end{array}$ & $\begin{array}{l}5,100 \\
5,900\end{array}$ & $\begin{array}{l}4.2 \\
4.9\end{array}$ \\
\hline $121^{\circ} \mathrm{C}$ vapor & - & $\begin{array}{l}2.33 \\
2.31\end{array}$ & $\begin{array}{l}145.1 \\
143.8\end{array}$ & $\begin{array}{l}397 \\
397\end{array}$ & $\begin{array}{l}14,600 \\
13,800\end{array}$ & $\begin{array}{l}6 \mathrm{mo} \\
1 \mathrm{yr}\end{array}$ & $\begin{array}{l}2.36 \\
2.34\end{array}$ & $\begin{array}{l}147.2 \\
145.4\end{array}$ & $\begin{array}{l}+3.9 \\
+8.2\end{array}$ & $\begin{array}{l}13,800 \\
14,500\end{array}$ & $\begin{array}{l}+2.0 \\
+1.9\end{array}$ & $\begin{array}{l}+361 \\
+374\end{array}$ & $\begin{array}{l}6,700 \\
7,400\end{array}$ & $\begin{array}{l}4.3 \\
5.1\end{array}$ \\
\hline $143^{\circ} \mathrm{C}$ brine & - & $\begin{array}{l}2.36 \\
2.32\end{array}$ & $\begin{array}{l}146.8 \\
144.9\end{array}$ & $\begin{array}{l}456 \\
456\end{array}$ & $\begin{array}{l}14,200 \\
14,000\end{array}$ & $\begin{array}{l}6 \mathrm{mo} \\
1 \mathrm{yr}\end{array}$ & $\begin{array}{c}2.37 \\
-\end{array}$ & $\begin{array}{c}147.5 \\
-\end{array}$ & $\begin{array}{l}-18.4 \\
-23.7\end{array}$ & $\begin{array}{c}13,100 \\
-\end{array}$ & $\begin{array}{l}+2.4 \\
+2.7\end{array}$ & $\begin{array}{r}+821 \\
+1157\end{array}$ & $\begin{array}{l}7,100 \\
8,300\end{array}$ & $\begin{array}{l}4.6 \\
4.4\end{array}$ \\
\hline $143^{\circ} \mathrm{C}$ brine/vapor & - & $\begin{array}{l}2.37 \\
2.35\end{array}$ & $\begin{array}{l}147.6 \\
146.6\end{array}$ & $\begin{array}{l}436 \\
436\end{array}$ & $\begin{array}{l}14,100 \\
14,200\end{array}$ & $\begin{array}{l}6 \mathrm{mo} \\
1 \mathrm{gr}\end{array}$ & $\begin{array}{c}2.38 \\
-\end{array}$ & $\begin{array}{c}148.3 \\
-\end{array}$ & $\begin{array}{l}-18.8 \\
-24.1\end{array}$ & $\begin{array}{c}13,400 \\
-\end{array}$ & $\begin{array}{l}+2.1 \\
+3.0\end{array}$ & $\begin{array}{l}+839 \\
+961\end{array}$ & $\begin{array}{l}6,800 \\
8,200\end{array}$ & $\begin{array}{l}4.3 \\
4.4\end{array}$ \\
\hline $143^{\circ} \mathrm{C}$ vapor & - & $\begin{array}{l}2.33 \\
2.33\end{array}$ & $\begin{array}{l}145.1 \\
145.0\end{array}$ & $\begin{array}{l}442 \\
442\end{array}$ & $\begin{array}{l}14,100 \\
13,500\end{array}$ & $\begin{array}{l}6 \mathrm{mo} \\
1 \mathrm{yr}\end{array}$ & $\begin{array}{c}2.33 \\
-\end{array}$ & $\begin{array}{c}145.3 \\
-\end{array}$ & $\begin{array}{r}-6.6 \\
-11.5\end{array}$ & $\begin{array}{c}14,100 \\
-\end{array}$ & $\begin{array}{l}+0.2 \\
+1.7\end{array}$ & $\begin{array}{l}+475 \\
+732\end{array}$ & $\begin{array}{l}8,200 \\
9,800\end{array}$ & $\begin{array}{l}4.7 \\
4.8\end{array}$ \\
\hline
\end{tabular}

60 wt \% styrene - 40 wt \% TMPTMA, thermal-catalytically polymerized.

Synthetic seawater concentrated to $73,000 \mathrm{ppm}$ tds for $143^{\circ} \mathrm{C}$ exposure and $38,000 \mathrm{ppm}$ ids for $121^{\circ} \mathrm{C}$ exposure.

-Values are averages for three $6 \times 12$-in. cylinders.

Values are averages for two $4 \times 4 \times 30$-in. prisms.

Tested at expoture temperature. 
5.2.2.4 Enynonmental TEsts. (a) EXPOSURE 10 5\% $\mathrm{NAOH}$. Specimens of unimpregnated concrete, 60 wt \% styrene - $40 \mathrm{wt} \%$ TMPTMA, and 90 wt \% DAP 10 wt \% MMA impregnated concrete showed no signs of deterioration after immersion for 382 days in a $5 \% \mathrm{NaOH}$ solution. The specimens showed small weight gains of about $0.5 \%$ for unimpregnated concrete, $0.5 \%$ for styrene-TMPTMA impregnated concrete, and $0.8 \%$ for DAP-MMA impregnated concrete. Compressive strengths after exposure were about 6300 psi for unimpregnated concrete, 16,000 to 19,300 psi for styrene-TMP. TMA specimens, and 12,200 to 16,300 psi for DAP-MMA specimens. Test results are given in Table 17.

(b) WEATHEROMETER TESTS. Unimpregnated concrete and concrete impregnated with $60 \mathrm{wt} \%$ styrene 40 wt \% TMPTMA and 90 wt \% DAP - 10 wt \% MMA have been exposed in a Weatherometer apparatus. The apparatus (Ref. 3) simulates exposure to sunlight and rain and is primarily used for accelerated testing of paints and protective coatings. Samples are exposed to a total of $20 \mathrm{hr} /$ day of light from two carbon arc lamps with a 12min cold demineralized water spray each hour. After $6000 \mathrm{hr}$ of exposure the styrene-TMPTMA specimens and the DAP-MMA specimens show some surface scaling affecting $<10 \%$ of the surface area. Unimpregnated samples show a fairly uniform leaching of cement paste over the entire surface area to a depth of about $1 / 16$ in. Test results are given in Table 20.

(c) EfFE of Soll Mcroorgayisus. Samples of unimpregnated concrete and PIC are under test for effects

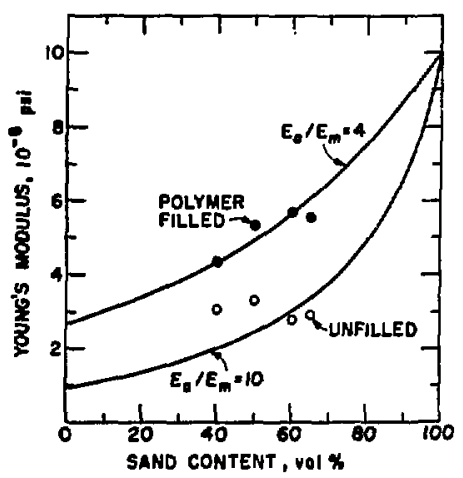

Figure 30. Predicted and experimental variation of Young's modulus for mortar with a water-to-cement ratio of 0.5 as a function of sand content. of soil microorganisms. The specimens are buried in compost-enriched soil with continuous exposure to a temperature of $27^{\circ} \mathrm{C}$ and $80 \%$ relative humidity, which are optimum conditions for soil microorganism growth. The specimens were examined visually after 18 months' burial for surface appearance and evidence of soil microorganism growth. The unimpregnated concrete, $60 \mathrm{wt} \%$ styrene - 40 wt \% TMPTMA, and 90 wt \% DAP $10 \mathrm{wt} \%$ MMA impregnated concrete showed no changes in surface appearance and no microorganism growth. These observations indicate that the materials are highly resisiant to soil microorganisms. Test results are given in Table 21.

\section{FUNDAMENTAL STUDIES}

Fundamental studies during the past year were conducted in the areas of application of composite materials theory to calculation of the modulus of elasticity for concrete-polymer materials, a porosimetry study of high-pressure steam-cured cement paste, the stability oi 60 wt \% styrene - 40 wt \% TMPTMA polymer exposed to brine at high temperature, and chemical reactions of monomers and polymers with cement paste. Studies on negative creep were not continued during the year.

\subsection{Polymen-Impregnated Conchete as a Compostre Material}

Concrete can be considered a composite material consisting of a dispersed phase (coarse aggregate) and a matrix phase (mortar). The theory of composite materials permits the elastic properties of the composite to be computed from the elastic properties and concentrations of the components.

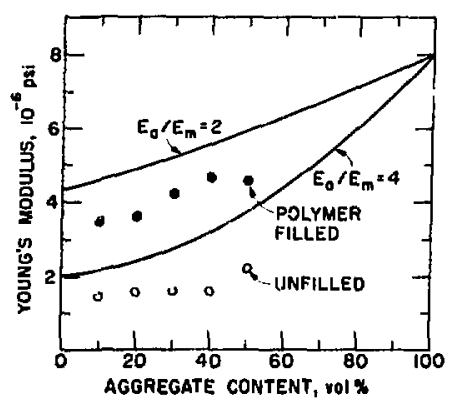

Figure 31. Predicted and experimental variation of Young's modulus for mortar with a - \% 8 -in. to +4 mesh aggregate content. 
Composite theory is most advanced for fiber-reinforced composites, in which the fibers are parallel and continuous. For particulate composites like concrete the theory is less well developed. However, a number of models are available which appear to predict the modulus of elasticity reasonably well for concrete.

In concrete the mortar phase is also a composite material, consisting of sand particles dispersed in a matrix of hardened cement paste. Thus, to predict the modulus of a mortar, the moduli of the hydrated cement and sand phases must be known, along with their concentrations.

The material becomes more complex when polymer is added to the system. The polymer fills the pores of the hardened cement paste phase and creates still another composite material. Earlier studies ${ }^{2,17}$ showed that the polymer raised the strength of the cement phase and improved the bond between matrix and aggregate. It appeared that the role of polymer could be more clearly brought out by applying composite theory to a simple composite system, and then to successively more complex systems. Elastic properties were calculated from a composite model for concrete developed by Hobbs 18 and compared with experimental results.

Hobbs' model states that

$$
\frac{E}{E_{m}}=1+\frac{2 V_{a}(r-1)}{(r+1)-V_{a}(r-1)},
$$

where $E$ refers to the composite modulus of elasticity, $V$ is the volume fraction, the subscripts $m$ and $a$ refer to matrix and aggregate (filler), respectively, and $r$ is the modulus ratio $E_{a} / E_{m}$.

Equation (1) may be used to predict the increase in modulus of elasticity when the pores of the cement become filled Assuming that the porosity of cement is about 0.45 , Young's modulus of cement is about $1 \times 10^{6} \mathrm{psi}$, and that of the polymer (the filler phase) is about $0.4 \times 10^{6} \mathrm{psi}$, Eq. (1) predicts an increase in modulus by a factor of 2.4 when the cement is impregnated. Experimentally an increase of 2.8 times was observed. Another independent empirical model predicted an increase of between 1.8 and 3.3 times. ${ }^{19}$

From both theoretical and experimental considerations it is seen that the incorporation of rigid polymer in the pores of the cement phase results in a cement phase of greatly increased stiffness.

Hobbs' model (Eq. 1) was next applied to mortar. A series of mortar specimens was prepared with an 0.40 to 0.65 volume fraction of sand. The experimental moduli for the normal and unimpregnated mortars were compared with the computed ones. The modulus of the unfilled hardened cement paste matrix was $1 \times 10^{6}$ psi, the polymerfilled matrix modulus was $2.8 \times 10^{6} \mathrm{psi}$, and the aggregate (silica sand) modulus was $10 \times 10^{6}$ psi. The results are shown in Figure 30. The calculated results are in fairly good agreement with the experimental results. Both indicate that the only effect polymer has is to increase the modulus of the cement phase and create a stiffer matrix.

The work was next extended to concretes. A $-3 / 8$-in. to +4 mesh limestone aggregate was added to a mortar in concentrations of 0.1 to 0.5 by volume. The expected moduli of the composite materials were calculated from Eq. (1) using 8 $\times 10^{6} \mathrm{psi}$ as the modulus for limestone aggregate (estimated from sonic velocity measurements), $2 \times 10^{6}$ psi for the unfilled mortar matrix, and $4.3 \times 10^{6}$ for the polymer-filled mortar matrix. The results are shown in Figure 31. Here the experimental results lie below the calculated curve and indicate an extrapolated mortar modulus $(0 \%$ aggregate) much lower than that used for the calculation. The reason for this discrepancy is not clear.

The results do, however, show some interesting features. For the unfilled concrete, there is very little compositional dependence of the modulus until the aggregate volume reaches $50 \%$. The polymer-filled concrete indicates a compositional dependence of approximately the proper magnitude. This suggests that in the unfilled material the adhesion between the aggregate and the matrix is poor.

In another extension of the composite model, the normal limestone aggregate with a modulus of about $8 \times 10^{6}$ psi was replaced with a comparable volume of steel bolts (modulus, $30 \times 10^{6} \mathrm{psi}$ ). The modulus of the polymer-impregnated steel-aggregate concrete predicted by Eq. (1) is about $8 \times 10^{6}$ psi. Measurements indicated a modulus of 7.8 to $8.2 \times 10^{6}$ psi. For the unfilled concrete the experimental modulus $\left(\approx 1 \times 10^{6} \mathrm{psi}\right)$ was much lower than that predicted $\left(\approx 5 \times 10^{6} \mathrm{psi}\right)$.

All the measurements so far indicate that the improvement in the elastic modulus of polymerimpregnated mortars and concretes arises from the filling of the pores of the cement phase with the rigid polymer. With concrete, the improvement in bond between the matrix and aggregate also increases the modulus of elasticity. 


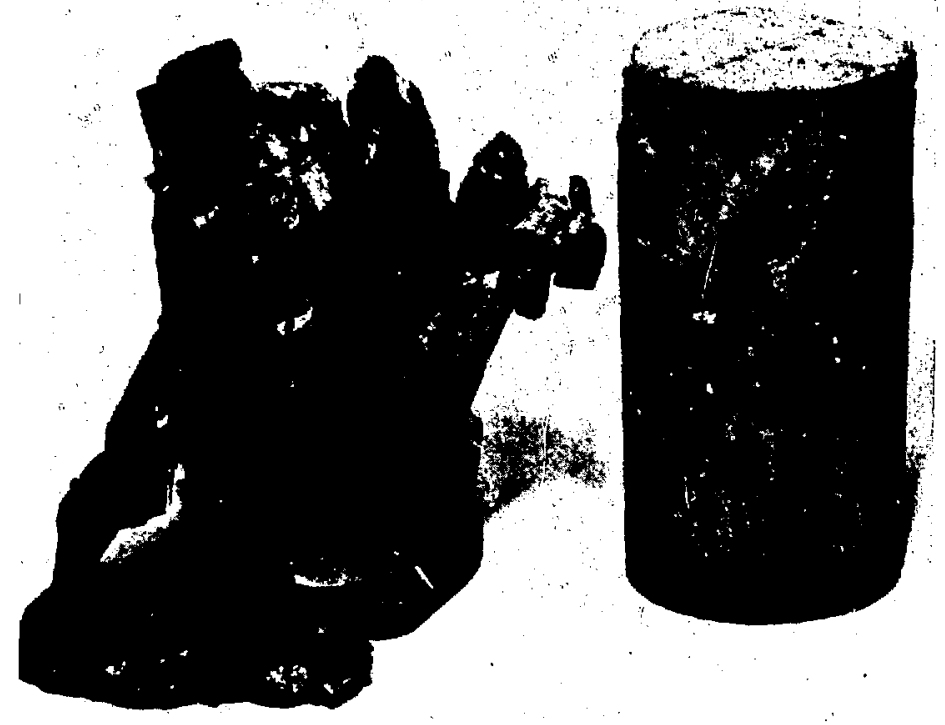

Figure 32. Polymer-impregnated concrete (left) and normal concrete after failure (3-in.-diam $\times 6$-in.-long cylinders).
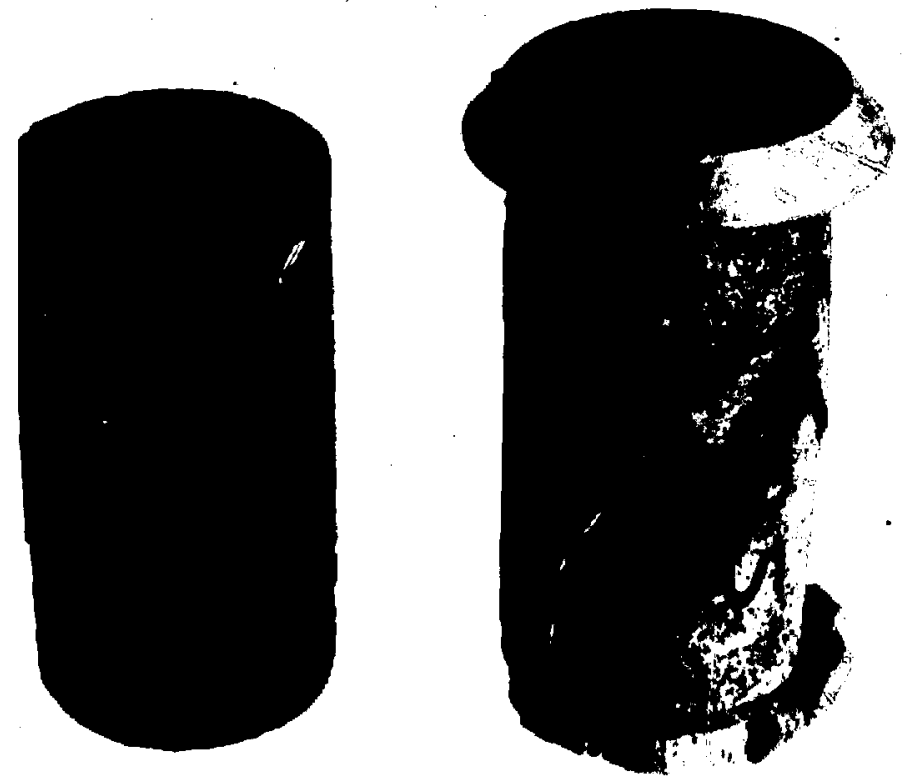

Figure 33. Polymer-impregnated steel-aggregate concrete (left) and unimpregnated steel-aggregate concrete after failure (11/2-in,-diam X3-in,-Jong cylinders).
As noted earlier, ${ }^{3}$ the fracture modes of concrete and PIC are different (see Figure 32). PIC shatters on failure; the fracture surface passes through the aggregate particles, and thus the strength of the aggregate is utilized completely. Normal concrete fails primarily by failure of the matrix-aggregate bond, ainu failure is less abrupt. One way to alter the relatively brittle fracture mode of PIC is to use a stronger and tougher aggregate. If the aggregate is strong enough the crack will be diverted around the aggregate rather than through it. This is the case when concrete. is made with steel bolts as the aggregate. The failure mode is no longer brittle, but much like that of normal concrete. After maximum stress the concrete is still capable of supporting a considerable load. At a strain of $1 \%$ the concrete sustained a load of 14,000 psi. Fractured polymer-impregnated steel-aggregate concrete is illustrated in Figure 33. In Figure 34 the stress-strain curve for polymerimpregnated steel-aggregate concrete is shown.

The fracture mode of PIC can also be made like that of normal concrete by incorporating a small quantity ( $\approx 1 \%$ by volume) of fiber in the matrix. The fiber does not alter the concrete's modulus because its volume concentration is so low, but it does inhibit the propagation of cracks. The stress-strain curve for steel-wire-reinforced mortar is also shown in Figure 34. At $1 \%$ strain the material still supports $17,000 \mathrm{psi}$. The fact that a small concentration of fiber can have such an appreciable effect at the high stress level suggests that the fiber is very well bonded to the matrix.

All the experimental evidence so far indicates that PIC behaves more like a true composite material than does normal concrete. This is probably because of the improved bonding between phases. Conversely, the improvement in the modulus of PIC results from the improved modulus of the hardened cement paste after impregnation.

\subsection{Pone Stauctuan of Hagdinto Cimint and Potymen-Imrrionated CEmint}

As an aid in understanding the relationships between cement cure, pore structure, rate of monomer loading, and polymer loading, the pore size. distribution of hardened cement paste has been studied. The distributions are measured by highpressure mercury porosimetry. This technique is capabie of measuring pores with diameters as small as $35 \mathrm{~A}$. Earlier porosimetry work has been summarized in previous topical reports. ${ }^{3,4}$ During 
the present repcrt period an extended study of the effect of the water-to-cement ratio $(w / c)$ and cure time for water-cured cements was completed and a report was published. ${ }^{20}$ Most of the conclusions drawn from the study bear directly on models of cement hydration developed by Powers and coworkers. ${ }^{21}$ One important observation is that the difference in capillary pore structure between pastes of different $w / c$ ratios lies mainly in the region of large pores; pastes with higher $w / c$ ratios have a group of large pores not present in the lower $w / c$ pastes. This holds approximately true at all stages of hydration. This is illustrated in Figure 35 for $w / c=0.35$ and 0.55 pastes cured for $2 \frac{1}{3}$ days.

A small-scale porosimetry study was made to see whether changes in porosity occurred when water-cured polymer-impregnated cement was subsequently exposed to a high-pressure steam environment. Steam-cured polymer-impregnated cements were also included in the test. Steam curing and steam treating were done for $24 \mathrm{hr}$ at 150 psi. All samples were impregnated with 60 wt \% styrene -40 wt \% TMPTMA.

The porosity changes resulting from the steam treatment were much greater for the water-cured than for the steam-cured cement (see Table 90). The results indicate that the polymer does not completely seal either water- or steam-cured cements, and that steam-cured cement is much more stable in a high-pressure steam environment than is water-cured cement. The changes in the pore structure of water-cured cement may be a factor in the continuous strength decrease observed in PIC filled with 60 wt \% styrene - 40 wt \% TMPTMA (see Section 5.2.2.1).

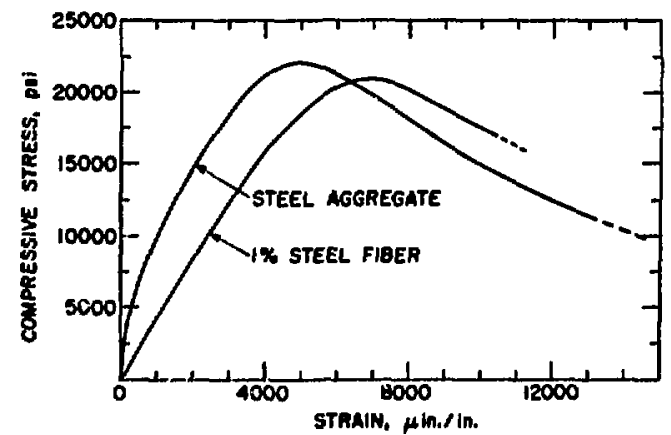

Figure 34. Strem-strain curve for polymer-impregnated xeel-aggregate concrete and polymer-impregnated steelivire-reinforced mortar.
Additional porosimetry studies are in progrem on steam-cured cements, cements cured with use of accelerators, and cements cured with waterreducing agents.

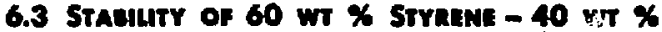 TMPTMA AND 70 wT $\%$ MMA -30 wr $\%$ TMPTMA PoLYMIRs}

Differential thermal analysis (DTA) studies were performed on polymer extracted from PIC that had been exposed to high-temperature brine. The analyzed polymer samples were taken from the larger filled void spaces of crushed PIC fragments. Changes in the DTA curves could indicate degradation of the polymer.

Figure 36 shows some DTA results for 60 wt \% styrene - 40 wt \% TMPTMA. After 5740 hr (239 days) at $143^{\circ} \mathrm{C}$, the thermal analysis of the polymer after removal from the concrete was exsentially identical to that of the original, as-prepared, bulk polymer, with prominent endotherms at $415^{\circ}$ and $460^{\circ} \mathrm{C}$. This indicates that 60 wi $\%$ styrene -40 wt \% TMPTMA is a very stable polymer system in concrete. The fact that the strength of PIC containing this monomer mixture decreases with prolonged exposure in $143^{\circ} \mathrm{C}$ brine suggests that the decrease is due to changes in the concrete, rather than the polymer. This was discusied in Section 5.2.2.1.

In Figure 37 some DTA results for 70 wt \% MMA30 wt \% TMPTMA are given. This polymer system shows continuous changes with exposure to hot brine. The as-prepared pure polymer thermogram is characterized by prominent endotherms at $305^{\circ}, 365^{\circ}$, and $470^{\circ} \mathrm{C}$. After exposing the PIC for $2000 \mathrm{hr}$ in $143^{\circ} \mathrm{C}$ brine, the DTA thermogram

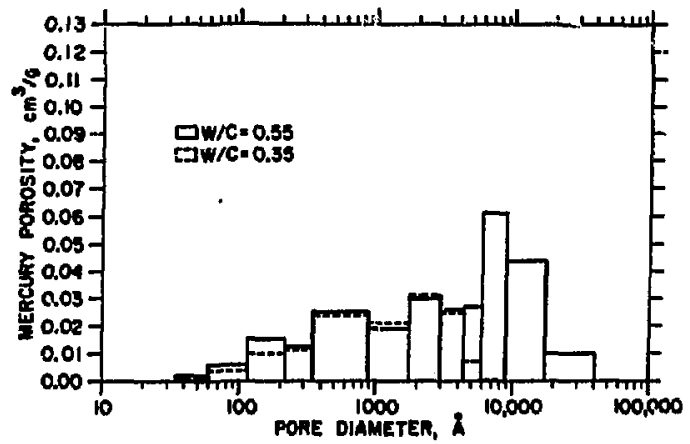

Figure 35. Cumparison of pore size distribution for cement pastes with water-to-ceinent ratios of 0.35 and 0.55, cuned for 245 dayi. 
shows that changes have occurred in the polymer, as indicated by the disappearance of the $305^{\circ}$ and $365^{\circ} \mathrm{C}$ endotherms, development of a large endotherm at $400^{\circ} \mathrm{C}$, and a decrease in the $470^{\circ} \mathrm{C} \mathrm{en}$ dotherm. Further exposure in $143^{\circ} \mathrm{C}$ brine shows the development of an exotherm at about $460^{\circ} \mathrm{C}$ and the development of an endotherm at $110^{\circ} \mathrm{C}$, probably indicative of free water. After $2000 \mathrm{hr}$ of exposure at $177^{\circ} \mathrm{C}$, the thermogram shows a large endotherm at $110^{\circ} \mathrm{C}$, the endotherm at $400^{\circ} \mathrm{C}$ is no longer present, the exotherm at $460^{\circ} \mathrm{C}$ is still present, and a small endotherm at $470^{\circ} \mathrm{C}$ is partially masked by the $460^{\circ} \mathrm{C}$ exotherm. Although the chemistry of these changes has not been developed, the changes in the thermograms show that the original 70 wt $\%$ MMA - 30 wt \% TMPTMA polymer system has changed considerably. P1C prepared with this polymer has failed under certain experimental conditions (see Section 5.2.2.1), so apparently the DTA changes reflect degradation of the polymer.

A limited investigation was conducted at the USBR to study the stability of 60 wt \% styrene 40 wt \% TMPTMA polymer exposed at $150^{\circ} \mathrm{C}$ to air, water, brine, and $\mathrm{Ca}(\mathrm{OH})_{2}$ solutions. Test specimens of polymer were cut and machined inte cylinders $\approx 1 / 2$ in. in diameter and $5 \%$ in. long. Two specimens were stored at room temperature to serve as controls, and eight specimens were sealed in stainless steel pressure vessels under the following conditions: Two specimens were sealed in air, two in distilled water, two in $38,000 \mathrm{ppm}$ seawater brine, and two in $\mathrm{Ca}(\mathrm{OH})_{2}$ slurry.

The specimens were measured and weighed before exposure and after exporure at $150^{\circ} \mathrm{C}$ for 7 days, 31 days, and 6 months (see Figure 38). The exposure was terminated after 6 months, and the specimens were tested for compressive strength. Test results are summarized in Table $\mathbf{9 1 .}$

\section{Table 90}

Pore Content of Polymer-Impregnated Concrete

\begin{tabular}{lrr}
\hline & $\begin{array}{c}\text { Water- } \\
\text { cured }\end{array}$ & $\begin{array}{r}\text { Stearn- } \\
\text { cured }\end{array}$ \\
\hline Porocity before steam exposure, cc/g & 0.0075 & 0.0204 \\
Porouity after steam exposure, $\mathrm{cc} / \mathrm{g}$ & $\mathbf{0 . 0 3 7 0}$ & $\mathbf{0 . 0 2 6 2}$ \\
Change in porosity, \% & +350 & +28
\end{tabular}

-Monomer, 60 wt \% styrene - 40 wt \% TMPTMA.

tTreatment conditions, 150 pai steam for $24 \mathrm{hr}$.
There were no significant changes in dimension or weight. Samples immersed in liquids expanded about $0.002 \mathrm{in}$. in both diameter and length at the 7-day measurement and did not appreciably change after that. The samples also showed a small increase in weight due to absorption of water. Specimens exposed to air at $150^{\circ} \mathrm{C}$ showed a correspondingly small contraction and slight decrease in weight. No evidence of deterioration or corrosion was seen. After 6 months' exposure, the specimens were generally darkened in color near the outer surfaces. The brine, air, and $\mathrm{Ca}(\mathrm{OH})_{2}$ specimens were a deep brown, and the water specimens were amber.

The effects of exposure on compressive strength could not be accurately evaluated because of small cracks inherent in the specimens. Compressive strengths averaged 23,900 psi for contruls, 26,000

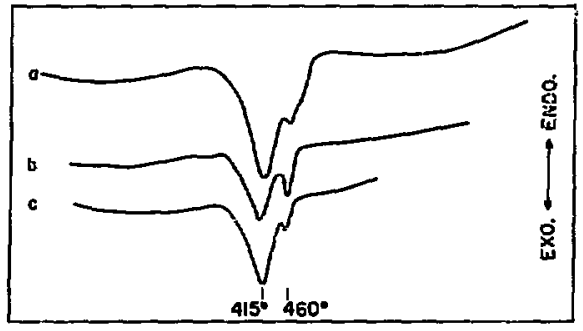

Figure 36. Differential thermai analysis of $60 \mathrm{wt} \%$ styrene -40 wt \% TMPTMA, after various exposures. $a$, as prepared, bulk polymer; $b, 48 \mathrm{hr}$ at $143^{\circ} \mathrm{C}$, bulk polymer; $c, 5740$ hr at $143^{\circ} \mathrm{C}$, from PIC. Argon atm, $10^{\circ} \mathrm{C} / \mathrm{min}$.

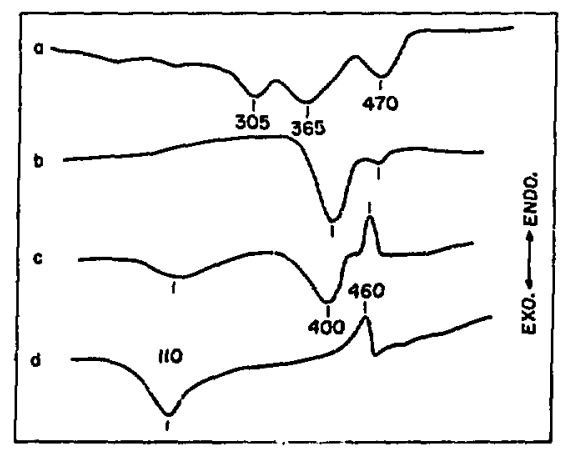

Figure 37. Differential thermal analysis of 70 wt $\%$ MMA - 30 wt \% TMPTMA, after various exposures. $a$, as prepared, bulk polymer; $b, 2000$ hr at $143^{\circ} \mathrm{C}$, from PIC; $c$, 6500 hr at $143^{\circ} \mathrm{C}$, froin PIC; $d, 2000 \mathrm{hr}$ at $177^{\circ} \mathrm{C}$, from HIC. Argon atm, $10^{\circ} \mathrm{C} / \mathrm{min}$. 
for specimens exposed to air at $150^{\circ}, 22,900$ for those exposed to distilled water, 21,600 for those exposed to $\mathrm{Ca}(\mathrm{OH})_{2}$, and 20,800 for those exposed to brine.

\subsection{Reactions of MONOMEns and Polymens With Cement Paste}

DTA studies of various cement-polymer systems are in progress. Studies of MMA in contact with

Figure 38. Cylinders of 60 wt \% styrene -40 wt \% TMPTMA polymer after 6 months of exposure at $150^{\circ} \mathrm{C}$. Specimens (from left to right) were exposed in brine (1 and 2), in $\mathrm{Ca}(\mathrm{OH})_{2}$ slurry (3 and 4 ), in distilled water (5 and 6 ), in air ( 7 and 8 ). Specimens 9 and 10 are unexposed controls. No signs of deterioration were apparent, but there were slight changes in size and weight, and some discoloration.
$\mathrm{Ca}(\mathrm{OH})_{2}$ and heated to $70^{\circ} \mathrm{C}$ have shown that MMA reacts with $\mathrm{Ca}(\mathrm{OH})_{2}$ during thermal polymerization. DTA using a flowing argon atmosphere revealed a reaction product that decomposes at $470^{\circ} \mathrm{C}$, and the absence of the $\mathrm{Ca}(\mathrm{OH})_{2}$ endotherm at $510^{\circ} \mathrm{C}$.

A brief study was conducted to obtain preliminary information on the reactivity and identification of the products of the reaction between MMA and $\mathrm{Ca}(\mathrm{OH})_{2}$. The work was mainly focused on the reaction of liquid MMA monomer and $\mathrm{Ca}(\mathrm{OH})_{2}$, although a sample of PMMA polymer was used in a separate test. Reaction systems were set up with $\mathrm{Ca}(\mathrm{OH})_{2}, \mathrm{MMA}$, and water in various proportions. The materials were sealed in small pressure vessels and reacted for various times and at various temperatures between room tempera-

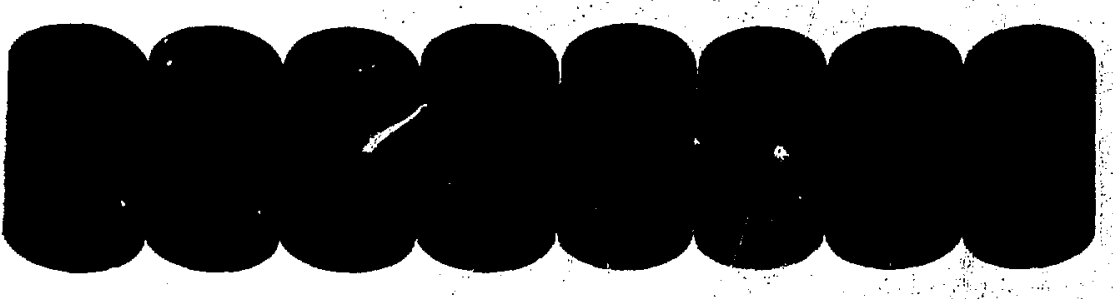

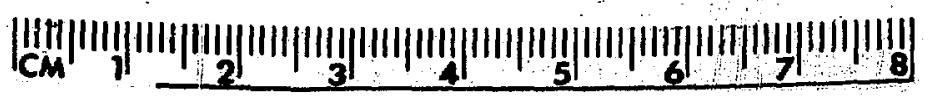

Table 91

Stability of 60 wt \% Styrene - 40 wt \% TMPTMA Polymer After 6 Months' Exposure at $150^{\circ} \mathrm{C}$ to Brine, Water, Air, and $\mathrm{Ca}(\mathrm{OH})_{2}$ Slurry

\begin{tabular}{|c|c|c|c|c|c|c|c|c|c|c|c|}
\hline \multirow{2}{*}{$\begin{array}{c}\text { Cyl- } \\
\text { inder } \\
\text { No. }\end{array}$} & \multirow[b]{2}{*}{ Exposure } & \multicolumn{3}{|c|}{ Before exposure } & \multicolumn{3}{|c|}{ After exposure } & \multicolumn{3}{|c|}{ Change in } & \multirow{2}{*}{$\begin{array}{c}\text { Compressive } \\
\text { strength, } \\
\text { psi }\end{array}$} \\
\hline & & $\begin{array}{l}\text { Diam, } \\
\text { in. }\end{array}$ & $\begin{array}{l}\text { Length, } \\
\text { in. }\end{array}$ & $\begin{array}{c}\text { Weight, } \\
\text { g }\end{array}$ & $\begin{array}{l}\text { Diam, } \\
\text { in. }\end{array}$ & $\begin{array}{l}\text { Length, } \\
\text { in. }\end{array}$ & $\begin{array}{c}\text { Weight, } \\
\text { g }\end{array}$ & $\begin{array}{l}\text { Diam, } \\
\text { in. }\end{array}$ & $\begin{array}{l}\text { Length, } \\
\text { in. }\end{array}$ & $\begin{array}{c}\text { Weight, } \\
\text { g }\end{array}$ & \\
\hline $\begin{array}{l}1 \\
2\end{array}$ & $\begin{array}{l}\text { Brine } \\
\text { Brine }\end{array}$ & $\begin{array}{l}0.487 \\
0.463\end{array}$ & $\begin{array}{l}0.623 \\
0.627\end{array}$ & $\begin{array}{l}2.08 B 1 \\
1.9036\end{array}$ & $\begin{array}{l}0.488 \\
0.464\end{array}$ & $\begin{array}{l}0.625 \\
0.629\end{array}$ & $\begin{array}{l}2.1147 \\
1.9234\end{array}$ & $\begin{array}{l}+0.001 \\
+0.001\end{array}$ & $\begin{array}{l}+0.002 \\
+0.002\end{array}$ & $\begin{array}{l}+0.0266 \\
+0.0198\end{array}$ & $\begin{array}{l}22,800 \\
18,700\end{array}$ \\
\hline $\begin{array}{l}3 \\
4\end{array}$ & $\begin{array}{l}\mathrm{Ca}(\mathrm{OH})_{2} \\
\mathrm{Ca}(\mathrm{OH})_{2}\end{array}$ & $\begin{array}{l}0.471 \\
0.480\end{array}$ & $\begin{array}{l}0.621 \\
0.622\end{array}$ & $\begin{array}{l}1.9491 \\
2.0309\end{array}$ & $\begin{array}{l}0.473 \\
0.482\end{array}$ & $\begin{array}{l}0.623 \\
0.625\end{array}$ & $\begin{array}{l}1.9805 \\
2.0602\end{array}$ & $\begin{array}{l}+0.002 \\
+0.002\end{array}$ & $\begin{array}{l}+0.002 \\
+0.003\end{array}$ & $\begin{array}{l}+0.0314 \\
+0.0293\end{array}$ & $\begin{array}{l}20,600 \\
22,600\end{array}$ \\
\hline $\begin{array}{l}5 \\
6\end{array}$ & $\begin{array}{l}\text { Water } \\
\text { Water }\end{array}$ & $\begin{array}{l}0.470 \\
0.449\end{array}$ & $\begin{array}{l}0.623 \\
0.624\end{array}$ & $\begin{array}{l}1.9471 \\
1.77 \mathrm{~B} 3\end{array}$ & $\begin{array}{l}0.472 \\
0.451\end{array}$ & $\begin{array}{l}0.625 \\
0.626\end{array}$ & $\begin{array}{l}1.9744 \\
1.8096\end{array}$ & $\begin{array}{l}+0.002 \\
+0.002\end{array}$ & $\begin{array}{l}+0.002 \\
+0.002\end{array}$ & $\begin{array}{l}+0.0273 \\
+0.0313\end{array}$ & $\begin{array}{l}22,900 \\
22,900\end{array}$ \\
\hline $\begin{array}{l}7 \\
8\end{array}$ & $\begin{array}{l}\text { Air } \\
\text { Air }\end{array}$ & $\begin{array}{l}0.475 \\
0.462\end{array}$ & $\begin{array}{l}0.613 \\
0.623\end{array}$ & $\begin{array}{l}1.9541 \\
1.8830\end{array}$ & $\begin{array}{l}0.474 \\
0.461\end{array}$ & $\begin{array}{l}0.612 \\
0.621\end{array}$ & $\begin{array}{l}1.9487 \\
1.8790\end{array}$ & $\begin{array}{l}-0.001 \\
-0.001\end{array}$ & $\begin{array}{l}-0.001 \\
-0.002\end{array}$ & $\begin{array}{l}-0.0054 \\
-0.0040\end{array}$ & $\begin{array}{l}23,300 \\
28,700\end{array}$ \\
\hline $\begin{array}{r}9 \\
10\end{array}$ & $\begin{array}{l}\text { Control } \\
\text { Control }\end{array}$ & - & - & - & - & - & - & - & - & - & $\begin{array}{l}25,400 \\
22,600\end{array}$ \\
\hline
\end{tabular}


ture and $105^{\circ} \mathrm{C}$. The MMA monomer was uninhibited and contained no initiators.

$\mathbf{X}$-ray diffraction analysis disclosed two distinct crystalline reaction products. One was identified as hydrated calcium methacrylate with an estimated $3 \mathrm{H}_{2} \mathrm{O}$ per molecule, which is very loosely held and casily removed by vacuum drying, ovendrying, and even air-drying at a low relative humidity. The other reaction product appears when the amount of water in the system is limited to about 1 to $5 \%$ by volume of monomer. This compround is thermally more stable than the hydrated calcium methacrylate and persists at a temperature of $105^{\circ} \mathrm{C}$ in air. The compound has not been positively identified but appears to be anhydrous calcium hydroxymethacrylate rather than an anhydrous form of calcium methacrylate.

The two reaction products are very soluble in water but, no matter which one is dissolved, only the hydrous form is recrystallized from solution. The hydrous form does not convert to the anhydrous reaction product on heating or drying.

The anhydrous reaction product is not formed as a result of reaction with dry monomer and dry $\mathrm{Ca}(\mathrm{OH})_{2}$. No reaction could be detected in a dry reaction system; even with the addition of methanol (a liquid reaction product), no reaction occurred. The anhydrous form apparently crystalizes from some mixture of monomer, methanol, an ' water, and the water must be present only in very low concentration or the hydrous salt will form instead.

DTA patterns of the reaction products are shown in Figure 39. The calcite endotherm at $800^{\circ}$ to $900^{\circ} \mathrm{C}$ is prominent in both reaction products. Since only minor calcite ( $<2 \%$ by $x$-ray analysis) is present in these preparations, the large amounts indicated by DTA must form during the analysis by reaction of carbon dioxide (formed by oxidation of the sample) with calcium from the salt or unreacted calcium hydroxide.

No reaction between polymerized MMA and calcium hydroxide in an aqueous system was detected. X-ray analysis of the solids present after the reaction period found only $\mathrm{Ca}(\mathrm{OH})_{2}$. A limited reaction might have built up some concentration of calcium methacrylate in solution, but this was not considered at the time, and the liquid was not evaporated to check this. Such a reaction may proceed slowly in a long exposure but does not compare with the rapid reaction of the monomer. This suggests that the loss of $\mathrm{Ca}(\mathrm{OH})_{2}$ when precured concrete is impregnated with MMA actually occurs before polymerization takes place.

Batching of the reaction systems was done on the basis of the reaction of two mols of methyl methacrylate with one of calcium hydroxide, with water added to produce one mol of hydrated salt and 2 mols of methyl alcohol:

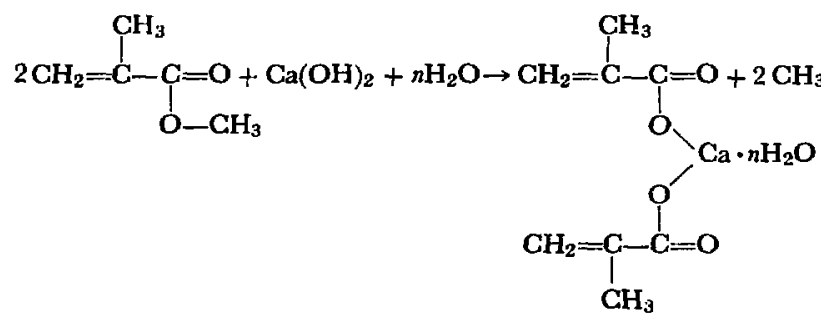

Systems of this composition appeared to react almost completely, the $\mathrm{Ca}(\mathrm{OH})_{2}$ being completely or nearly absent in the solid reaction products and the odor of monomer not very strong. The odor of methanol was very evident. Systems batched with double the amount of $\mathrm{Ca}(\mathrm{OH})_{2}$ in an effort to form the hydroxy salt simply used up the monomer completely and the excess $\mathrm{Ca}(\mathrm{OH})_{2}$ remained, except when a very limited amount of water, say 1 to $5 \%$ of the volume of monomer, was used. In this case the anhydrous salt formed but was generally accompanied by a little of the hydrated salt and never completely used up the
Figure 39. Differential thermal analysis of calcium methacrylate reaction products: (1) calcium methacrylate hydrate, preparation No. 5 ; (2) calcium (hydroxy?) methacrylate, preparation No. 9. Sample (2) contains 10 to $20 \%$ of unreacted calcium hydroxide. Analyses were made at $10^{\circ} \mathrm{C} / \mathrm{min}$ with limited access of air to samples. 
$\mathrm{Ca}(\mathrm{OH})_{2}$ or monomer. It is suggested, but not proved, that the reaction is<smiles>C=C(C)C(=O)OCCCC(=O)OC</smiles>

Temperatures of $25^{\circ}, 70^{\circ}$, and $105^{\circ} \mathrm{C}$ were used witk. no effect on the different types of product, but the reaction was more rapid at the higher temperatures. In several cases some of the monomer succeeded in polymerizing in spite of the lack of initiator.

Findings are summarized below.

(1) MMA monomer reacts rapidly with $\mathrm{Ca}(\mathrm{OH})_{2}$ in the presence of water (water appears essential) to form calcium methacrylate and methyl alcohol. With less water present $(\approx 1$ to $5 \%$ ), the solid product formed is not calcium methacrylate. This product has not been positively identified but may be calcium hydroxymethacrylate.

(2) The reaction is fairly rapid and goes to completion.

(3) PMMA does not react, or at least does not react to any comparable degree. The reaction of $\mathrm{Ca}(\mathrm{OH})_{2}$ when concrete is impregnated actually occurs before polymerization takes place.

(4) The calcium methacrylate salts are highly soluble in water. In themselves they do not appear harmful to concrete but possibly are subject to leaching by water in PIC.

\section{QUALITY AND PROCESS CONTROL}

\subsection{Qualtry Control}

The objective of the effort in quality control is to develop nondestructive techniques that will sii nply and rapidly indicate the degree to which concrete has been polymer filled. In past topical reports, ${ }^{2-4}$ senic velocity, impact hammer measurements, and other techniques have been reported and discussed. Both sonic velocity and impact hammer tests indicate that significant changes occur in the measured parameters when concrete is polymer filled. However, both methods suffer from inherent limitations. Impact hammer measurements indicate the condition of the concrete in regions within 1 to 2 in. of the surface. If the regions are polymer filled, there is a significant increase (by a factor of $\approx 1.6$ ) in rebound number. Regions near the surface that are monomer filled show no increase in rebound number. As previously mentioned,4 the impact hammer may have application to thin-wall concrete sections.

Sonic velocity measurements, on the other hand, show the condition of the whole sample. In polymer-filled concrete the sonic velocity is increased by a few thousand feet per second over that in unfilled concrete. However, since the sonic velocity is very sensitive to the presence of moisture or liquid monomer, such an increase is not unambiguously related to polymer content.

Considerable effort was spent at BNL during the past year in evaluating resonant frequency techniques for testing polymer-impregnated concrete. The resonant frequency approach evolved from the acoustic impact technique, which was briefly discussed in Ref. 4 . In the acoustic impact technique the specimen is mechanically struck and the intensity of the transmitted sonic signal is measured. Preliminary measurements indicated large differences in the received acoustic impact signals which correlated with polymer loadings. Subsequent work showed that the acoustic impact instrumentation was indeed more suitable for determining the vibration frequencies than the relative damping of transmitted signals. When used to measure the vibration spectrum of concrete, the acoustic impact instrumentation gives. the same information as the ASTM standard technique described in ASTM C 215-60. In Figure 40 the acoustic impact equipment is illus-

Figure 40. Acoustic impact testing unit with a concrete beam set in the transverse mode. The hammer is taped to the center of the beam, and the pickup is at the end.

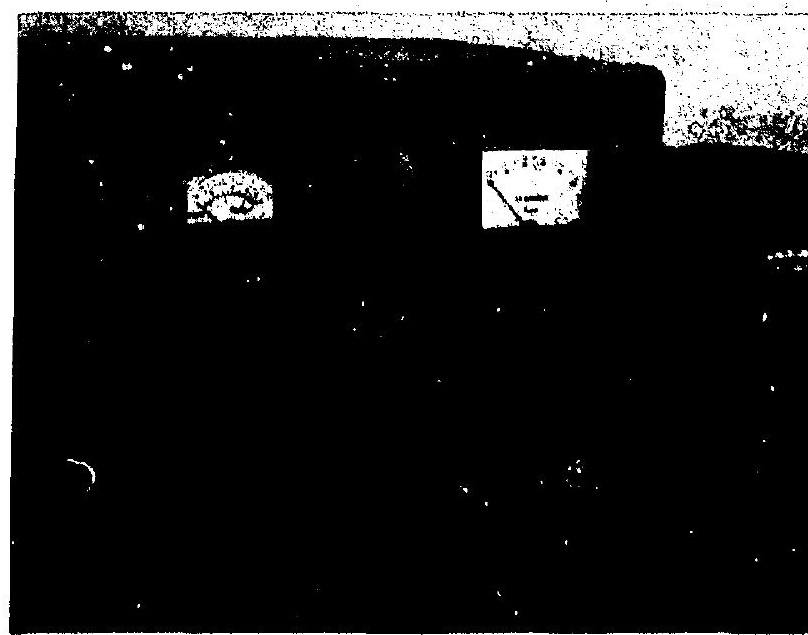




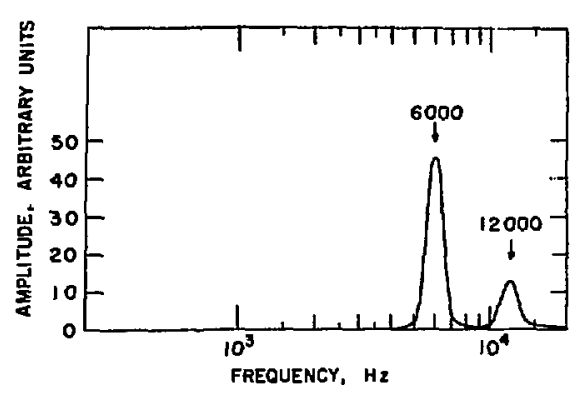

Figure 41. Vibration spectrum of a $4 \frac{1}{2}$-in.-diam $\times 12 \frac{1}{2}-$ in.-long concrete cylinder in the longitudinal mode, showing the fundamental and first-harmonic frequencies.

trated. Figure 41 shows the vibration spectrum, in the longitudinal mode, of a concrete cylinder; the fundamental and the first-harmonic frequencies are present. An extensive series of measurements using the standard ASTM C 215-60 instrumertation and the acoustic impact instrumentation showed that the two methods were identical. This work has been summarized. ${ }^{22}$

Measurements of the resonant frequencies of unimpregnated and polymer-impregnated bars and cylinders showed significant increases in the resonant frequency of the impregnated samples, in accordance with theory. For example, 6-in.diam $\times 12$-in.-long cylinders of CP-type concrete have the fundamental resonant frequency at 6000 Hz. After polymer impregnation the fundamental changes to $7300 \mathrm{~Hz}$. Measurements of watersaturated cylinders indicated no change in resonant frequency. It thus appears that the technique of resonant frequency analysis may be valuable for nondestructive testing of PIC. It has the imporlant advantages of responding to the total sample and of being unaffected by liquid (water or monomer) in the pores.

It is conceivable that a specimen of PIC may not be completely polymer filled. Partial filling may be due to incomplete drying, partial polymerization, evaporation, etc. An investigation is under way utilizing sonic velocity, impact hammer, and resonant frequency techniques to identify various types of partially loaded concrete test cylinders.

A preliminary investigation at the USBR indilcated that the use of electrical resistivity and dielectric measurements showed some promise as a nondestructive quality control test for PIC.4 The test results revealec' 3 ignificant differences in dielectric constant and resistivity between unim-

\begin{tabular}{|c|c|c|c|}
\hline \multicolumn{4}{|c|}{$\begin{array}{c}\text { Table } 92 \\
\text { Dielectric Tests } \\
\text { MMA-Impregnated Concrete }\end{array}$} \\
\hline $\begin{array}{c}\text { Specimen } \\
\text { No. }\end{array}$ & $\begin{array}{c}\text { Polymer } \\
\text { loading, } \\
\text { wt \% }\end{array}$ & $\begin{array}{c}\text { Dielectric } \\
\text { constant }\end{array}$ & $\begin{array}{l}\text { Electrical } \\
\text { resistivity, } \\
10^{6} \text { ohmmeters }\end{array}$ \\
\hline $\begin{array}{l}1 \\
2 \\
3 \\
4 \\
5 \\
6 \\
7 \\
8 \\
9\end{array}$ & $\begin{array}{l}6.7 \\
7.9 \\
7.3 \\
6.3 \\
8.0 \\
8.0 \\
6.7 \\
7.4 \\
7.6\end{array}$ & $\begin{array}{l}7.23 \\
6.56 \\
6.82 \\
7.13 \\
6.87 \\
6.94 \\
6.84 \\
7.18 \\
7.00\end{array}$ & $\begin{array}{l}46.9 \\
69.0 \\
62.0 \\
52.2 \\
63.8 \\
63.2 \\
58.4 \\
54.2 \\
57.0\end{array}$ \\
\hline $\begin{array}{l}16^{a} \\
17^{a} \\
18^{a}\end{array}$ & $\begin{array}{l}4.5 \\
3.9 \\
5.2\end{array}$ & $\begin{array}{l}6.87 \\
7.18 \\
7.00\end{array}$ & $\begin{array}{l}56.9 \\
50.1 \\
54.7\end{array}$ \\
\hline $\begin{array}{l}10 \\
11 \\
12\end{array}$ & $\begin{array}{l}- \\
- \\
-\end{array}$ & $\begin{array}{l}10.81 \\
46.33 \\
60.76\end{array}$ & $\begin{array}{l}7.2 \\
1.5 \\
1.9\end{array}$ \\
\hline
\end{tabular}

a Specimen only partially impregnated.

pregnated concrete and PIC. A subsequent investigation with specially prepared samples of MMAimpregnated concrete indicated that the observed values for dielectric constant and electrical resistance (Table 92) showed poor correlation with variations in polymer loading. A set of nine fully impregnated specimens with polymer loadings of 6.7 to $8.0 \mathrm{wt} \%$ had dielectric constants ranging from 6.56 to 7.23 and resistivities ranging from 46.9 to 69.0 million ohmmeters. A set of three partially impregnated speciments with polymer loadings of 3.9 to $5.2 \mathrm{wt} \%$ had dielectric constants from 6.87 to 7.18 and resistivities of 50.1 to 56.9 million ohmmeters. Since the results indicated that dielectric constant and electrical resistance had poor correlation with polymer loading, development of dielectric methods as a quality control test has been discontinued.

\subsection{Process Control}

Experiments have been performed to determine the stability of catalyzed MMA systems after repeated contact with concrete. For comparison, the shelf life of uncontacted catalyzed MMA was also measured. Chemical initiators studied were 2,2azobisisobutyronitrile (AIBN), tert.-butylazoisobutyronitrile (D-A79), and benzoyl peroxide (BP). The results of this study are summarized in Table 93. 
Table 93

Stability of Various Chemical Initiators in Methyl Methacrylate at $23^{\circ} \pm 2^{\circ} \mathrm{C}$

\begin{tabular}{|c|c|c|c|c|c|c|c|c|}
\hline \multirow{3}{*}{$\begin{array}{l}\text { Storage } \\
\text { time, days }\end{array}$} & \multirow{2}{*}{\multicolumn{3}{|c|}{ Shelf life }} & \multirow[b]{3}{*}{$\begin{array}{l}\text { Storage } \\
\text { time, hr }\end{array}$} & \multicolumn{4}{|c|}{ Shelf life after concrete contact } \\
\hline & & & & & \multicolumn{3}{|c|}{ Peak exotherm time, $\min ^{\mathrm{a}}$} & \multirow[b]{2}{*}{$\begin{array}{l}\text { Peak exotherm } \\
\text { time, min }{ }^{\mathrm{a}, \mathrm{o}}\end{array}$} \\
\hline & \multicolumn{2}{|c|}{ Peak exotherm time, min $^{\mathrm{a}}$} & BPd & & AIBNB & D-A79c & BPd & \\
\hline $\mathbf{0}$ & 46 & 160 & 94 & 0 & 46 & 160 & 94 & 94 \\
\hline 6 & - & - & 83 & 22 & 48 & 159 & 87 & 95 \\
\hline 7 & 43 & 159 & 85 & 24 & 43 & 137 & 87 & 96 \\
\hline 8 & 38 & 161 & 84 & 66 & - & - & 85 & - \\
\hline 10 & $33^{t}$ & - & - & 88 & - & - & 84 & - \\
\hline 14 & & 159 & 83 & 114 & 38 & 128 & - & 92 \\
\hline 16 & & 160 & 78 & 136 & 38 & 128 & - & \\
\hline 21 & & - & 78 & 153 & $32^{t}$ & 119 & 73 & \\
\hline \multirow{2}{*}{23} & & 144 & 76 & 175 & & 120 & 68 & \\
\hline & & & & 197 & & 119 & $64^{2}$ & \\
\hline
\end{tabular}

- Measurements conducted at $70^{\circ} \pm 0.1^{\circ} \mathrm{C}$.

' $2,2^{\prime}$ azobisisobutyronitrile (conc., 1 wt \%).

c tert.-butylazoisobutyronitrile (conc., 1 wt \%).

dBenzoyl peroxide (conc., 1 wt \%).

- Benzoyl peroxide catalyst added after contact of monomer with concrete.

r Onset of polymerization.

The stability of the catalyzed MMA was determined by measuring the peak exotherm time. This procedure was described in Ref. 3.

The uncontacted monomer containing AIBN showed a $30 \%$ decrease in peak exotherm time and onset of polymerization after 10 days. The D-A79 and BP systems remained essentially stable for a period exceeding $\mathbf{2 3}$ days, although decreases in peak exotherm time of 10 and $21 \%$, respectively, occurred. These data are tabulated in Table 93. All MMA systems contained 1 wt \% catalyst and $35 \mathrm{ppm}$ hydroquinone inhibitor.

The same monomer systems were contacted with concrete. In these tests, a different concrete specimen was used during each contacting. After a contact period of $153 \mathrm{hr}$, the MMA containing AIBN showed onset of polymerization. With DA79 the MMA had not started to polymerize after $197 \mathrm{hr}$, although the peak exotherm time had decreased by $26 \%$. The BP showed onset of polymerization at $197 \mathrm{hr}$. The data indicate that the stability of MMA-catalyst systems is decreased with repeated concrete contact. However, they also indicate that the catalyzed monomer can be used repeatedly in a process plant for rather long periods of contact time, depending on the catalyst used. Additions of inhibitor will also further extene? the service time.
To determine whether the decrease in peak exotherm time for monomer-contacted concrete was due to instability of catalyst or of inhibitor, a series of experiments was performed. MMA containing inhibitor was contacted with concrete for a total of $114 \mathrm{hr}$. Periodically catalyst was added to samplus of the monomer and peak exotherm time measurements were made. The peak exotherm time remained essentially the same for the time periods listed in Table 93. This indicates that the inhibitor remains stable and that the decrease in stability observed in the earlier experiments is due to catalyst instability.

\section{APPLICATIONS DEVELOPMENT}

\subsection{Pipt Aprlications}

8.1.1 Conerete Dreinfile. Field and laboratory tests started in 1968 to evaluate PIC draintile are continuing. The following draintiles are under investigation: (1) 30 lengths of poor quality (PQ) made with type I cement, not acceptable for use in USBR projects; (2) 20 lengths of average quality (AQ) made with type II cement, meeting the requirements of ASTM Designation C 118; and (3) 30 lengths of high quality (HQ) made with type $\mathrm{V}$ cement and fly ash, meeting USBR special re- 
quirements for exposure to high-sulfate environments. From each class of pipe, 10 lengths were fully impregnated with MMA, 10 were fully impregnated with epoxy-styrene, and the remainder served as controls. The average polymer content for each experimental condition is given below.

\begin{tabular}{clc}
\hline $\begin{array}{c}\text { Glass } \\
\text { of pipe }\end{array}$ & Monomer & $\begin{array}{c}\text { Polymer loading, } \\
\text { wt \% }\end{array}$ \\
\hline PQ & MMA & 6.8 \\
AQ & MMA & 6.3 \\
HQ & MMA & 5.8 \\
PQ & epoxy-styrene & 9.1 \\
AQ & epoxy-styrene & 7.7 \\
HQ & epoxy-styrene & 5.0 \\
\hline
\end{tabular}

Nine sections of draintile, each representative of a different experimental condition, are continuing to undergo laboratory testing at the USBR in Denver: The remaining sections are installed in drainage lines at the Westlands Experimental Drainage Plot, Tranquillity, California. Sulfate concentrations in this area are extremely high; analyses indicate concentrations ranging up to $7.5 \%$ in the soil and $5.9 \%$ in water taken from the drainage lines. The first periodic inspection of the lines was made after 2 years of exposure. A borehole TV camera was used, and the results were included in the Fourth Topical Report." All draintiles were in good condition and no signs of deterioration were observed. Further inspections will be made at appropriate intervals.

The laboratory tests include three-edge bearing strengths, water absorption, and resistance to sulfate attack in both the accelerated sulfate test and the continuous soaking test in $10 \% \mathrm{Na}_{2} \mathrm{SO}_{4}$ solution.

Results of three-edge bearing and water absorption tests can be found in the Third Topical Report. ${ }^{3}$ They indicated that impregnation with MMA gave increases in strength ranging from 73 to $121 \%$, depending on the combined effect of quality of pipe and the resultant polymer loading. With epoxy-styrene, increases in strength over those for unimpregnated pipe ranged from 100

\begin{tabular}{|c|c|c|c|c|c|c|c|}
\hline \multicolumn{8}{|c|}{$\begin{array}{l}\text { Table } 94 \\
\text { Resistance to Sulfate Attack } \\
\text { r-Impregnated Concrete Draintile }\end{array}$} \\
\hline \multirow{2}{*}{$\begin{array}{l}\text { Class } \\
\text { of pipe: }\end{array}$} & \multirow[b]{2}{*}{ Monomer ${ }^{b}$} & \multirow{2}{*}{$\begin{array}{c}\text { Polymer } \\
\text { loading, \% }\end{array}$} & \multirow{2}{*}{$\begin{array}{l}\text { Sample } \\
\text { No. }\end{array}$} & \multicolumn{2}{|c|}{ Immersion test $t^{\mathfrak{c}}$} & \multicolumn{2}{|c|}{ Accelerated test ${ }^{d}$} \\
\hline & & & & Days & Expansion, ${ }^{\ominus} \%$ & Cycles & Expansion, ${ }^{\theta} \%$ \\
\hline $\begin{array}{l}\mathbf{P Q} \\
\mathbf{P Q}\end{array}$ & - & - & $\begin{array}{l}\text { A1 } \\
\text { B1 }\end{array}$ & $\begin{array}{l}931 \\
931\end{array}$ & $\begin{array}{l}0.287 \\
0.213\end{array}$ & $\begin{array}{l}361 \\
615\end{array}$ & $\begin{array}{l}0.536^{t} \\
0.500^{t}\end{array}$ \\
\hline $\begin{array}{l}\mathbf{A Q} \\
\mathbf{A Q}\end{array}$ & - & - & $\begin{array}{l}\mathrm{A} 2 \\
\mathrm{~B} 2\end{array}$ & $\begin{array}{l}931 \\
931\end{array}$ & $\begin{array}{l}0.195 \\
0.099\end{array}$ & $\begin{array}{l}300 \\
300\end{array}$ & $\begin{array}{l}0.580^{t} \\
0.634^{t}\end{array}$ \\
\hline $\begin{array}{l}\mathbf{H Q} \\
\mathbf{H Q}\end{array}$ & $\begin{array}{l}- \\
-\end{array}$ & - & $\begin{array}{l}\text { A3 } \\
\text { B3 }\end{array}$ & $\begin{array}{l}931 \\
931\end{array}$ & $\begin{array}{l}0.075 \\
0.091\end{array}$ & $\begin{array}{l}931 \\
931\end{array}$ & $\begin{array}{l}0.036 \\
0.416\end{array}$ \\
\hline $\begin{array}{l}\mathbf{P Q} \\
\mathbf{P Q}\end{array}$ & $\begin{array}{l}\text { MMA } \\
\text { ES }\end{array}$ & $\begin{array}{l}7.4 \\
9.5\end{array}$ & $\begin{array}{l}1-5 \\
1-12\end{array}$ & $\begin{array}{l}549 \\
931\end{array}$ & $\begin{array}{l}0.538 \\
0.226\end{array}$ & $\begin{array}{l}225 \\
931\end{array}$ & $\begin{array}{l}0.536^{t} \\
0.064\end{array}$ \\
\hline $\begin{array}{l}\mathbf{A Q} \\
\mathbf{A Q}\end{array}$ & $\begin{array}{l}\text { MMA } \\
\text { ES }\end{array}$ & $\begin{array}{l}7.1 \\
8.6\end{array}$ & $\begin{array}{l}2-3 \\
2-13\end{array}$ & $\begin{array}{l}931 \\
931\end{array}$ & $\begin{array}{l}0.308 \\
0.254\end{array}$ & $\begin{array}{l}931 \\
931\end{array}$ & $\begin{array}{l}0.2058 \\
0.160\end{array}$ \\
\hline $\begin{array}{l}\mathbf{H Q} \\
\mathbf{H Q}\end{array}$ & $\begin{array}{l}\text { MMA } \\
\text { ES }\end{array}$ & $\begin{array}{l}6.6 \\
5.8\end{array}$ & $\begin{array}{l}3-2 \\
3-19\end{array}$ & $\begin{array}{l}931 \\
931\end{array}$ & $\begin{array}{l}0.394 \\
0.105\end{array}$ & $\begin{array}{l}931 \\
931\end{array}$ & $\begin{array}{l}0.344 \mathrm{~g} \\
0.106\end{array}$ \\
\hline
\end{tabular}

Specimens cut from 4-in,-diam draintile to $\approx 1 \times ! \times 6$-in. size, oven-dried at $150^{\circ} \mathrm{C}$ prior to impregnation, and radiation polymerized.

$\mathbf{P Q}=$ poor quality; $\mathbf{A Q}=$ average quality; $H Q=$ high quality.

bMMA = methyl methacrylate; $\mathrm{ES}=$ epoxy-styrene.

- Continuous soaking in $10 \% \mathrm{Na}_{2} \mathrm{SO}_{4}$ solution.

¿Soaking in $2.1 \% \mathrm{Na}_{2} \mathrm{SO}_{4}$ colution at $22^{\circ} \mathrm{C}$ and drying at $54^{\circ} \mathrm{C} ; 1$ cycle/day.

- Values are averages for three specimens.

Removed from test (expansion $>0.5 \%$ ).

*Average net expansion for two specimens (third specimen removed from test for examination). 
to $\mathbf{2 8 1 \%}$. In water absorption tests, epoxy-styrene impregnated $P Q, A Q$, and $H Q$ samples exhibited less absorption than the corresponding MMAimpregnated samples. Compared with unimpregnated specimens, reductions in absorption ranging from 73 to $85 \%$ were obtained for MMA specimens, and from 86 to $95 \%$ for specimens impregnated with epoxy-styrene.

Results are given in Table 94 for the $10 \%$ $\mathrm{Na}_{2} \mathrm{SO}_{4}$ immersion test and the accelerated (1day wetting and drying cycle) $2.1 \% \mathrm{Na}_{2} \mathrm{SO}_{4}$ test. In both tests, the resistance to sulfate of unimpregnated control specimens is generally related to the quality of the tile, with the accelerated test showing a generally more severe effect.

In the accelerated test, epoxy-styrene specimens show greater resistance than MMA-impregnated or unimpregnated specimens. All the impregnated specimens are about two to three times more resistant than the unimpregnated specimens, although the MMA specimens are somewhat erratic in performance and in general somewhat less resistant than the epoxy-styrene specimens. In the immersion test the trend is reversed, with the unimpregnated specimens showing less expansion than impregnated specimens. The reason for this discrepancy has not been ascertained.

\subsubsection{Sewer and Culvert Pipe: Cooperative} Program With American Concrete Pipe Associotion. A PIC pipe research program was initiated as a cooperative effort of the American Concrete Pipe Association (ACPA), the AEC, BNL, and the USBR. Results of the initial study were given in Ref. 3. The current program is designed to compare unreinforced PIC pipe with reinforced precast concrete pipe. Steel-fiber reinforced concrete pipe has also been included in the program. Goals of the program are to obtain complete design information, service requirements, manufacturing techniques, and an evaluation of the economic benefits.

The test program includes three-edge bearing and hydrost:atic burst tests of full-size pipe sections to provide basic design data, and durability test? on cores drilled from pipe sections to determine resistance to attack by sulfate and sulfuric acid. Cores will also be tested to determine shear strength and water absorption.

Following completion of tests, the development of an impregnation facility at an existing pipe plant will be studied jointly by ACPA, BNL, and USBR. An economic reconnaissance evaluation of polymer-impregnated concrete pipe will then be made.

A total of 56 pipe sections have been commercially manufactured by the packerhead and roller suspension methods. The pipe sections are 36-in. in i.d. and $6 \mathrm{ft}$ long, with a wall thickness of $4 \mathrm{in}$. The test series consists of 36 sections of nonreinforced pipe for polymer impregnation, 12 sections of steel-reinforced pipe, and 8 sections of steel-fiber reinforced pipe. An equal number of each type of pipe was made by each manufacturing method.

The steel-reinforced pipes were manufactured in accordance with ASTM D C76 Class III Rein: forced Pipe. These pipes are to be used as controls and will not be impregnated.

The steel-fiber reinforced pipe contains $198 \mathrm{lb}$ of fiber/cu yd of concrete (about $1.5 \mathrm{vol} \%$ ). The fibers are $0.010 \times 0.022 \times 1 \mathrm{in}$. in size. Six sections will be impregnated at BNL and the remaining two will be left unimpregnated.

Thirty-six sections of the unreinforced pipe are to be impregnated and polymerized. Thirty sections are now being impregnated at the BNL facility. ${ }^{4}$ Fifteen will be polymerized by radiation and 15 by thermal-catalytic methods. This work is in progress (see Figures 42 to 46 ).

Six pipe sections have been impregnated at the USBR facility 4 (Figures 47 to 52 ) with MMA by the vacuum-soak process and thermal-catalytically polymerized while in the impregnation vessel: The first section was polymerized in air and the other five sections were polymerized unders water. Steam was used as a source of heat. Polymer loadings of the pipe sections are given in Table 95 .

Table 95

Preliminary Impregnation Data for ACPA Teat Program

\begin{tabular}{cccc}
\hline $\begin{array}{c}\text { Manufacturing } \\
\text { method }\end{array}$ & $\begin{array}{c}\text { Specimen } \\
\text { No, }\end{array}$ & $\begin{array}{c}\text { Oven-dry } \\
\text { weight, lb }\end{array}$ & $\begin{array}{c}\text { Polymer } \\
\text { loading, wt } \%\end{array}$ \\
\hline Roller sus- & 412 Na & 3272 & 2.4 \\
pension & 422 NT & 3306 & 2.5 \\
& 432 NT & 3219 & 2.9 \\
Packerhead & 151 N & 3044 & - \\
& 161 NT & 3056 & 4.2 \\
& 171 NT & 3074 & 3.9 \\
\hline
\end{tabular}

Monomer, MMA.

specimens, 36-in.-i.d. $\times 6$-ft-long sections with walls $1 / 4$ in. thick, thermal-catalytically polymerized under water.

- Polymerized in air. 


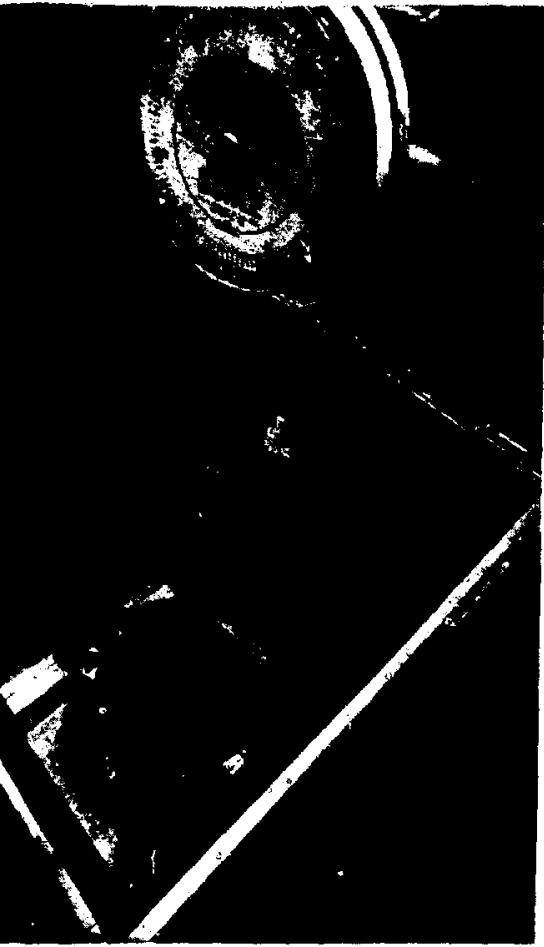

Figure 42. ACPA pipe being removed from drying oven prior to impregnation at BNL.

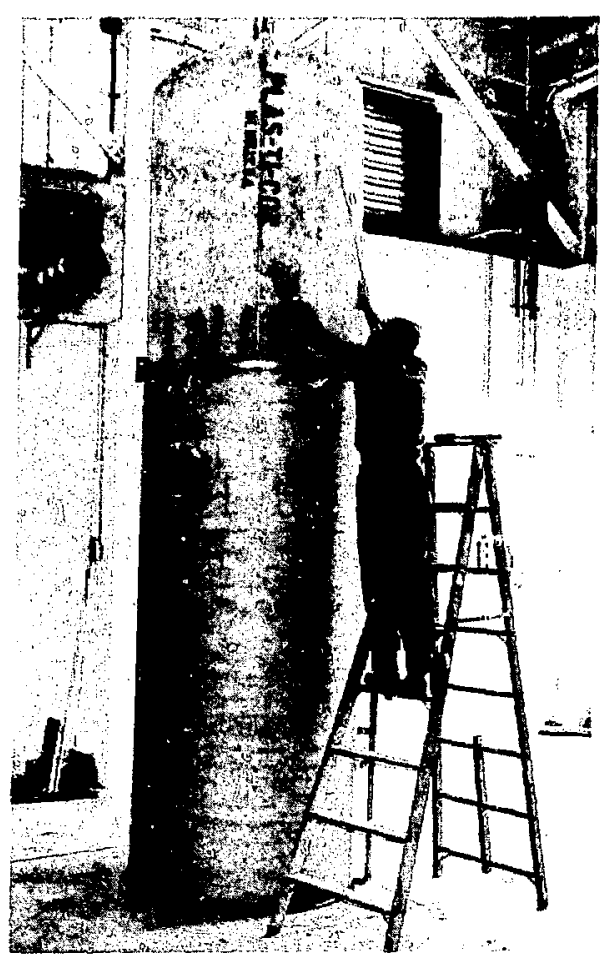

Figure 43. ACPA pipe being placed in steel container prior to impregnation at BNL.

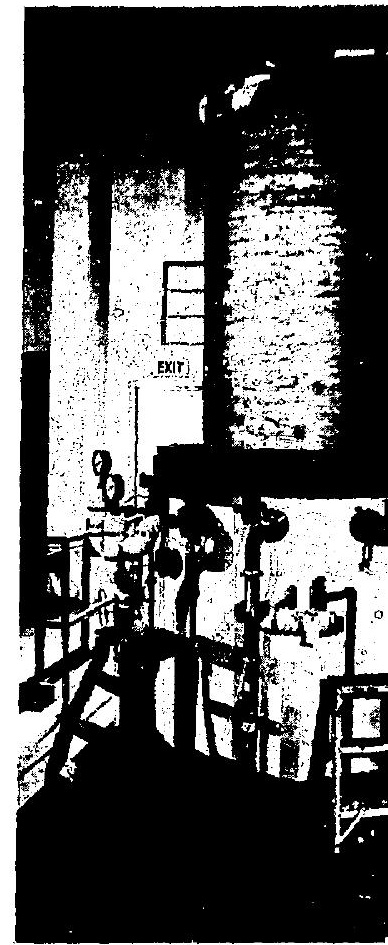

Figure 44. ACPA pipe and si being lowered into BNL impres

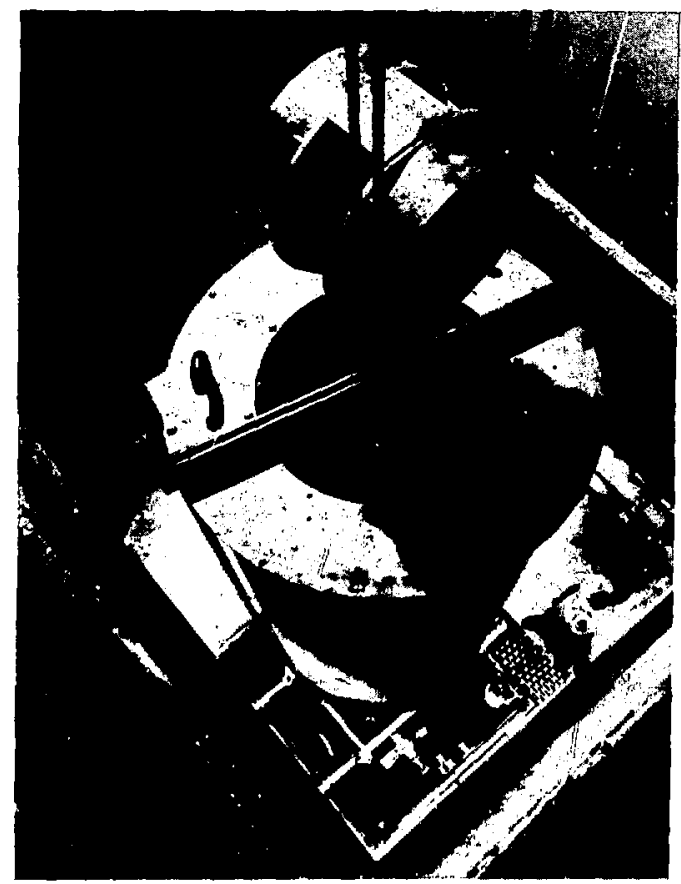

Figure 45. ACPA pipe and container being lowered into BNL irradiation facility.

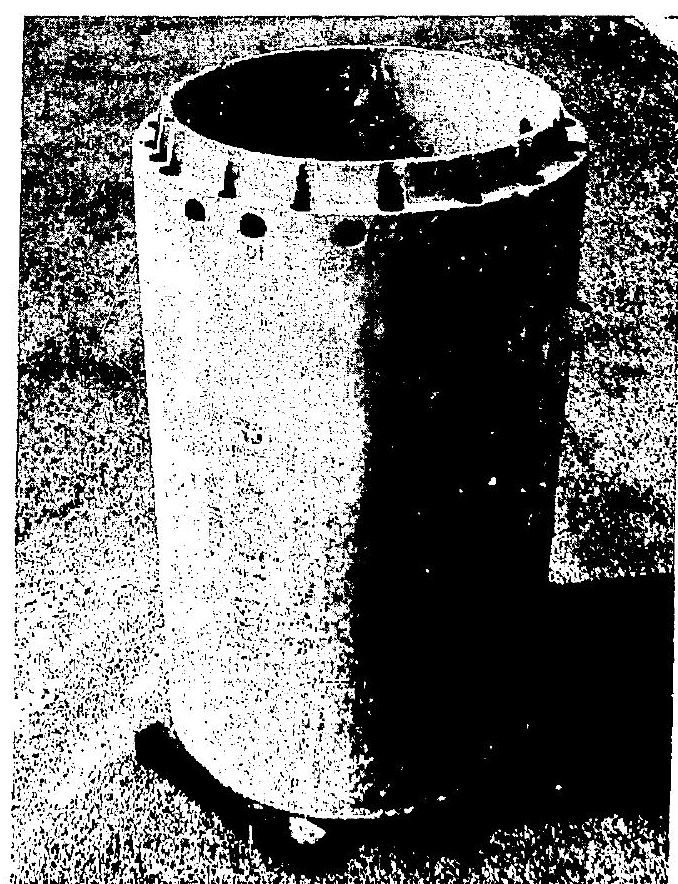

Figure 46. ACPA pipe after impregnation with MMA and radiation polymerization. Core samples have been taken from top end for use in strength and durability tests. 


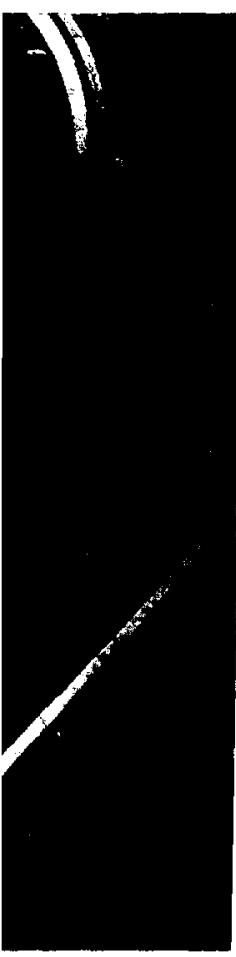

being removed from pregnation at BNL.

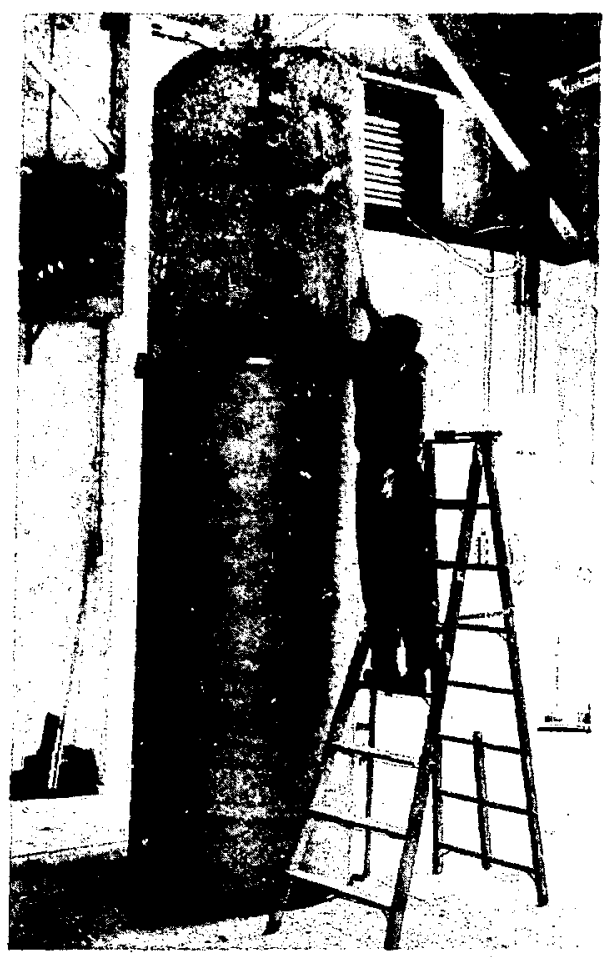

Figure 43. ACPA pipe being placed in steel container prior to impregnation at BNL.

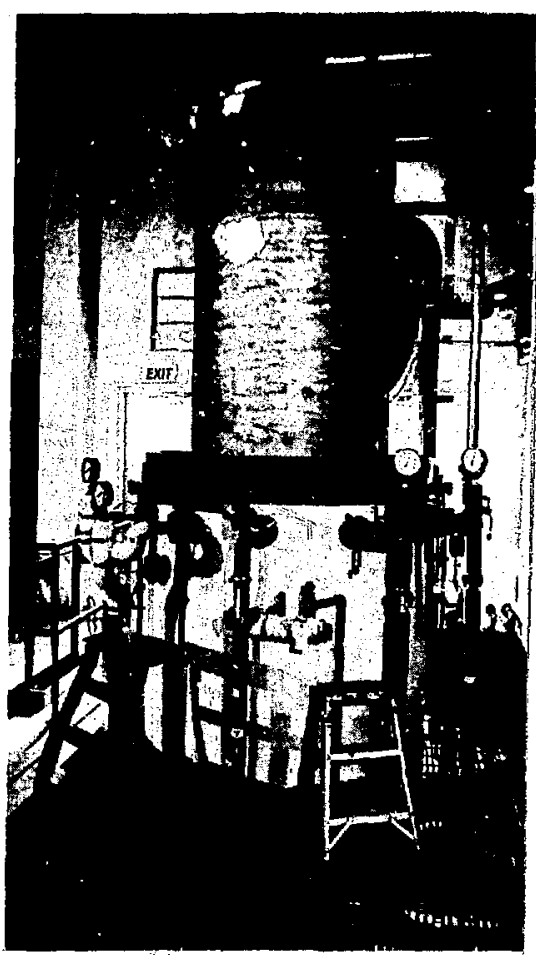

Figure 44. ACPA pipe and steel containei being lowered into BNL impregnation facili

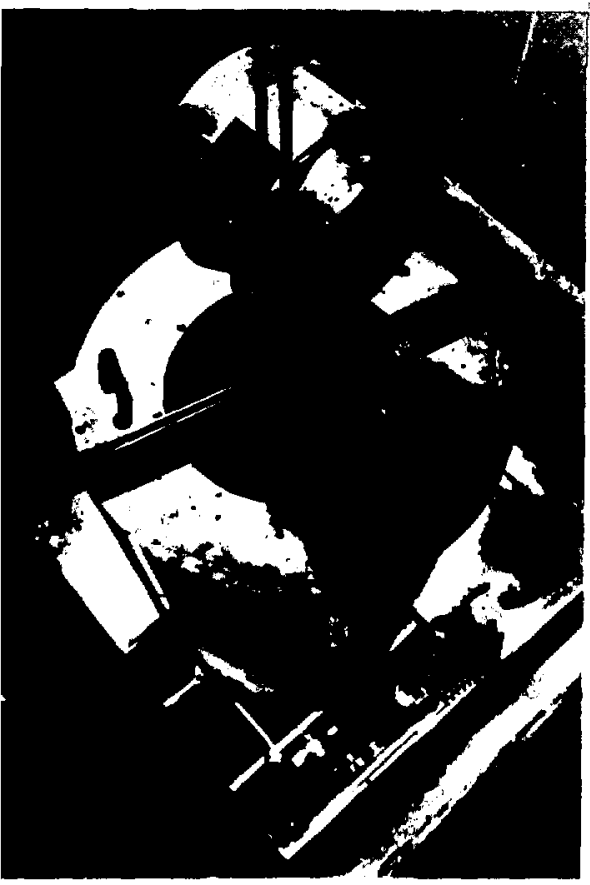

ure 45. ACPA pipe and container being lowered into BNL irradiation facility.

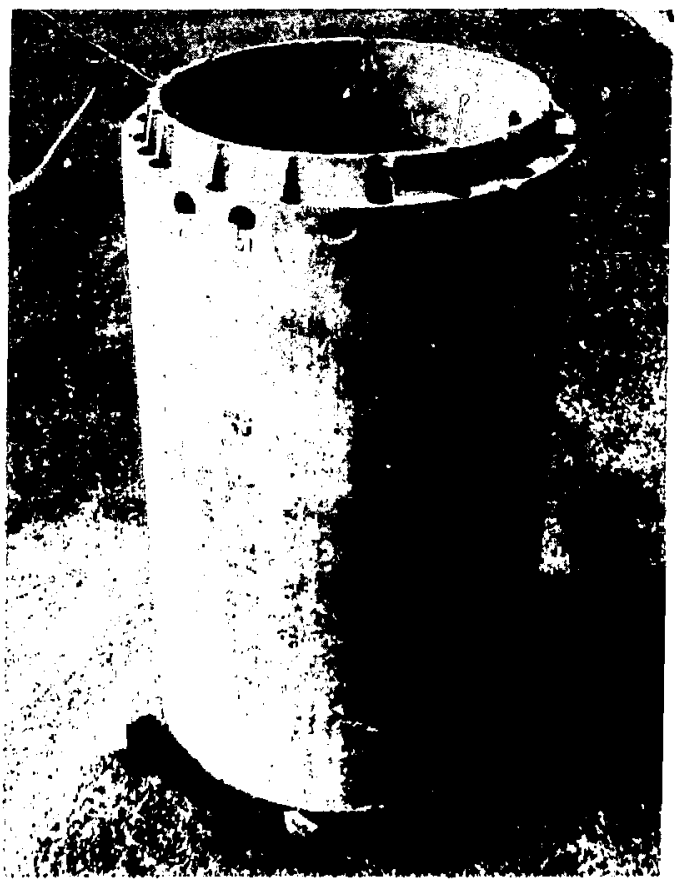

Figure 46. ACPA pipe after impregnation with MIMA and radiation polymerization. Core samples have been taken from top end for use in strength and durability tents. 


\begin{tabular}{|c|c|c|}
\hline \multicolumn{3}{|c|}{$\begin{array}{l}\text { San Diego Sewer Pipe } \\
\text { Summary of Results }\end{array}$} \\
\hline Specimen No. & $\begin{array}{l}\text { Polymer loading, } \\
\% \text { of dried weight }\end{array}$ & $\begin{array}{c}\text { Coating, } \% \text { of } \\
\text { impregnated weight }\end{array}$ \\
\hline SD-2 & 5.8 & 2.4 \\
\hline 3 & 5.0 & 2.4 \\
\hline 4 & 5.0 & 2.0 \\
\hline 5 & 5.6 & 2.1 \\
\hline 6 & 5.8 & 2.7 \\
\hline 7 & 5.8 & 2.0 \\
\hline 8 & 5.8 & 2.1 \\
\hline 9 & 5.1 & 2.4 \\
\hline 10 & 5.0 & 2.1 \\
\hline 11 & 5.9 & 2.4 \\
\hline 12 & 6.1 & 2.2 \\
\hline 13 & 6.1 & 2.9 \\
\hline 16 & 6.3 & 2.4 \\
\hline 17. & 5.8 & 2.1 \\
\hline 18 & 6.7 & 2.4 \\
\hline
\end{tabular}

Monomer, 90 wt \% styrene - 10 wt \% polyester.

Specimens, 8-in.-i.d. $\times 4$-ft-long sections, oven-dried at $110^{\circ} \mathrm{C}$; vacuum-soak impregnation and radiation-induced polymerization.

Coating material, 42 wt \% resin $623,42 \mathrm{wt} \%$ resin 6.44, 15 wt \% resin 511 (manufacturer, W.R. Grace).

Catalyst, 1 wt \% methyl ethyl ketone peroxide. is

8.1.3. Sewrer Pipe: Cooperative Program With Cify of San Diego. Based on the improvements found in structural and durability properties in laboratory experiments, field tests of PIC pipe were undertaken in the city of San Diego sewage system. In the initial test, six pieces of 8-in.-diam ×24-in.-Iong pipe were impregnated with tert.butyl styrene and radiation polymerized. Three of the sections are in test at San Diego and a fourth is being used as a control. Details of this work were given in Refs. 3 and 4. The test was started in January 1971 and data are not yet available.

A laboratory test of an additional piece of tert.butyl styrene impregnated pipe in $5 \mathrm{wt} \%$ sulfuric acid indicated severe attack after a 57-day exposure. Because of this poor result, a program was initiated to seleci an improved monomer system and impregnation method for use in the preparation of additional specimens to be tested under laboratory and field conditions. On the basis of results from previous tests, 4 fifteen 4 -ft lengths $o_{\text {. }}$ pipe were impregnated and doubly coated with polyester-styrene. In February 1972 nine lengths were installed in the city of San Diego sewage system at a location with a high hydrogen sulfide concentration. Another length was installed in the Alvarado Filtration Plant, where it will be compared with the tert.-butyl styrene imr regnated pipe that has been in service for $\approx 18$ months. Five other lengths are being laboratory tested. Impregnation data for all specimens are given in Table 96.

A 30-in.-long section of an impregnated length of sewer pipe (specimen SD-3 in Table 96) was subjected to a three-edge bearing test. Compared with a control strength of $2260 \mathrm{lb} /$ linear $\mathrm{ft}$, the impregnated specimen failed at a load of $5460 \mathrm{lb} /$ linear $\mathrm{ft}$. This corresponds to improvement by a factor of 2.4 and is in agreement with earlier work. ${ }^{3}$

Two lengths of pipe (specimens SD-6 and SD13) were sent to a consulting firm for evaluation. Upon receipt by the consultant, examination of SD-13 indicated that an 8-in.-long longitudinal hairline crack in the polymer coating on the end opposite the bell-end had developed during shipping. No defects were found in specimen SD-6.

Testing of both sections in $5 \% \mathrm{H}_{2} \mathrm{SO}_{4}$ was started on December 14, 1971. As of July 1972, no evidence of attack was apparent on sample SD-6. Surface blistering and discoloration near the hairline crack in sample SD-13 had progressively increased to the point where the coating was considered to have failed. ${ }^{23}$

Laboratory testing of two 1.5-ft lengths and one 4-ft length of sewer pipe is in progress at BNL. Initial data were given in Ref. 4. After the test specimens had been exposed to $5 \% \mathrm{H}_{2} \mathrm{SO}_{4}$ for 150 days, the acid was removed and the specimens were visually examined. Compared with earlier work in which unimpregnated sewer pipe showed severe attack after exposure for 17 days, no attack was apparent on the walls of the PIC pipe. However, pealing of the coating and some deterioration were apparent at the bottom end of each specimen (see Figure 53). Since in all cases the attack occurred at corners or joints, it was decided to repair the specimens, using a polyester-styrene resin that would produce a tougher and more flexible polymer.

A mixture consisting of $50 \mathrm{wt} \%$ W.R. Grace Co. resin 210, 15 wt \% W.R. Grace Co. resin 511, and $35 \%$ Hetron 197 was used to repair the attacked area on the 4-ft length and to completely recoat the specimens shown in Figure 53. Testing 


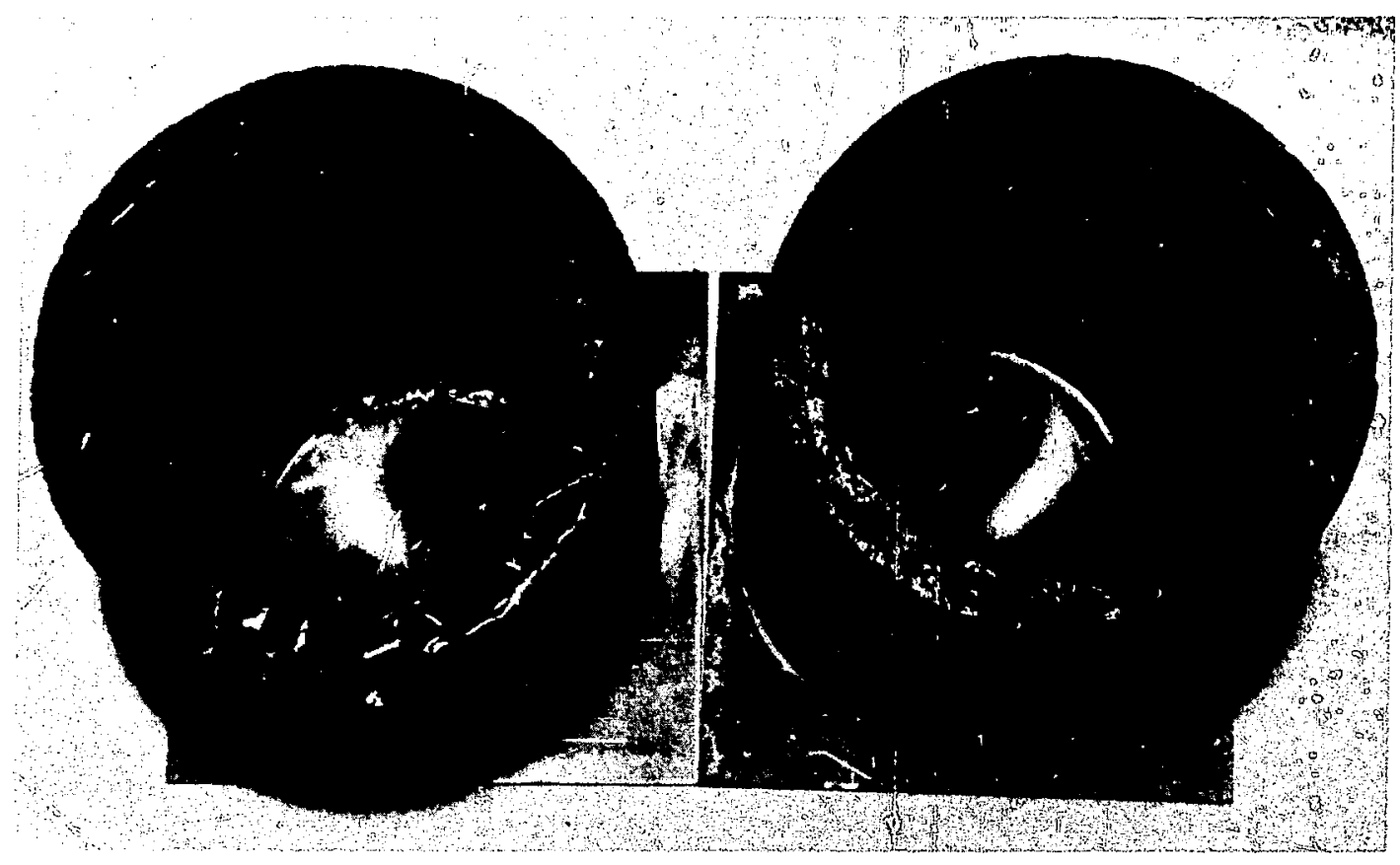

Figure 53. Concrete sewer pipes fully impregnated with 10 wt \% polyester - 90 wt \% styrene and the inner surfaces coated with two coats of polyester-styrene. After exposure to $5 \% \mathrm{H}_{2} \mathrm{SO}_{4}$ for 150 days, both specimens show no attack on the walls, but the coating has lifted and blistered at the joint between the pipe and the stainless steel bottom plate.

in $5 \% \mathrm{H}_{2} \mathrm{SO}_{4}$ has been resumed and the completely recoated sections have shown no attack after exposure for an additional 120 days. The pipe with only the deteriorated areas recoated has been in test for $\mathbf{4 5}$ days. No further attack is apparent. These tests are continuing.

\subsection{Pareast Tunmil Surponts and Lunines}

The USBR has conducted a research program to investigate, develop, and test PIC tunnel support and lining systems for gravity flow, circularcross-section, water conveyance tunnels. The system consists of segmented precast rings, backfilled with concrete.

A description of the experimental program and the facility used to impregnate the precast segments is given in Ref. 4. Sixty-three tunnel liner segments were impregnated with MMA by the vacuum-soak method and thermal-catalytically polymerized. Tests were performed on single seg- ments and on an 8-ft-diam full-scale segment system. The results of the investigation 24 are summarized below.

Individual tests on single segments indicate that PIC segments have an ultimate strength 2.25 times that of conventional concrete segments. Full-scale tests showed that a system comprised of 2-in.-thick PIC segments and 3.5 in. of conventional backfill concrete can support $60 \%$ more load than a similar system comprised entirely of conventional concrete.

The feasibility of using PIC for tunnel support lining systems can be determined only by continued investigation. Results to date as to strength, durability, and economics are favorable.

\subsection{Highway Apmications}

The FHWA is interested in the potential use of concrete-polymer materials for a number of highway applications and is sponsoring research and development efforts at BNL and the USBR. Highest priority has been assigned to the development of techniques for repairing deteriorated bridge decks and improving the durability of sound bridge decks. A materials development program to yield data for use in the design of precast prestressed, or post-tensioned, PIC bridge 
decks is also in progress. Two reports describing this work have recently been published. ${ }^{8,9}$

\section{CONCLUSIONS AND RECOMMENDATIONS}

Remarkable improvements in the structural properties and durability of concrete can be achieved by monomer impregnation and in situ polymerization by either radiation or thermalcatalytic means. The impregnation and polymerization process has been developed to the point where polymer-impregnated concrete is no longer limited to small-scale production in the laboratory; it can now be successfully produced in a technically feasible large-scale facility. New developments in process technology have demonstrated the feasibility of polymerizing MMA-impregnated concrete witlun the impregnation vessel (by the thermal-catalytic method) or in a separate suitable container (by the radiation method). These processing improvements have eliminated the need for specimen wrapping and have greatly assisted in the development of PIC as a practical construction material.

A notable achievement in the development of $P C$ as a practical construction material was the successful fabrication of PC with use of conventional concrete mixing and placing equipment. The new process produces $P C$ having about the same polymer content and compressive strength as standard PIC.

Investigations of PCC have been limited and so far have not shown improvements comparable to those achieved with PIC and PC. A preliminary study of furfuryl alcohol PCC has shown it to have some promise, and investigations are continuing oll a limi' ed basis.

Investigations of the structural properties and durability of PIC for ambient-temperature applications have included testing of seven monomer systems: MMA, styrene, MMA - 10 wt \% TMP. TMA, acrylonitrile, chlorostyrene, $10 \mathrm{wt} \%$ puiyester -90 wt \% styrene, and MMA polymerized in contact with water. These systems have produced PIC with improved structural properties and durability as compared with unimpregnated concrete. Improvements in the properties of cuncrete impregnated with MMA, MMA - 10 wt \% TMPTMA, 10 wt \% polyester - 90 wt \% styrene, and MMA polymerized in contact with water are particularly good. Investigations have shown that good-quality PIC can be made with concrete that varies widely in composition and quality. The primary factors in producing good-quality highstrength PIC appear to be achievement of a high degree of impregnation and complete polymerization. The highest compressive strength obtained to date was 32,400 psi for an MMA-impregnated specimen made from a high-strength, high-pressure steam-cured concrete mix.

Data on structural properties have been obtained from direct tension tests at $-12^{\circ} \mathrm{C}$ and $20^{\circ} \mathrm{C}$, shear tests, long-term tensile and compressive creep tests, tests of flexural strength of beams impregnated from one and two sides, and flexure and shear tests of steel-reinforced PIC beams. Preliminary tensile strength design values were obtained at $-12^{\circ}$ and $20^{\circ} \mathrm{C}$ for concrete impregnated with MMA and $10 \mathrm{wt} \%$ polyester - $90 \mathrm{wt} \%$ styrene PIC.

Durability tests of PIC continue to give generally excellent results. MMA-impregnated concrete, which shows good performance and has been under test longer than PIC made with other monomer systems, has shown improvements over unimpregnated concrete of $>1523 \%$ for freeze-thaw durability, $1200 \%$ for resistance to attack by $15 \%$ $\mathrm{HCl}$, and $200 \%$ for resistance to sulfate attack. PIC exposed to $5 \%$ sodium hydroxide exhibits no sign of deterioration after 1 year's exposure. Specimens exposed to sulfuric acid have shown moderate improvements, but it appears that a suitable surface seal coat in addition to complete impregnation will be required for good durability.

Development of PIC for desalting plant applications continued with work on the structural properties and durability of $60 \mathrm{wt} \%$ styrene -40 wt \% TMPTMA and 70 wt \% MMA - 30 wt \% T'MPTMA impregnated concrete. Tests include compressive strength, tensile strength, flexural strength, shear strength, thermal properties, creep deformation, and long-term exposure to hot distilled water, brine, and vapor. Tests were conducted at temperatures ranging from $-23^{\circ}$ to $177^{\circ} \mathrm{C}$. Preliminary design values have been calculated for compressive strength, moduli is of elasticity, and Poisson's ratio at the various iemperatures. A trend toward lower values with increasing temperature was observed. The preliminary design values for compressive strength at $143^{\circ} \mathrm{C}$ are 13,700 psi for the styrene-TMPTMA and 12,000 for the MMA-TMPTMA impregnated concrete.

Resistance to chemical attack by hot brine and distilled water is being measured in autoclave ex- 
periments and recirculating loops. Tests have been in progress on styrene-TMP ГMA PIC for 2 years in brine and for 1 year in brine and vapor at temperatures of $121^{\circ}$ and $143^{\circ} \mathrm{C}$. The PIC specimens show a trend toward lower compressive strength with an increase in exposure time and temperature, ranging downward to 10,300 psi for specimens exposed 2 years in $143^{\circ} \mathrm{C}$ brine. Tests with MMA-TMPTMA PIC were started, but results are not yet available. Autoclave tests disclosed a failure of MMA-TMPTMA PIC, and the desirability of continued testing is being determined.

Experiments are being conducted to improve the process technology for producing PIC and to determine the process requirements for full impregnation of various types of concrete. These studies include determination of the effects of concrete composition and methods for curing concrete, monomer impregnation methods, the use of different catalysts and polymerization techniques, and methods to reduce monomer evaporation and drainage losses. A recommended process has been developed for impregnation of standard weight, high-pressure steam-cured concrete specimens of up to 12-in. thickness.

A number of potential applications for PIC are being evaluated in cooperative programs with several governmental and industrial organizations. The applications include desalting plants, concrete pipe, bridge decks, housing construction, underwater structures, and tunnel lining and support systems. Concrete culvert and sewer pipe sections $3 \mathrm{ft}$ in diameter and $6 \mathrm{ft}$ long are being impregnated and tested in a cooperative program with the American Concrete Pipe Association. PIC draintiles have been under field test for three years at the Westlands Experimental Drainage Plot in California, where the soil has a high concentration of sulfate. Field tests of PIC sewer pipe are being conducted in cooperation with the city of San Diego. A cooperative program with the Federal Highway Administration is investigating the repair of deteriorated bridge decks, treatment of new bridge decks to improve durability, and, in a joint effort with the Prestressed Concrete Institute, the design of a precast, prestressed PIC bridge-deck system. A PIC tunnei lining and support system is under developmerpt in a joint program with the Bureau of Mines and the Department of Transportation. This program involves design of the system and full-scale laboratory testing.
The following recommendations are made for continuation of the program.

1. Efforts to improve process technology should be continued, in order to produce a product of optimum quality at minimum cost.

2. Studies should be continued to obtain a better understanding of the major factors controlling the physical and chemical properties of PIC. Information on the effects of variations in concrete composition, concrete curing conditions, aggregate type and gradation, and polymer loadings provides a basis for establishing product specifications.

3. The testing program on PIC for ambienttemperature applications should be continued, to develop structural properties data and design criteria over a range of temperatures. Durability tests in progress should be continued, and a study should be made to determine the rate of loss in strength of specimens exposed to freezing and thawing and to acid.

4. Development of PIC for desalting plant applications should be continued for the determination of structural properties and design criteria based on long-term exposure to air, brine, and vapor at elevated temperatures.

5. Periodic inspections should be made of the surface treatment work performed (partial impregnation and coating tecisniques were used to protect mortar-lined distillation chambers and pipe sections) at the OSW Water Desalting Facility, Freeport, Texas.

6. Experiments should be performed to determine the effects of coupling agents, wetting agents, fire retardants, plasticizers, and thixotropic materials.

7. A standard flame resistance test should be performed and the effects of exposure to fire should be determined.

8. Preliminary process and product designs and economic studies for specific applications should be made with use of test data for prototype and full-scale units. Such applications would include precast concrete pipe, tunnel linings and supports, bridge decks, and piling.

9. Development of PC should be accelerated and testing performed to determine structural properties over a range of temperature conditions and durability on exposure to adverse conditions.

10. Potential applications for PIC and PC should be identified and evaluated in laboratory and ficld investigations. These applications include the use of PIC and PC in the treatment or repair of existing concrete to improve durability, 
marine applications, shoterete, and panels and structural elements in building construction.

11. Construction methods for the utilization of concrete-polymer materials for specific applications should be developed and tested.

12. The major emphasis in the program should now be shifted from the laboratory to the field. With the development of technically feasible processes for the production of PIC and PC, and the determination of design criteria and performance data, these materials are ready for field installation. The ultimate success or failure of these materials will depend upon demonstration of feasible production methods and actual performance under field service conditions.

\section{REFERENCES}

1. Steinberg, M., Dikeou, J.T., Kukacka, L.E., Backstrom, J.E., Colombo, P., Rubenstein, S., Kelsch, J.J., and Manowitz, B., Concrete-Polymer Materials, First Topical Report, BNL 50134 (T-509) and USBR General Report No. 41, Dec. 1968.

2. Steinherg, M., Dikeou, J.T., Kukacka, L.E., Backstrom, J.E., Colombo, P., Hickey, K.B., Auskern, A., Rubenstein, S., Manowitz, B., and Jones, C.W., Concrete-Pobymer Materials, Second Topical Report, BNL 50218 (T-560) and USBR REC-OCE-70-1, Dec. 1969.

3. Dikeou,J.T., Steingerg, M., Cowan, W.C., Kukacka, L.E.; DePuy, G.W., Auskern, A., Smoak, W.G., Colombo, P., Wallace, G.B., Hendre, J.M., and Manowtrz, B., Concrete-Polymer Materials, Third Topical Report, USBR REC-ERC-71-6 and BNL 50275 (T602), Jan. 1971.

4. Dikeou, J.T., Stennerg, M., Cowan, W.C., Kukacka, L.E., DePuy, G.W., Auskern, A., Smoak, W.G., Colombo, P., Wallace, G.B., Hendre, J.M., and Manowirz, B., Concrete-Polymer Materials, Fourth Topical Report, USBR REC-ERC-72-10 and BNL 50328, Jan. 1972.

5. Steinberg, M., Colombo, P., Kukacka, L.E., and Manowitz, B., Method for Producing Plastic Impregnated Concrele, Assigned to U.S. Atomic Energy Commission, United States Patent 3,567,469, Mar. 2, 1971.

6. Steingerg, M., Kukacka, L.E., Colombo, P., Auskern, A., Reich, M, and Pike, R., Concrete-Polymer Mulerials for Highway Applications, Progress Report No. l, Informal Report BNL 15395, Sept. 1970.

7. Reich, N. ANv Hendrie, J.M., Report on Polymer-Concrete Applications for the Bureau of Public Roads, Design Studies on Highway Bridge Decking and Luminaire Supports, Informal Report BNL 15139, Aug. 1970.

8. Kukacka, L.E., Romano, A.J., Reich, M., Auskern, A., Golomeo, P., Klamut, C.J., Prke, R.G., And Steinbero, M., Concrete-Polymer Malerials for Highway
Applications, Progress Report No. 2, BNL 50348, Apr. 1972.

9. Reich, M., Koplick, B., ANd Hendrie, J.M., Reprtt on Polymer-Concrete Applications Development for the Bureau of Public Roads, Finite Element Approach to Polymer-Concrele Bridge-Deck Design Analysis, Informal Report BNL 16890, May 1972.

10. Haynes, H.H. and Albertsen, N.D., Polymer-Impregnated Concrete Spherical Hulls Under Hydrostatic Loading, Nav. Civil Eng. Lab. Tech. Rep. R-753, Dec. 1971.

11. Keeton, J.R., Alumbaugh, R.L., and Hearet, P.J., Concrete-Polymer Composite for Military Underseas Facilities, Nav. Civil Eng. Lab. Tech. Note N-1230, Apr. 1972.

12. Walde, C.H., Reich, M., Colombo, P., KIAmut, C.J., Beller, M., and Steinberg, M., Mine Safety and Underground Support Structures, Rock Impregnation and Pumpable Rockbolt Development, First Annual Report, Informal Report BNL 16187, Sept. 1971.

13. Kuracka, L. E., Perlite-Polymer Concrete, Concrete (J. Concrete Soc.) 7. :7o. 7, 28-33 (1973).

14. Razf, R.A.V., Polymer Cement Concrele With Furfuryl Alcohol Resins, Res. Rep. No. 72/4-58, Washington State Univ. College of Engineering, Pullman, Wash., June 5, 1972.

15. Antonova, I.T, Prokhorov, V.Kh., Erokhin, V.D., Kerimov, S.I., AND Grokhotov, V.A., Use of Polymer-Cement Concrete on a Base of Furfural Resins, Hydrotech. Constr. 8, 750-2 (Aug. 1970).

16. Graham, J.R., Backstrom, J.E., Redmond, M.C., Backstrom, T.E., AND RuBENStern, S.R., Evaluation of Concrete for Desalination Plants,USBR REC-ERC-71-15, Denver, Mar. 1971.

17. Auskern, A. and Horn, W, Some Properties of Polymer Impregnated Cements and Concretes, $J$. Amer. Ceram. Soc. 54, 282-5 (1971).

18. Hones, D.W., The Dependence of the Bulk Modulus, roung's Modulus, Shrinkage and Thermal Expansion of Concrete Upon Aggregate Volume Concentration, TRA 437, Cement and Concrete Ass., London, Dec. 1969.

19. Auskern, A., A Model for the Elastic Constants of Polymer Impregnated Composites, Informal Report BNL 16731, Mar. 1972.

20. Auskern, A. and Horn, W., Capillary Porosity in Hardened Cement Paste, J. Testing Eval. 1, 74-9 (1973).

21. Powers, T.C. And Brownyard, T.L., Studies of the Physical Properties of Hardened Portland Cement Paste, Bull. 22, Portland Cement Ass., Chicago, 1948.

22. Wong, J.C.K., Auskern, A., and Horn, W, Determination of Resonant Vibration Frequency of Concrete by an Acoustic Impact Technique, Informal Report BNL 17187, Sept. 1972; J. Testing Eval. 1, 291-4 (1973).

23. Baumann, F.J. (Pomeroy, Johnson, and Bailey, Inc.), letter to $M$. Steinberg, July 19, 1972.

24. Cowan, W.C., Carpenter, L., and Spencer, R., Polymer-Impregnated Tunnel Support and Lining System, in Proc. N. Amer. Rapid Excavation and Tunneling Conf., Chicago, June 1972, Vol. 1, Chap. 37, Amer. Inst. Mining Met. Petrol. Eng., Port City Press, Baltimore, 1972. 